Drawn Interruption

Drawn Interruption
Visualising the Ephemeral

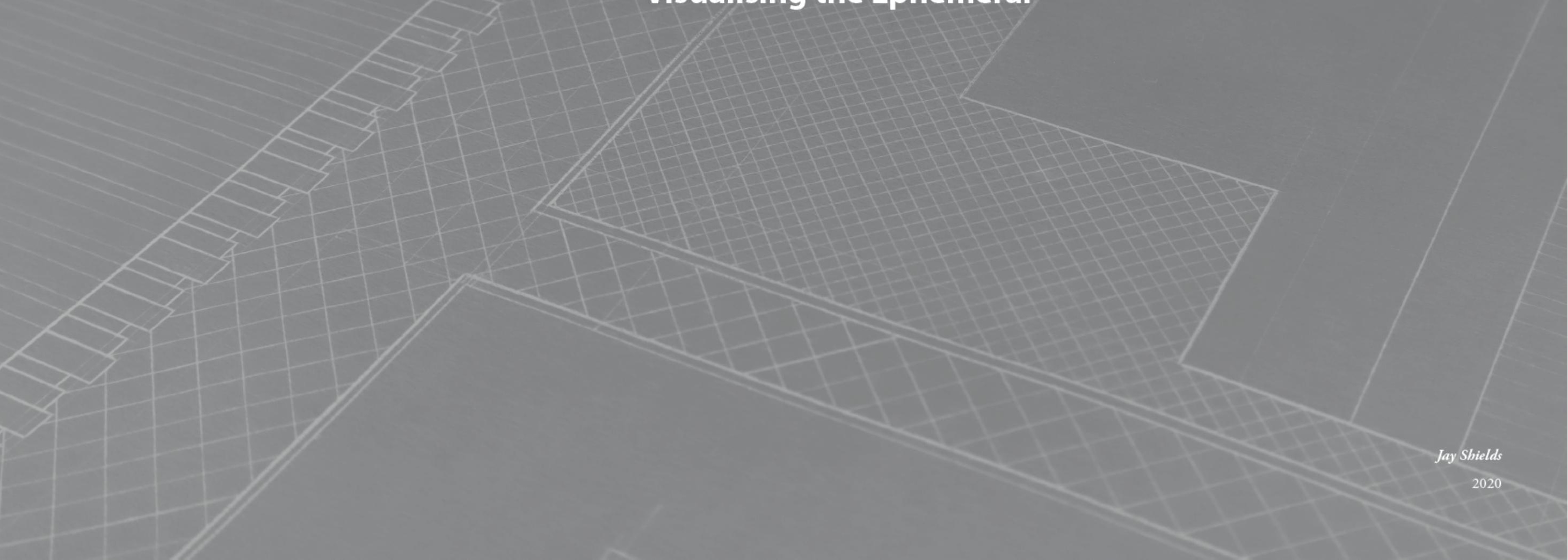


Page Intentionally Left Blank 


\section{Drawn Interruption:}

Visualising the Ephemeral

A 120 point thesis submitted Victoria University of Wellington school of architecture and design in partial fulfilment of the requirements for the degree. Master of Architecture (Professional)

\section{Victoria University of Wellington}

School of Architecture and Design

Jay Shields

2020 


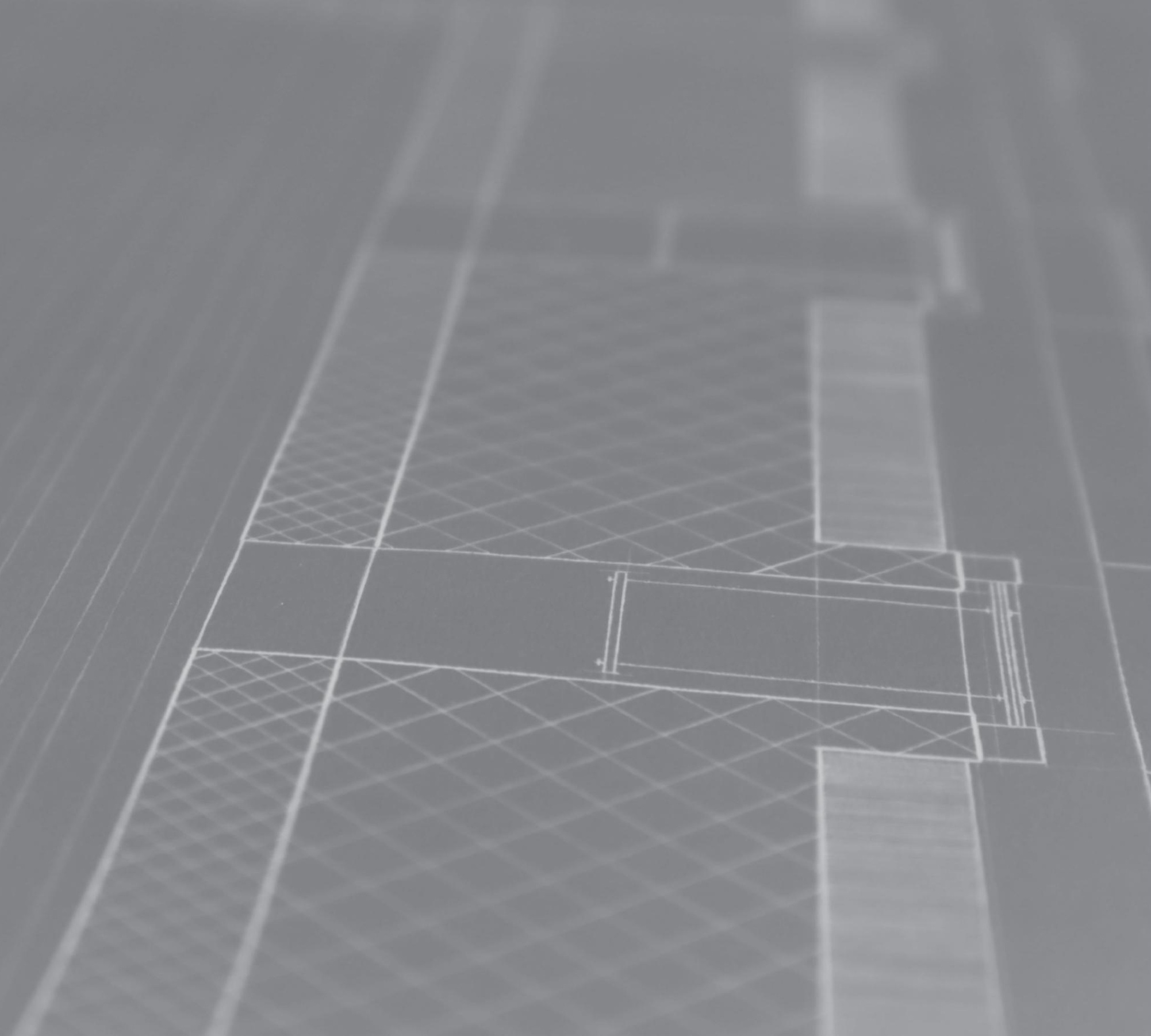


To my friends, family and loving partner, without your love and support I wouldn't have made it through these past five years. 


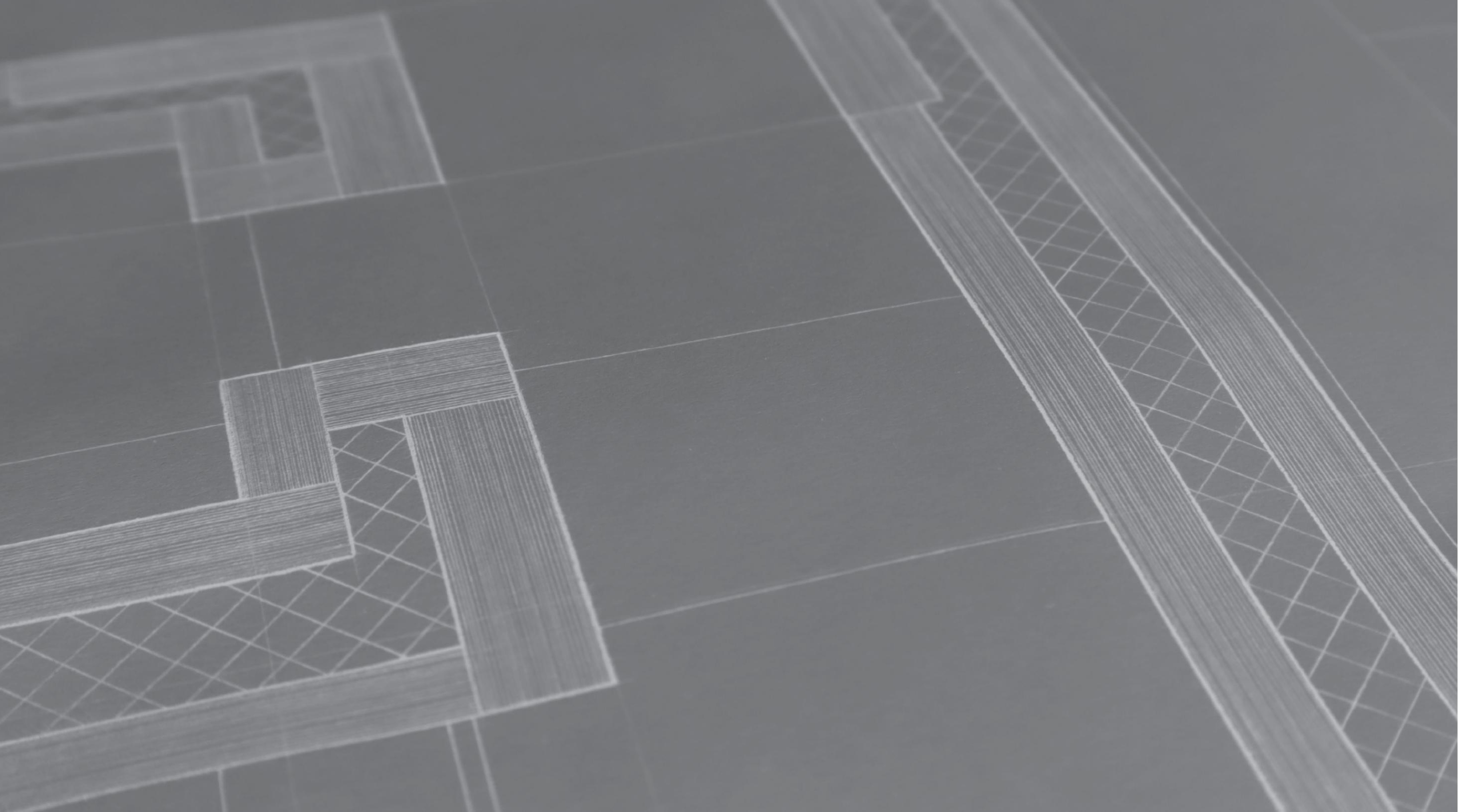




\section{Abstract:}

Architectural atmosphere is often characterised by loose descriptors which, rather than represent actual spatial qualities, depict an abstraction. Atmosphere is represented as an ephemeral quality that seems to naturally emanate from a given design. As a result, many refer to atmosphere as unable to be documented using traditional media. In response, this thesis seeks to examine the architectural representation of atmosphere, and identify an effective method of codifying and representing specific atmospheric qualities by examining the specific phenomenon of interruption, taking the contemporary workplace as its site of investigation. Its larger aim, is the creation of a notational system that better enables the design of atmosphere, specifically the design of atmospheres of interruption. 


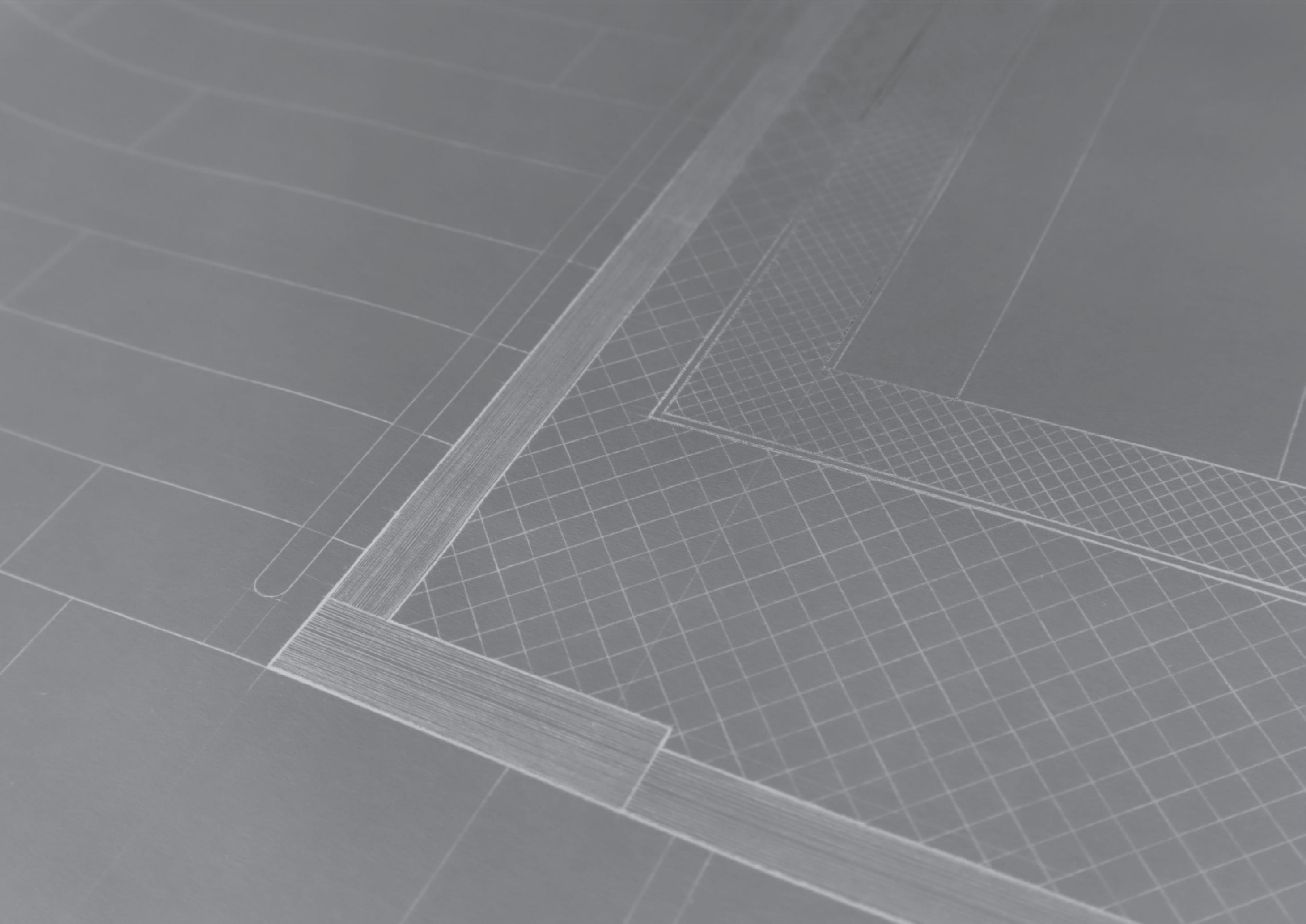


Table Of Contents:

$|0|$

\section{Thesis Preface:}

\begin{tabular}{lr}
\hline Acknowledgements & III \\
\hline Abstract & V \\
\hline Thesis Structure & IX
\end{tabular}

|1 |

\section{Introduction:}

\begin{tabular}{ll} 
Research Question & 14 \\
\hline Research Aims & 16 \\
\hline Research Background & 18 \\
\hline Research Methodology & 22 \\
\hline
\end{tabular}

|2|

\section{Literature Review:}

Literature Review

|3|

\section{Case Studies:}

Agile Workspaces

Vodafone Headquarters - InnoV8

Sky Central Headquarters

Sharecuse Coworking Space

|4|

\section{Notational Design:}

Notational Background

Notational Design

Sensorial Tools

Notational Application
$|5|$

\section{Notational Development:}

Notational Context

Notational Application 64

Notational Context Redesign

Notational Testing 86

$|6|$

\section{Notational Utilisation:}

Sharecuse Office - Interruptive Analysis 99

Sharecuse Office - Redesign

Sharecuse Office - Design Outcome

|7|

\section{Conclusion:}

Research Conclusion

$|8|$

\section{Appendices:}

Design Stage One - Documentation 151

Design Stage Two - Notational Ruleset

$|9|$

\section{References:}

Figure List

Bibliography 196 


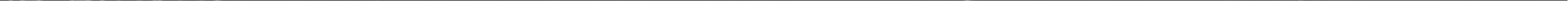




\section{Chapter One:}

Broadly discusses atmosphere in reference to workplace interruption and comments on the effects of this phenomenon within the agile workplace. Outlines how this issue will be addressed within the context of these works.

\section{Chapter Two:}

Literature review examining works such as "The Architecture of Atmosphere" and The Social Logic of Space after an initial selection of literary works were screened for relevance to the topic. In examining these works, it becomes clear that the architectural discipline often disregards social atmosphere - and by extension the atmosphere of interruption - in turn leading to passively designing interruptive spaces.

\section{Chapter Three:}

Presents three case studies, each of which discusses an architecturally designed office of varying scope and size. The main theme emerging from these discussions identified that architectural practitioners rarely prioritize interruption in the design process, and as such, this atmospheric phenomenon rarely serves as a design driver. Several effective and ineffective design strategies for managing an interruptive atmosphere were identified throughout this chapter.

\section{Chapter Four:}

Details the process by which an interruptive notational system was developed to assist in the design of interruption aware spaces. A dataset produced by authors Gonzalez and Mark served as the foundation for this system and enabled it to rapidly develop. Toolsets and calculative processes were derived from this dataset and allowed for the interruptive atmosphere of a given design to be mapped in response to its spatial qualities.

\section{Chapter Five:}

Discusses a series of trials of the interruptive notational system, examining how it operates across a number of design instances and drafting views to highlight potential issues. This process was facilitated through the design of a standardised office, based upon the New Zealand Government Property Procurement Group’s (NZGPPG) office design guidelines.

\section{Chapter Six:}

Endeavours to apply the interruptive notational system in the context of the Sharecuse office. This office was discussed in Chapter Three and its design was determined to promote an unnecessarily interruptive atmosphere. Through the notational system and considerate site analysis, this design was reworked to promote an effective working environment. 


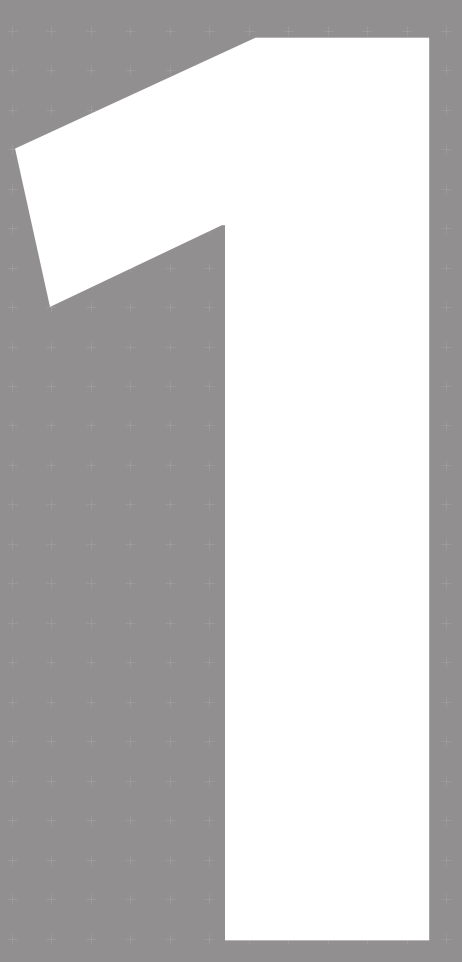

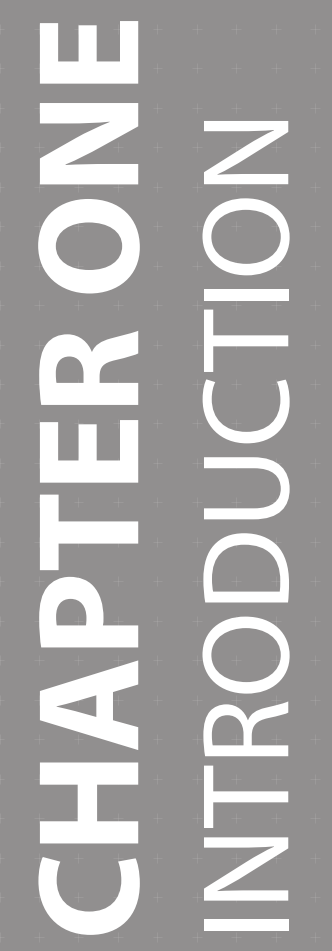





\section{Research Question:}

How can the interruptive elements of architectural atmosphere be codified to facilitate the design of interruption aware spaces through a medium such as drawing? 


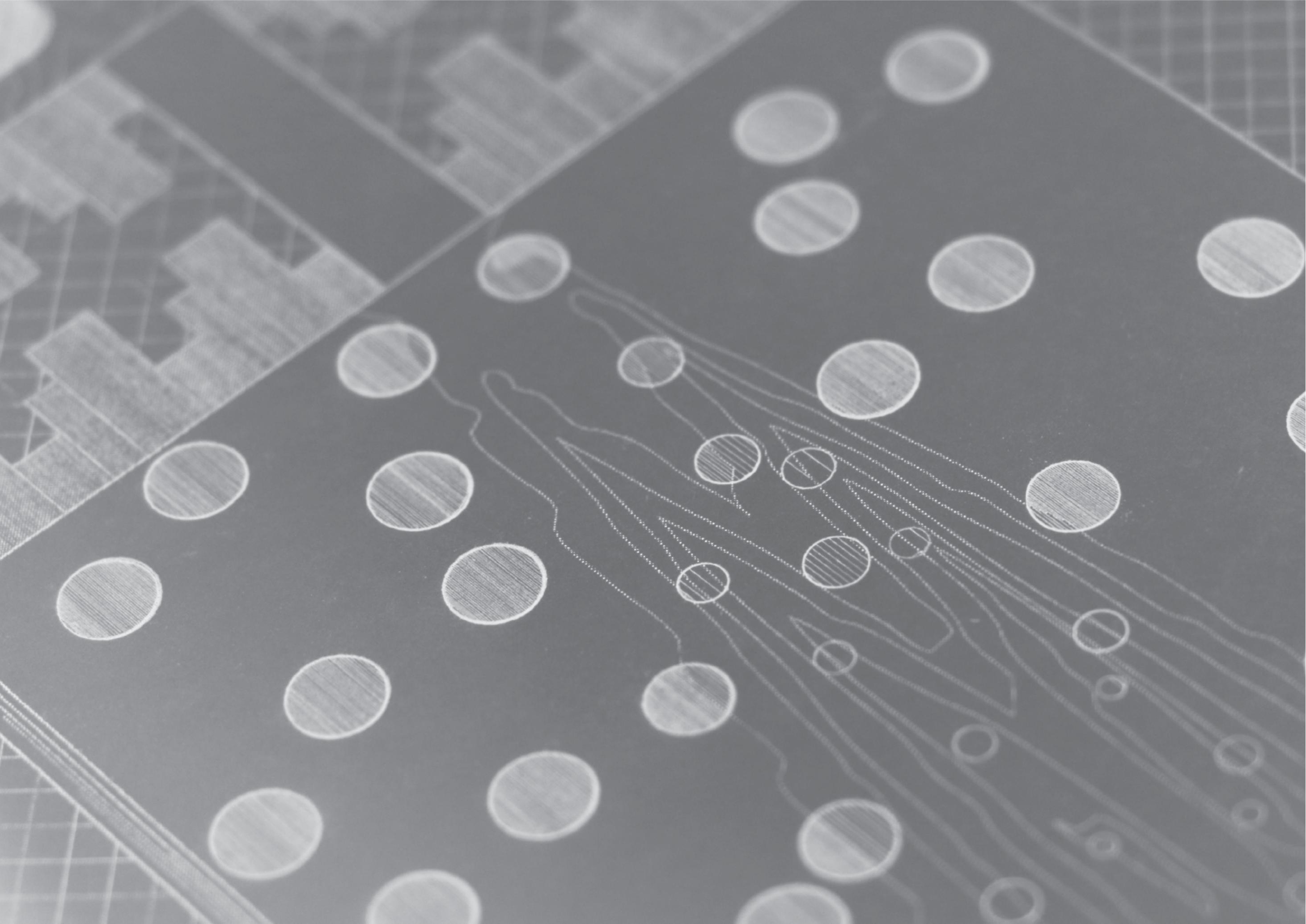




\section{Research Aims:}

This thesis seeks to examine the architectural representation of atmosphere with the aim of facilitating a more proactive design of its qualities. Atmosphere is an important aspect of architecture but it is typically narrowly defined. For example, Mark Wigley, in his article "The Architecture of Atmosphere", states that the primary aspects by which any given architectural atmosphere is formulated is a composition of "sound, light, heat, smell and moisture" (Wigley, 1998, p. 18). Although not mentioned by Wigley time and change are also important aspects to consider.

Initially, this thesis intended to focus only on these aspects heralded by Wigley. In the preliminary design period of this body of work, the research aimed to codify these aspects to allow specific architectural atmospheres to be identified and designed [Figure $0.1-1.5$ ]. This was to be facilitated through digital simulation and traditional drawing techniques, but despite best efforts it was made clear that these aspects alone do not formulate atmosphere, only a piece of its totality (these processes and their results are explained further in Appendix 1). In response to these findings, the research pivoted to narrow its focus towards the atmospheric phenomena of interruption, this being an issue which cannot be readily simulated. In response, the research aims also shifted to create a representational process centred around drawing conventions to assist in the design of interruption-aware spaces. 


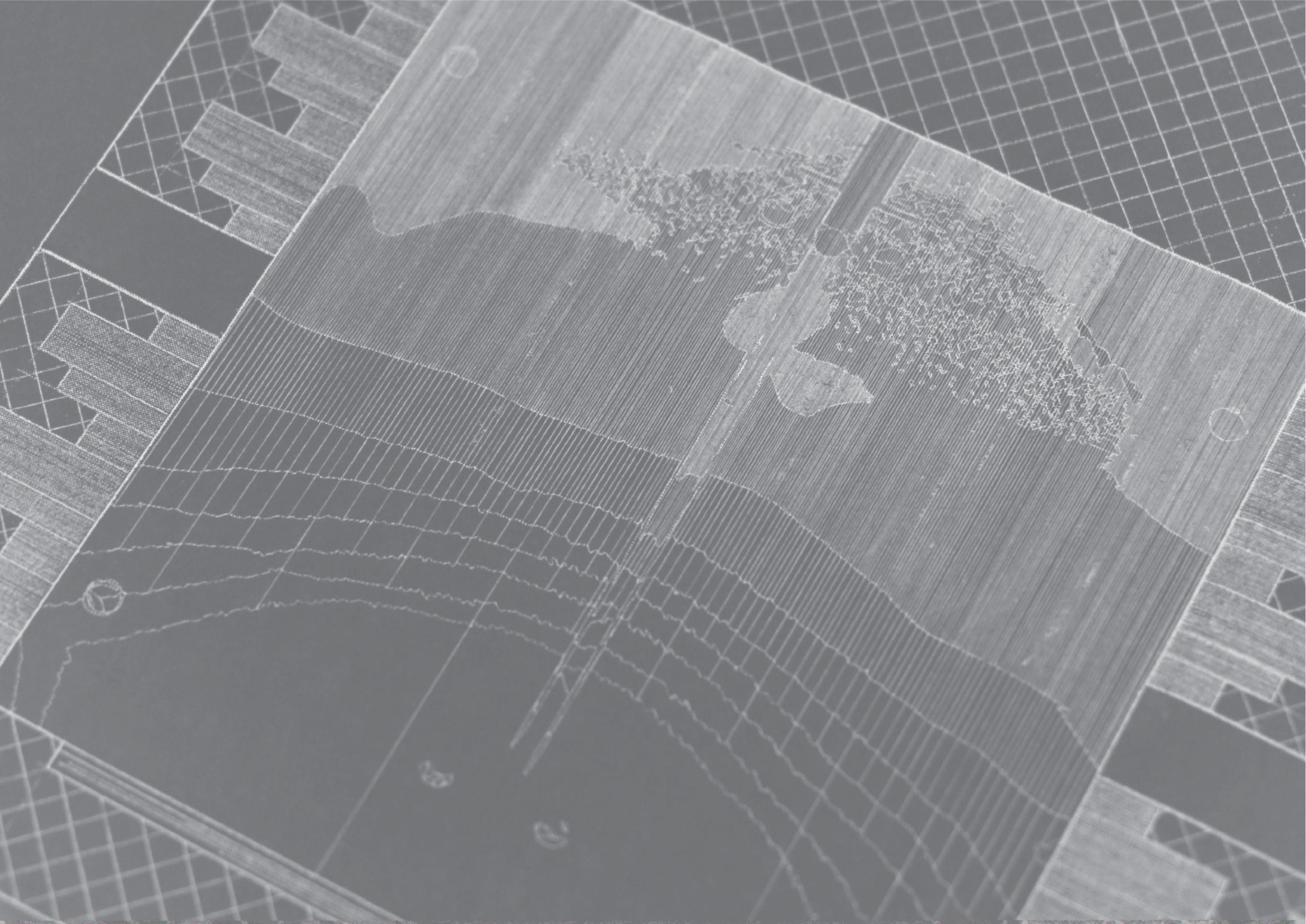




\section{Research Background:}

The social atmosphere of interruption has been shown to have negative impact on employee productivity ${ }^{[1]}$ and is becoming an area of concern for organisations which stand to see reduced profits, a higher staff turnover and increased stress in the work environment as a result. Interruptions may continue to adversely affect productivity as a result of office design shifting to support greater collaboration through ideas such as the agile workflow. ${ }^{[2]}$ Through design-led research, focusing on both the climatic and social aspects of interruptive atmosphere, this research will explore a potential framework for engaging with interruption-aware design.

The agile workplace typology, now gaining popularity amongst corporate architecture, is designed to offer employees a higher degree of workplace flexibility and collaboration. The agile office aims to cater to the employee, providing them with a series of workspaces designed to meet their individual needs in a given moment. Work areas such as quiet pods, telephone booths, collaborative areas and lounge spaces ensure that employees always have access to a space which best suits their needs. These spaces, and the more traditional work desks included within the office, are not designated to any one individual. Employee ownership, like in a hot desking scheme is removed, and instead promotes movement, agility and the transfer of ideas and information. Central hubs and locker systems support this movement and provide a space for employees to return to throughout the day. ${ }^{[3]}$

1 Mark, G., Klocke, U., \& Gudith, D. (2008). The Cost of Interrupted Work: More Speed and Stress. Conference on Human Factors in Computing Systems (pp. 107-110). Florence: Association for Computing Machinery.

2 Nottage, S. (2018, January 4). Go With The Flow: your scrum teams are interrupted 2,000 times per sprint, choking velocity by 40 per cent. Retrieved from Linkedin: https://www.linkedin.com/pulse/go-flow-your-scrum-teams-interrupted-2000-times-per-sprint-nottage

3 Ramidus Consulting Limited. (2015). Future Workstyles and Future Workspaces in the City of London. London: The City of London Corporation and The City Property Association. 

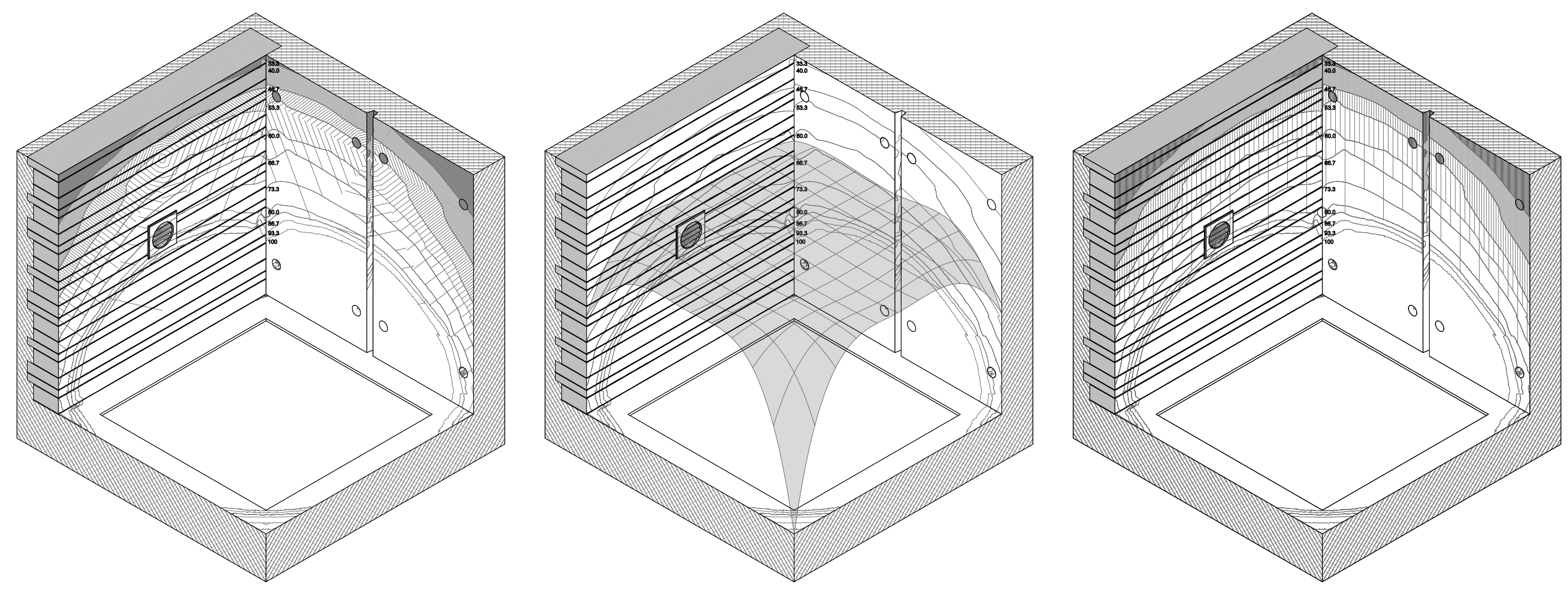
In this emerging typology of the agile workplace it is critical that designers understand the impact of workplace interruption to ensure that interruptive outcomes are not amplified. Researchers understand that an employee once interrupted may take up to 23 minutes and 15 seconds to resume their original task. ${ }^{[1]}$ This alone is damaging to employee productivity, but is escalated by the fact that employees will resume their original task after an interruption only $41 \%$ of the time. ${ }^{[2]}$ In workplaces which unintentionally promote frequent interruptions, this becomes detrimental to employee productivity. Acknowledging this, architects designing for the agile workplace must fully understand and consider interruption in the design process. In instances where this is disregarded there is potential to heighten undesirable outcomes, especially given employees collaborative and mobile tendencies.

Building upon this issue, it is pertinent that architects grasp the effects of workplace interruption, as the agile typology aims to introduce a number of new facilities not commonly found within the traditional office. Facilities such as the quiet booths and lounge areas are now expected aspects of the agile office, ${ }^{[3]}$ each of which share a nuanced relationship with one another. These facilities require an understanding of their interruptive interaction to effectively place them within the office, as without this understanding it is unlikely that they will meet employee needs, thus reducing the effectiveness of this newfound typology.

Consequently, in order to facilitate the research, the commercial office - specifically agile and flexible workspaces - were identified as a specific site from which this thesis can base its inquiry.

1 Rasheed, E., Khoshbakht, M., \& Baird, G. (2021). Office Distractions and the Productivity of Building Users: The Effect of Workgroup Sizes and Demographic Characteristics. Buildings, 1-17.

2 Gonzalez, V. M., \& Mark, G. (2004). “Constant, Constant, Multi-tasking Craziness”: Managing Multiple Working Spheres. CHI Conference on Human Factors in Computing Systems (pp. 113-120). Vienna: Association for Computing Machinery.

3 K2 Space. (N.D). Enabling Agile Working Through Office Design. Retrieved from K2 Space: https://k2space.co.uk/knowledge/enabling-agileworking-office-design/ 


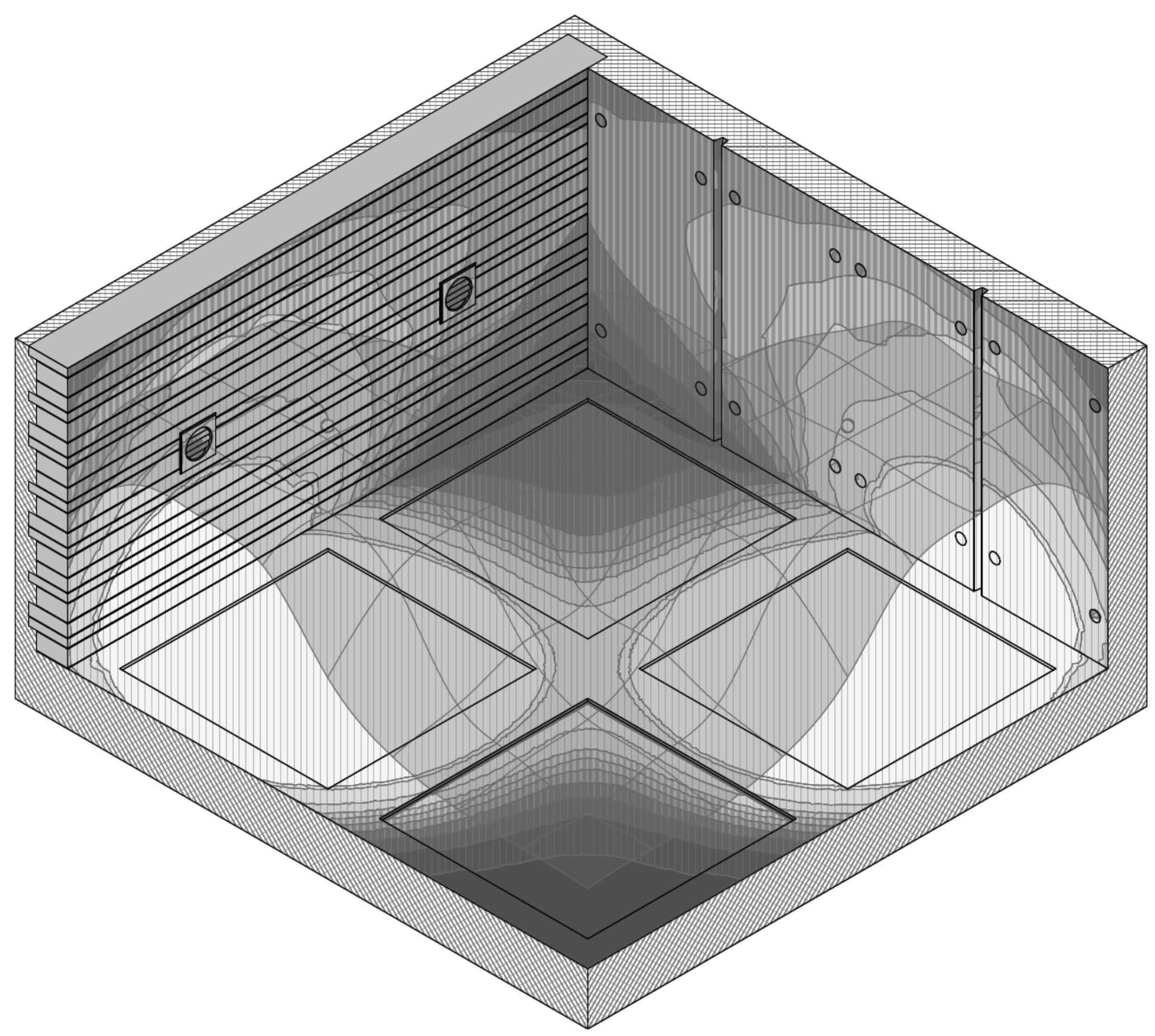




\section{Research Methodology:}

The initial stages of this thesis examined atmosphere through a broad context, and aimed to represent specific elements such as sound and temperature through a notational system. The research methodology supported this by examining existing notational standards found outside of architecture and applying them to prominent architectural works such as Peter Zumthor's Thermas Vals. Through the analysis of the interaction between these various notational systems, the atmosphere of these works could be codified and then utilised to design future works that exhibit original atmospheric qualities. These processes and their results are explained further in Appendix 1.

As the initial processes of this thesis elected to examine atmosphere through a broader context, the research methodology had to shift to reflect an interruptive agenda. The initial research period was highly influential in the development of the interruptive notational system, as it provided both the datasets and background knowledge required to develop its initial systems. Once developed these systems were trialled within a standardised office environment to identify the system's strengths and limitations prior to a full-scale implementation. After refining the system further, it was then utilised to retrofit an instance of office architecture with a non-interruptive agile outcome, this offering an insight into the implications which surround the design of interruption-aware spaces at scale. 


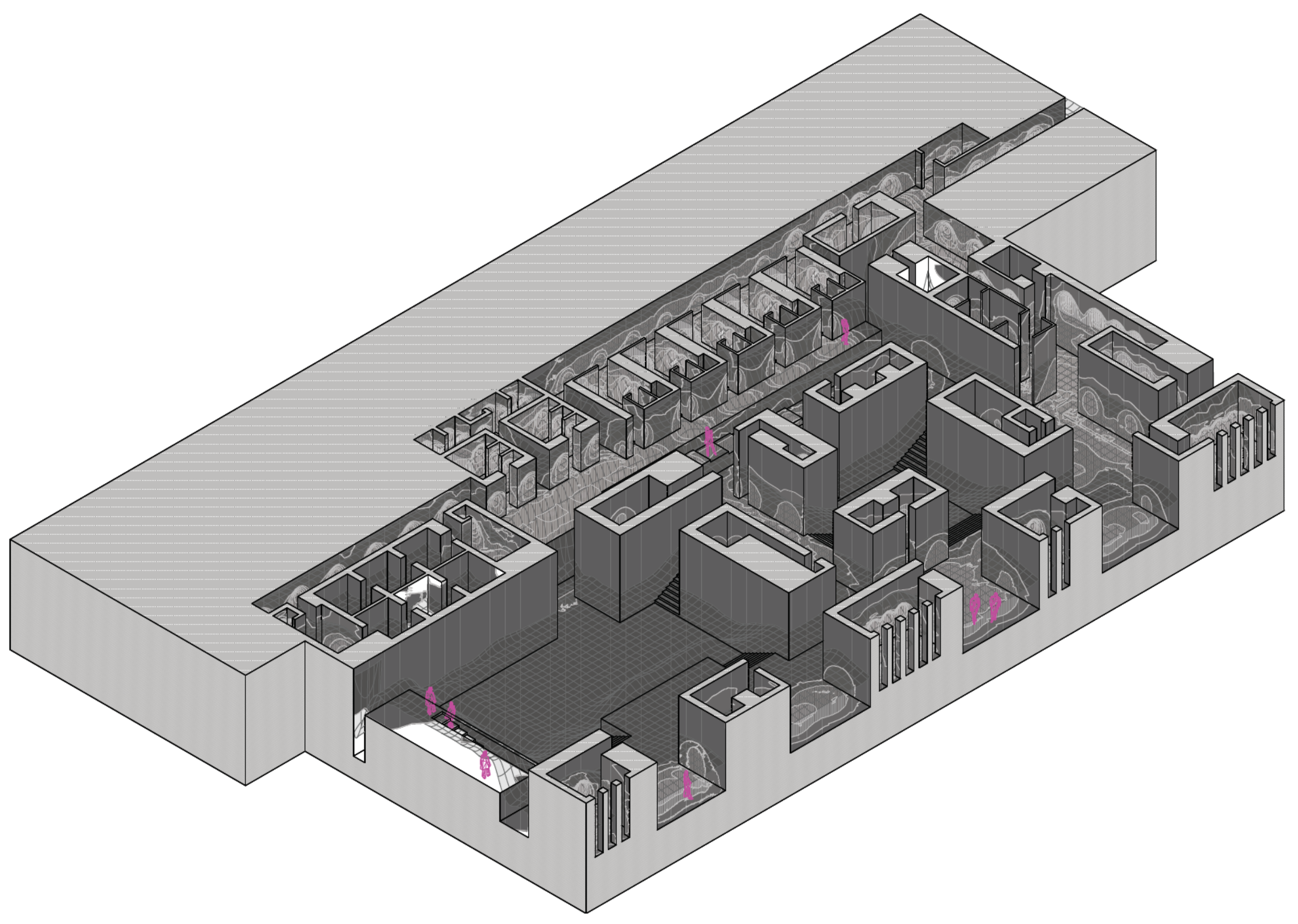




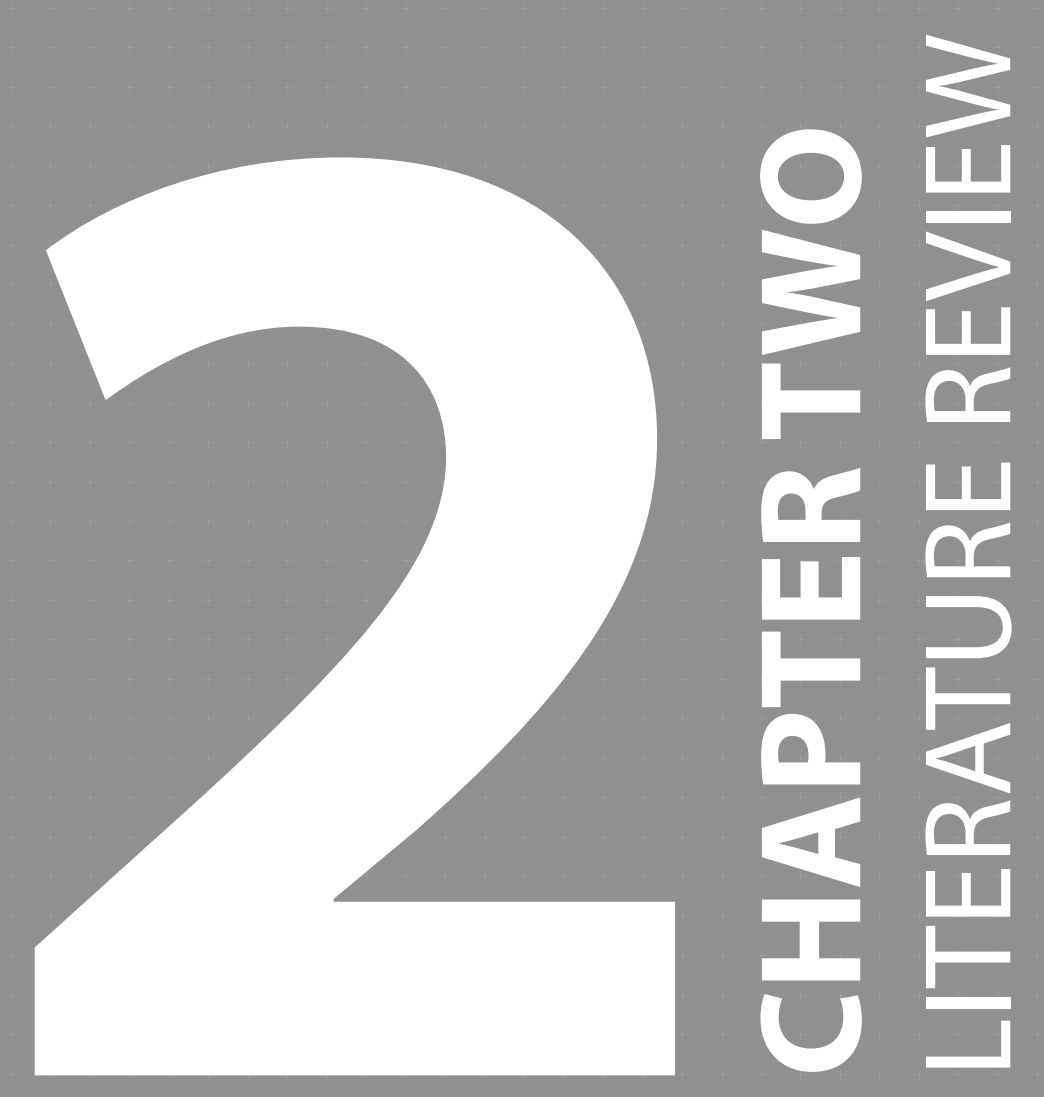






\section{Literature Review:}

Architectural literature often represents and discusses atmosphere in terms of the climatic, and rarely in terms of its social aspects. A notable instance of this is displayed in the photography of the Milstein Hall [Figure 2.1-2.2]. This is an active university campus normally filled with students. However, this project is almost exclusively shot devoid of life and at night in architectural publications. Likewise, architectural drawing do not nativly or explicitly engage with these factors meaning that social atmosphere, although often contributing greatly to the feel of a space is seemingly ignored by the wider discipline. This means that architects are ill equipped to proactively design and address atmospheric issues that arise from these aspects. A specific example of this occurs with the recent development of agile and flexible workspaces, where interruption has emerged as an important issue. The following chapter explores these issues through an examination of selected lititary works.

Mark Wigley can be viewed as an advocate of climatic atmosphere within the discipline, heralding that atmosphere is generated exclusively through a "sensuous emission of sound, light, heat, smell, and moisture" (Wigley, 1998, p. 18). This argument raised by Wigley in "The Architecture of Atmosphere," leaves little impression upon readers that atmosphere may be generated through any other means.

This sentiment creates a divide amongst the discipline when authors such as Gernot Bohme discuss atmosphere from a holistic viewpoint. Bohme addresses the social aspects as part of a wider understanding of atmosphere's climatic aspects, framing the two as "corporeal" and "non-corporeal,"[1] thus acknowledging the inherent ephemerality associated with social atmosphere. Bohme argues that these aspects must coexist as "the scientific consideration

1 Bohme, G. (2013). Atmosphere as Mindful Physical Presence in Space. OASE, 21-32. of human environments cannot rely solely on the categories of the natural sciences but must also involve concepts from the humanities" (Bohme, 2014, p. 92). This notion is also shared by Harpa Stefansdottir when discussing the scale of a city, suggesting that its atmosphere is temporal by nature and is thus defined by the "social interactions of people, places and objects" (Stefansdottir, 2018, p. 321).

Hillier and Hanson in their book The Social Logic of Space, discuss the notion of a boundary. This boundary is a barrier which disconnects an "arena of encounter possibilities" from a "domain of social knowledge" (Buildings and their Genotypes, 1984, p. 145). This arena is characterised as the wider city by the authors and defines its temporal atmosphere by the "social interactions of people, places and objects," this being the same concept discussed by Stefansdottir. By shifting from this collectively defined temporal atmosphere into to that contained within a building, users move into an atmosphere defined either by a predetermined collective or a governing force, this being the "domain of social knowledge." Within this space, Hillier and Hanson state that users will take either the role of the "inhabitant" or the "stranger." In the traditional office, users would likely embody the role of the inhabitant which the authors state allows for them to map their social existence to the confines of a given "cell" (room). In the agile office individual ownership is stripped from employees to allow for them to engage in the agile / flexible workflow, this meaning that employees no longer "own" a set desk. ${ }^{[2]}$ This protocol moves employees from the role of the inhabitant to that of the stranger, as they are now unable to pin their social existence to the "cell", as

2 Office Principles. (N.D). Designing an Agile Workspace for a Flexible Office. Retrieved from Office Principles: https://officeprinciples.com/5872-designing-an-agile-workspacefor-a-flexible-workforce/ 

they only occupy its various spaces temporarily, moving from one workspace to another to meet their needs. Employees "enter the building temporarily, but may not control it" (Buildings and their Genotypes, 1984, p. 146), Hillier and Hanson compare this to patients in a hospital or guests in a home.

Bohme acknowledges that the social aspects of atmosphere are rarely a primary generator of their totality, stating that they are mostly a function of "light and sound... specifically: music and illumination” (Bohme, 2014, p. 93). Despite this, Bohme posits that atmosphere in most cases is not noticed "precisely because of its ordinariness" (Bohme, 2014, p. 93). It could be argued that the social aspects of atmosphere in most cases are rarely more than ordinary when compared against their climatic counterpart, and consequently social atmosphere is often dismissed as having little significance. This is shown visually through the previously mentioned photography of the Milstein Hall, but is also discussed within the editorial "Building Atmosphere", by Havik, Teerds and Tielens. In this text, the trio draw upon their own experience and memory of atmosphere and recall instances such as the light filtered through the trees, and chairs located in the dark as atmospheric generators. They then place an emphasis on material, texture, tactility, light, shadow and aging. ${ }^{[3]}$ This line of thinking completely overlooks potential social aspects, possibly due to their ordinary nature.

It is this dichotomy and confusion between atmospheric elements that formulates the divide within the discipline. Bohme identifies social atmosphere as intrinsic to the creation of architectural atmosphere. Despite this, little research been conducted with regard to its architectural formulation. Wigley wrote that climatic atmosphere is formulated through a building's "sensuous

\footnotetext{
3 Havik, K., Teerds, H., \& Tielens, G. (2013). Building Atmosphere. OASE, 3-12.
}

emission of sound, light, heat, smell, and moisture" (Wigley, 1998, p. 18), but Bohme offers no similar criteria to generate social atmosphere.

As employees have been stripped of their status as inhabitants within the agile office, its governing force is now defined through architecture. Employees no longer have control over their spatial surroundings, meaning that if architecture formulates an interruptive social atmosphere, this is what employees must work within. While this may be influenced in part through employee behavioural patterns, their status as a stranger within the workplace keeps employees from pinning down any lasting social permanence. As the discipline fails to perceive this atmospheric outcome as more than ordinary it is able to operate unregulated within the office environment, resulting in the damages discussed prior (increased employee stress and lowered productivity).

Throughout the wider architectural discipline, it is evident that the effects of climatic atmosphere are well understood, but many publications often overlook or dismiss the social aspects of atmosphere that work in tandem with these phenomena. This disciplinary divide is critical in nuanced atmospheric environments as it allows for undesirable qualities such as those of an interruptive nature to generate. Within the agile office this is amplified through the removal of an employee's status as an inhabitant, and creates a need for architectural designers to not just understand but also recognise and engage with the ordinary aspects of social atmosphere in the design process. 


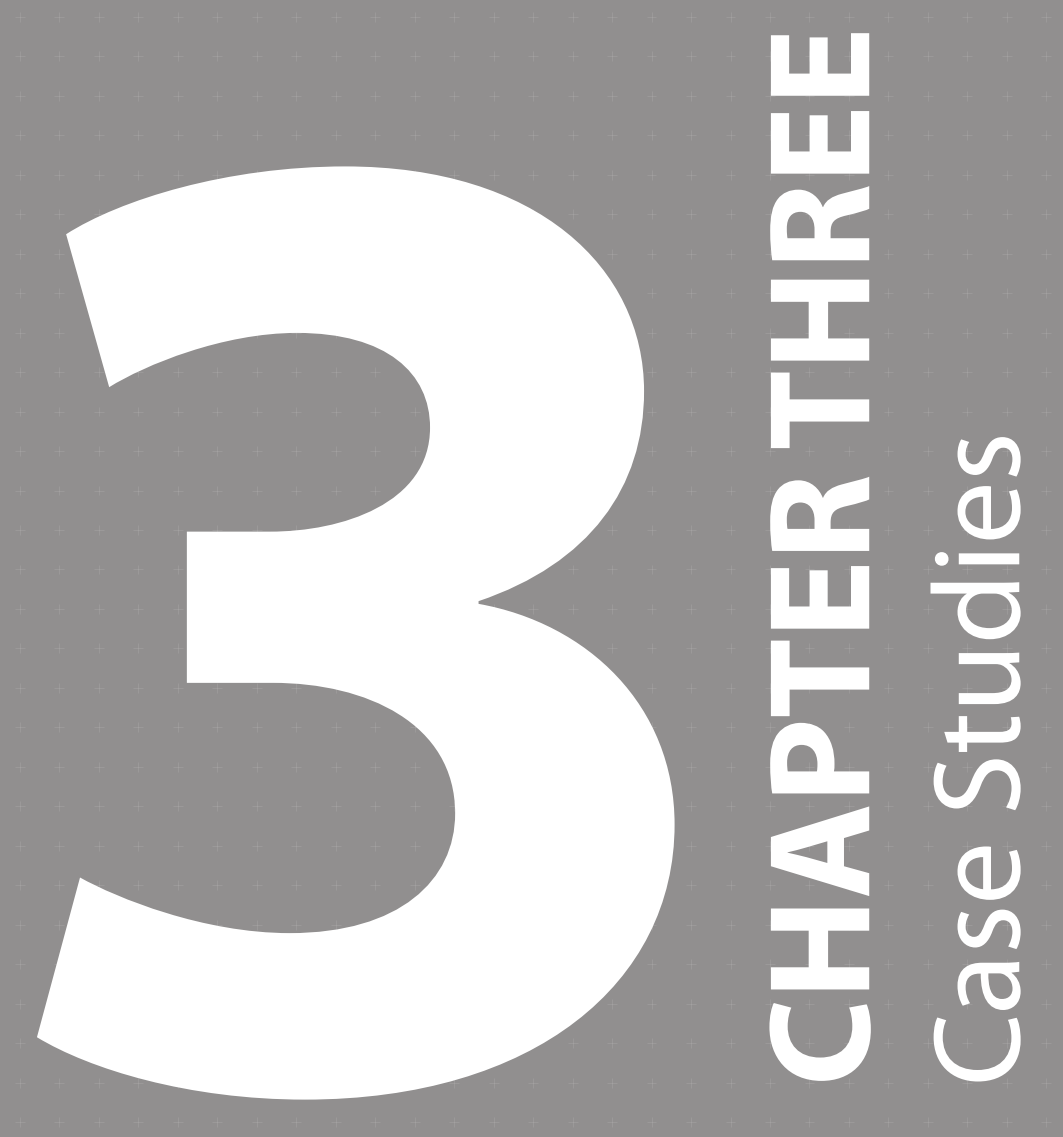



As the agile office is an emerging typology in the corporate world, many practitioners have yet to establish a number of design standards which would enable it to operate effectively. Practitioners who do not yet fully understand the facilities and functions of the agile office often overlook key aspects of its operation. Specialist companies such as K2 Space, HMC Architects, and Zenbooth serve as a point of reference for this, outlining throughout various articles the immediate needs and requirements of an effective agile office for practitioners.

Workplace variety is a common theme among these articles, as each firm advocates for spaces such as concentration pods, meeting booths, tall tables and informal meeting spaces [Figure 3.1]. This workspace variety enables employees to work where their needs are best met, regardless of whether their work is collaborative or individual. ${ }^{[1]}$ Each firm advocates for the reconfigurability of these spaces as the needs of an agile office are rarely fixed, and must allow for a number of configurations to suit a given project. ${ }^{[2]}$ Spatial tailoring builds upon this variety to ensure that departments are not provided with redundant facilities. The assignment of open collaborative space to a human resource department exemplifies this issue, as the private nature of the work requires an individual agile workspace to operate effectively. ${ }^{[3]}$

1 Zenbooth. (2018, May 14). A Guide to Agile Workspaces: Why You Should Transform Your Office Now. Retrieved from Zenbooth: https:// zenbooth.net/blogs/zenbooth-blog/an-ode-to-agile-workspaces-why-you-should-transform-your-office-now

2 K2 Space. (N.D). Enabling Agile Working Through Office Design. Retrieved from K2 Space: https://k2space.co.uk/knowledge/enabling-agileworking-office-design/

3 HMC Architects. (N.D). The Best Flexible Workspace Design Strategies. Retrieved from HMC Architects: https://hmcarchitects.com/ thought-leadership/flexible-workspace-design-strategies-slp/ 

Vodafone Headquarters - Innov8:

\section{Project Information:}

Client:

Location:

Vodafone
Auckland, New Zealand

Completion:

Project Type:

Architect:

Warren \& Mahoney

The Vodafone Headquarters [Figures 3.2 - 3.5] located in Auckland serve as the company's first foray into the agile and flexible workflow in New Zealand. The project was designed by Warren \& Mahoney and completed in 2018. The design retrofits the Telstraclear building acquired by Vodafone in 2012 and enables them to house up to 2000 staff across six levels. The buildings design centres around a central atrium which serves as the main circulatory pathway from which all offices diverge from. Throughout the building, staff are met with several amenities such as an onsite café, recreational facilities and a medical consultation space. ${ }^{[1]}$

Throughout the documentation that surrounds this build, no formal mention has been made regarding interruption and the design decisions employed to mitigate its effects. This is not to say that interruption was not a concern within the build, but rather that it was not a driving design consideration for this particular project. Despite this, it is evident that interruption was a consideration at points in the design process.

1 South, G. (2018, September 7). The future of the workplace: Inside Vodafone's new North Shore HQ. Retrieved from New Zealand Herald: https://www.nzherald.co.nz/business/the-future-of-the-workplace-inside-vodafones-new-north-shore-

hq/4YPWLEISTZTADZZWYTUNMFBCBE/ 

Warren \& Mahoney state that the atrium serves as a "vibrant heart within the building [that] encourages occupants to interact” (Warren \& Mahoney, N.D). This design decision moves casual employee interaction outside of the office work area, resulting in increased productivity for those in these workspaces. This is then reinforced through the implementation of staff hubs at the atrium's edge and connecting bridges between offices. These spaces act as buffers, providing employees with additional space to interact outside of the office work area, thus reducing disruption within. This design strategy is one that the New Zealand Government Property Procurement Group (NZGPPG) advocates for in the design of their offices. ${ }^{[1]}$

Expanding upon this, expected elements such as collaborative areas, private spaces and meeting rooms have been provided by Warren \& Mahoney. These spaces are accessed and booked by staff via a mobile phone app which also enables them to enter the building and their lockers through various sensors. ${ }^{[2]}$ This technological implementation enables staff to move and work freely throughout the building, ensuring their needs are best met without impedance [Figures 3.3 - 3.4].

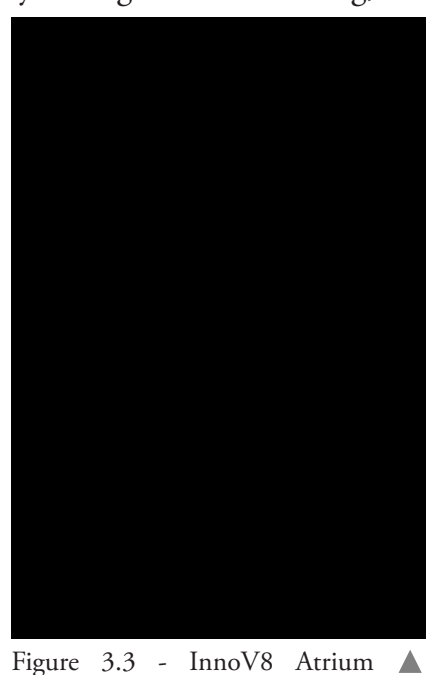

Office View - Warren\& Aahoney

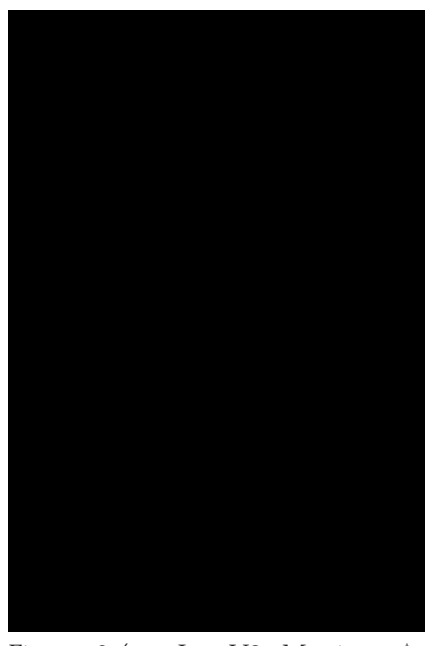

Figure 3.4 - InnoV8 Meeting $\Delta$ Space - Warren\& Mahoney

1 New Zealand Government Property Procurement Group. (N.D). Open-plan working environment and consistent design. Retrieved from New Zealand Government Property Procurement Group: https://www.procurement.govt.nz/property/workplace-design-guidelines/principles-for-office-design/open-plan-working-environment-and-consistent-design/

2 Vodafone. (2018, September 5). Vodafone officially opens workplace of the future in Auckland. Retrieved from Vodafone: https://news. vodafone.co.nz/article/vodafone-officially-opens-workplace-future-auckland 



\section{Sky Central Headquarters:}

\section{Project Information:}

\section{Client:}

Location:

Completion:

Project Type:

London, England

New Build

Architect: AL A, PLP Architecture, Hassell

The Sky Central Headquarters [Figures 3.6 - 3.8] located in London serve as a major leap for the agile and flexible workflow, exploring its possibilities through a large-scale new build. The building was a collaborative design created by architects AL_A, Hassell and PLP Architecture and was completed in 2016. The building distributes 3,500 staff across three floors, these cut along their centre to form an enlarged atrium for staff to work, relax and move throughout. The building's design centres around this space and aims to create a series of village-style work environments which radiate outwards. Throughout the building, staff have access to several amenities such as restaurants, a 200-seat cinema and even a supermarket. ${ }^{[1]}$

Like the Vodafone Headquarters, little formal documentation surrounds the interruptive design strategies of the Sky Central building. PLP Architecture alludes to this design focus, stating that the "unique and high-quality design promotes collaboration and efficient task-based working" (PLP Architecture, N.D) but fails to disclose which design decisions led to this efficiency. Despite this, it is evident that workplace interruption was at least a consideration throughout the design process.

1 Arch Daily. (2016, December 26). Sky Central / AL A + PLP Architecture + HASSELL. Retrieved from Arch Daily: https://www.archdaily. com/802043/sky-central-al-a-plus-plp-architecture-plus-hassell 

Hassell's involvement with the project was through its workplace design, and from their input the concept of the village was developed. Hassell elected to segment the open stylings of the office into distinct neighbourhoods, and intersperse lounge seating and planting throughout. Hassell claims that this makes the space "naturally easy to use" (Hassell, N.D) but it is also likely to reduce workplace interruption. In this scheme [Figure 3.7] solo workspaces have been provided as expected of an agile office, but are located at the furthest radial points from the design's central atrium. This likely reduces the noise and disruption within these areas and allows for collaborative space to remain central where these effects may be beneficial. ${ }^{[1]}$

This ease of use that Hassell discusses is likely reinforced through a visual disconnection between these neighbourhoods. Partitions both solid and permeable, are arranged throughout these neighbourhoods to create zones that house up to 200 people [Figure 3.8]. "This prevents the loss of intimacy often found in vast spaces and instead makes each neighbourhood feel more homely and communal" (Workagile, 2019). This reduced scale likely contributes to further reductions in workplace interruption by minimising visual sightlines and workgroup sizes.

Sky, to ease the transition to agile working for employees and ensure an efficient workplace, implemented a series of programmes such as live labs, roadshows, and agile work training seminars prior to moving into the new building. It was this "change management programme that brought the space to life" (Pak, 2019).

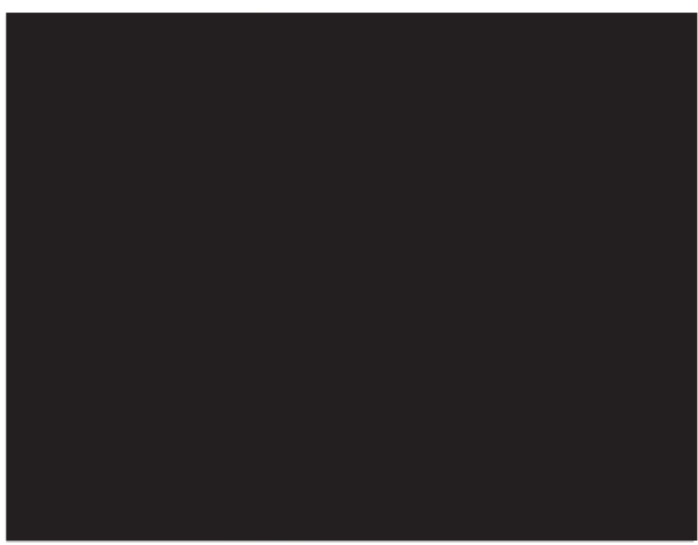

Figure 3.7 - Sky Central Village Model Diagram - PLP Architecture $\Delta$

1 Mehta, R., Zhu, R. J., \& Cheema, A. (2012). Is Noise Always Bad? Exploring the Effects of Ambient Noise on Creative Cognition. Journal of Consumer Research, 784-799. 



\section{Sharecuse Coworking Space:}

\section{Project Information:}

\section{Client:}

Location:

Sharecuse

Completion:

Syracuse, United States of America

Project Type:

Retrofit

Architect: Architecture Office

The Sharecuse Coworking Space [Figures 3.9 - 3.11] located in Syracuse serves as an example of poor agile workplace design. The project, designed by Architecture Office, was completed in 2019 and retrofits the 1928 Syracuse office building. Up to 25 employees can be housed and distributed throughout this $220 \mathrm{~m}^{2}$ rentable coworking space, the design of which centres around a series of mesh cubicles and collaborative areas. Unlike in the design of the Vodafone and Sky Headquarters, employees are met with few workplace amenities outside of a kitchenette and locker space. This is likely a factor of its scale rather than its design.

Across the documentation that surrounds this retrofit released by both the architect and media publications, no formal mention has been made regarding interruption and the design decisions which effect it. This does not necessarily indicate that it was not a design consideration, but rather that it was not a design driver. Despite this it is evident that the decisions made throughout this project may worsen the overall interruptive atmosphere.

In the design of this space, Architecture Office elected to create a series of bespoke office cubicles, these built primarily from mesh screens. The firm claims that this was to "filter the appearance of the spaces behind" whilst allowing the cubicles to "appear monolithic as single black forms" when viewed from a distance. ${ }^{[1]}$ In examining the photos taken by Caylon Hackwith this is shown to be ineffective, as the cubicles appear near transparent regardless of viewing distance [Figure 3.9]. This encourages an interruptive atmosphere in the workplace, as visual disruptions are likely to ensue with limited employee privacy. In addition to this, these mesh screens when combined with minimal sound damping materials and hard surfaces, create a space in which allows for aural disruptions.

1 Architecture Office. (N.D). Sharecuse. Retrieved from Architecture Office: https://architectureoffice.org/sharecuse/ 

The lighting systems that are built into these cubicles allow for employees to tailor the lighting level at their workstations, but at the same time it is hardwired through the buildings floor and acts as a tether. The lighting thus immobilises the workstations and pins them to their current positions in the office, meaning the space cannot be modified later to meet changing employee needs [Figure 3.10].

Building upon this, the seven individual workspaces provided in the design are glazed and directly face the central office space. This glazed frontage can create unnecessary visual or aural distractions for employees [Figure 3.11]. These distractions are then amplified through the placement of the kitchen island which runs alongside the solo workstations. The architects claim that this acts as a "conduit for congregation and interaction," ${ }^{[1]}$ but only provides an additional source of interruption. This furthers the visual disruption but also introduces increased noise levels around the solo workspaces.

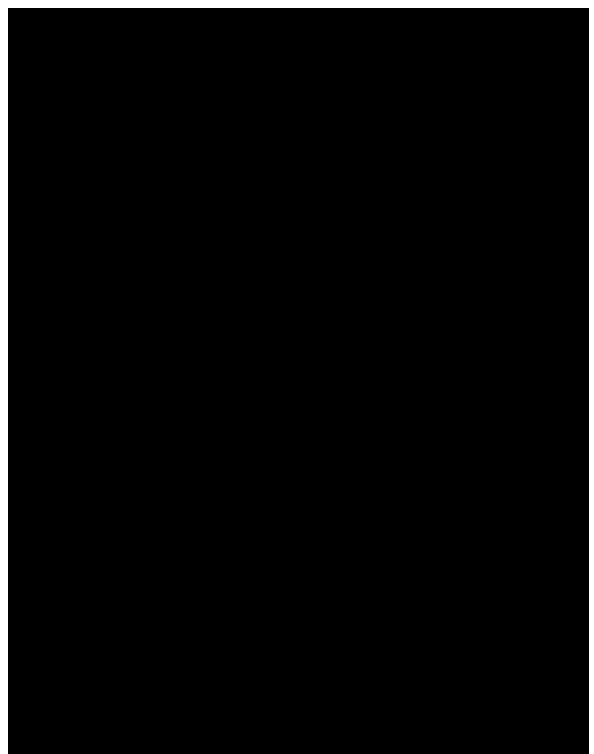

Figure 3.10 - Hardwired Electrical Connection Through Floor - Caylon Hackwith

1 Archipreneur. (2019, November 25). New Work Environment: A Flexible Office Space by Architecture Office. Retrieved from Archipreneur: https://archipreneur.com/new-work-environment-a-flexible-office-space/ 



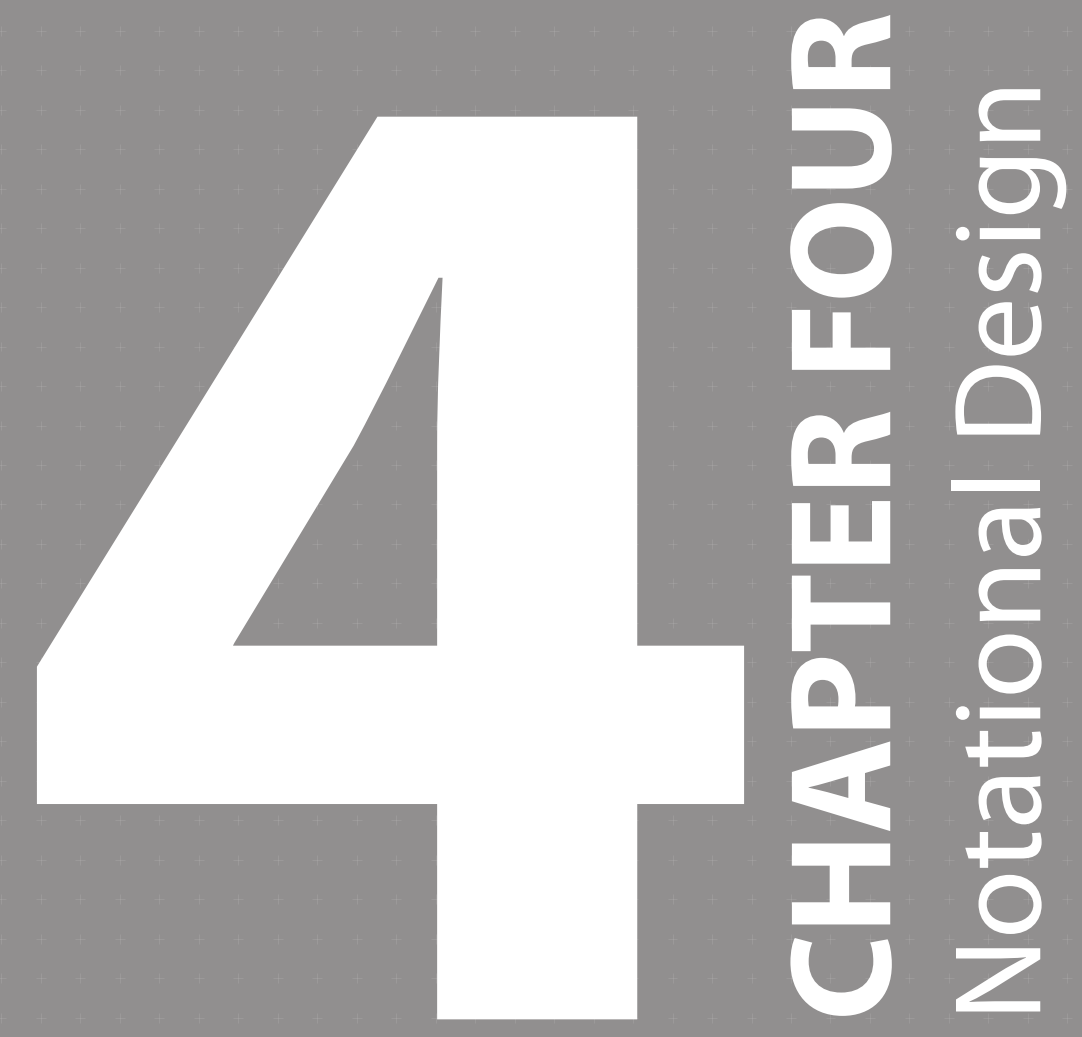





\section{Notational Background:}

The initial design stage of this thesis aimed to address the generators of atmosphere heralded by Mark Wigley in "The Architecture of Atmosphere." Again, in this text Wigley outlines "sound, light, heat, smell, and moisture" as the primary generators by which atmosphere is formulated. Design Stage One made attempts to codify these aspects to allow for the identification and design of these specific atmospheric qualities. This was facilitated through digital simulation and traditional drawing techniques (these processes and their findings are discussed further in Appendix 1). Despite these efforts this design stage solely identified that the atmospheric qualities heralded by Wigley formulate only a piece of an atmosphere's totality, thus necessitating a change in focus.

The approach adopted to decode architectural atmosphere in this design stage was heavily limited. The adopted processes established an overreliance on digital simulations and their various software packages, many of which notational users may not have access to, or familiarity with. This overreliance resulted in the system becomes cumbersome and creates a disconnect between the drawing and the atmospheric outcome.

Acknowledging this issue, it was critical that this thesis' goal of creating an interruptive notational system did not demonstrate these same limitations. To reflect this, the system heavily prioritised a direct connection between the drawing and the atmospheric outcome. This connection was facilitated through the design of various drafting tools and calculative processes - these not reliant on the computer to obtain results but merely utilising it to streamline their formulation.

Acknowledging the limitations of the previous works, this design phase endeavours to explore the nuances of social atmosphere in terms of interruption and the corporate office. In the corporate world, interruption is an increasingly important issue heightened by the shift from the open plan offices to the agile flexible workspace. This shift introduces employees to a higher degree of workplace collaboration and removes employee ownership from items such as desks. These changes induce a higher degree of interruption into the workspace and it is pertinent that this is addressed in the coming years. Acting upon this, this stage of the research aims to establish drawing conventions to represent and assist in designing for workplace interruption.

The data obtained from Victor M Gonzalez \& Gloria Mark's paper “'Constant, Constant, Multi-tasking Craziness': Managing Multiple Working Spheres" serves as the basis of the interruptive notational system. The paper explores workplace interruption in depth, examining its various types and their interruptive capabilities. This establishes the interruptive events that the notational system aims to examine and sets their baseline interruptive weightings. Gonzalez 
\& Mark obtained this data through participant observation and long form interviews. For the purposes and intents of this thesis this data has been assumed as an accurate representation of workplace interruption and is considered to be applicable to all offices. The data obtained by Gonzalez \& Mark [Figure 4.1] highlights that $50 \%$ of our interruptive experience is internally created, meaning that it is generated by the employee. This data also provides an indication of the most common workplace interruptions. Interruptions such as a person arriving $(21.45 \%)$, leaving the cubical $(17.87 \%)$ or a new email notification $(12.68 \%)^{[1]}$ are most present, this forming a line of inquiry for the notational system to address.

To articulate the data provided by Gonzalez \& Mark, author Lawrence D Rosenblum's book See What I'm Saying: The Extraordinary Powers of Our Five Senses was used as reference. Here Rosenblum broadly discusses the human senses, examining how they are used to perceive our surroundings. Rosenblum touches on the extent to which each sense is utilised, claiming that sight accounts for $83 \%$ of our sensorial usage, hearing $11 \%$, smell $3.5 \%$, touch $1.5 \%$, and taste $1 \%{ }^{[2]}$ This identifies a basis by which the interruptive weightings established by Gonzalez and Mark can be altered through user perception.

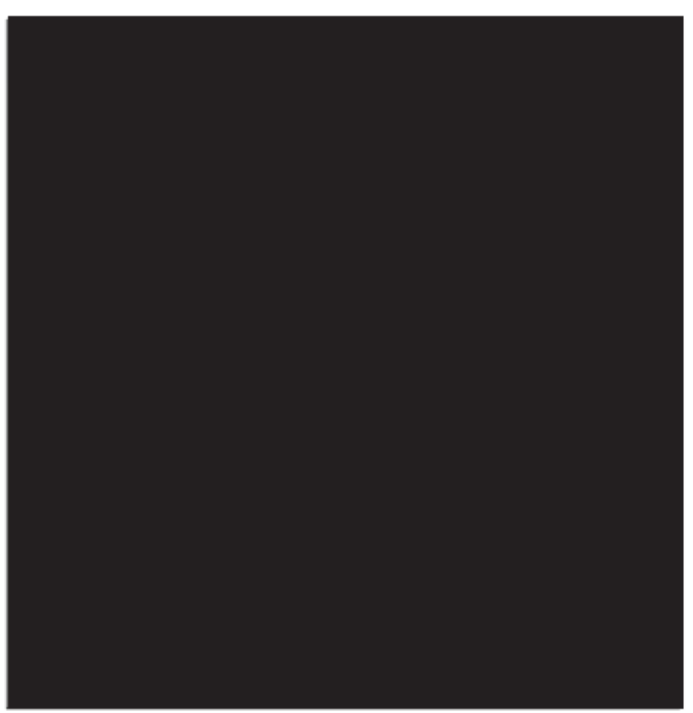

1 Gonzalez, V. M., \& Mark, G. (2004). “Constant, Constant, Multi-tasking Craziness”: Managing Multiple Working Spheres. CHI Conference on Human Factors in Computing Systems (pp. 113-120). Vienna: Association for Computing Machinery.

2 Rosenblum, L. D. (2010). See What I'm Saying: The Extraordinary Powers of Our Five Senses. New York: W. W. Norton \& Company. 


\section{Notational Design:}

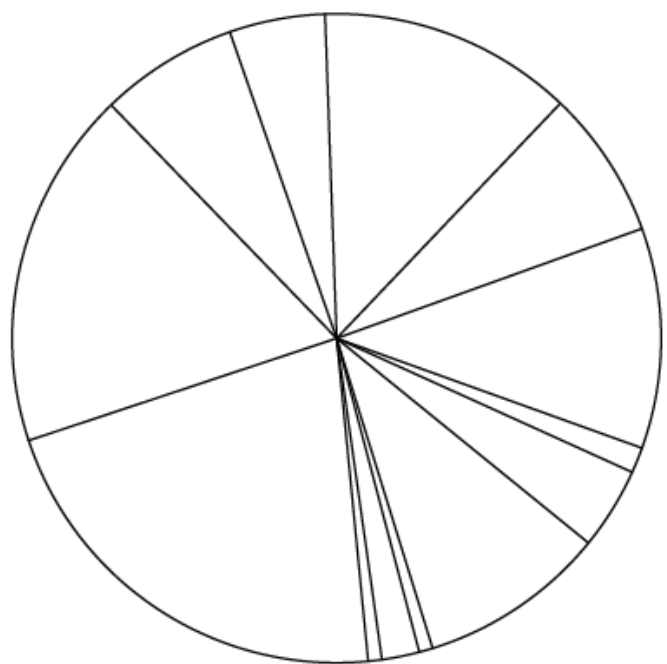

Default Circular Sections

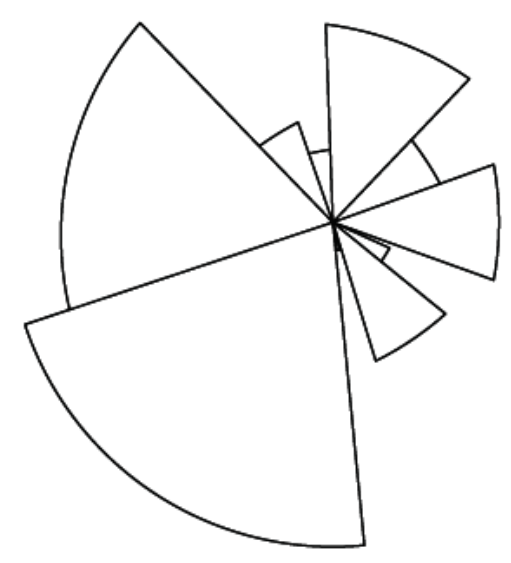

Radially Scaled Circular Sections

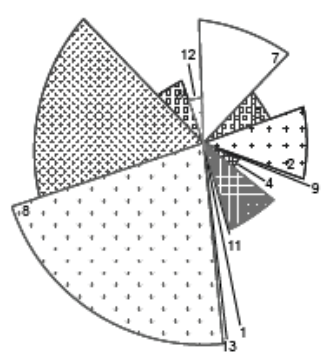

\begin{tabular}{|c|c|}
\hline & $\underset{1}{\text { Using / Checking Paper Documen }}$ \\
\hline & $\begin{array}{l}\text { E-mail Use } \\
5\end{array}$ \\
\hline & $\underset{9}{\text { Checking Terminal Status }}$ \\
\hline & $\begin{array}{l}\text { Reminder Notification } \\
13\end{array}$ \\
\hline
\end{tabular}

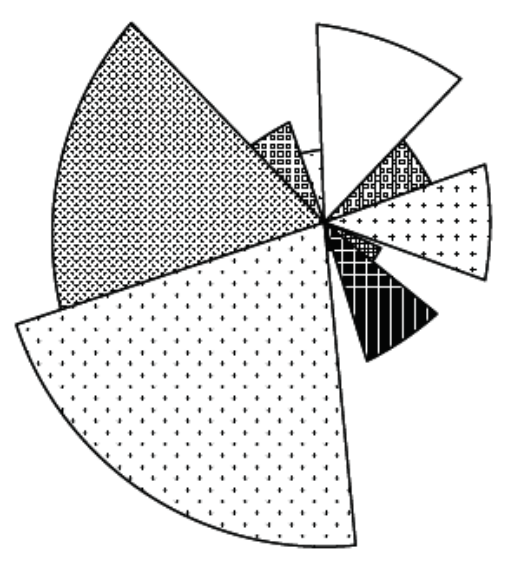

Hatched Circular Sections

\begin{tabular}{|c|c|}
\hline 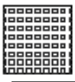 & $\begin{array}{l}\text { Talking Through The Wall } \\
3\end{array}$ \\
\hline & $\begin{array}{l}\text { New E-mail Notification } \\
7\end{array}$ \\
\hline & $\begin{array}{l}\text { Voice Message Light } \\
11\end{array}$ \\
\hline
\end{tabular}

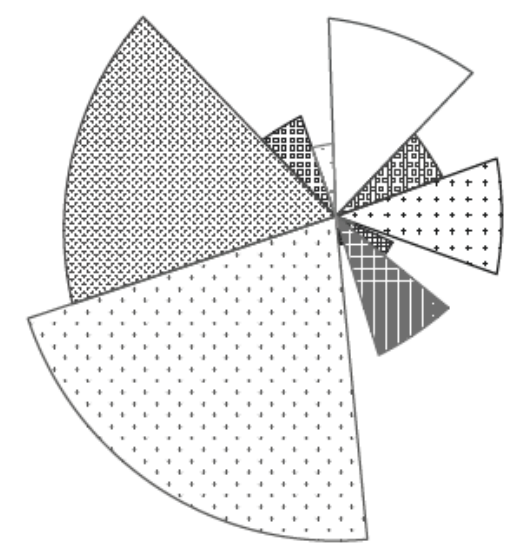

Colourised Circular Sections

\begin{tabular}{|c|c|}
\hline 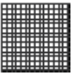 & $\begin{array}{l}\text { Phone Call } \\
4\end{array}$ \\
\hline & $\begin{array}{l}\text { Person Arrives } \\
8\end{array}$ \\
\hline & $\begin{array}{l}\text { Call Through Wall } \\
12\end{array}$ \\
\hline
\end{tabular}

When beginning to first map the interruptive data provided by Gonzalez and Mark, circular sections were selected as the representational basis of this notational system. This mode of representation was chosen as it provides a simple means of distinguishing one interruptive event from another, while indicating which interruptive event is most significant or heavily weighted upon the employee. To visually distinguish one interruptive event from another, each circular section was radially scaled based upon its interruptive weighting. These scaled events were later hatched and colourised using standard AutoCAD fill patterns and a grayscale to further this visual distinction. The scale at which this system is drafted within a drawing does not bear influence over the interruptive outcome, only its visual presence in the drawing [Figures 4.2 -4.3] 


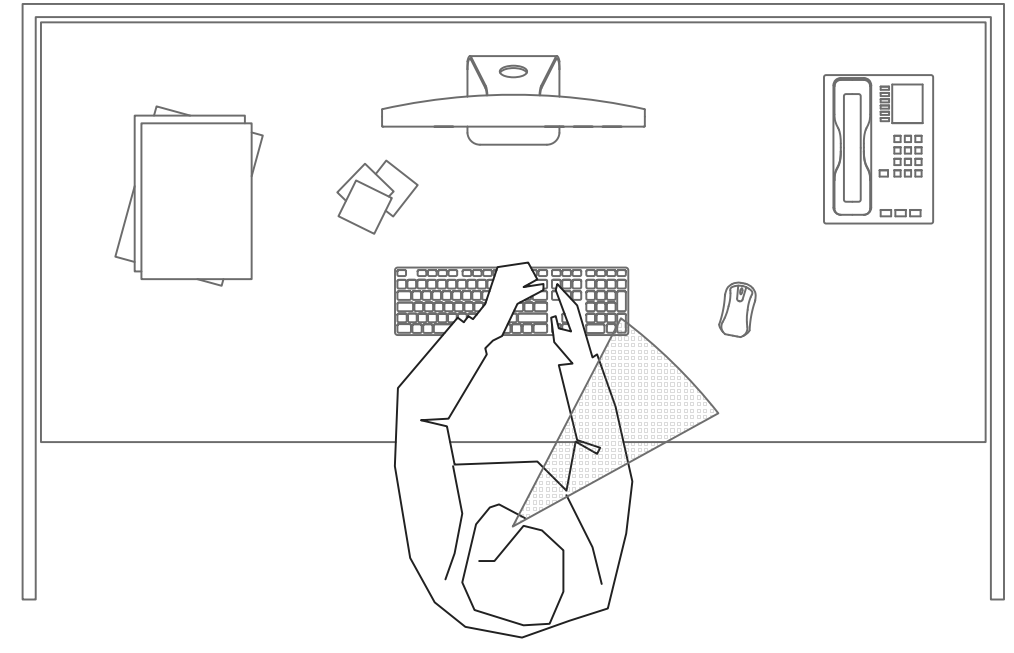

Interruptive Event - Phone Call - Interruptive Weighting

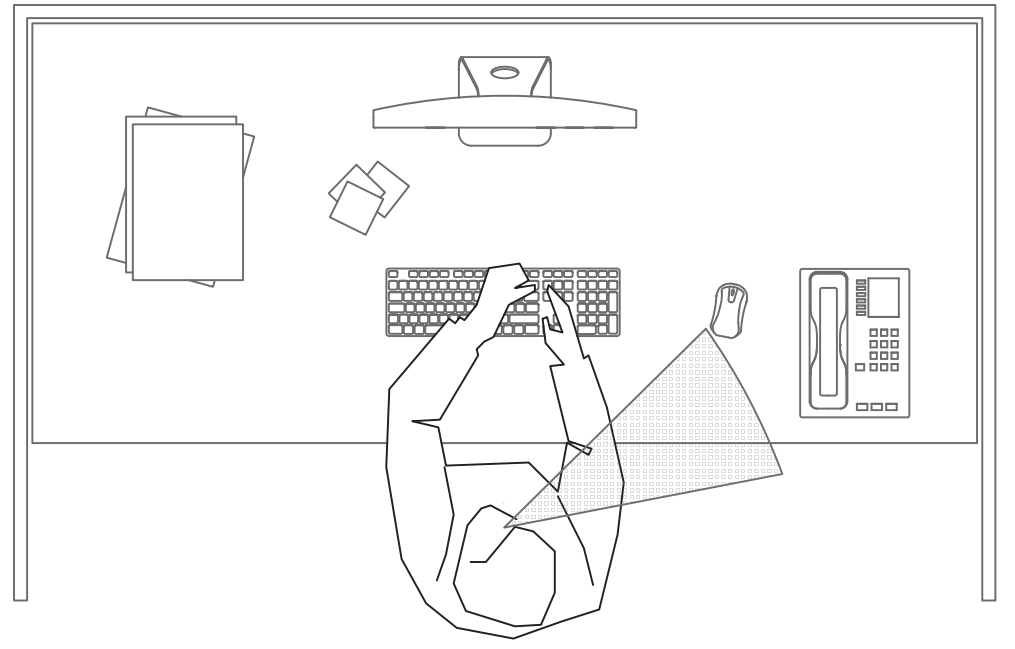

Interruptive Event - Phone Call - Increase In Interruptive Weighting

This notational system is beneficial in representing the relationship between the employee, the interruptive event and the architecture. Through the system's implementation, users are able to visually tie the interruptive source to the employee through its draft angle, thus establishing a relationship between the two. The system, by then responding to architectural alteration through an increase or decrease in the interruptive outcome, establishes a relationship between architecture and the employee, and architecture and the interruptive event [Figure 4.4]. 


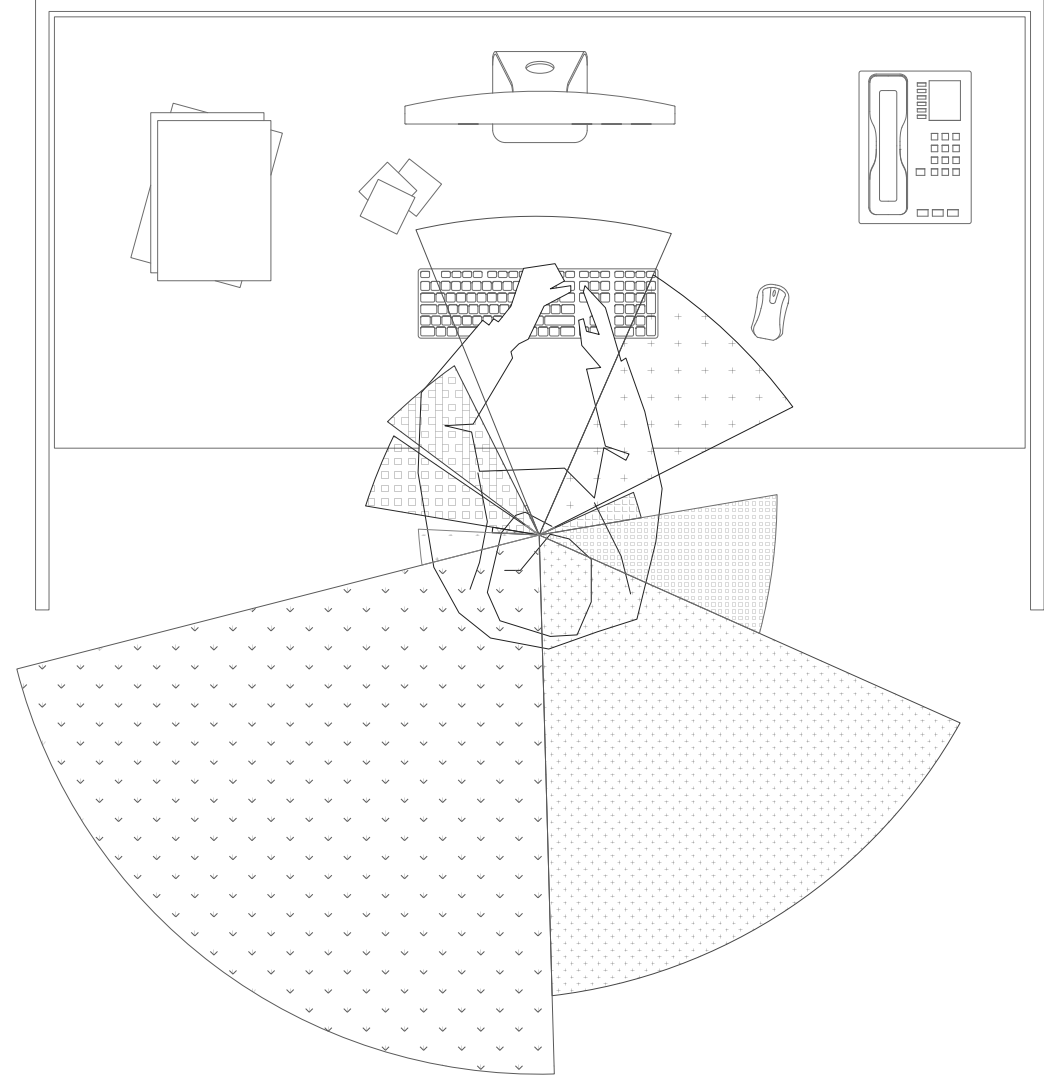

No Overlap In Circular Sections

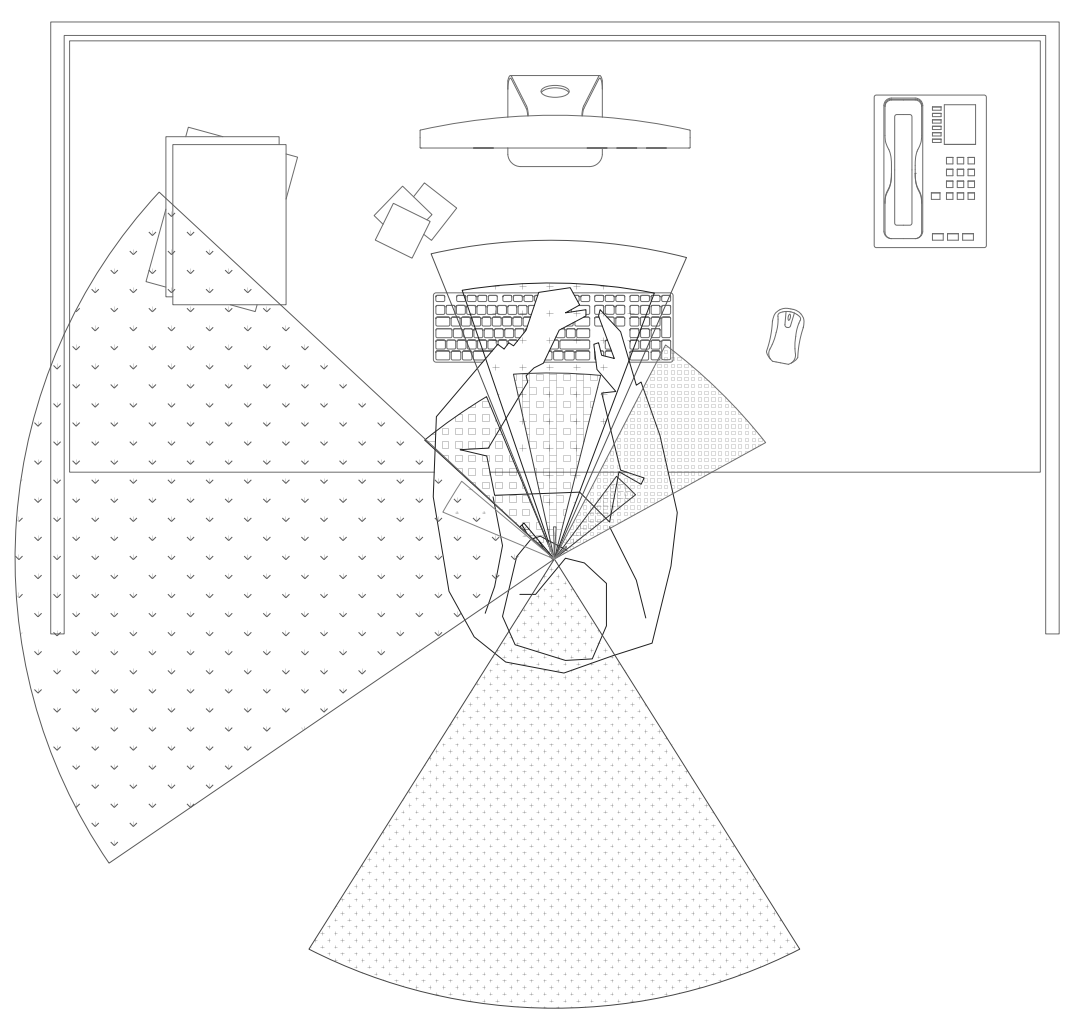

Overlap In Circular Sections

The circular sections developed to represent an employee's perceived interruptive outcomes were designed to act as an overlay. In the initial trial of these circular sections, legibility was considered critical to the systems success and so these sections were kept from overlapping with one another. This action created a disconnect between the employee interruption relationship and in turn these sections were allowed to overlap where appropriate to maintain the visual connection. [Figure 4.5]. 


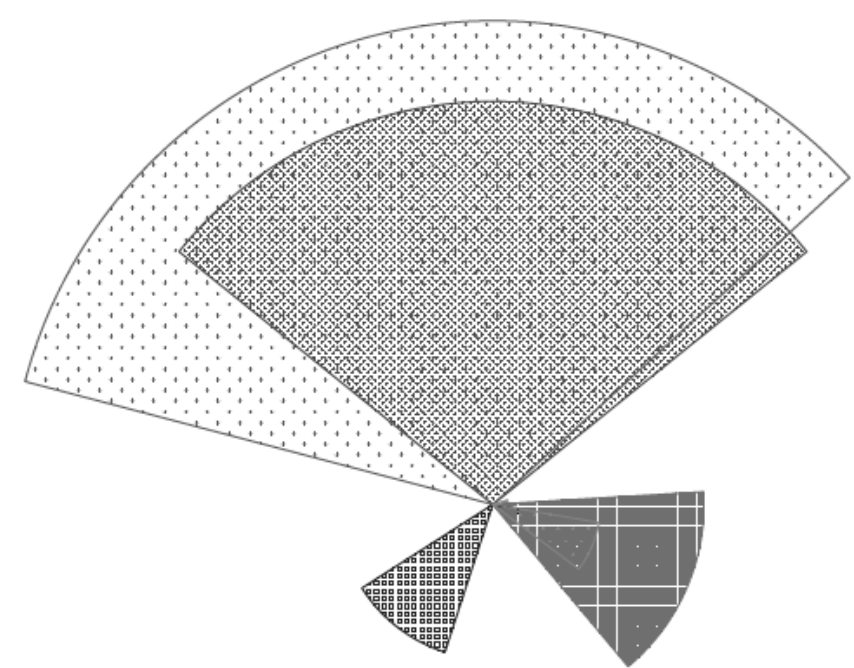

Proportional Division Of Removed Interruptions

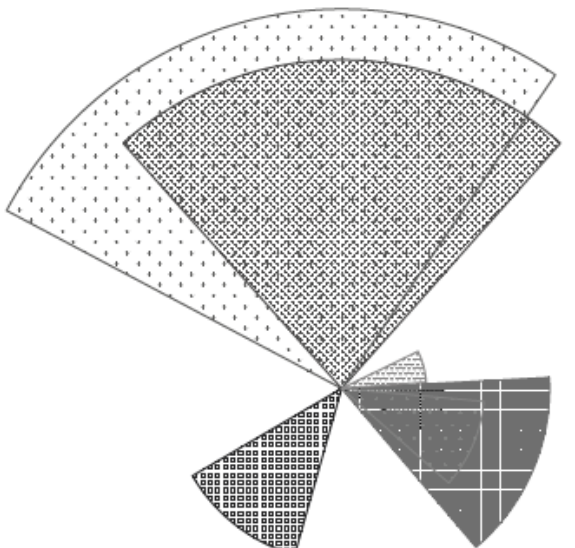

Equal Division Of Removed Interruptions

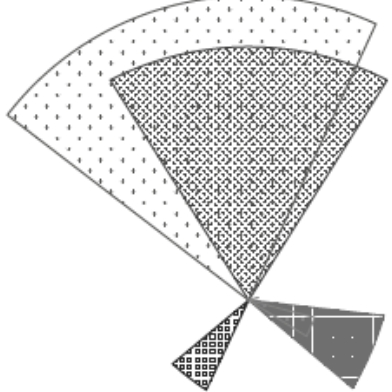

No Division Of Removed Interruption

Throughout subsequent trials of the notational system, it was clear that not all interruption types are applicable to a given employee in any one instance. An employee's interruptive outcome is a factor of the interruptions they are subjected to. In instances were an employee moves from their desk to attend a meeting, they remove themselves from specific interruptions such as those experienced through the computer. Because an employee is no longer exposed to these interruptions, their sensitivities to others are heightened ${ }^{[1]}$. Consequently, absent interruptions are assigned a zero value and their prior weighting values are distributed proportionally amongst the remaining interruption types to maintain accurate relativities. [Figure 4.6].

1 Vernet, M., Japee, S., Lokey, S., Ahmed, S., Zachariou, V., \& Ungerleider, L. G. (2019). Endogenous visuospatial attention increases visual awareness independent of visual discrimination sensitivity. Neuropsychologia, 297-304. 

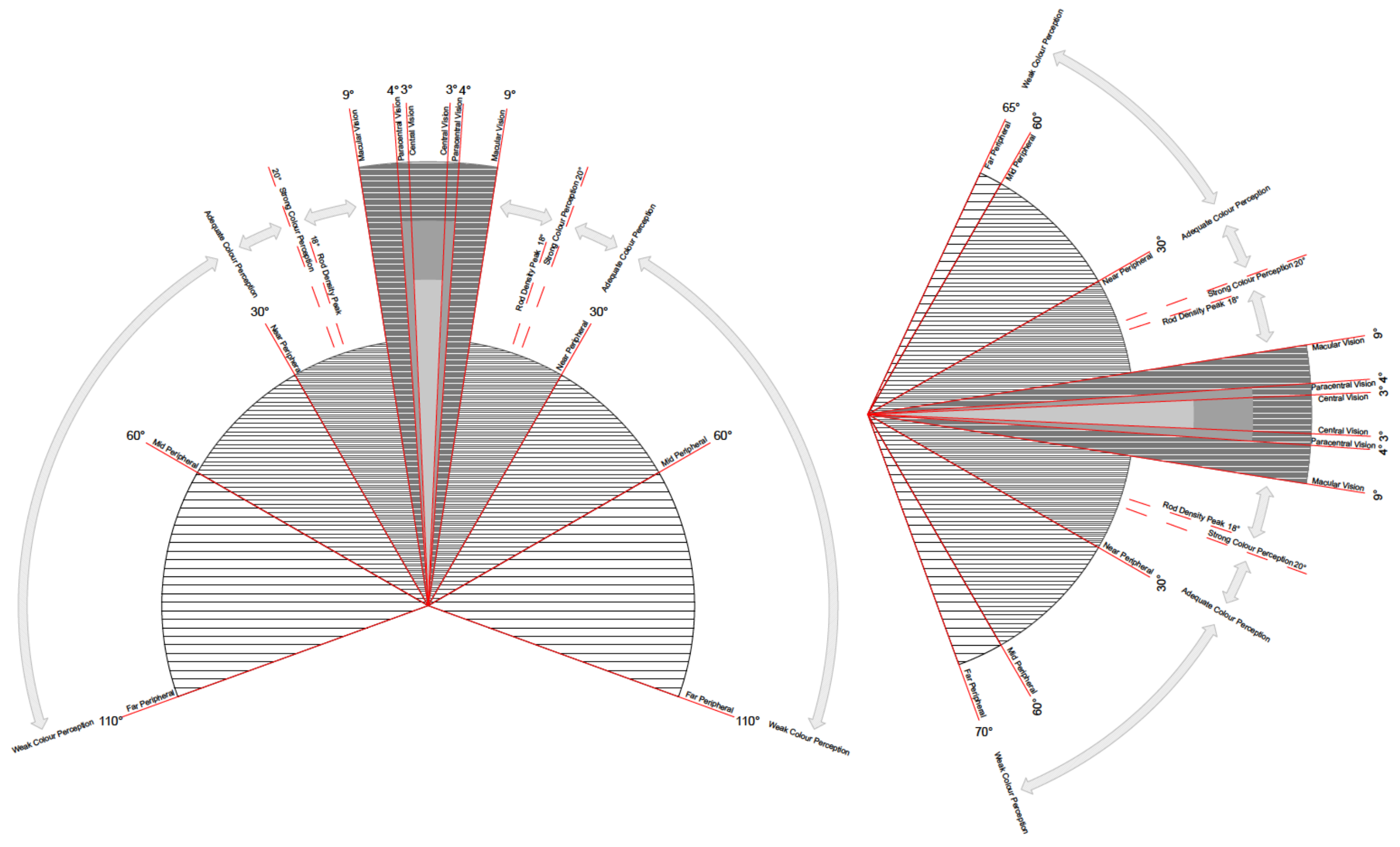
Four sensorial tools were developed to reflect an employee's sense of sight, hearing, smell and touch. Taste was excluded as it has a minimal impact upon interruption in the workplace. These tools were modelled to reflect an employee's physiological perceptibility such as their peripheral vision. These tools were split into a series of zones which reflect the changing perceptibility due to a spatial relationship (e.g. proximity for smell; distance and angle for sight etc). This series of zones and patterns present in each sensorial tool have been labelled as Alteration Zones and each have been assigned an Alteration Factor.

The alteration factors established by these tools act as multipliers, altering the baseline interruptive weighting established by Gonzalez \& Mark. The degree to which these tools alter said weightings is derived through a series of logarithmic and parabolic functions which are formulated to approximate subjective perceptibility of an employee. The validity could be tested and revised following future research if required.

The vision cone / alteration zones of the sight sense tool [Figure 4.7] are derived from the typical human range of vision, including peripheral vision. The central vision cone represents where sight is strongest, but this weakens peripherally allowing for alterations factors to be derived and applied. ${ }^{[1]}$

1 Lungaro, P., Sjoberg, R., Valero, A. J., \& Mittal, A. (2018). Gaze-Aware Streaming Solutions for the Next Generation of Mobile VR Experiences. IEEE Transactions on Visualization and Computer Graphics, 99-109. 


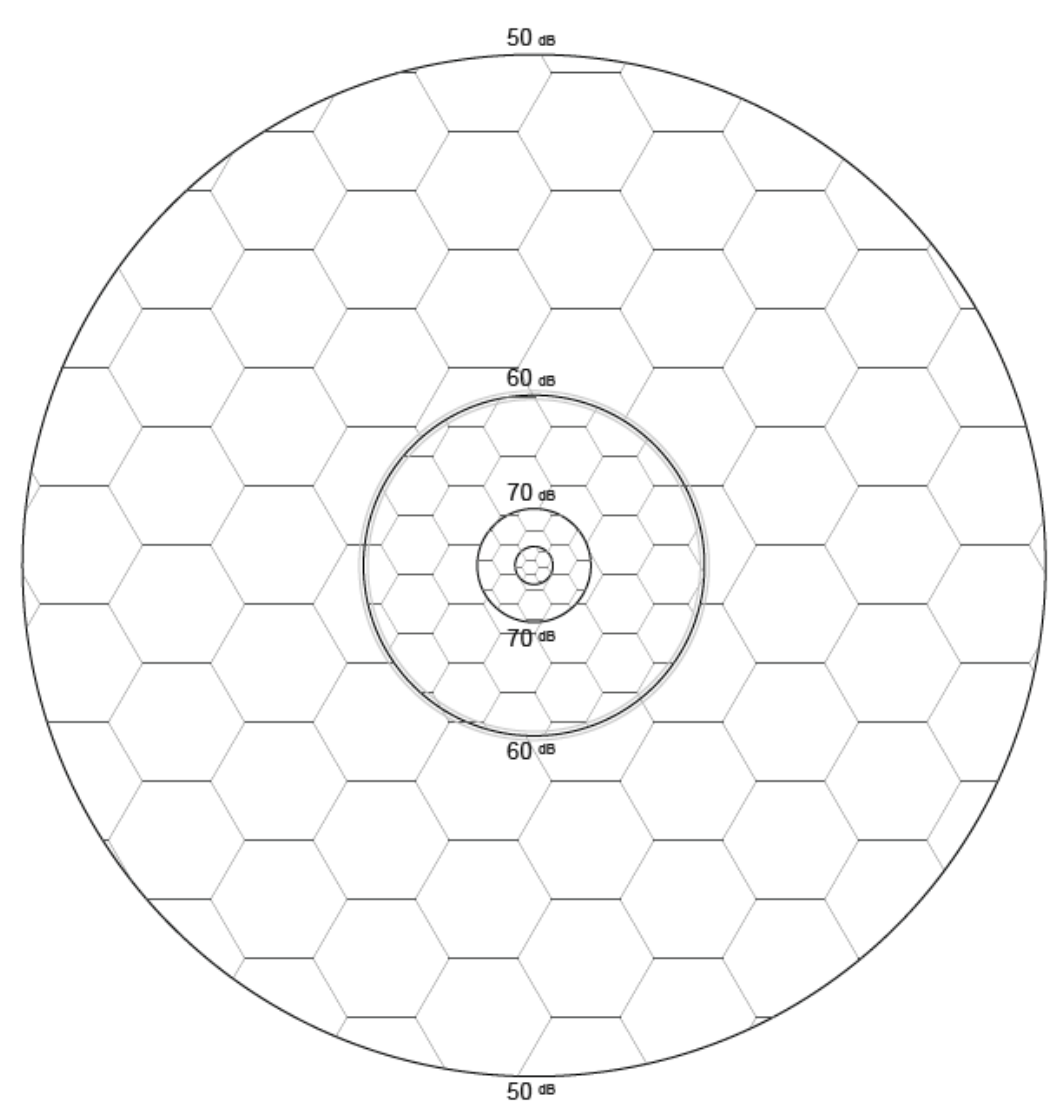

Figure 4.8 - Interruptive Notation - Hearing Sense Tools - Occupant Talking 60Db Base - Author

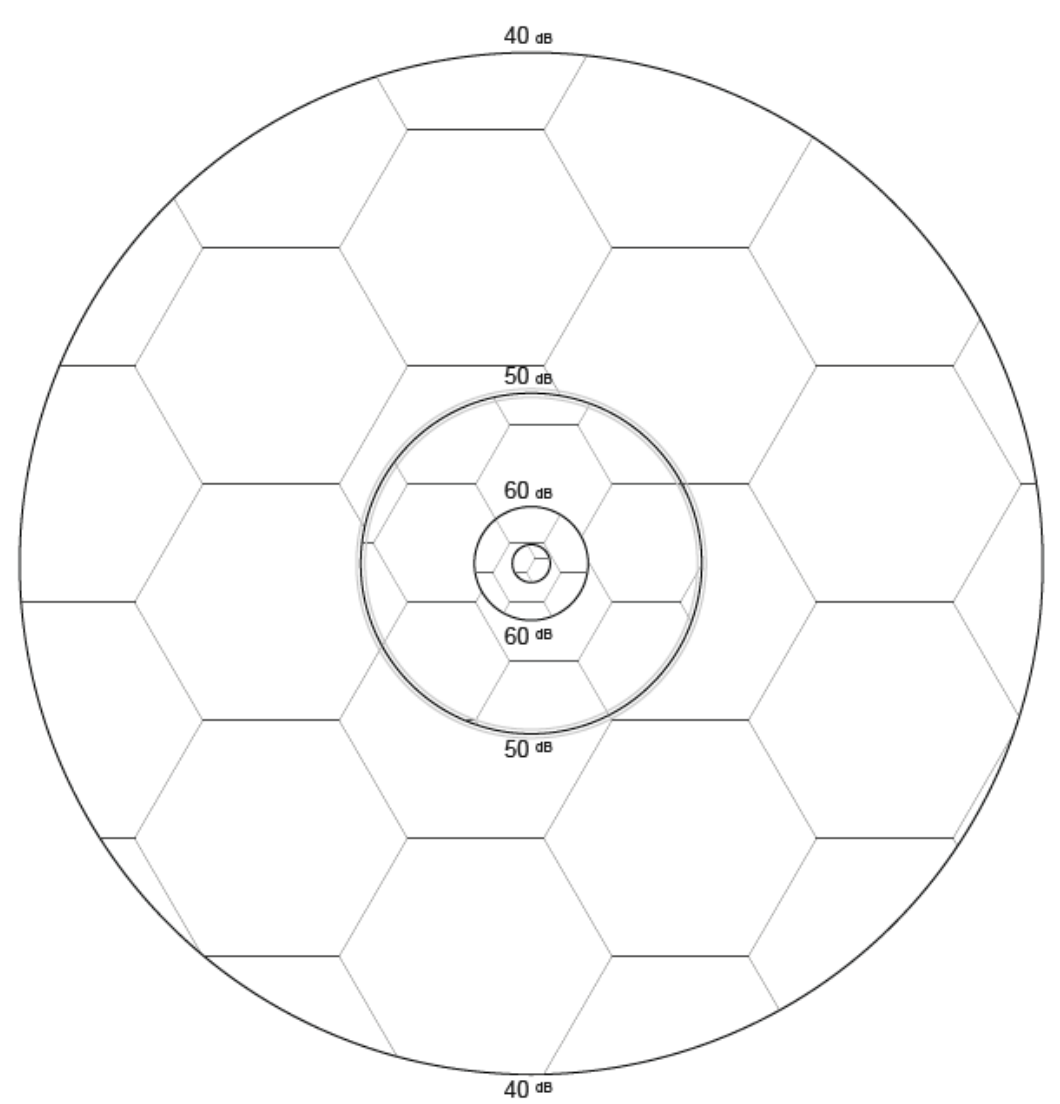

Figure 4.9 - Interruptive Notation - Hearing Sense Tools - Occupant Walking 50Db Base - Author 


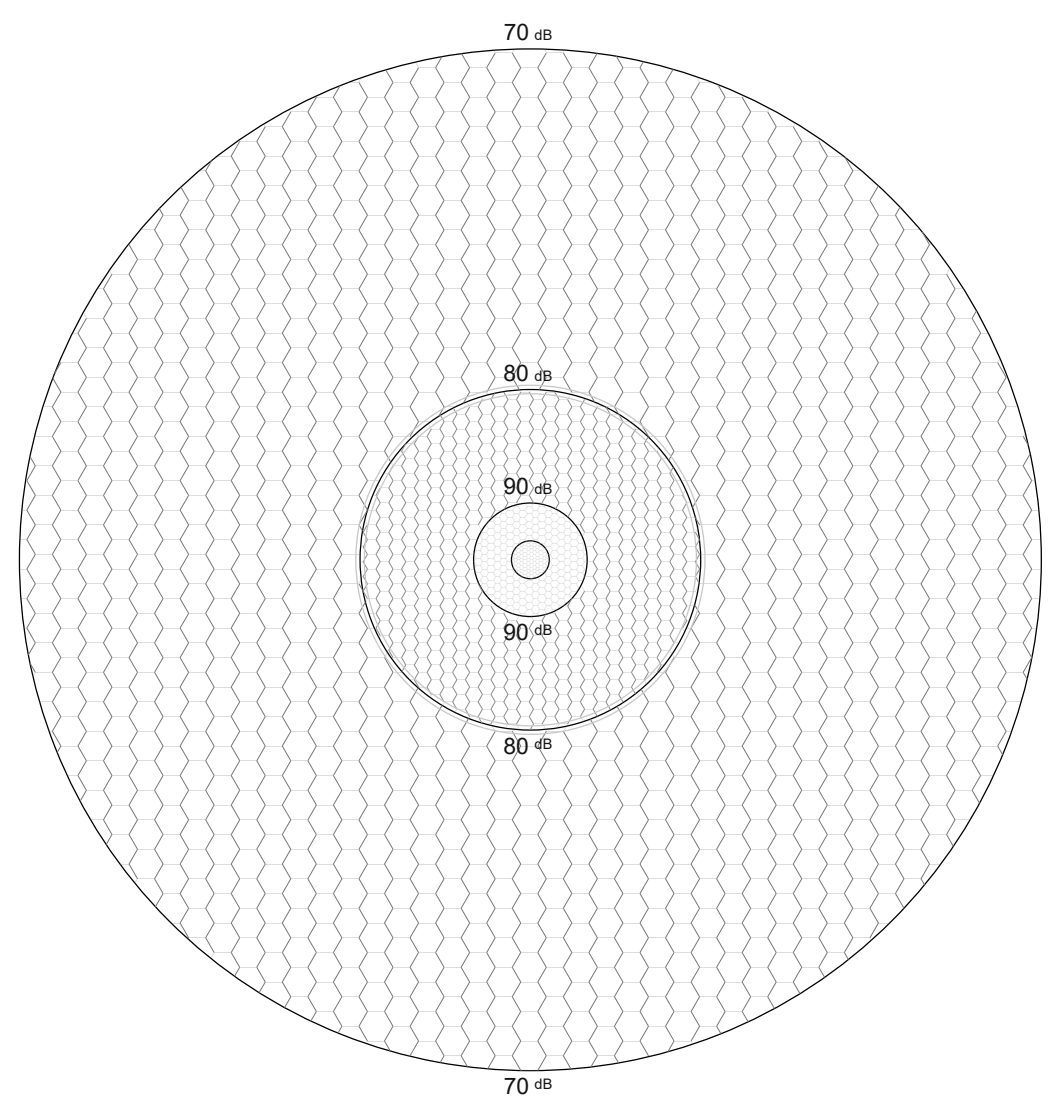

Figure 4.10 - Interruptive Notation - Hearing Sense Tools - Phone Ringing 80Db Base - Author

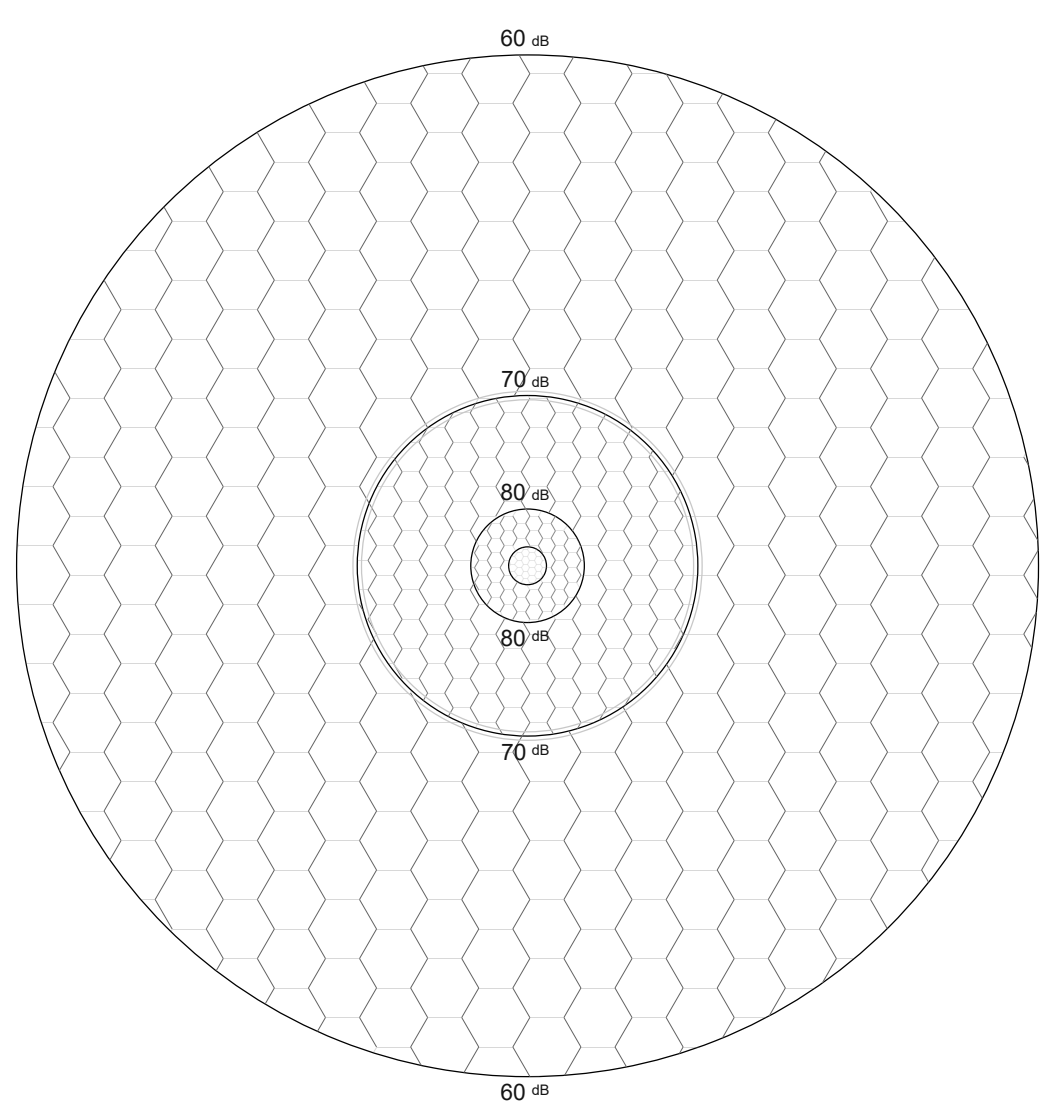

Figure 4.11 - Interruptive Notation - Hearing Sense Tools - Air Conditioning 70Db Base - Author

The decibel bands / alterations zones of the hearing sense tools [Figures 4.8 - 4.11] are derived from the principle that with every scalar change of three in the employees' distance from the noise source, the perceived decibel level increases or decreases by ten. These ten decibel changes in the employee's perception results in a perceived doubling or halving of total noise, and in turn provides a basis by which alteration factors can be derived and applied. ${ }^{[1]}$

1 Centre of Hearing and Communication. (N.D). Common Environment Noise Levels. Retrieved from Centre of Hearing and Communication: http://chchearing.org/noise/common-environmental-noise-levels/; Sengpiel, E. (N.D). Sound (music) and Noise (bang). Retrieved from Sengpiel Audio: http://www.sengpielaudio.com/calculator-levelchange.htm\#: :text=Doubling\%20of\%20the\%20volume\%20(loudness,\%2B10\%20 dB\%20\%E2\%88\%92\%20acousticians\%20say.\&text=Doubling\%20of\%20sound\%20intensity\%20(acoustic,)\%20in\%20psychoacoustics\%20\%E2\%88\%92\%20mostly\%20sensed 


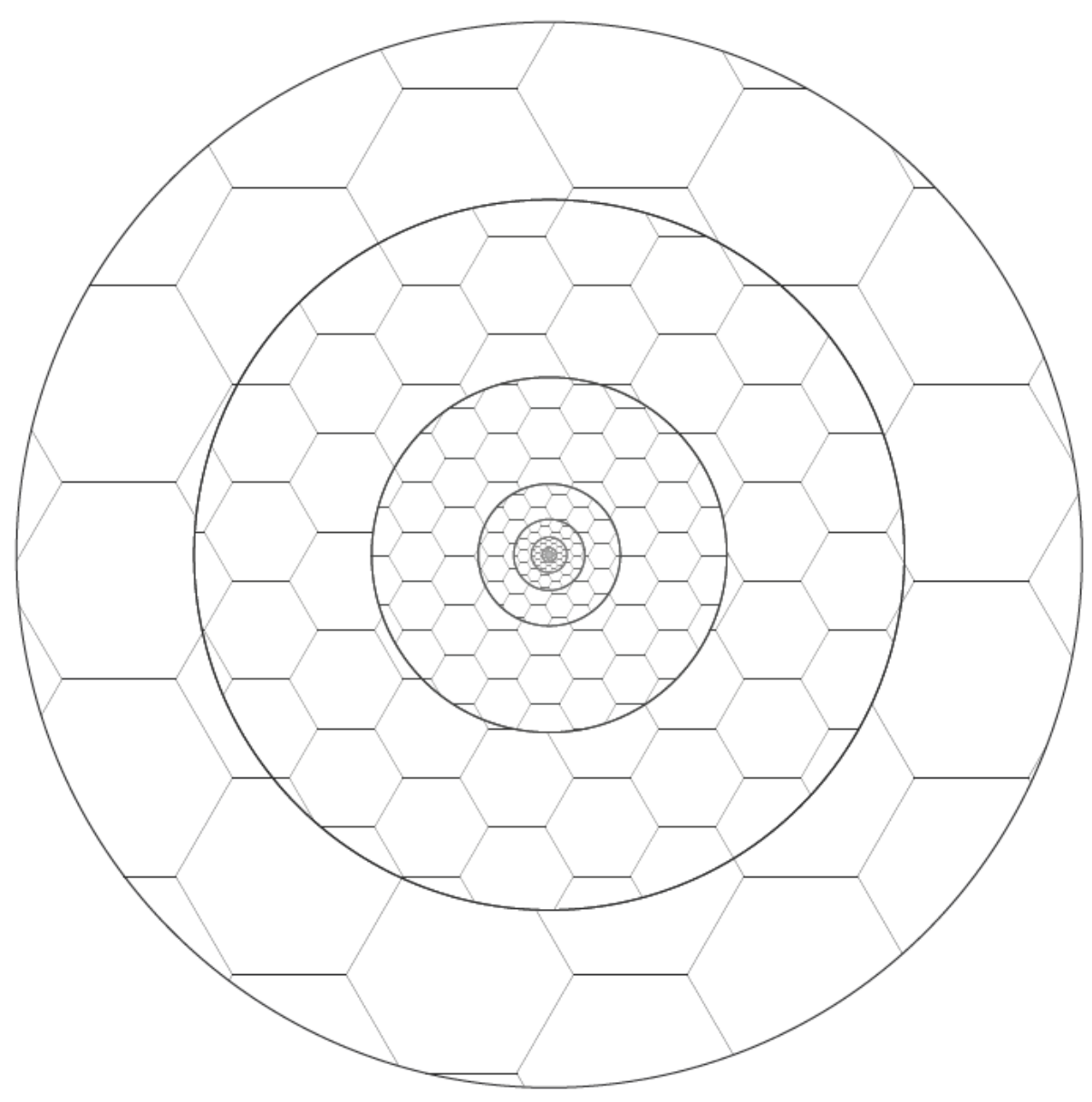

\section{Scent Zones:}

$\begin{array}{cc} & \text { Scent Zone One } \\ 1\end{array}$

The scent zones / alteration zones of the smell sense tool [Figure 4.12] are derived from the distance at which scent dissipates when carried through the air by affixed particles such as dust. This dissipation distance is based upon an employees' perception, which in turn provides a basis from which alteration factors can be derived and applied. ${ }^{\left[{ }^{[I]}\right.}$

1 Piringer, M., Knauder, W., Petz, E., \& Schauberger, G. (2016). Factors Influencing Separation Distances Against Odour Annoyance Calculated by Gaussian and Lagrangian Dispersion Models. Elsevier, 69-83. 


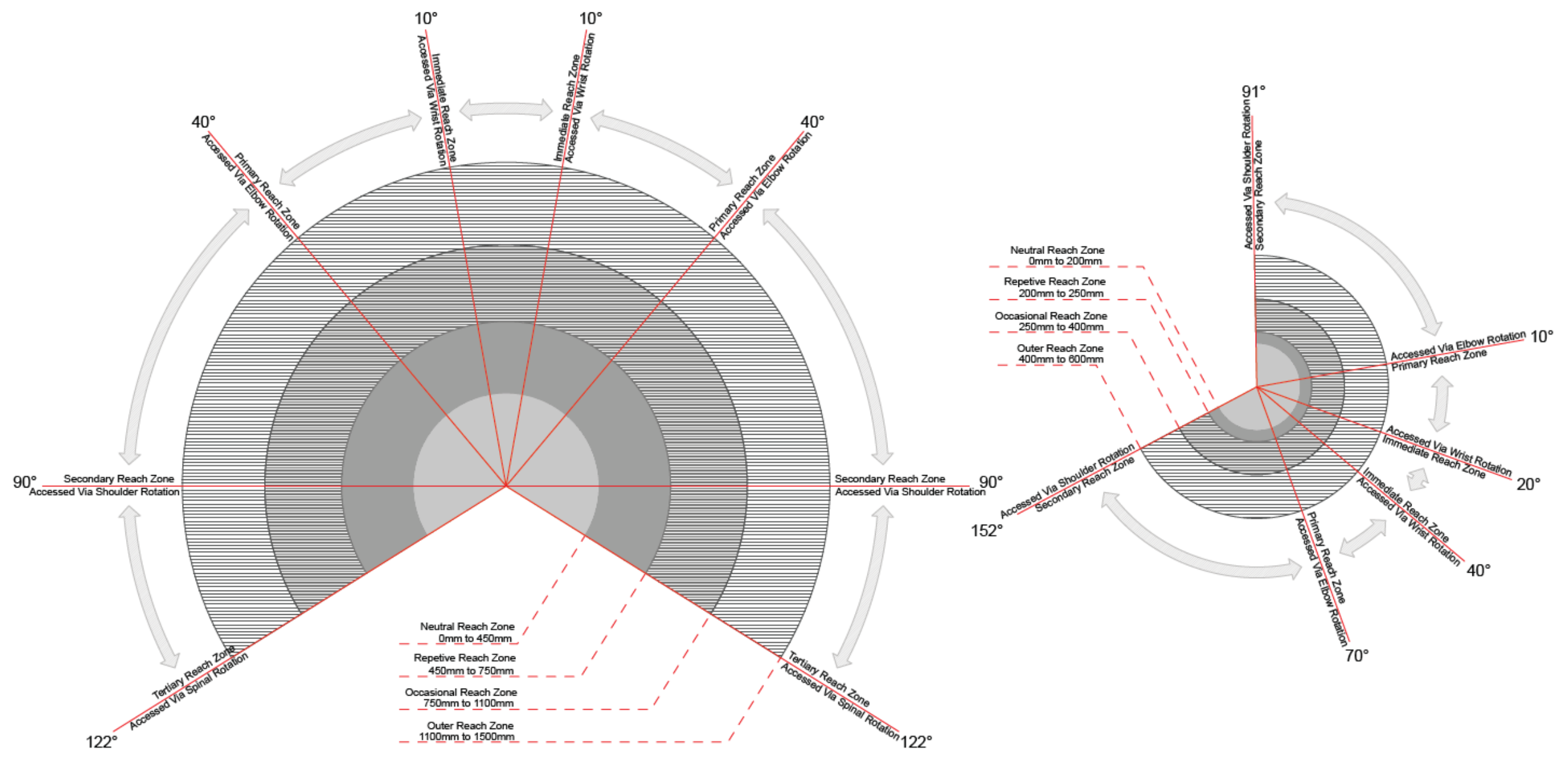

The reach zones / alteration zones of the touch sense tool [Figure 4.13] are derived from the movement ranges within which employees can comfortably work. These ranges reflect what areas an employee would work in. In turn, this provides a basis by which alteration factors can be derived an applied. ${ }^{[1]}$

1 Looker, J. (2015). Reaching for Holograms: Assessing the Ergonomics of the Microsoft"m HoloLens ${ }^{\text {TM }}$ 3D Gesture Known as the "Air Tap". International Design Congress (pp. 17-23). Gwangju: International Design Congress.; Ward, B. (2019, August 23). The Importance of The Neutral Reach Zone. Retrieved from Beyond The Office Door: https://www.btod.com/blog/2017/01/26/the-importance-of-the-neutral-reach-zone/ 


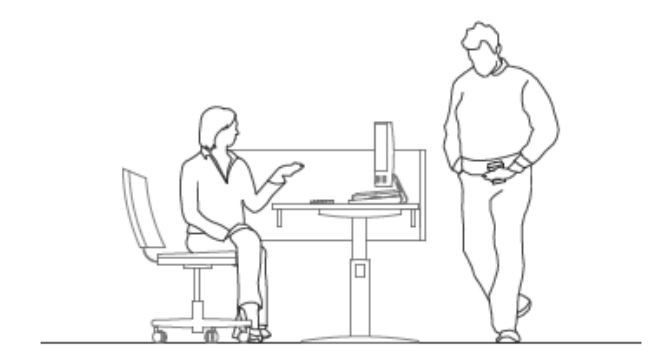

Figure 4.14 - Employee Seated At Desk While User Walks By - Author

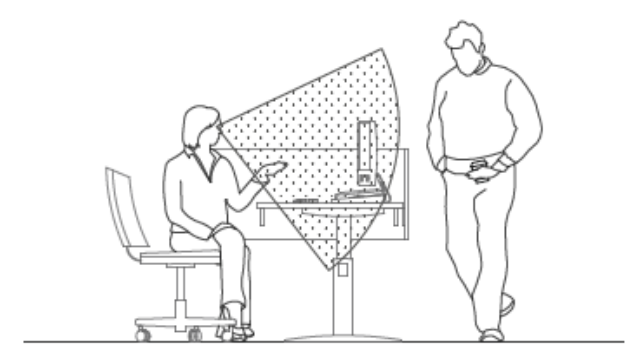

Figure 4.15 - Default Interruptive Weighting Of Person Arriving - Author $\quad \boldsymbol{A}$

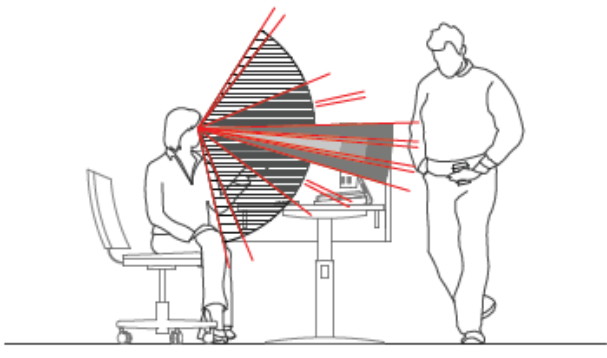

Figure 4.16 - Sight Sense Tool Usage - Author

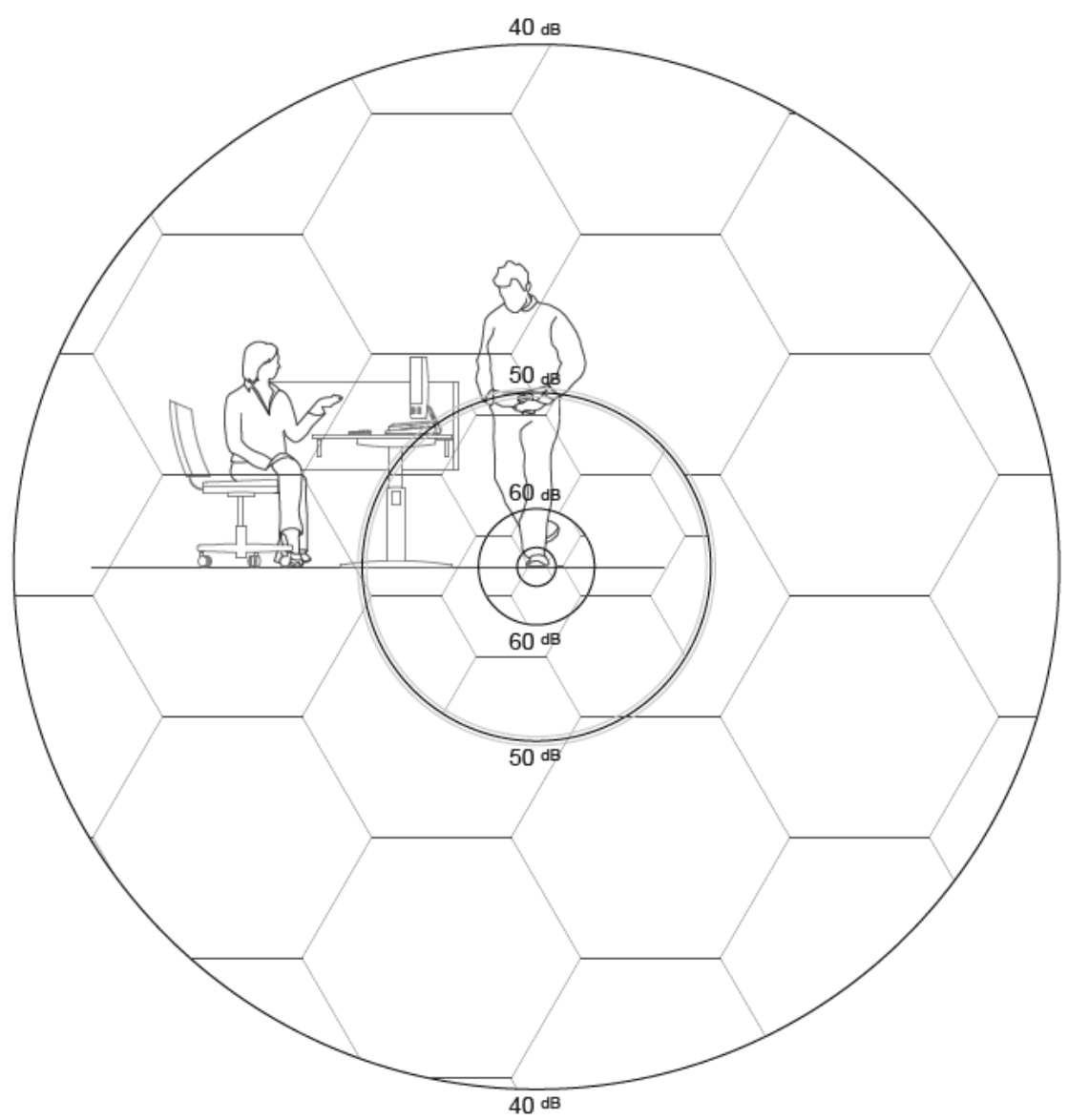

Figure 4.17 - Hearing Sense Tool Usage - Author

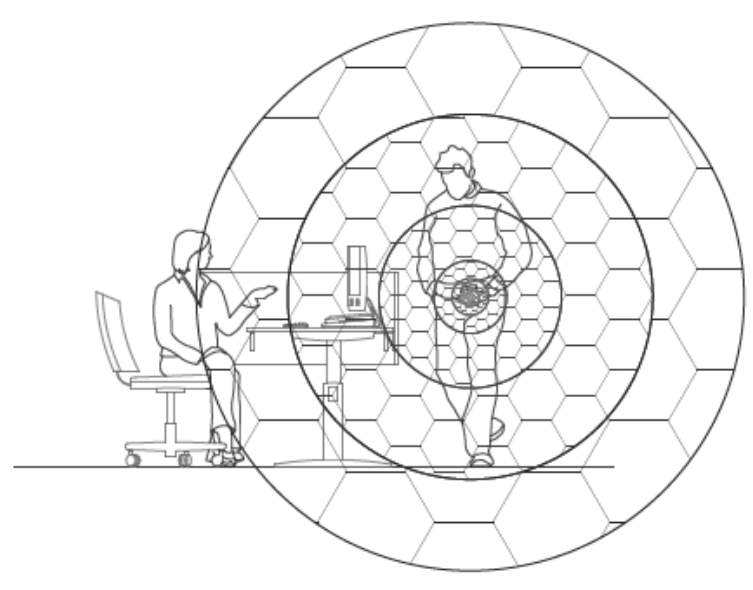

Figure 4.18 - Smell Sense Tool Usage - Author

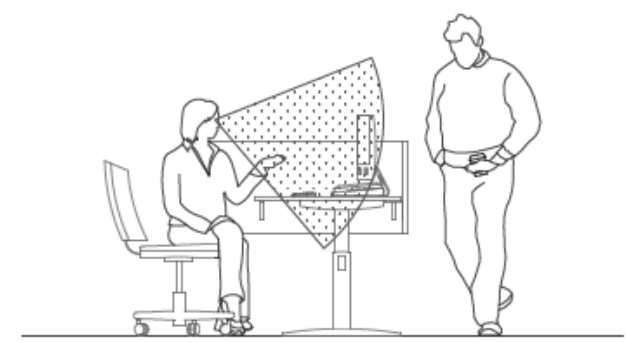

Page 60 


\section{Notational Application:}

A worked example demonstrating how a user could analyse the interruptive event of a person arriving is discussed here through a series of section drawings. In this example, an employee is depicted to be working from their desk whilst another employee, coffee in hand is shown to be passing by. This mediated through a low hung partition [Figure 4.14]. In this example the employee perceives this interruptive event through their sense of sight, hearing and smell. These sense tools are in turn utilised to determine the altered interruptive weighting of said employee.

The baseline interruptive weighting of a person arriving accounts for $21.45 \%$ of an employee's perceived interruption as dictated by Gonzalez \& Mark [Figure 4.15]. In this worked example it has been assumed that the employee is exposed to the full range of interruptive events established by Gonzalez \& Mark, meaning that this baseline interruptive weighting is maintained as the employee's sensitivities to other events have not been heightened.

Practitioners may utilise the notational system by overlaying the relevant sensorial tools on top of the employee and measuring their perceptibility of the interruptive source [Figure 4.16 - 4.18]. This practice identifies a series of alteration factors which when logged within the excel calculator will determine the resulting interruptive outcome and compare it against the baseline weighting of that event, thus showing if it has improved or worsened. The practitioner then drafts this resulting outcome within the drawing, ensuring that the circular section is angled towards the interruptive source. When multiple events are examined, this process is repeated for each remaining employee and event.

Once logged within the excel calculator, the factors in this example indicate that the interruptive weighting of this instance now accounts for only $19.49 \%$ of an employee's perceived interruption. This reduction of $1.96 \%$ from the baseline interruptive weighting accounts for a $9.13 \%$ improvement in the overall interruptive weighting [Figure 4.19]. This may be improved further if measures such as a more effective partition, or greater distance between the employee and arriving persons are provided through the architectural design.

A rule set outlining how the interruptive notational system has been used here is discussed in detail within Appendix 2.

The notational mode of representation discussed throughout this chapter was continually developed and expanded upon throughout this thesis, as it offered a simplistic means of graphically representing complex interruptive information. In turn it allowed for the rapid depiction of an employee's perceived interruptive outcome that was not reliant on labour intensive software - unlike Design Stage One. This allows for system users to quickly identify problematic interruptive events and then address them through architectural design.

To further the effectiveness of this system it must be examined in the context of an office environment. This chapter lacked site information that would be critical in providing the context through which the system would develop further. Acknowledging this, subsequent sections of this thesis attempt to address this issue. 


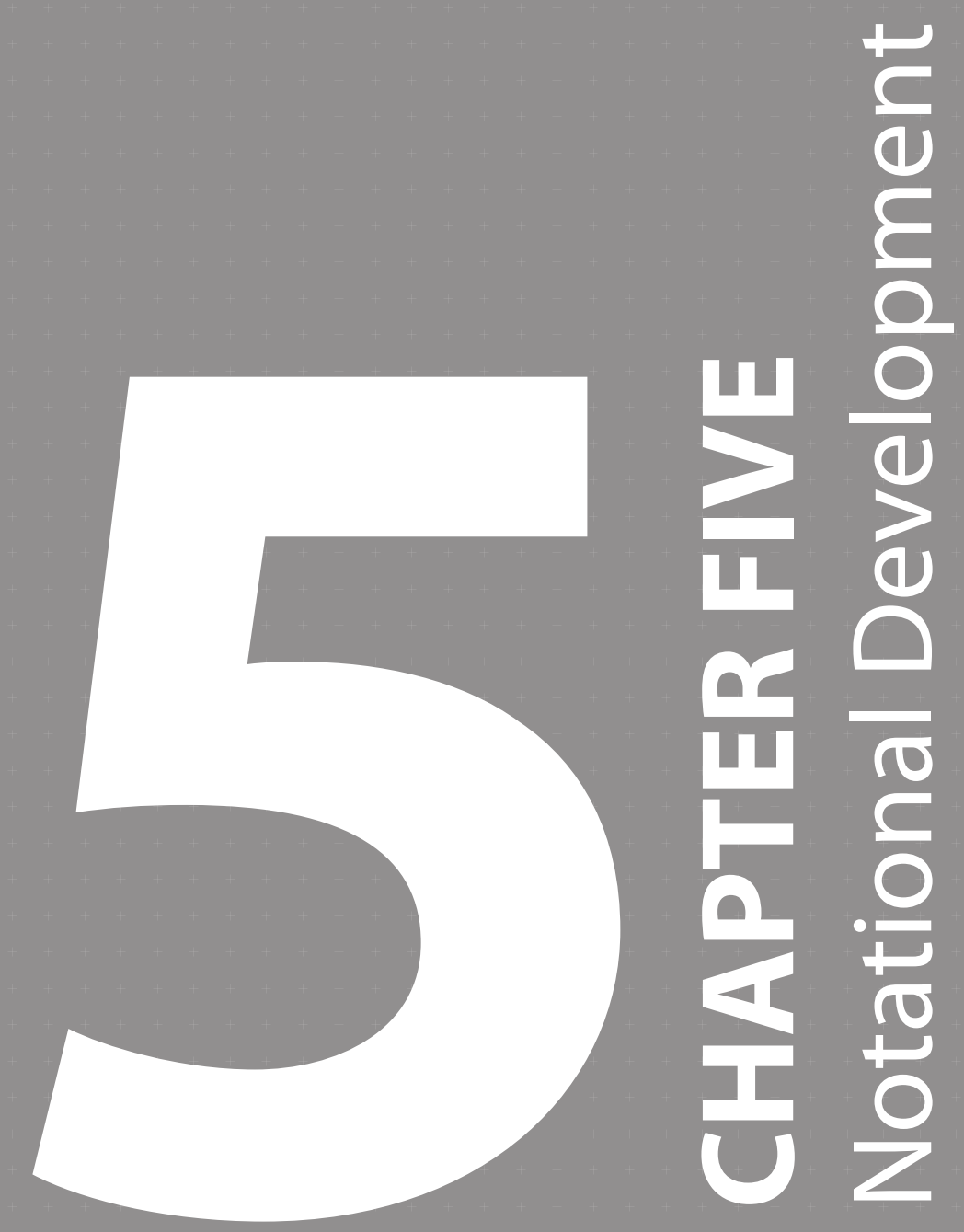





\section{Notational Context:}

To facilitate testing of the interruptive notational system, a standardised office was designed based upon the office design guidelines set by the NZGPPG [Figures $5.1-5.3$ ]. These guidelines offer employees features such as a $1800 \mathrm{~mm}^{*} 800 \mathrm{~mm}$ desk capable of moving between a sitting or standing position, fully adjustable chairs capable of moving between heights of $370 \mathrm{~mm}$ and $560 \mathrm{~mm}$ and both formal and informal working arrangements. In this office, temporary use is normalised and consequently desks do not provide space for personal storage. Workplace density of one person to every $16 \mathrm{~m}^{2}$ of net lettable area minimum ensures that the space is used effectively. ${ }^{[1]}$

1 New Zealand Government Property Procurement Group. (N.D). Open-plan working environment and consistent design. Retrieved from New Zealand Government Property Procurement Group: https://www.procurement.govt.nz/property/workplace-design-guidelines/princi-

ples-for-office-design/open-plan-working-environment-and-consistent-design/ 


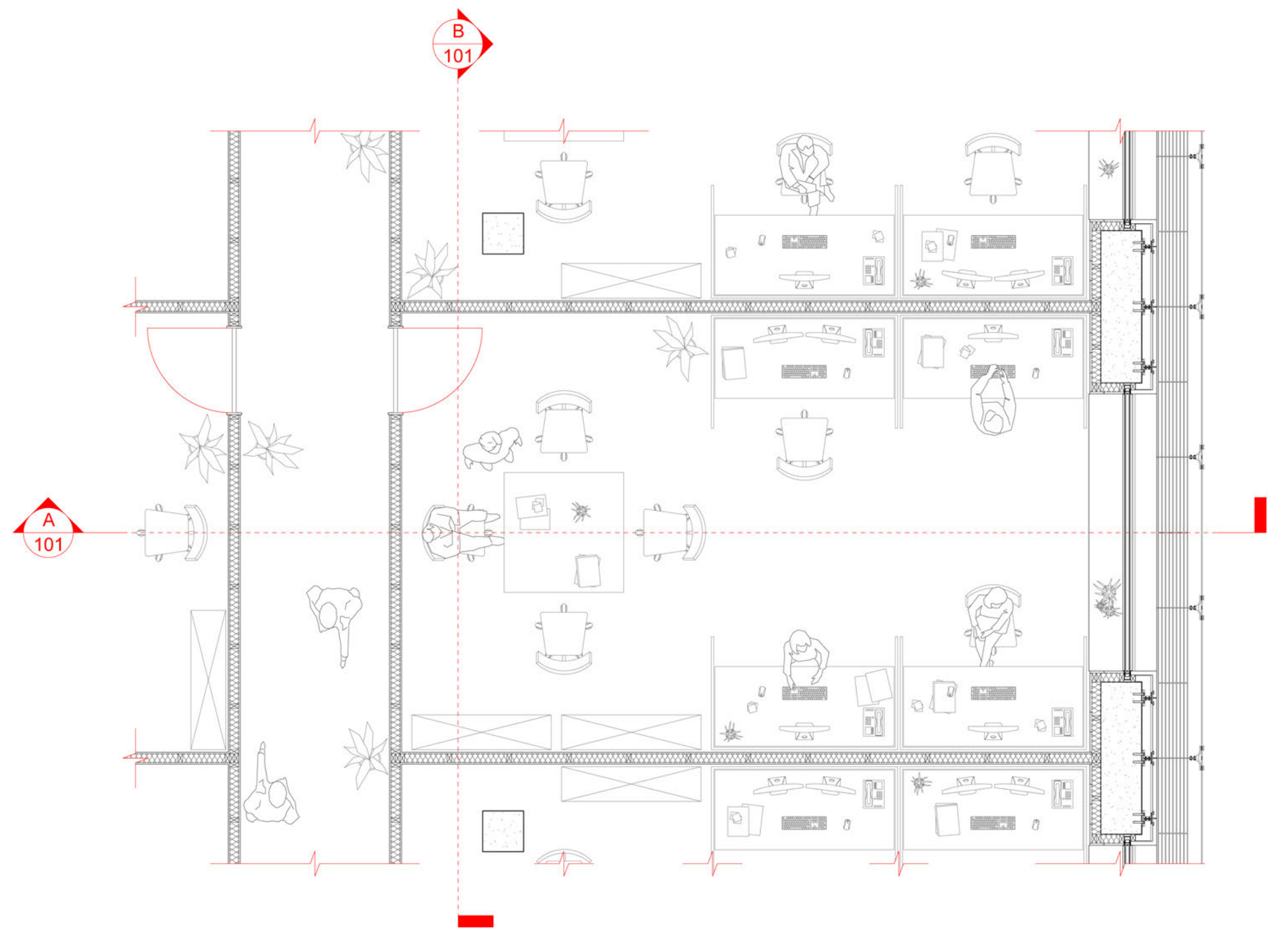




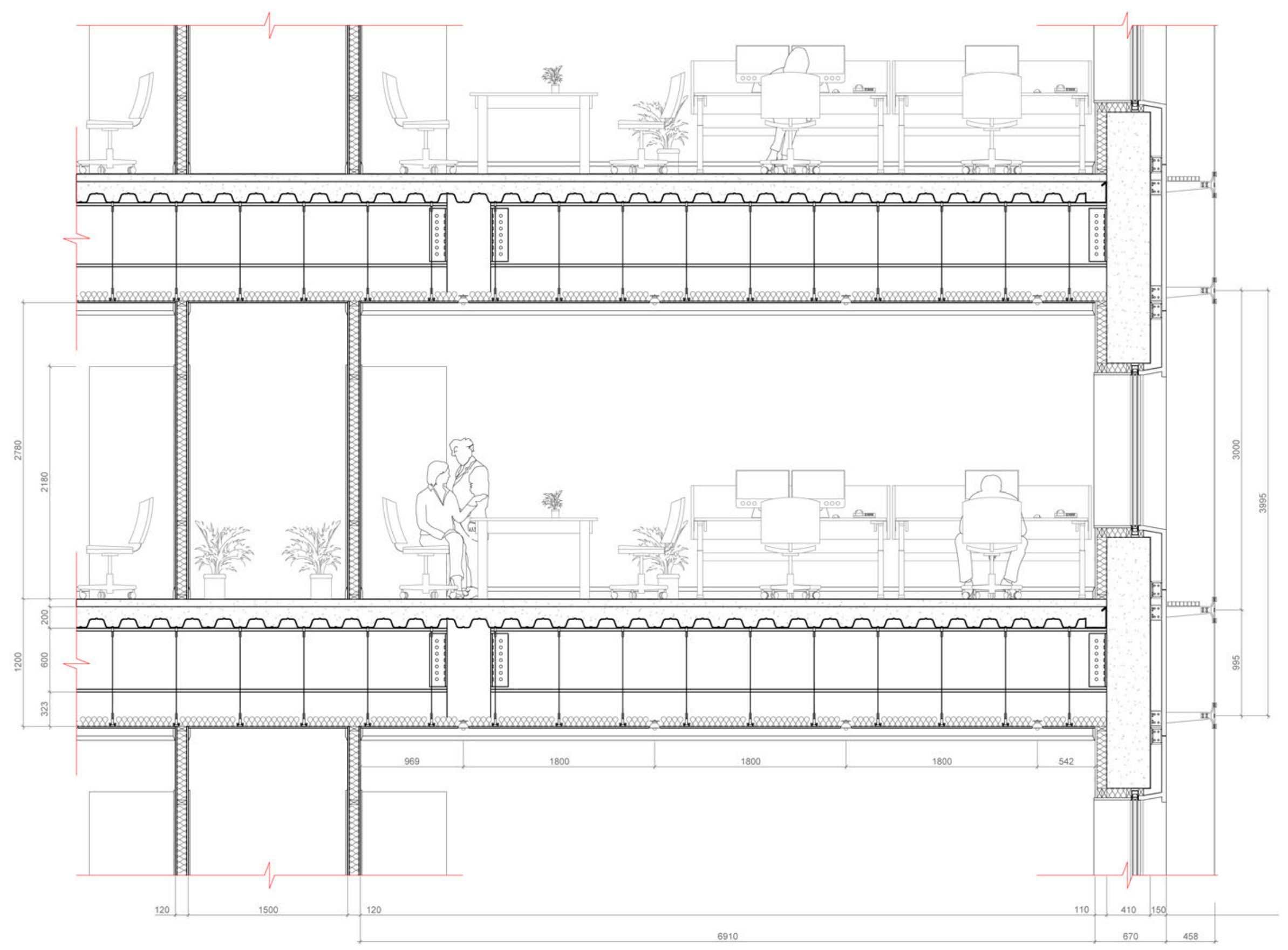




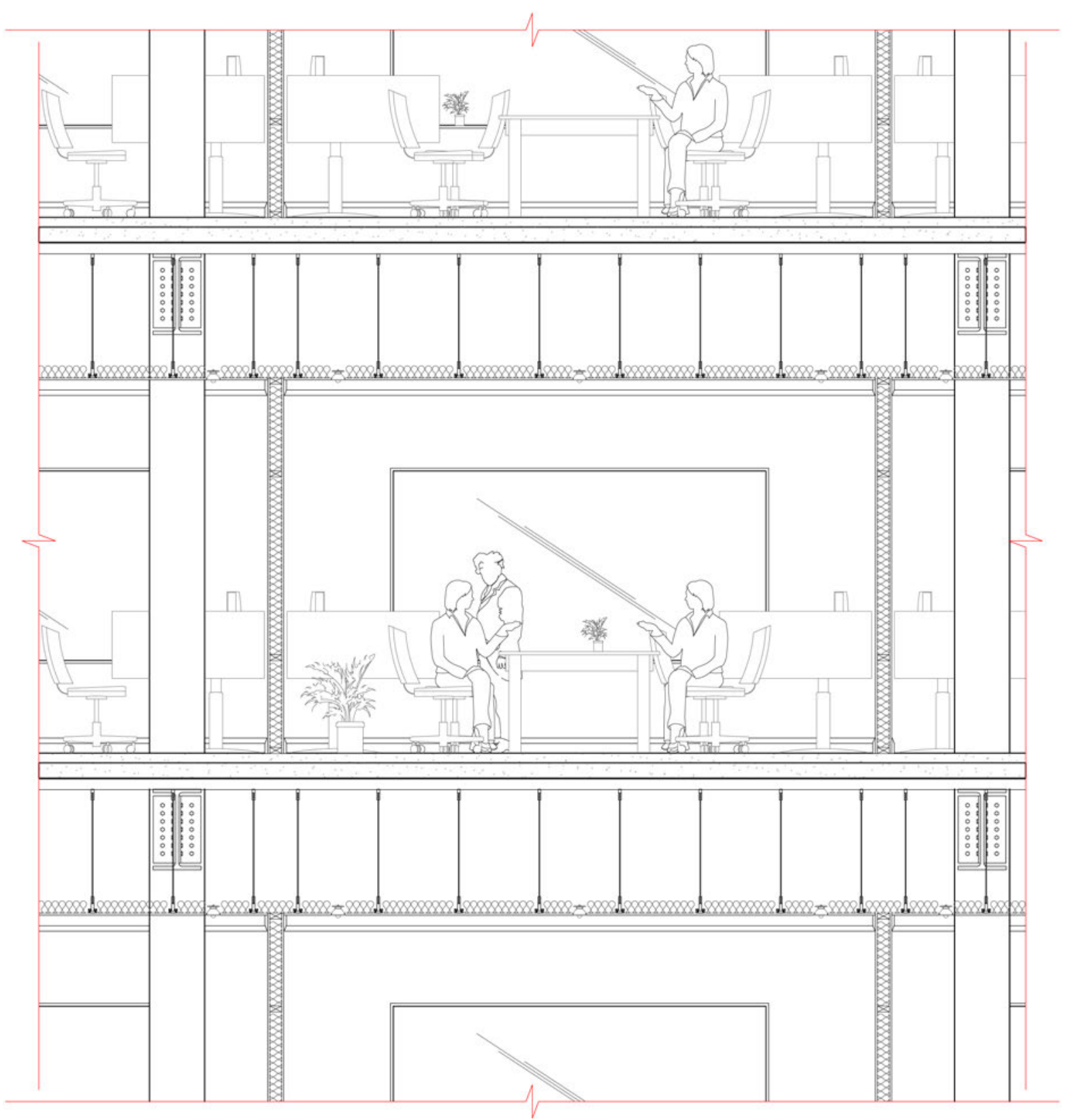

A Figure 5.3 - Standard Office Section - B 101 - Scale 1 to 50 @ A4 - Author 


\section{Notational Application:}

The NZGPPG design was utilised in the early notational development trials and was tested in both plan and section. These initial tests were conducted prior to the development of the sense tools and in turn map only the default interruptive weighting of each event. When testing the notational system in plan [Figure 5.4] few issues were found and clear visual relationships were established between the employee and the interruptive events. This test demonstrated for each employee, where the interruptive density is greatest (expectedly surrounding the work surface), but also showed that this does not necessarily align with the major interruptive events e.g. a person arriving. 


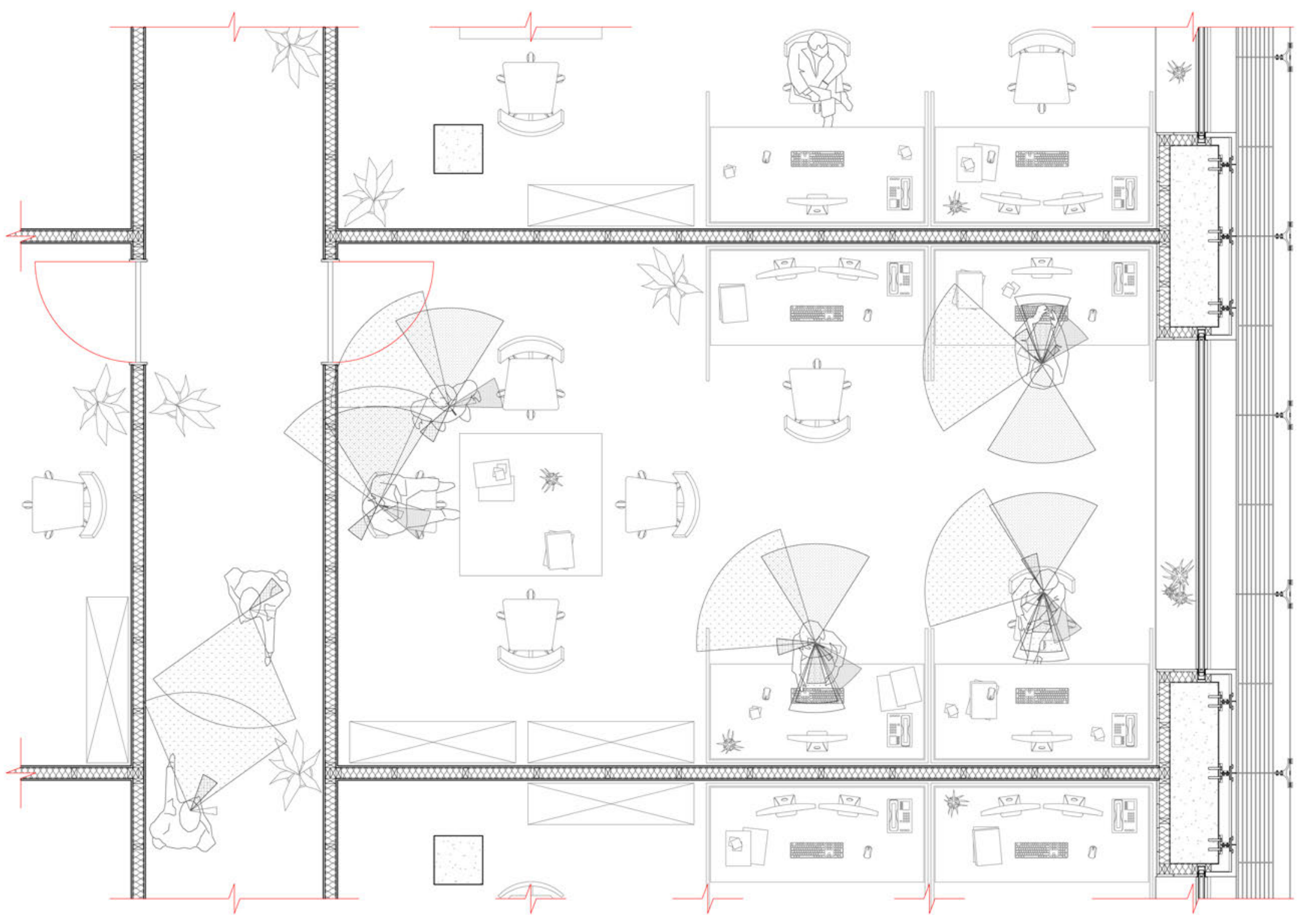

Interruption Events:

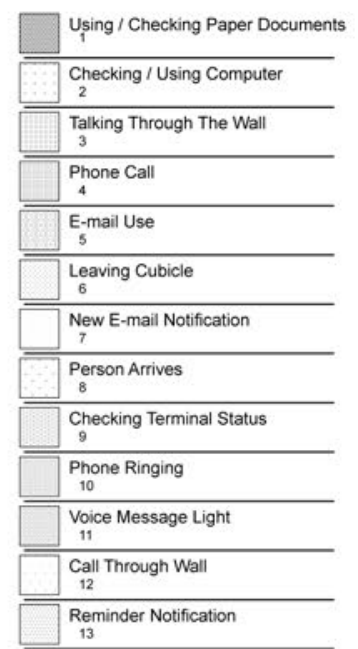

Mapped Interuption Events

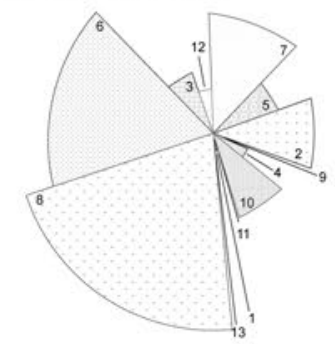


When employing the same notational ruleset in section [Figure 5.5] the same relationships established in plan between the employee and the interruptive event could not be easily replicated. This indicated through the circular elements which do not appear to demonstrate a clear connection. This was problematic for interruptive events tangential to the section plane but less so for those operating in parallel. These findings indicate that the system through this view may need to provide different information to users or adapt the ruleset to allow for it to function appropriately. 


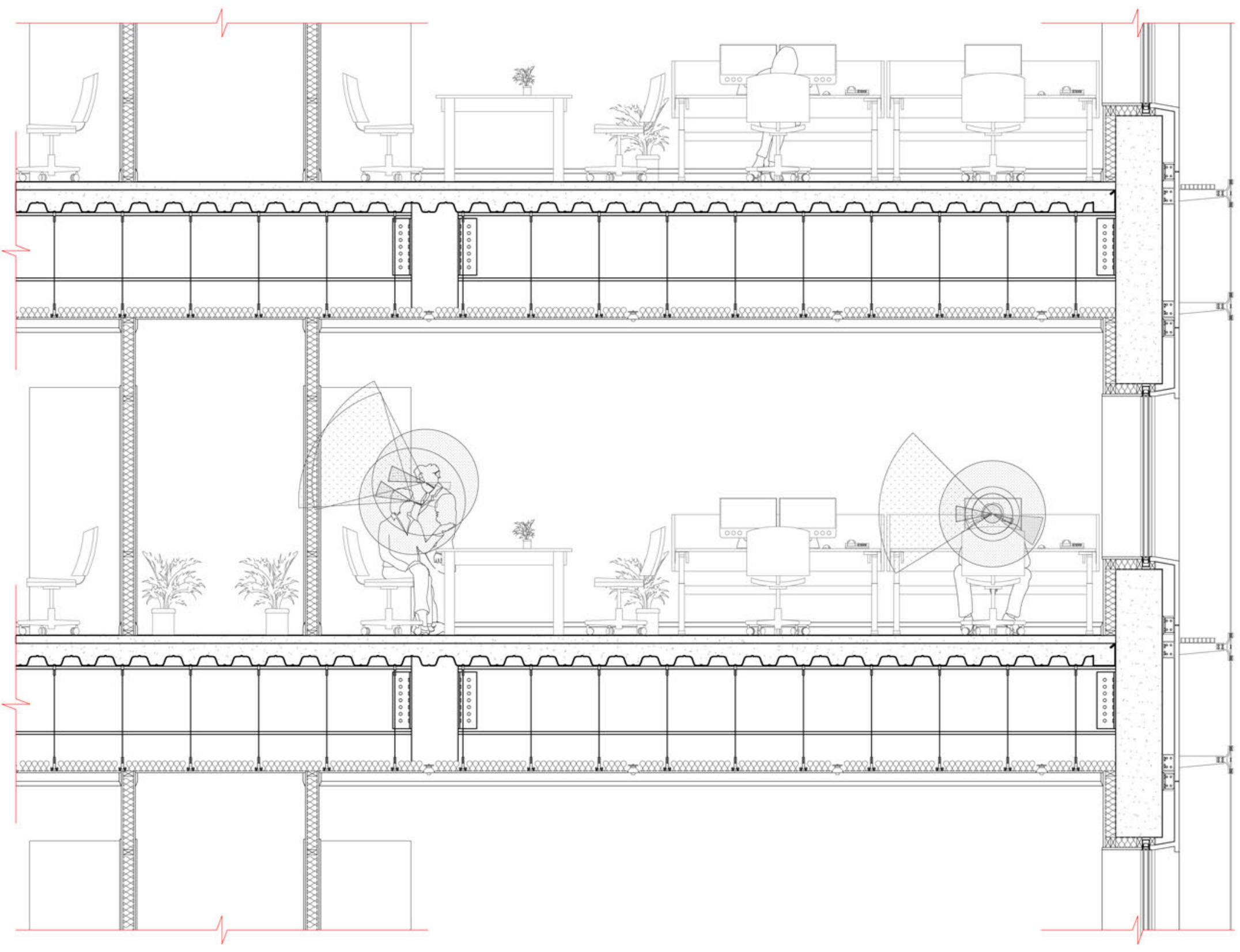

Interruption Events:

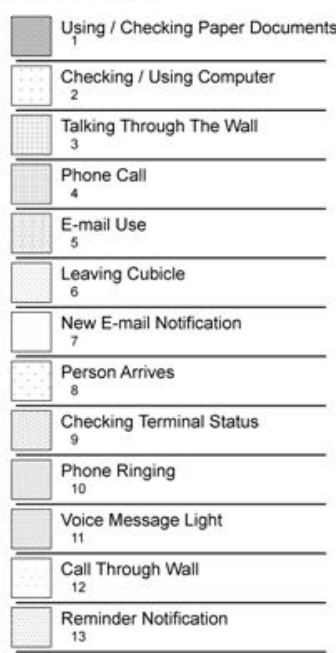

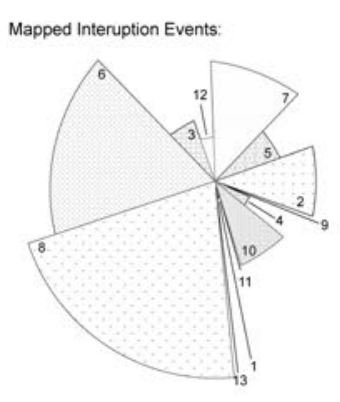


The proportional division of excluded interruptive events was explored in plan, to examine its effects upon the drawing's legibility [Figure 5.6]. From this test it was immediately evident that for those away from their desks, events such as person arriving become much more prevalent within the drawing, as demonstrated through the heightened interruptive weightings of events. While this does work as intended, it is problematic as it creates excess visual complexity throughout the drawing. This unnecessary visual complexity in future iterations of the notational ruleset should be limited to its spatial origin to mitigate this issue, as it only worsens through the implementation of the sense tools. 


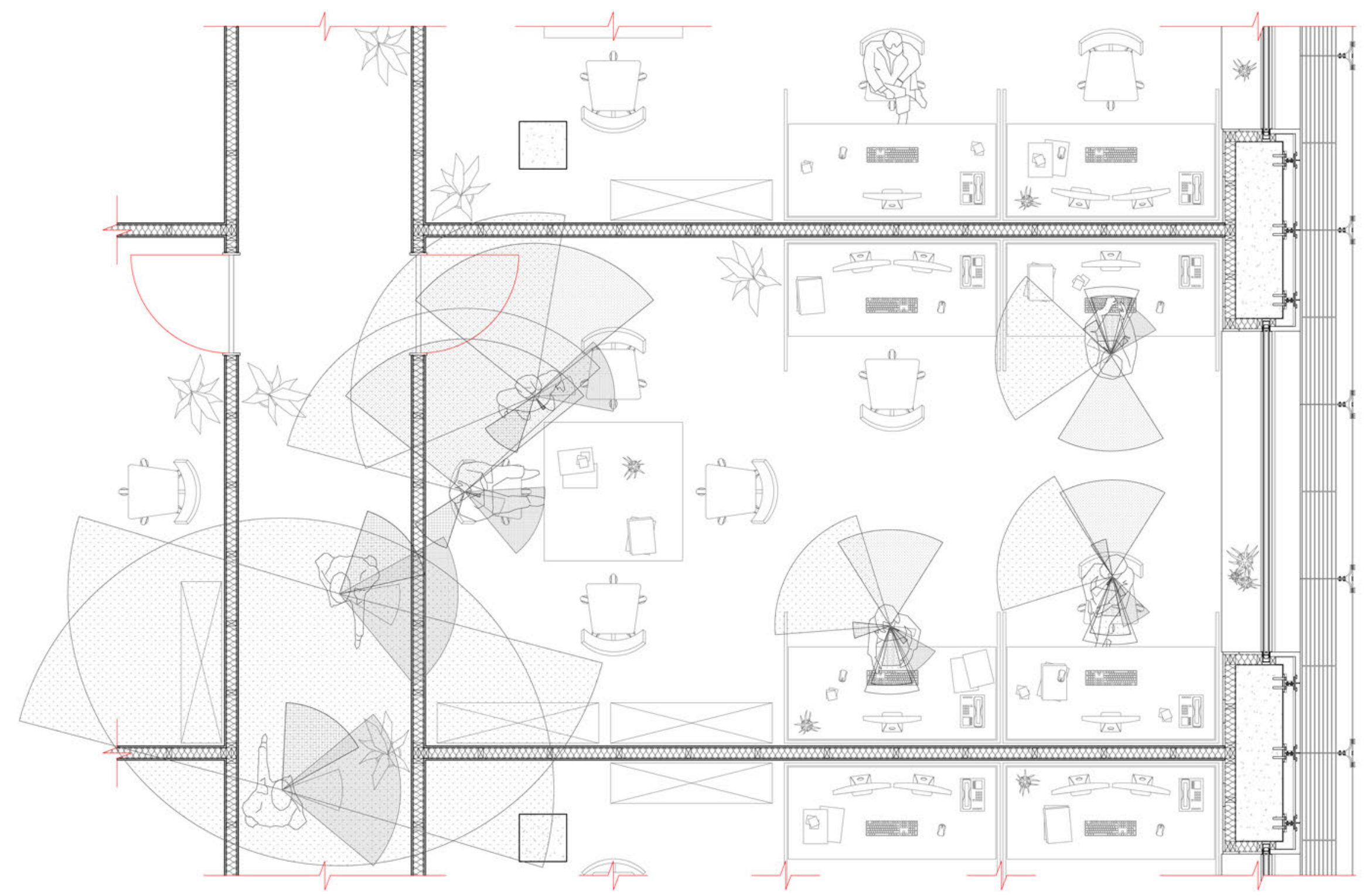

Interruption Events:

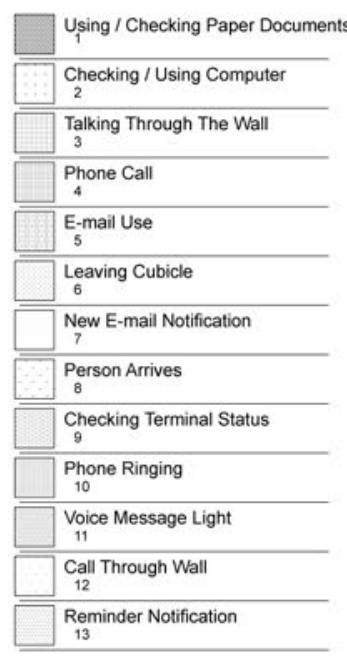

Mapped Interuption Events

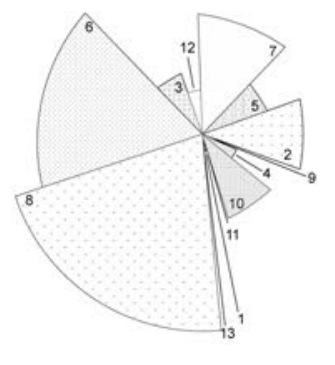


The sense tools when first developed were tested at a reduced scale, examining only the interruptive event of a person arriving [Figure 5.7]. This arriving party was depicted in the plan to be passing behind an employee standing and working at their desk (this shown without a partition). The purpose of this test was to explore the alteration factors of the relevant senses and ensure that they are operating as expected. But this also serves as a demonstration of Rosenblum's work, visually depicting the level to which each sense alters an employee's perceived interruptive outcome. Through this test it is evident that an employee's visual perceptibility accounts for the greatest reduction in interruptive outcome, this indicates the tool is operating as expected when considering that sight represents $83 \%$ of our sensorial usage. An employee's sense of hearing and smell contribute little toward reducing the effects of this interruptive event, which makes sense given that they account for only $11 \%$ and $3.5 \%$ of our respective sensorial usage. In this spatial instance, the baseline interruptive weighting of a person arriving has reduced from $21.45 \%$ to $13.43 \%$. This $8.02 \%$ reduction is the result of sight reducing the baseline by $7.55 \%$, hearing $0.16 \%$ and smell $0.31 \%$. This overall reduction accounts for a $37.41 \%$ improvement over the baseline perceived interruptive outcome. 


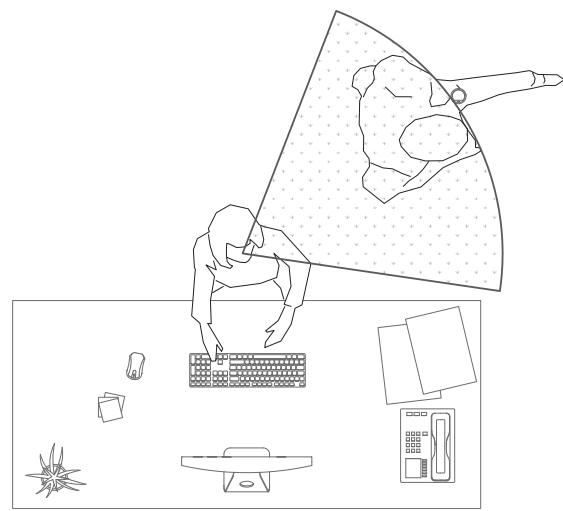

Default Interruptive Weighting

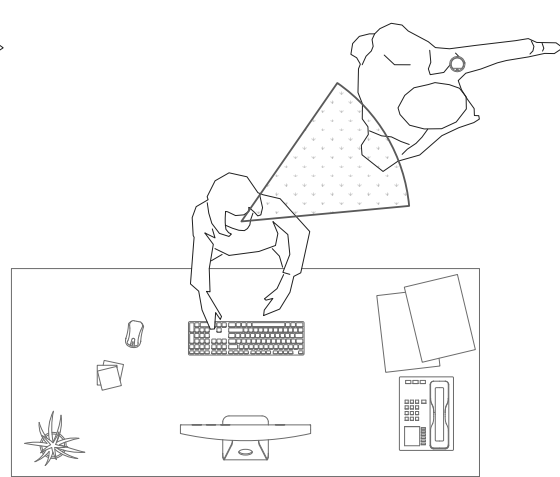

Sight -Based Interruptive Reduction

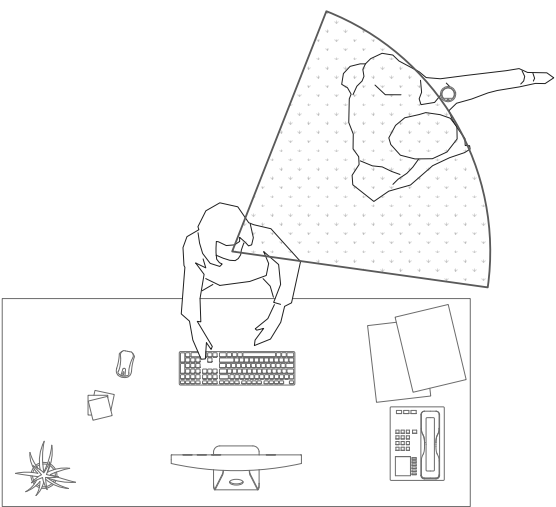

Hearing-Based Interruptive Reduction

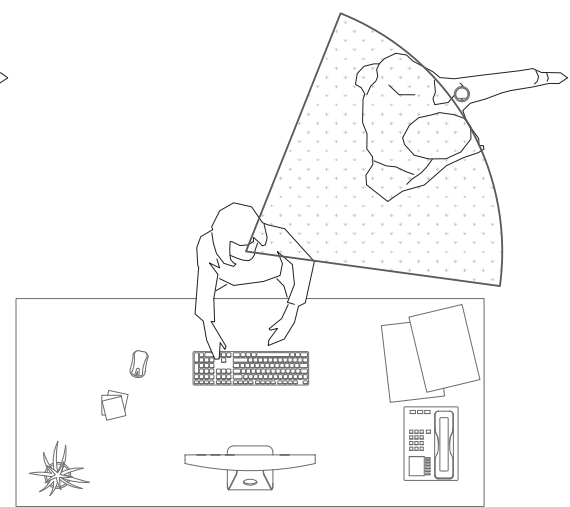

Smell-Based Interruptive Reduction

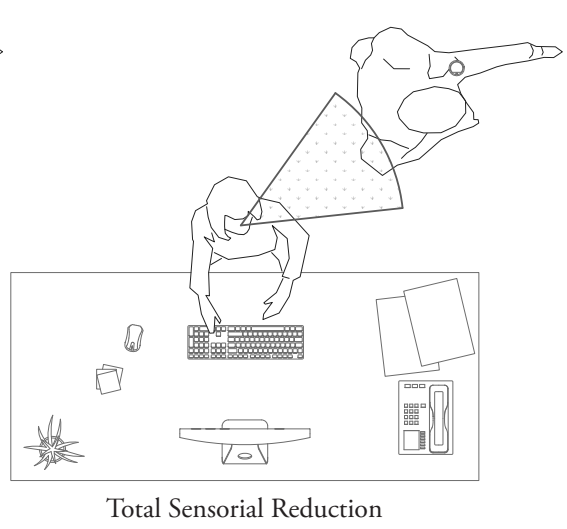


After exploring the sense tools at a reduced scale and confirming that they operate as intended, they were later tested within the context of the standard office plan [Figure 5.8]. This aimed to document the full range of interruptive events and explore the implications of employing the system at this scale. For employees with their backs toward the office door, the heavily interruptive event of a person arriving was mitigated almost entirely as it moved the interruption source outside of their visual perception. As a result this interruption could only be perceived aurally and through scent. These senses account for a minimal proportion of our sensorial usage enabling this mitigation. Interruptive events centred around the employee desk remained largely unchanged and, in some instances, worsened through the sense tools. This was a result of many of these events occupying primary employee perception zones such as the central vision cone. In an attempt to document each interruptive event, the system was shown to exhibit laborious tendencies. Notational users in the process of deriving the altered interruptive outcomes must continually shift focus between the drawing, the sense tools, and the calculator. This creates a disconnect in the design process that is labour intensive for users and must be repeated later if the design is altered based upon these findings, which in turn deters iteration. 


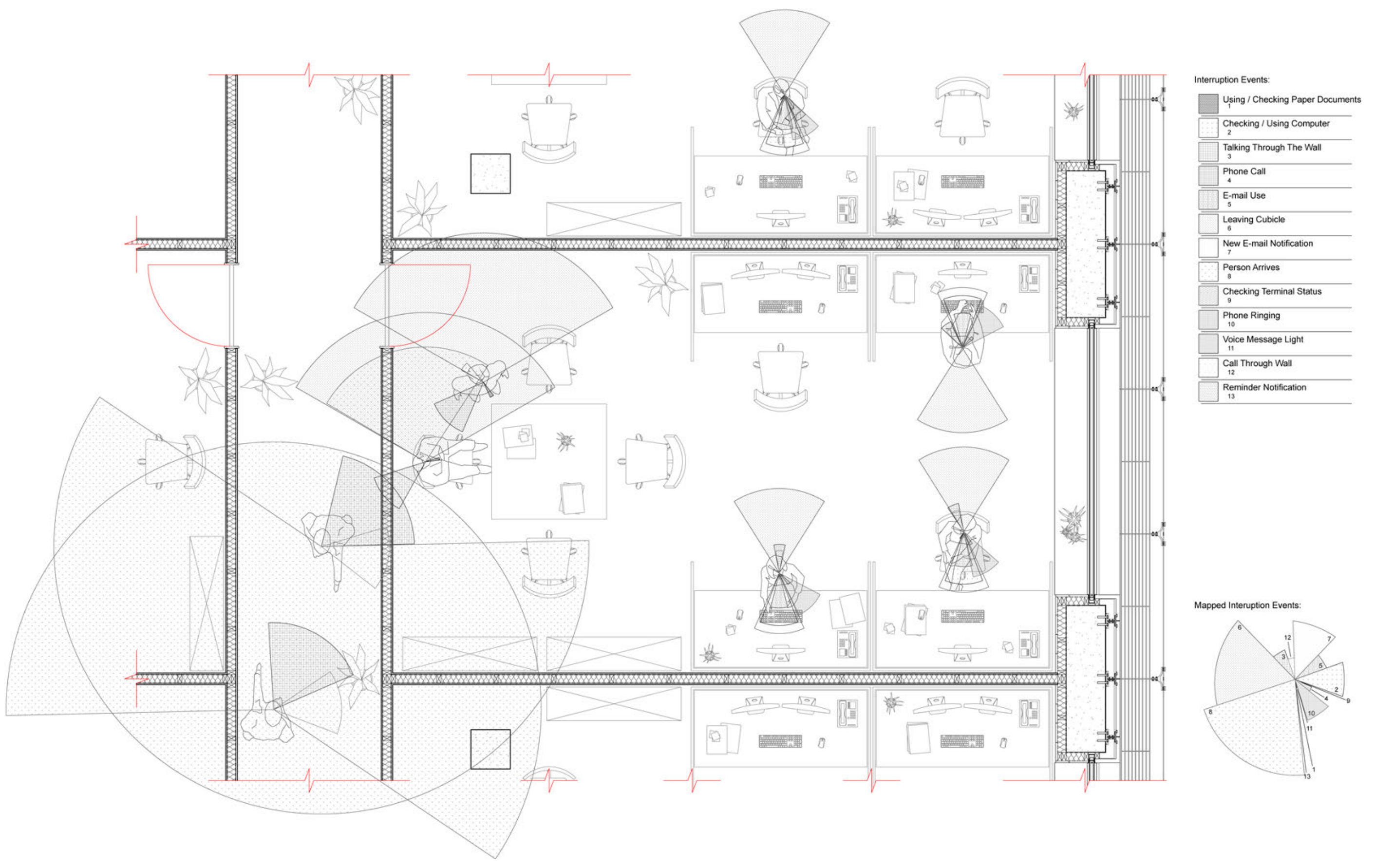


Notational Context Redesign:

When exploring the notational system in the context of an office environment previously, the interruptive effects of a person arriving were made apparent. Within the standard office, this interruptive event appeared to have a significant impact on employees adjacent to or nearby the designs entrance. As the notational tool has not yet been utilised within a traditional design process, this following series of drawings aims to evaluate its performance and explore the possible improvements that could be made to the space through simplistic alterations.

A sequence of a person moving throughout the office space was constructed and then mapped to facilitate these aims. This process established a baseline interruptive outcome amongst employees for future comparison. In this instance it was assumed that an employee is exposed to the full range of interruptive events established by Gonzalez and Mark, meaning that their sensitivities to other events - and their baseline interruptive weighting of this event - has not been altered [Figures 5.9 - 5.10].

As the arriving person moved throughout the workspace, the greatest level of perceived interruption was demonstrated in Sequences 1 through 3, this perceived primarily by Occupants 1, 2 and 4. Beyond Sequence 3 a minimal level of interruption was perceived amongst employees. This excludes Occupant 4 who continued to demonstrate a high level of perceptual awareness of the arriving person [Figure 5.11].

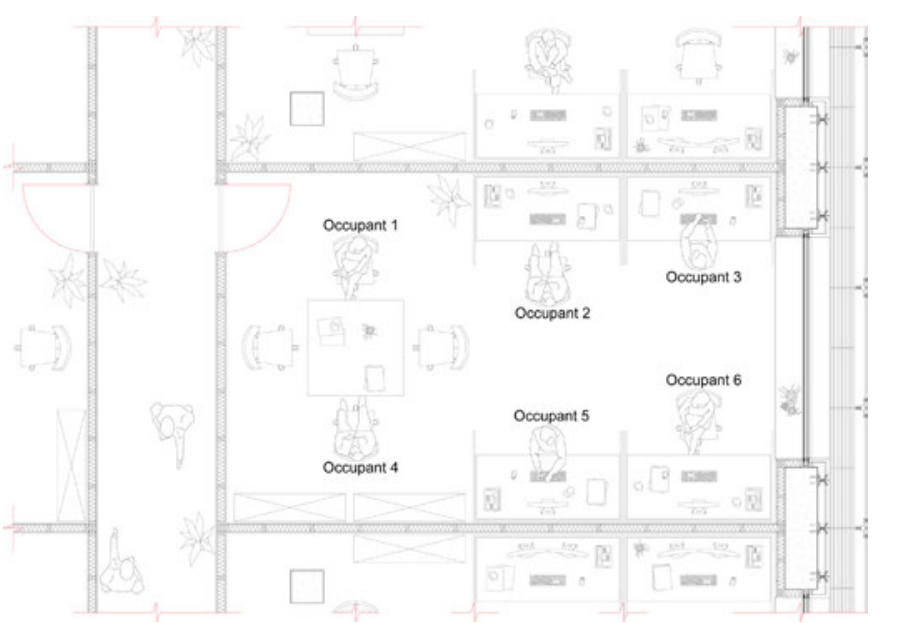

Figure 5.9 - Occupant List - Author $\Delta$

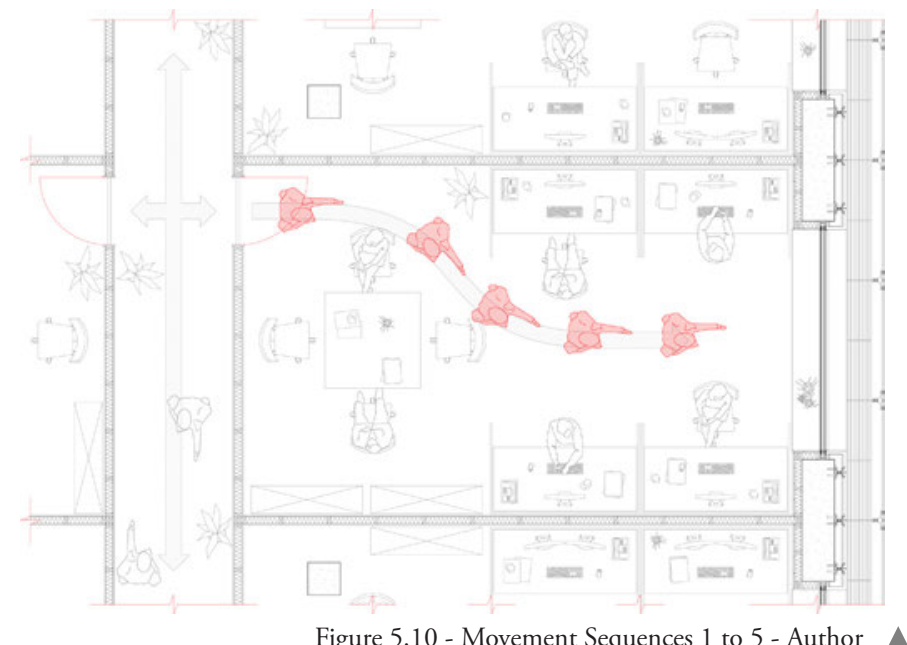

Figure 5.10 - Movement Sequences 1 to 5 - Author 


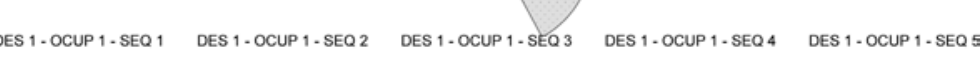

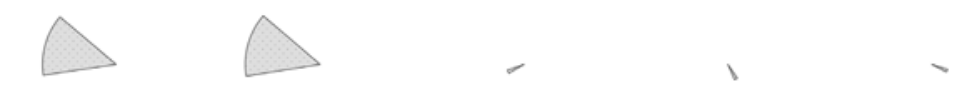

DES 1-OCUP2-SEQ1 DES 1-OCUP2-SEQ2 DES1-OCUP2-SEQ 3 DES 1-OCUP2-SEQ4 DES 1-OCUP2-SEQ S

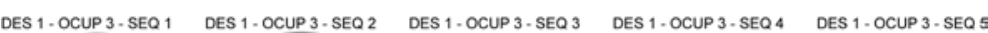

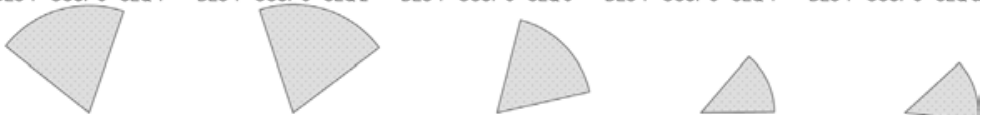

DES 1-OCUP 4-SEQ1 DES 1-OCUP 4-SEQ 2 DES 1-OCUP 4-SEQ 3 DES 1-OCUP 4-SEQ 4 DES 1-OCUP 4-SEO 5

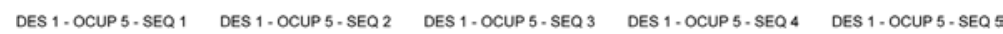

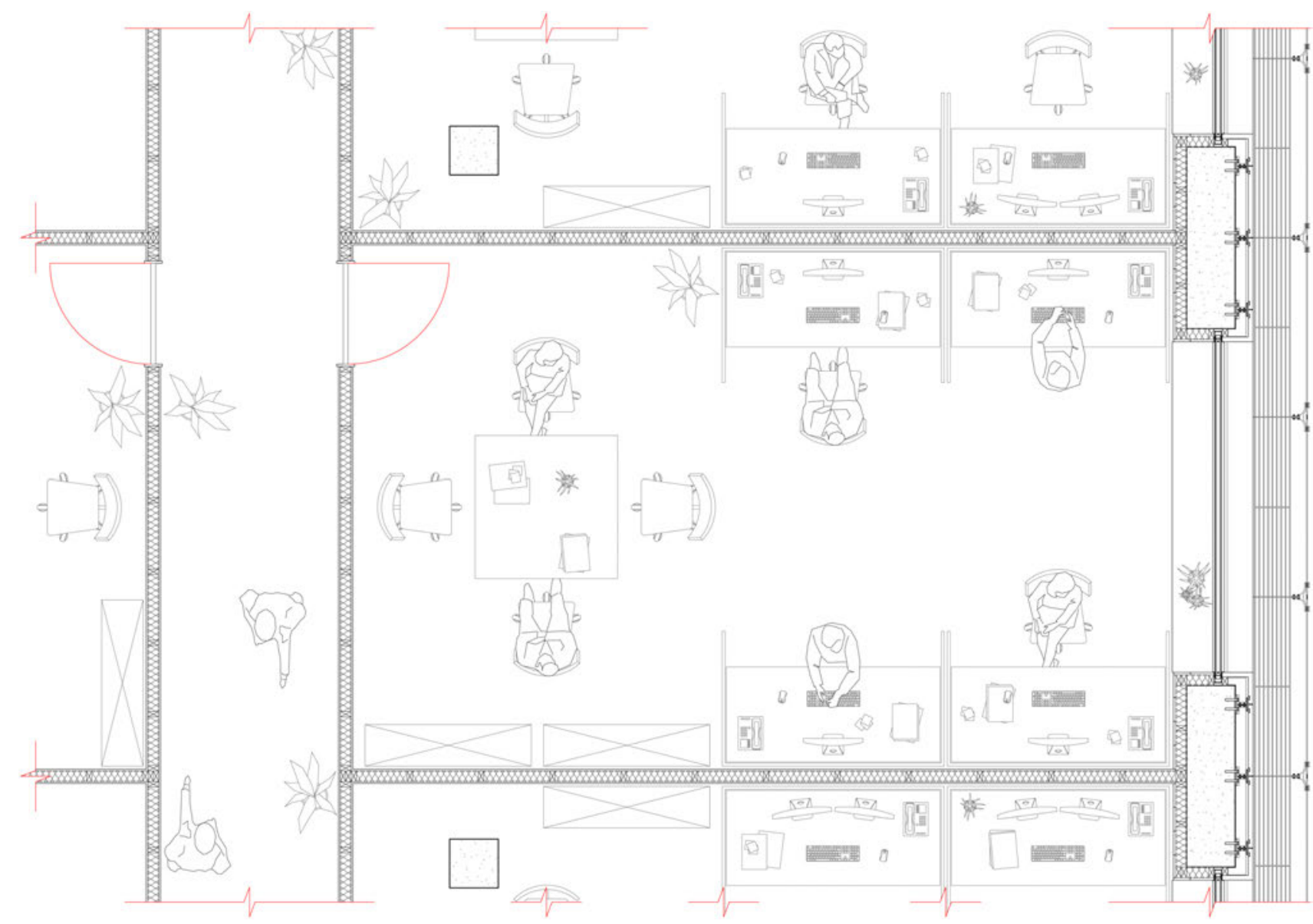


In examining the plan of this space and utilising the system's sensorial tools it is evident that these interruptive outcomes are a result of the arriving person intersecting with and occupying centralised portions of employees' vision. Acknowledging this, the space was altered to minimise visual transparency through the office particularly in and around the design's entryway [Figure 5.16].

By extending the partition depth around the employee desks and introducing a wall between the doorway and meeting space, the average interruptive outcome perceived by the occupants was improved by $28.83 \%$. However, it was found that the interruptive outcome for Occupant 1 worsened by $10.84 \%$, and this is likely a result of the introduced wall shifting their peripheral vision to align with the office's central movement pathway. Despite this shortcoming in the design regarding the interruptive outcome for Occupant 1, a significant improvement in the average interruptive outcome of Occupants 2, 3, and 4 was observed. This improvement was made whilst maintaining the interruptive outcome of Occupants 5 and 6, who were not overly affected by these changes as their base line level of interruption was low to begin with [Figures 5.13 - 5.15].

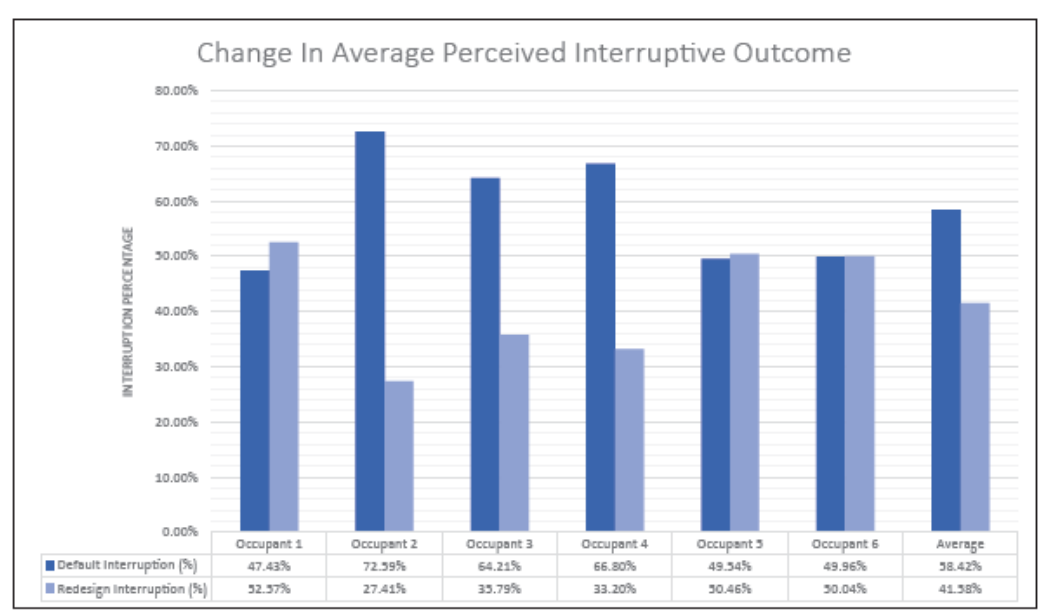

Figure 5.13 - Change In Average Perceived Interruptive Outcome - Author

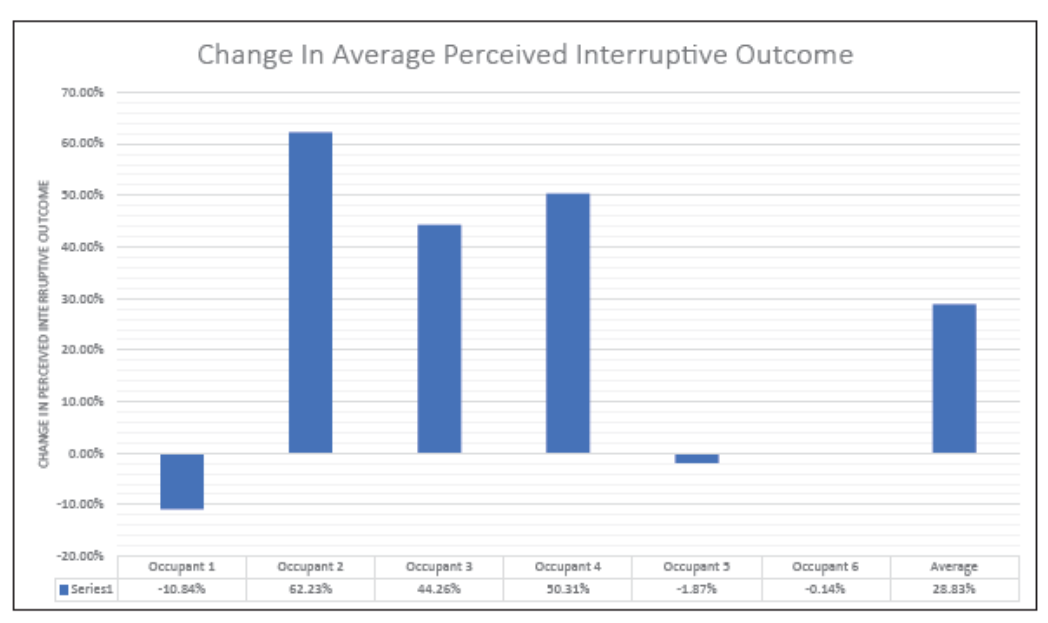

Figure 5.14 - Percentage Change In Average Perceived Interruptive Outcome - Author 


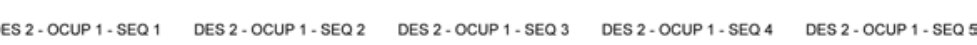
a.t.

DES 2-OCUP 2-SEQ 1 DES 2-OCUP 2-SEQ 2 DES 2-OCUP 2-SEQ 3 DES 2-OCUP 2-SEQ 4 DES 2-OCUP 2-SEQ 5

DES 2-OCUP 3-SEQ1 DES 2-OCUP 3-SEQ 2 DES 2-OCUP 3-SEQ 3 DES 2-OCUP 3-SEQ 4 DES 2-OCUP 3-SEQ S
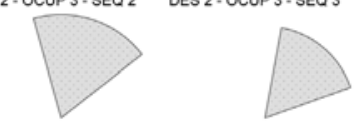

DES 2-OCUP 4-SEQ 1 DES 2-OCUP 4-SEQ 2 DES 2-OCUP 4-SEQ 3 DES 2-OCUP 4-SEQ 4 DES 2-OCUP 4-SEQ S

DES 2-OCUP 5-SEQ1 DES 2-OCUP 5.SEQ2 DES2-OCUP 5.SEQ3 DES 2-OCUP 5-SEQ4 DES2-OCUP 5-SEQ 5

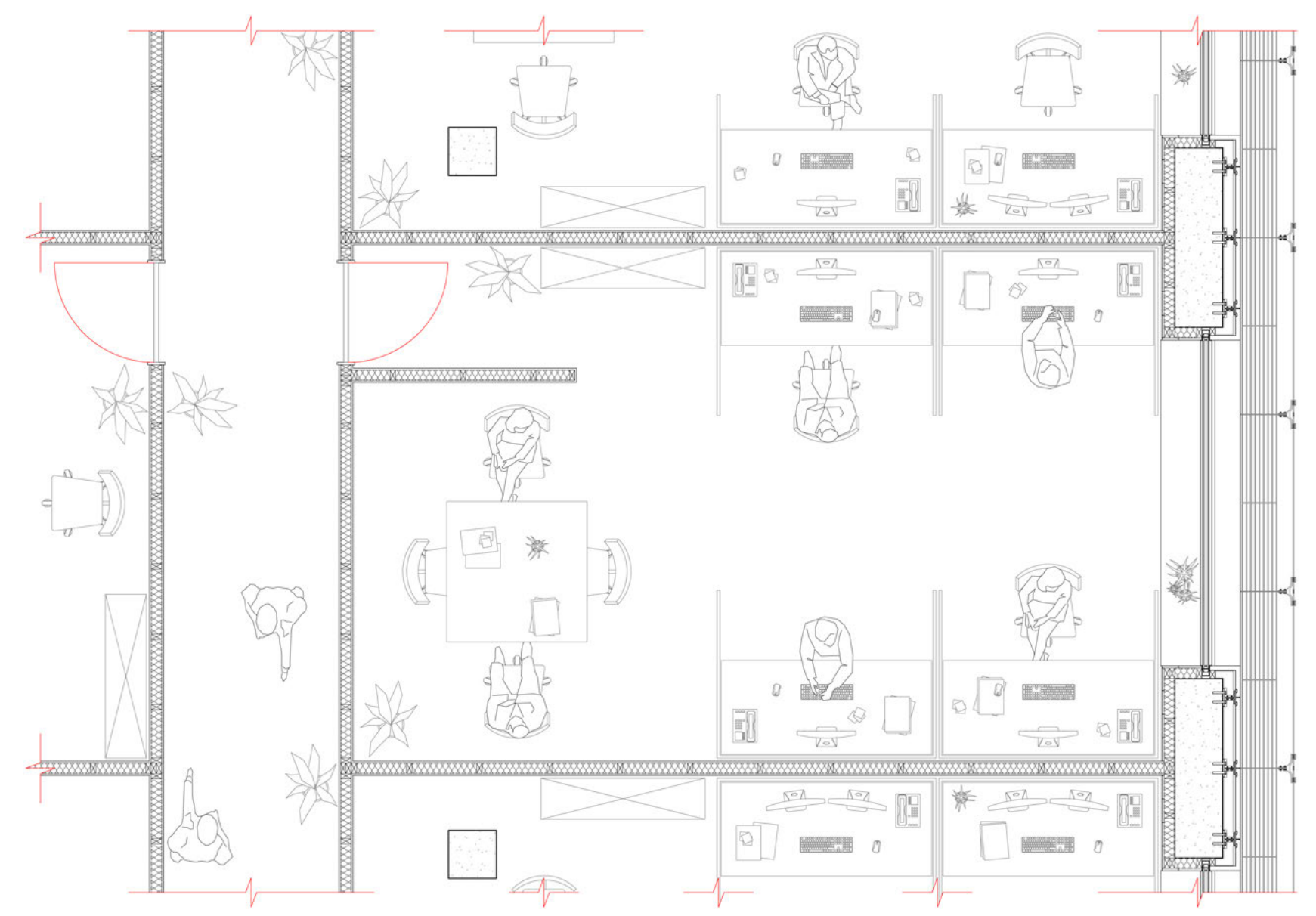


Movement Sequences 1 to 5 - Standard Office Floorplan - No Scale
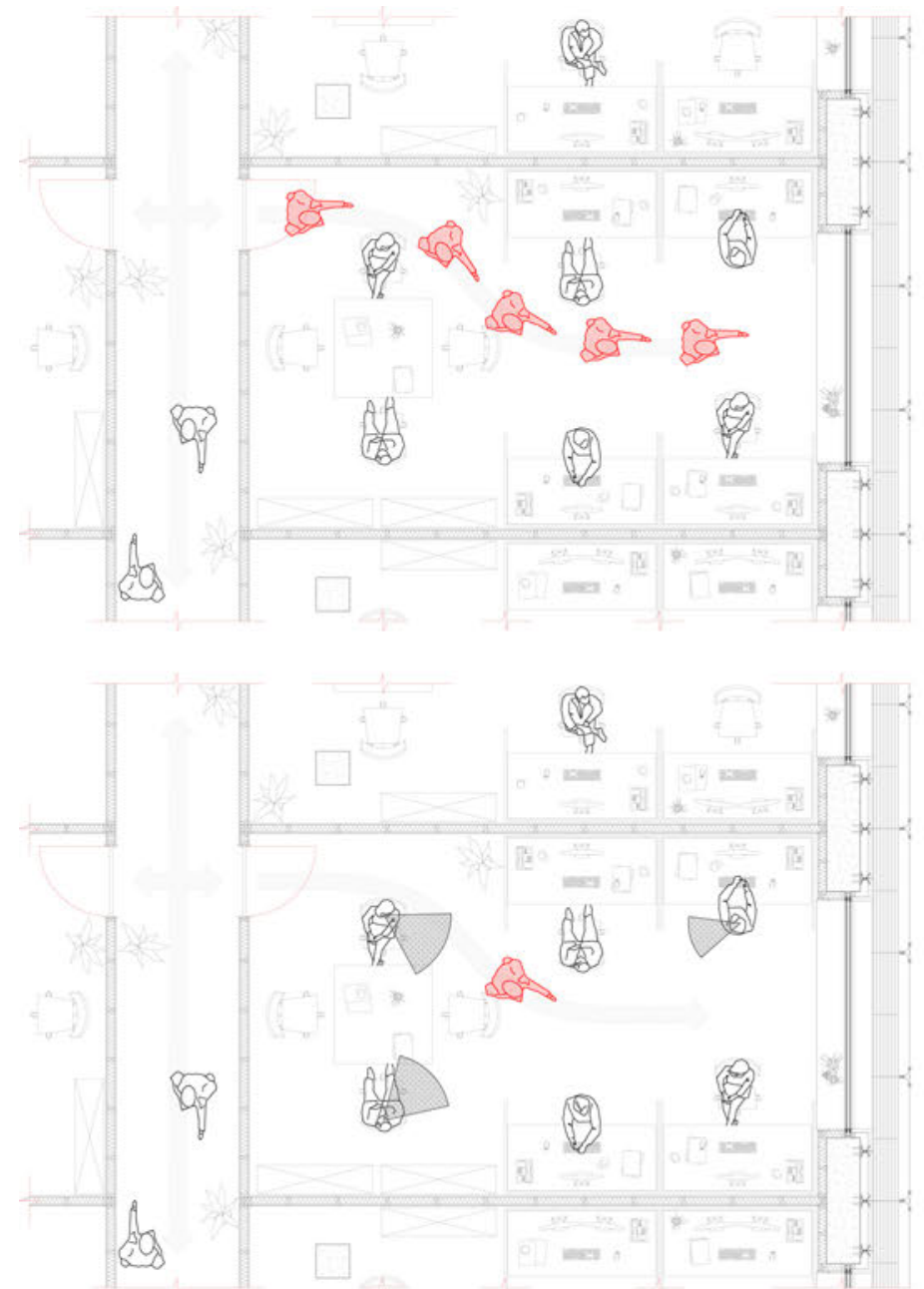

Sequence 3 - Standard Office Floorplan - No Scale
Sequence 1 - Standard Office Floorplan - No Scale
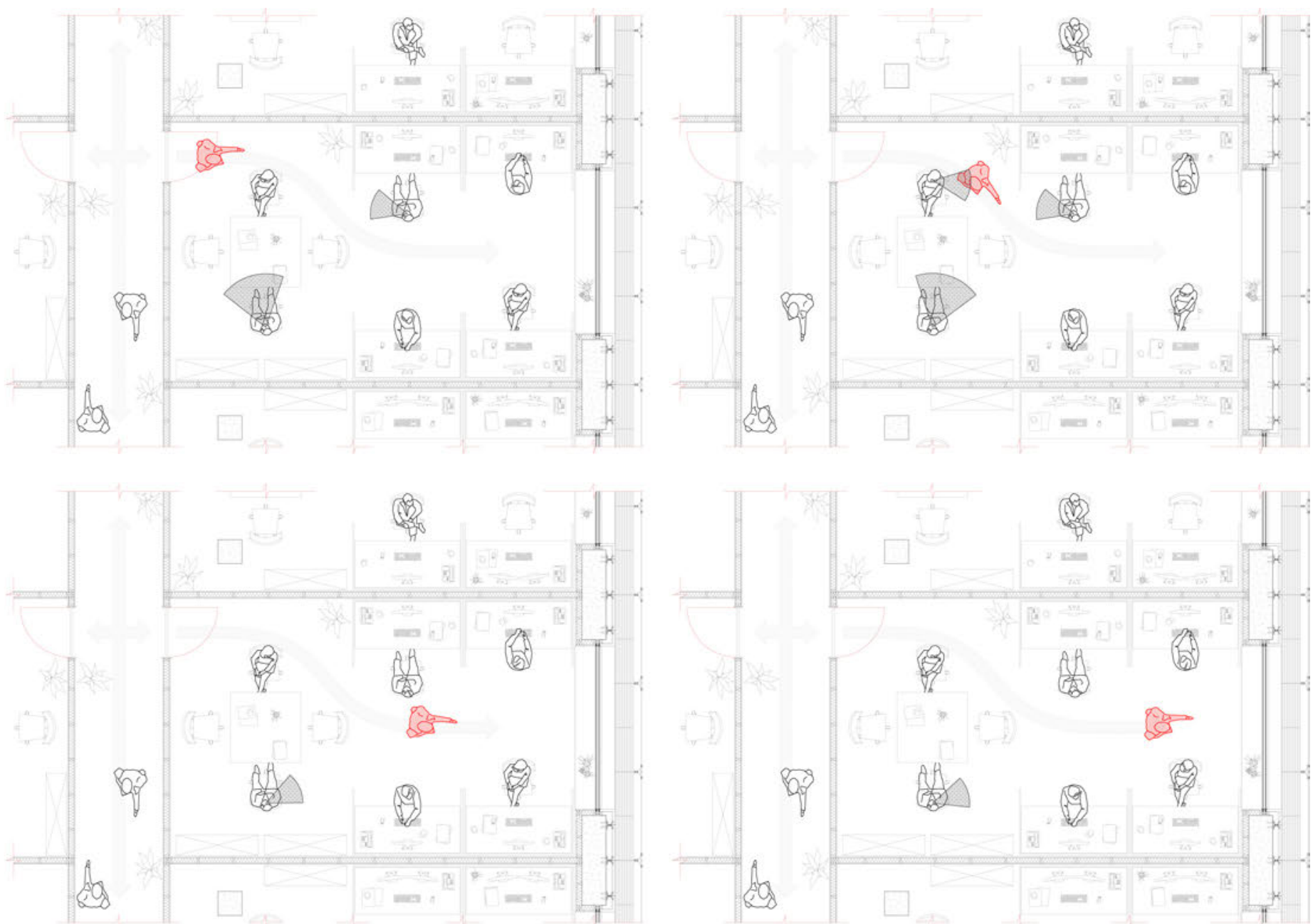

Sequence 4 - Standard Office Floorplan - No Scale

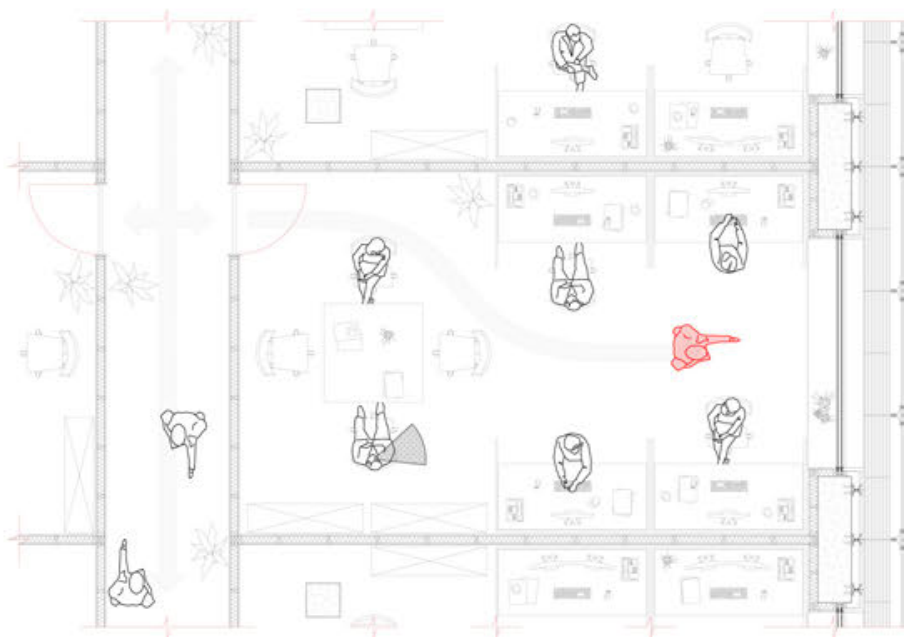

Sequence 5 - Standard Office Floorplan - No Scale 
Movement Sequences 1 to 5 - Revised Office Floorplan - No Scale
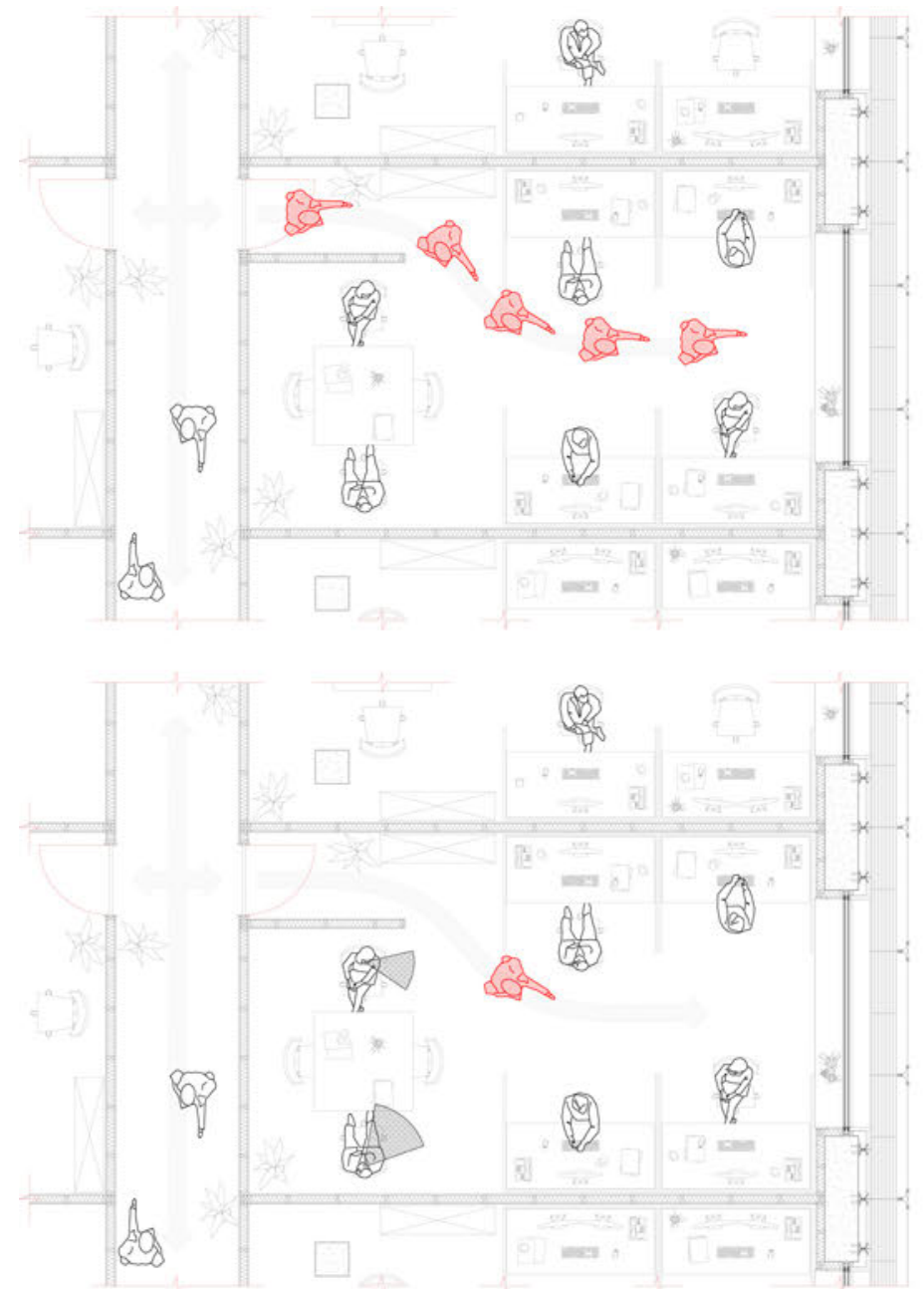

Sequence 3 - Revised Office Floorplan - No Scale

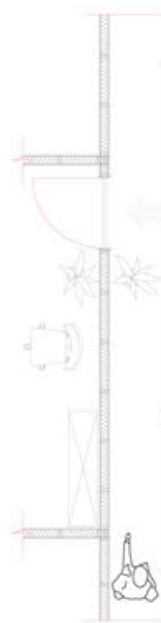

Sequence 1 - Revised Office Floorplan - No Scale

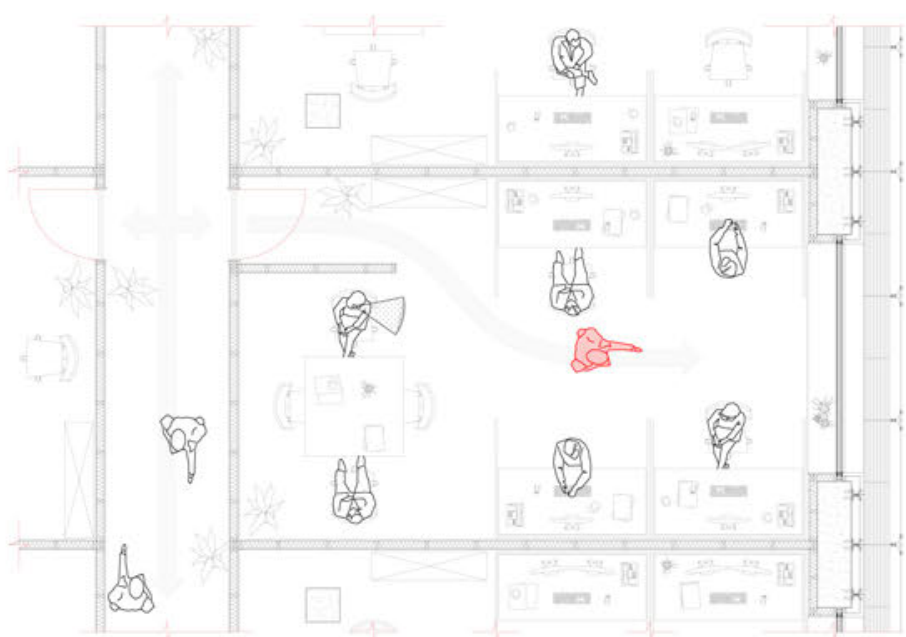

Sequence 4 - Revised Office Floorplan - No Scale
Sequence 2 - Revised Office Floorplan - No Scale
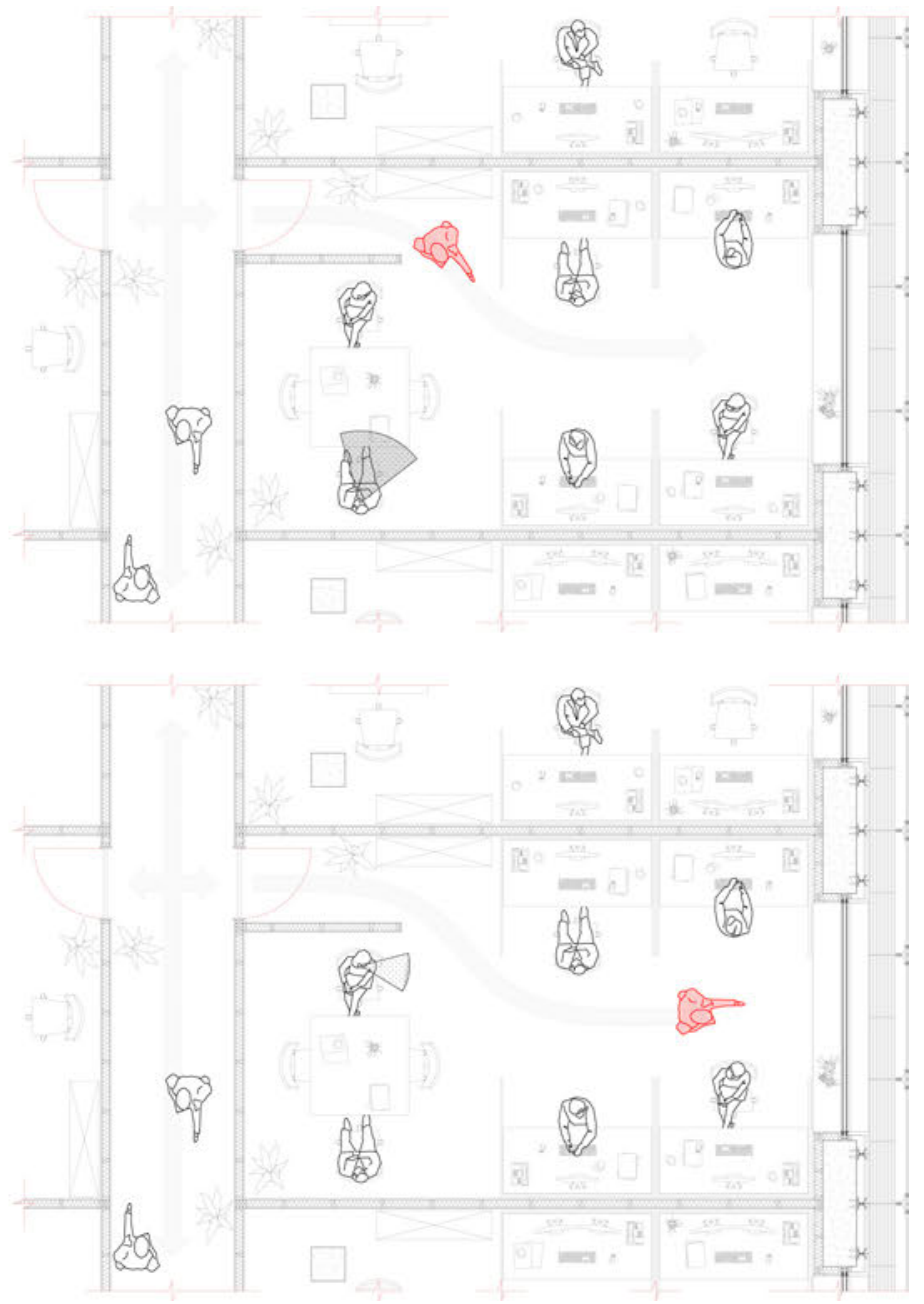

Sequence 5 - Revised Office Floorplan - No Scale 
The process of applying the notational system in both this instance and prior demonstrations has proven to be laborious. When examining multiple occupants and multiple interruptive events, the practitioner utilising the system must continually measure an employee's sensorial perceptibility, logging this within the excel calculator and drafting the resulting outcome within the drawing. This process begins to disconnect the practitioner from the design of an interruption aware space, and is an issue which must be acknowledged within the system if utilising it at a larger scale [Figure 5.19]. 


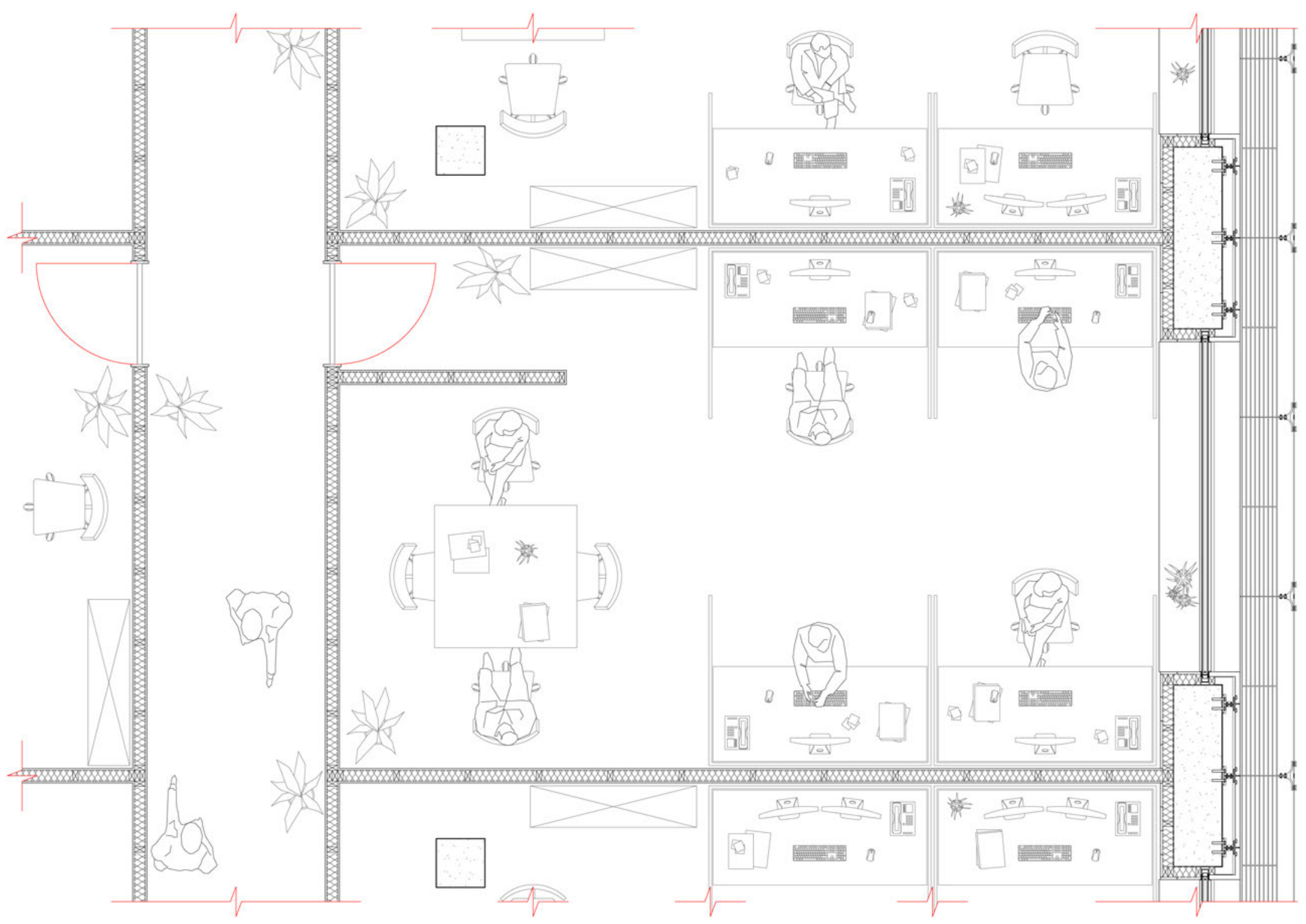




\section{Notational Testing:}

Wigan 501 occupies approximately one half of the Victoria University of Wellington Te Aro Campus' fifth floor. It is designed as a workplace for students, and operates in a centralised open work area bounded by staff offices [Figure 5.20]. Users enter the space primarily through the main door, although a secondary entry is available through the Wigan 507 student workspace. The design of the central work area is sparse, offering only a desk and computer for each student to work from. These workstations are not separated by partitions, and are assembled from modular furniture indicating that this space is intended to act as a student overflow or hot desking area. Despite these design intentions, it is evident that the space does not operate in this manner, as students do not treat this space as a temporary workspace.

To strengthen the findings of the work conducted thus far, Wigan 501 was utilised as a test site to gather data reflecting my personal interruptive experience. From here the accuracy of the notational system could be examined alongside its sensorial weighting. To gather the data required for this, my interruptive experience was recorded through my sensorial perceptibility. Interruptive events were logged based upon the senses that I perceived them through, noting the events source, magnitude, duration and time. I acknowledge that this student workspace is not truly representational of a typical office, but it functions as an approximate representation and it allows for interruptive data to be gathered. The recording of this data was conducted between $9 \mathrm{am}$ and $5 \mathrm{pm}$ and gathered across two workdays.

It should be acknowledged however, that students are not constricted by a 9-5 schedule. They often arrive and leave based upon their own schedule, but the timing of most interruptions remains applicable.

The interruptive magnitude of a given event was defined as either small, medium or large. Interruptions between 1 and 30 seconds were labelled as small, 30 seconds and 2 minutes were labelled as medium, and greater than 2 minutes were labelled as large. This range was dictated by the knowledge that employees, once interrupted for more than 2 minutes, may take up to 23 minutes and 15 seconds to resume their original task, thus decreasing their productivity. ${ }^{[1]}$

1 Rasheed, E., Khoshbakht, M., \& Baird, G. (2021). Office Distractions and the Productivity of Building Users: The Effect of Workgroup Sizes and Demographic Characteristics. Buildings, 1-17 


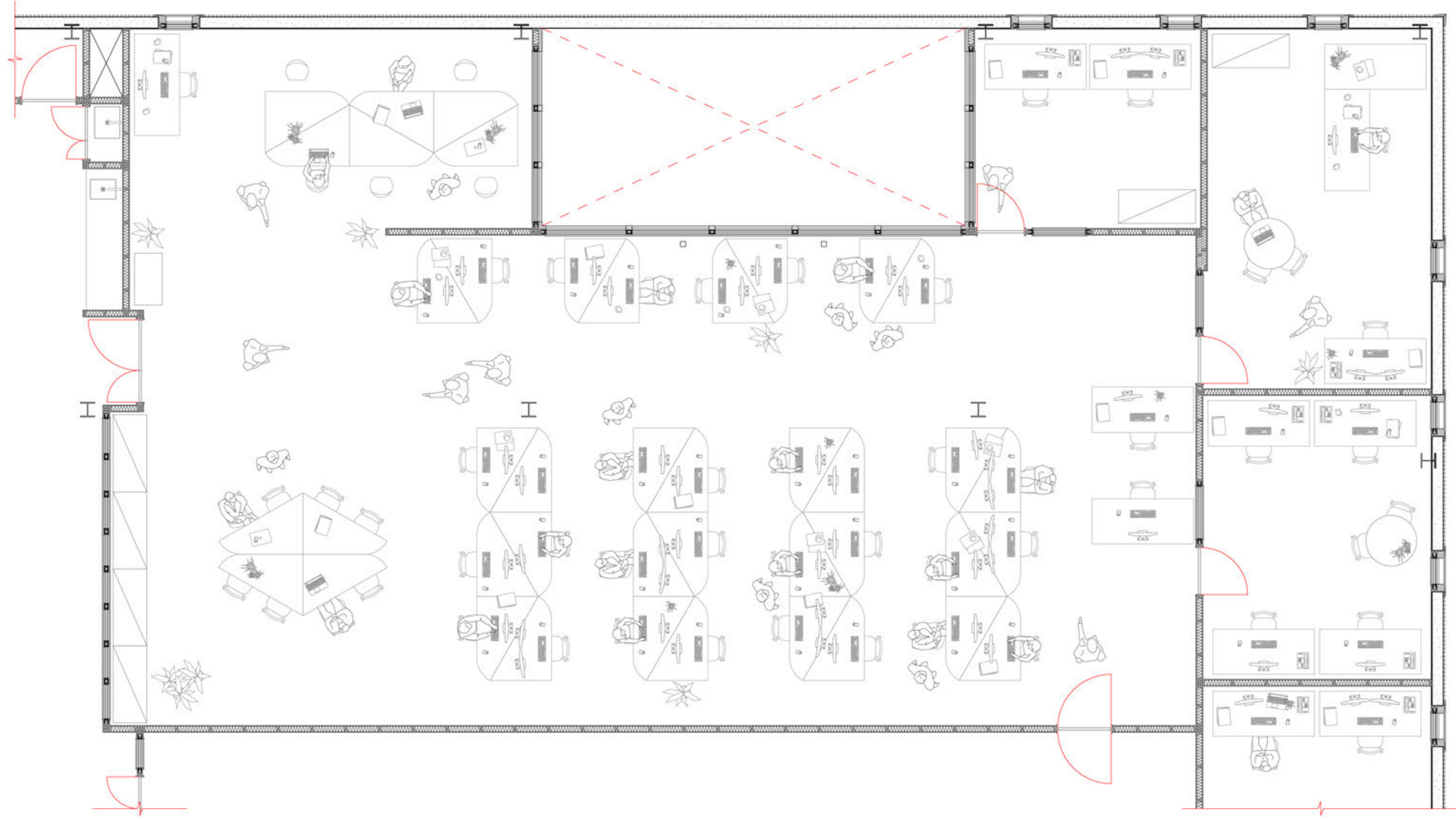


The number of interruptions perceived in the particular workspace of Wigan 501 peaks early in the morning at $10 \mathrm{am}$ as users arrive and settle into their workday, conversing with one another whilst moving throughout the workspace. This rapidly decreases over the next hour as users turn their focus from their fellow students to their work. This period of focus is later broken around lunch, which results in many users congregating to reheat food, converse and exit the workspace. Users are staggered in returning to Wigan 501 , resulting in a steady rise in interruption, this peaking again at $2 \mathrm{pm}$. Beyond this point users regain their focus. Their numbers begin to thin as they leave the workplace, resulting in a decrease in perceived interruptions. By $5 \mathrm{pm}$ the number of hourly interruptions is as its lowest point, this indicating that the number of perceived interruptions lessen as the day progresses. These finding are supported by the downward trendline. [Figure 5.21].

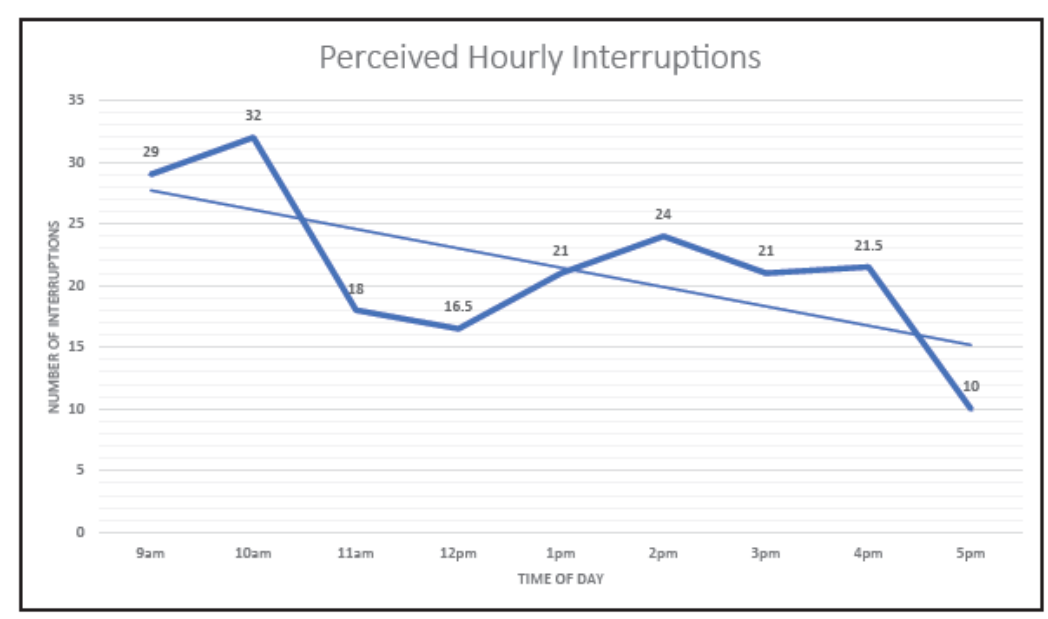

Figure 5.21 - Wigan 501 Perceived Hourly Interruptions - Author
The majority of these perceived interruptions were a result of people passing my workstation (44.79\%) and engaging in background conversations (24.21\%) [Figure 5.22]. This creates a potential line of inquiry for the notational system to address, as they more prevalent than the other interruptive events outlined by Gonzalez \& Mark within their work. These issues are pressing in both my perception of Wigan 501 and the notational systems measure of the space (the system measuring these events account for $35.15 \%$ and $10.41 \%$ of my perceived interruptions). The system should in turn strive to address these events as a priority amongst the broad list of interruptive events provided by Gonzalez \& Mark.

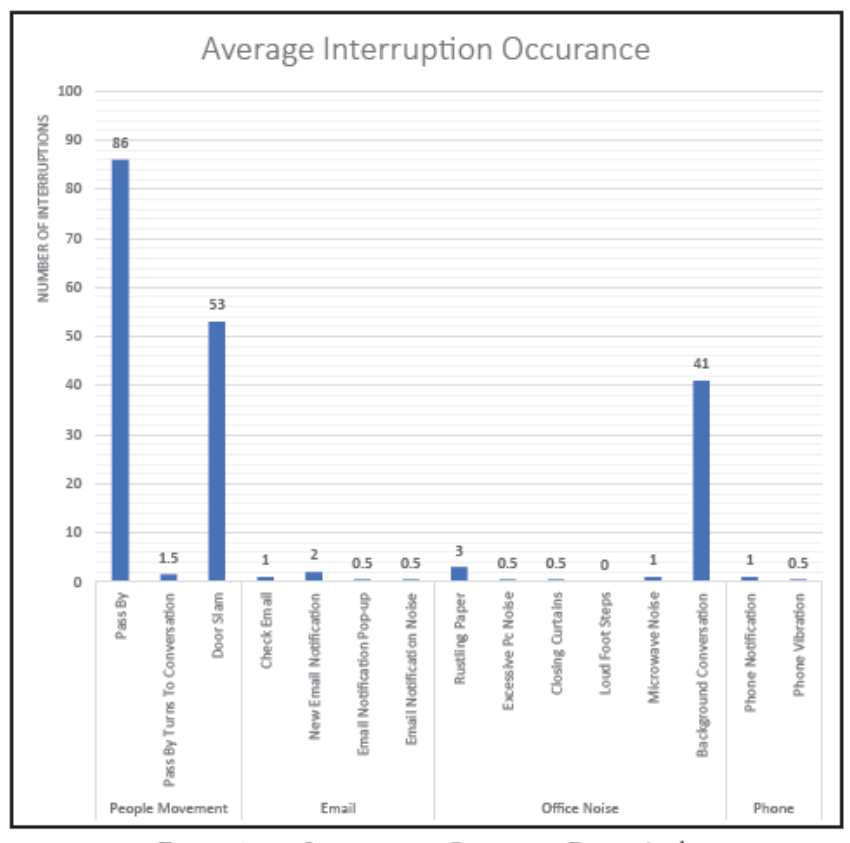

Figure 5.22 - Interruption Occurance Rate - Author 

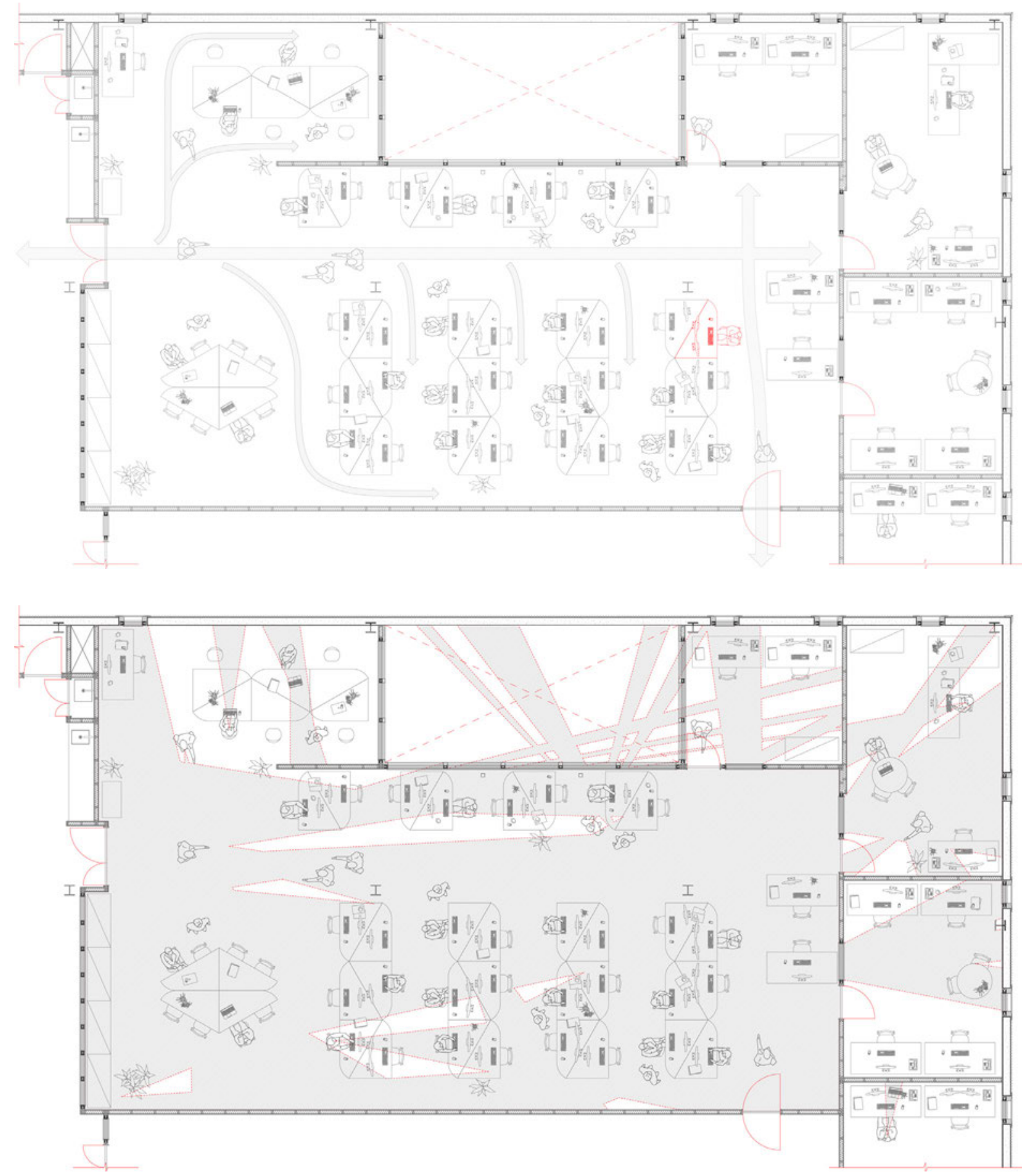
What should be addressed is the discrepancy in the data between my perceptibility of Wigan 501 and the systems measure of it. As stated prior, people moving through the workplace accounted for $44.79 \%$ of my perceived interruptions and background conversations accounted for $24.21 \%$. In employing the notational system, these interruptive events were in fact measured to account for $35.15 \%$ and $10.41 \%$ of my perceived interruptions respectively. On average this depicting a $12.29 \%$ difference in the data [Figure 5.25 - 5.27].

This discrepancy in the data is likely a result of several factors. The data recorded within Wigan 501 was taken across only two days, and does not reflect a full interruptive understanding of the space. In addition to this, the data acquired by Gonzalez and Mark which the system uses as a baseline for its interruptive events, has been assumed as applicable to all office types for the purposes of this thesis. However, the workspace in which Gonzalez and Mark's Data was recorded operates in the financial sector and does not accurately reflect a student workspace. Therefore the discrepancy in the data can be treated as minimal, although future works should endeavour to garner interruptive data specific to the office that is being redesigned. As a whole, the notational system for the intents and purposes of this thesis can be assumed to be an accurate measure of a spaces interruptive outcome.

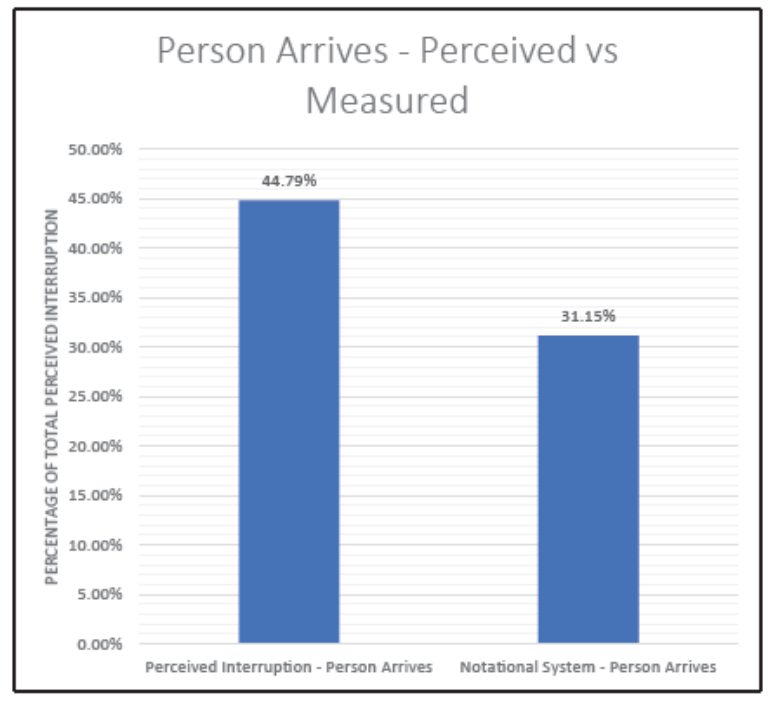

Figure 5.25 - Wigan 501 - Person Arrives - Author

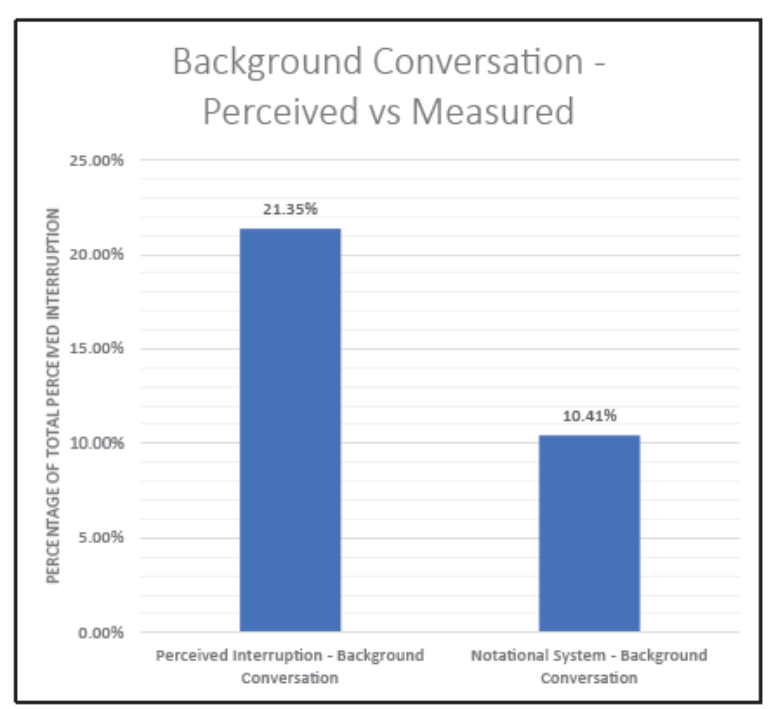

Figure 5.26 - Wigan 501 - Background Conversation - Author 


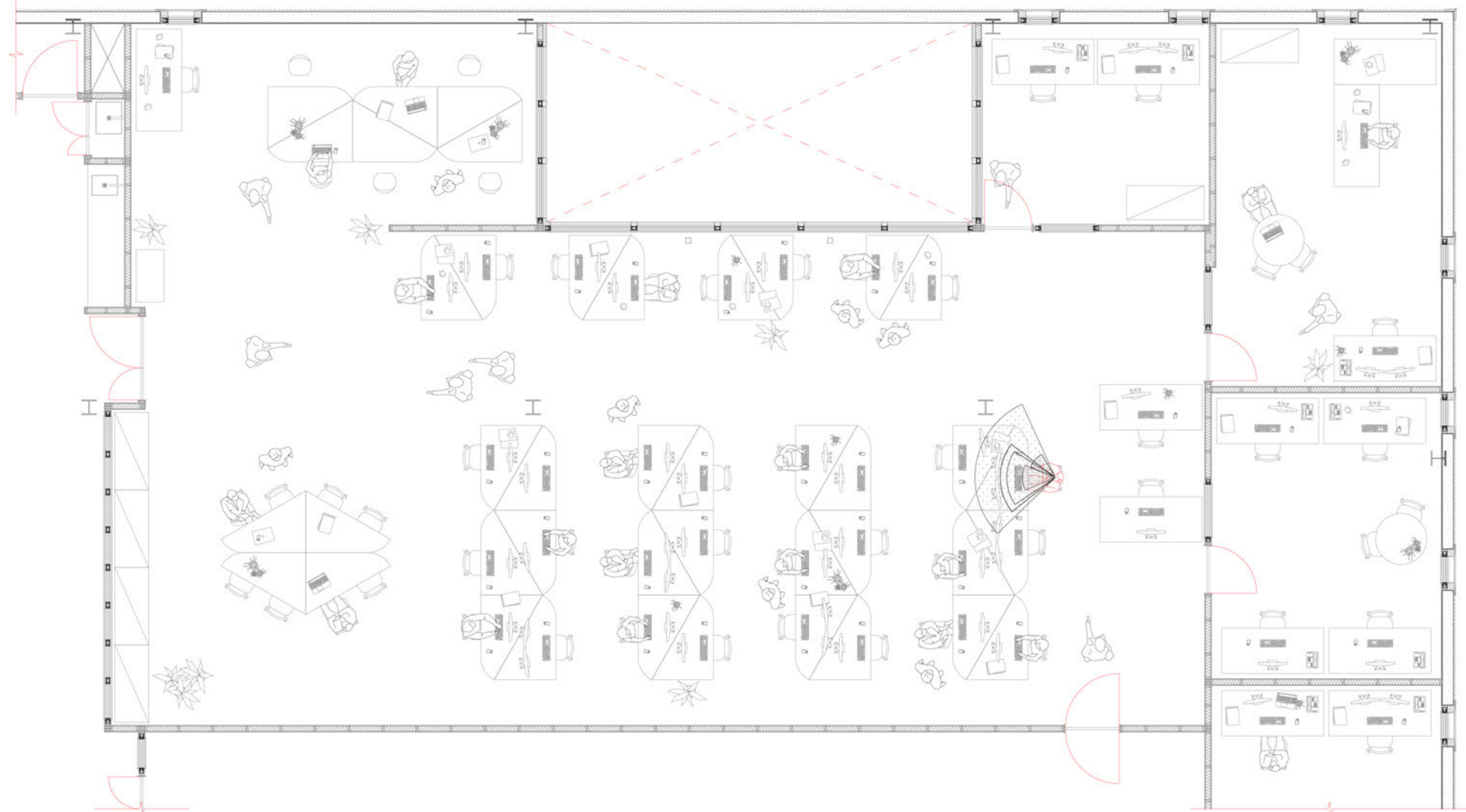

Mapped Interruption Events:Interruption Events:

Not To interusution Scale

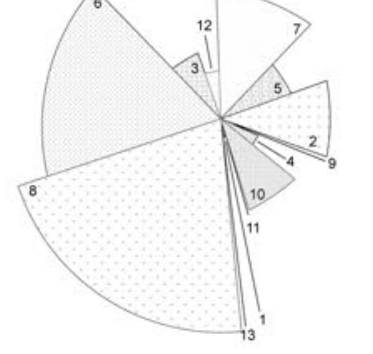

E-Mail Use
Interuption 5

$\square$ Leaving Cubicle

$\underset{\substack{\text { Phone Ringing } \\ \text { Interuption } 10}}{\text { 10 }}$

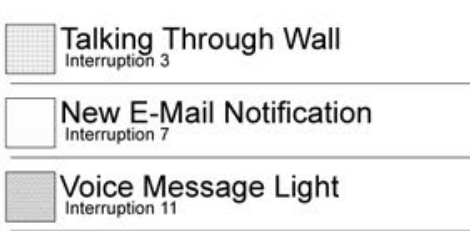

Phone Call

Person Arrives

Reminder Notification

Call Through Wall
Interrupition 12 
The data gathered from this exercise indicates that the majority of perceived interruptions are small in magnitude [Figure 5.28]. When recording this data, many of the interruptions were of short duration, often drawing my attention only for a moment to acknowledge a person walking by or react to the sound of a door slamming. Medium and large interruptions were rare within the workspace and often occurred as a result of overheard conversations. This is reflected in the breakdown of this data, indicating that sight accounts for the majority of small magnitude interruptions, whereas hearing accounts for the majority of medium to large interruptions \{Figure 5.29].

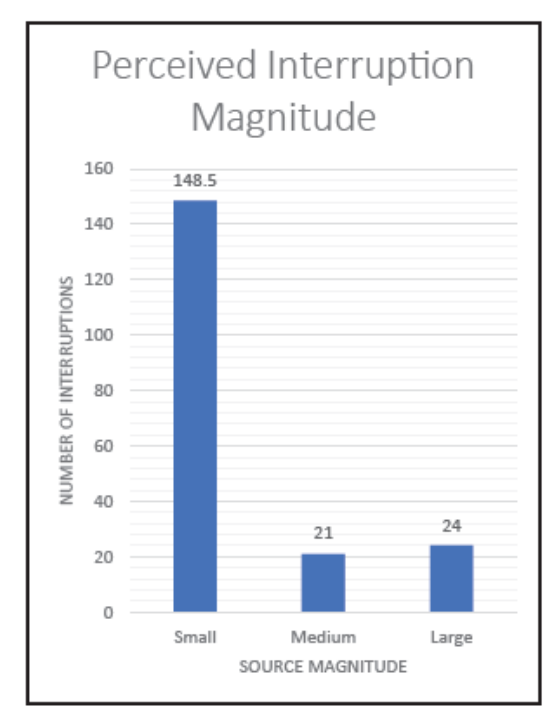

Figure 5.28 - Interruption Magnatude - Author

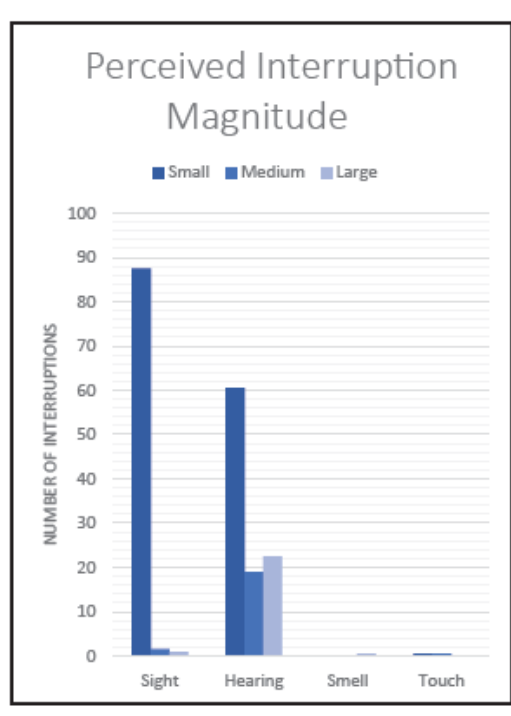

Figure 5.29 - Interruption Magnatude - Autho 


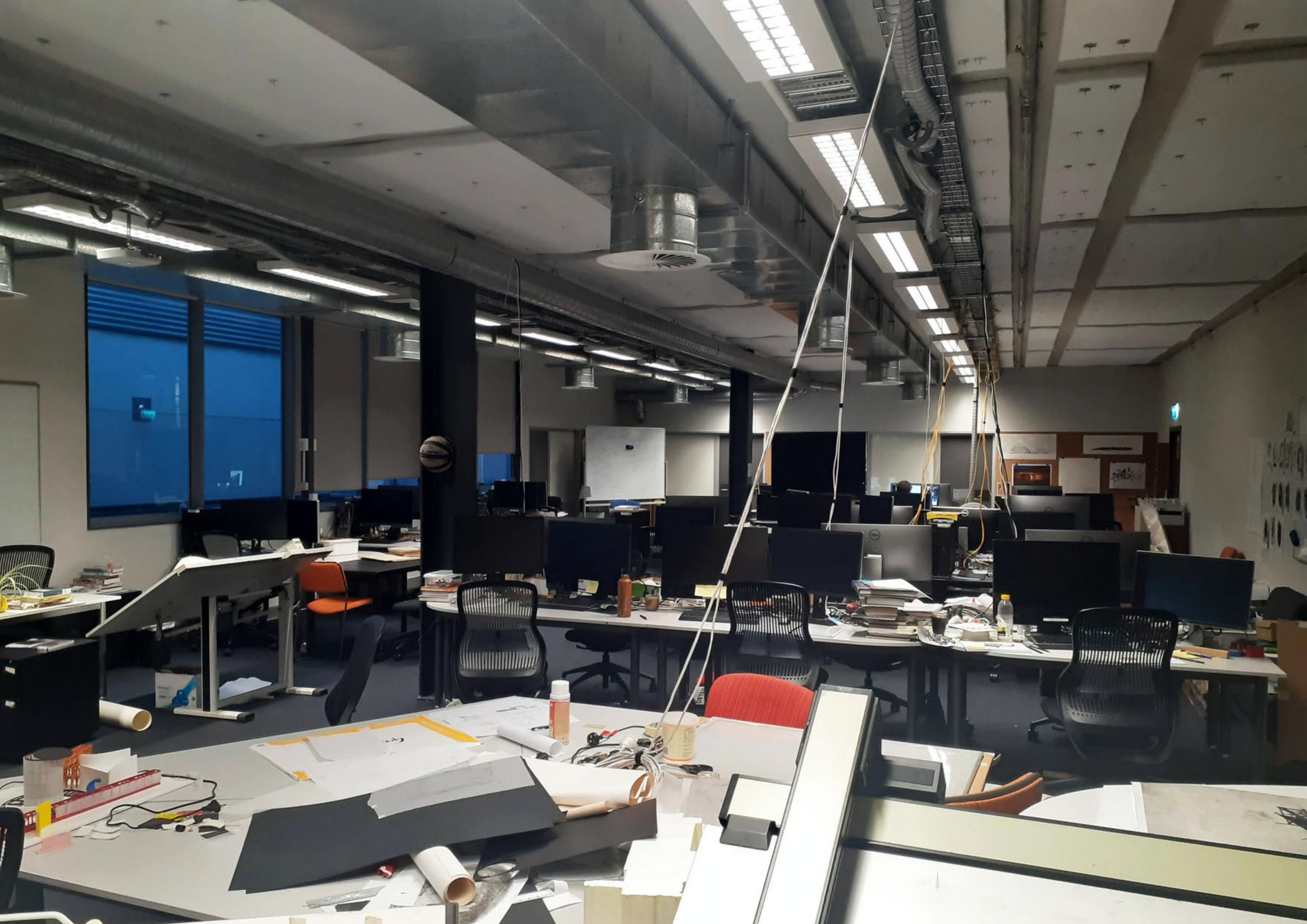


This notion is reinforced when comparing the average interruption time of each sense [Figure 5.31]. As sight contributes to mostly small magnitude interruptions, its average interruption time is 14.5 seconds. As hearing contributes more frequently to medium and large interruptions, its average interruption time is skewed higher at 113.7 seconds. In this workspace the average interruption time of smell and touch can be treated as an outlier, as few instances were recorded regarding these senses and the data is insufficient in determining the average interruption time.

The overall data gathered from this exercise indicates that my sensorial usage primarily relies upon my sense of hearing (52.72\%) [Figure 5.32]. This opposes Rosenblum's work in which he suggests only $11 \%$ of our sensorial perceptibility is determined through hearing ${ }^{[l]}$. This discrepancy is critical, as the notational system relies upon these values to determine the interruptive outcome of a given workspace. In response to this, the system has been reconfigured to work with the average between my recorded values and Rosenblum's findings (Sight 64.76\%, Hearing 31.86\%, Smell 1.87\%, Taste $1.51 \%)$.
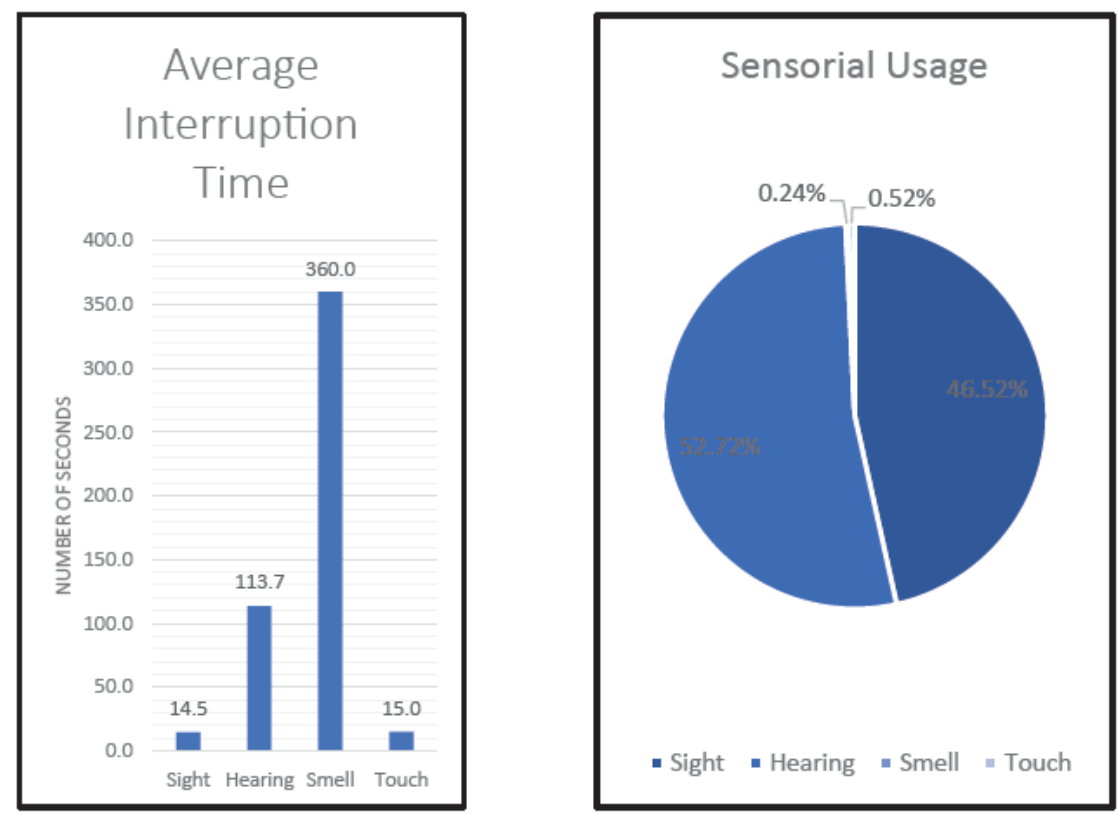

Figure 5.31 - Average Interruption Time - Author

1 Rosenblum, L. D. (2010). See What I'm Saying: The Extraordinary Powers of Our Five Senses. New York: W. W. Norton \& Company. 


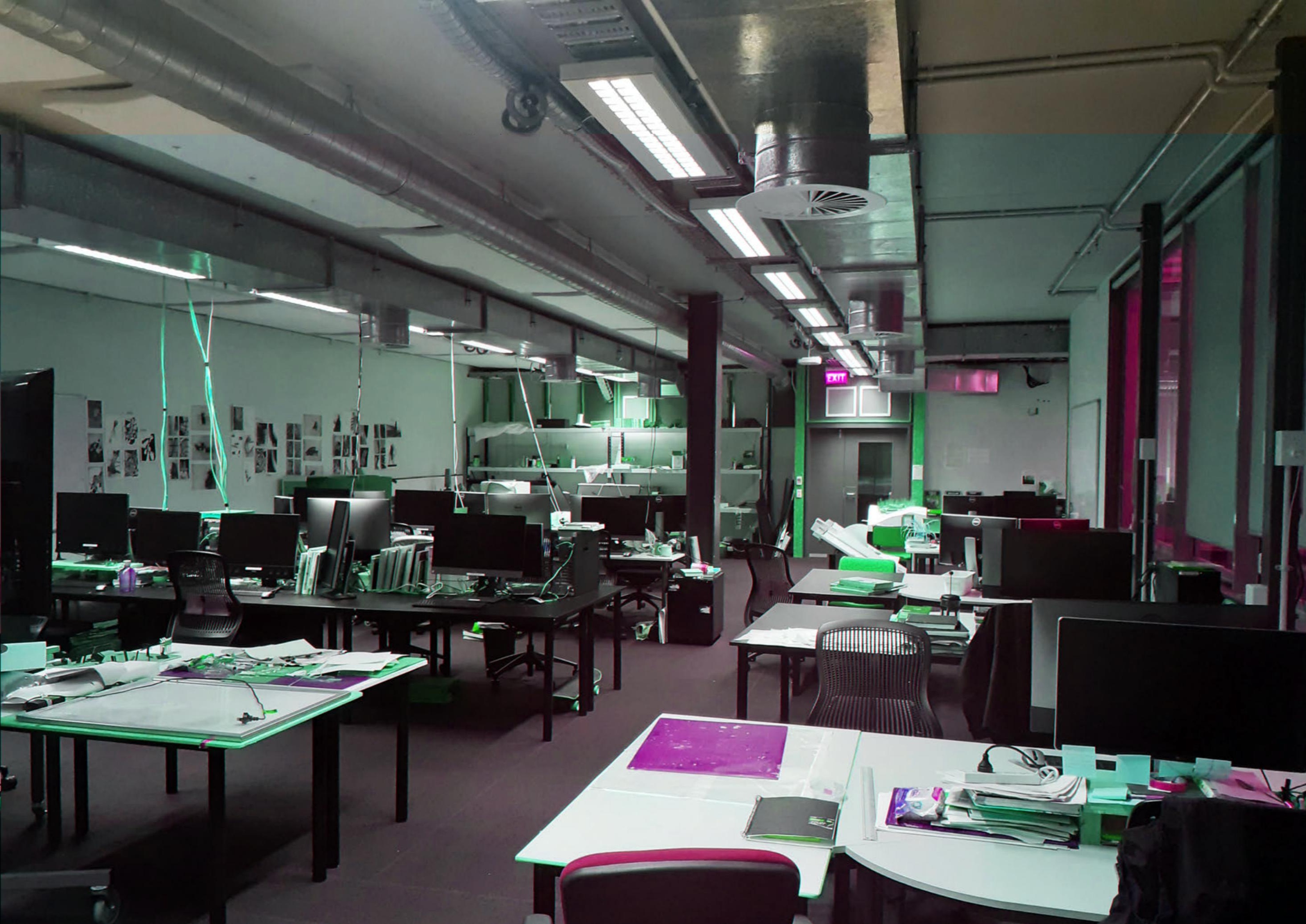




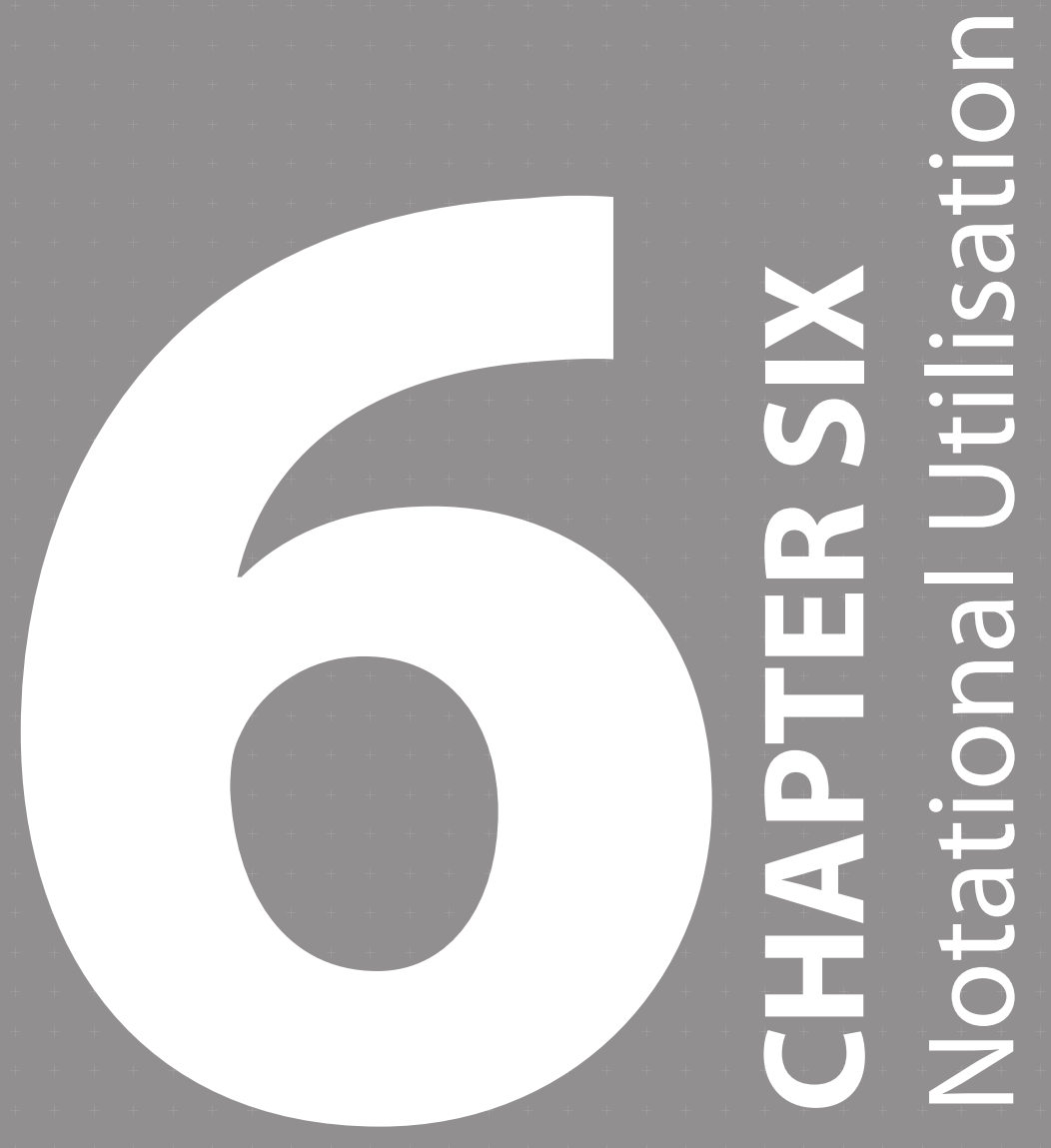





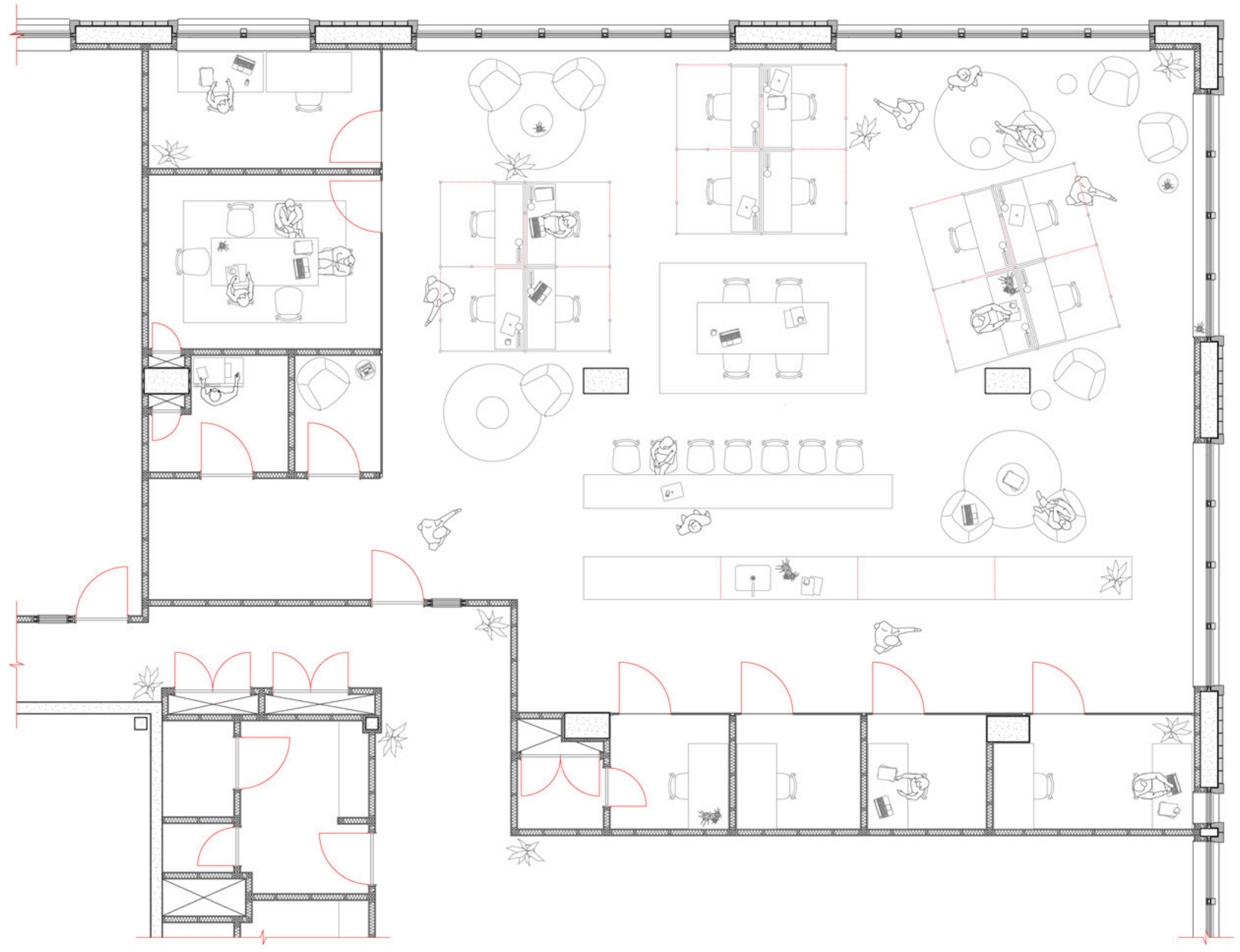




\section{Sharecuse Office - Interruptive Analysis:}

The Sharecuse office [Figure 6.1] discussed in Chapter Three has been selected to serve as a foundation from which the final design of this thesis will be generated. When discussing this office prior, its design was identified to allow for an interruptive atmosphere to develop unchecked. The redesign through the use of the notational system aims to address these issues, and formulate a truly agile workspace in which employees can freely move, engage with one another and work effectively. 
Acknowledging that the Sharecuse office operates within the 1928 Syracuse Office Building, there are several fixtures which must be considered in its redesign. Columns spaced at $7,000 \mathrm{~mm}$ centres and a series of riser cores penetrate the Sharecuse workspace, occupying not only the central work area but also portions of its periphery. This creates a series of obstacles which the final design must work around [Figure 6.2].

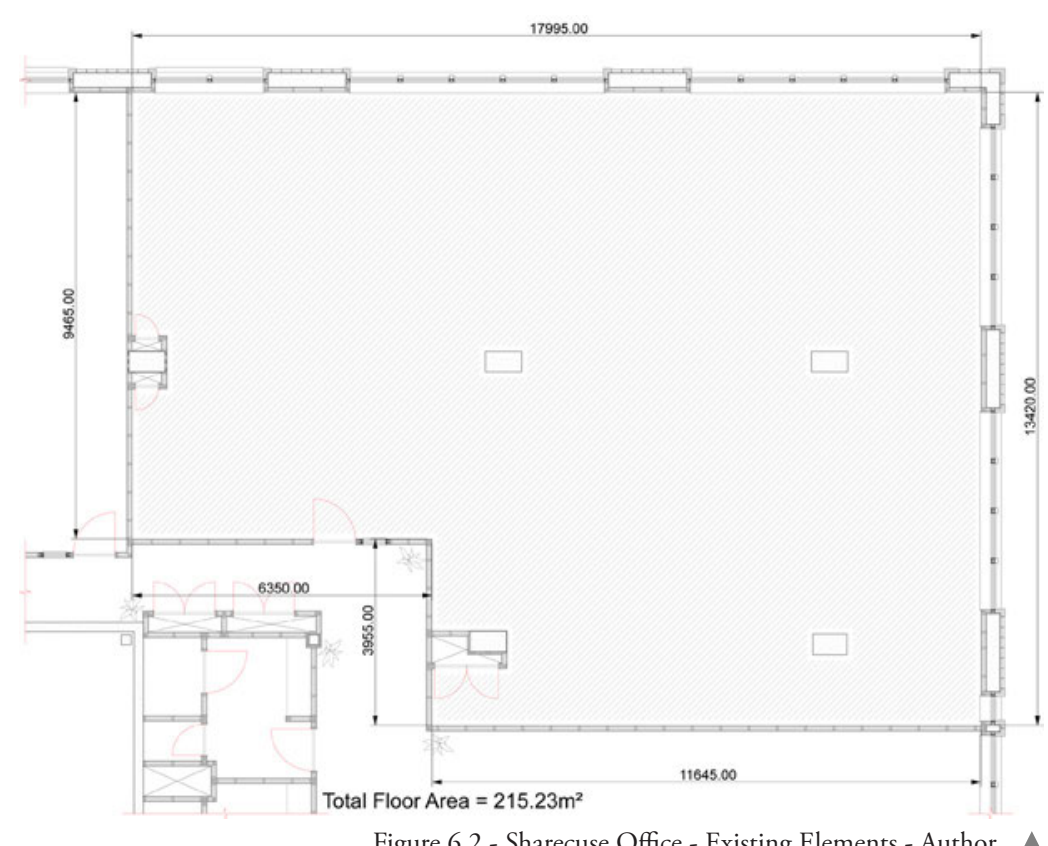

The current design of the Sharecuse office is able to comfortably seat 25 employees at a density of $8.61 \mathrm{~m}^{2}$ per person, although it could in theory seat up to 46 at a maximum density of $4.68 \mathrm{~m}^{2}$ per person. As such, the redesign of the Sharecuse office should endeavour to maintain a similar level of employee density as the current design [Figure 6.3].

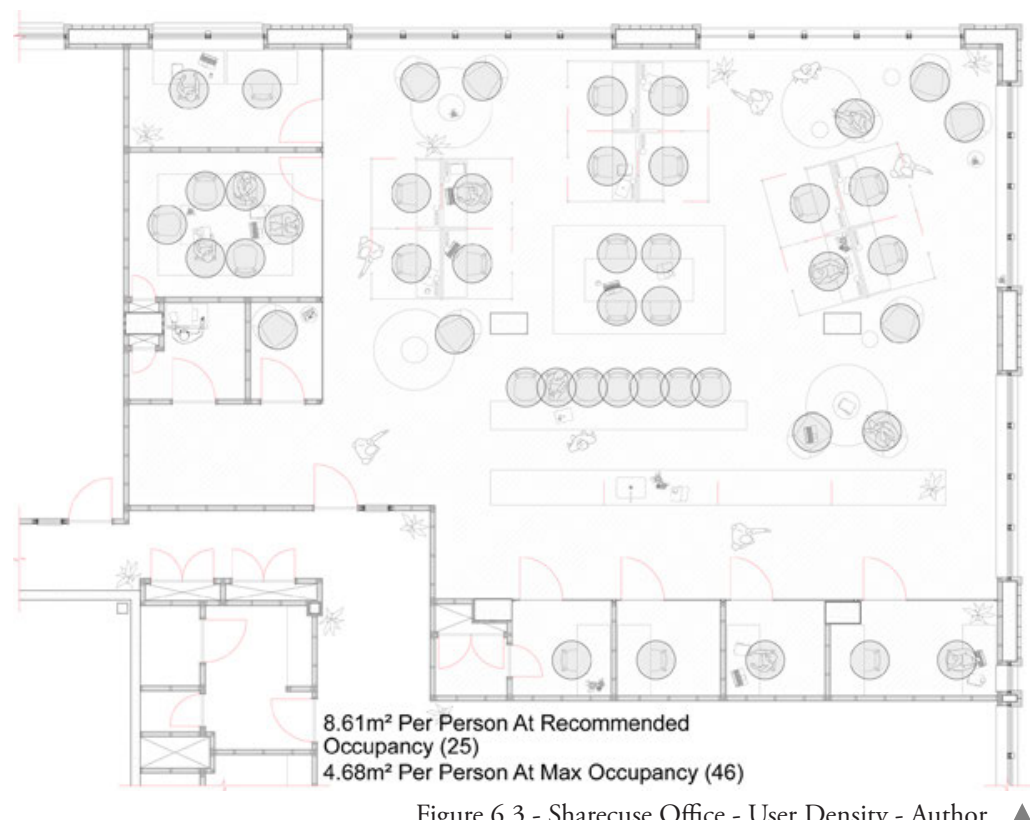


In this mocked-up instance of the Sharecuse office, employee sightlines have been examined based only upon their macular vision cone. This reductive examination highlights the level of visual transparency throughout the office as a result of the poorly performing mesh partitions, and illustrates why visual interruption increases. This in turn raises an issue which the final design must address through use of the notational system [Figure 6.4].

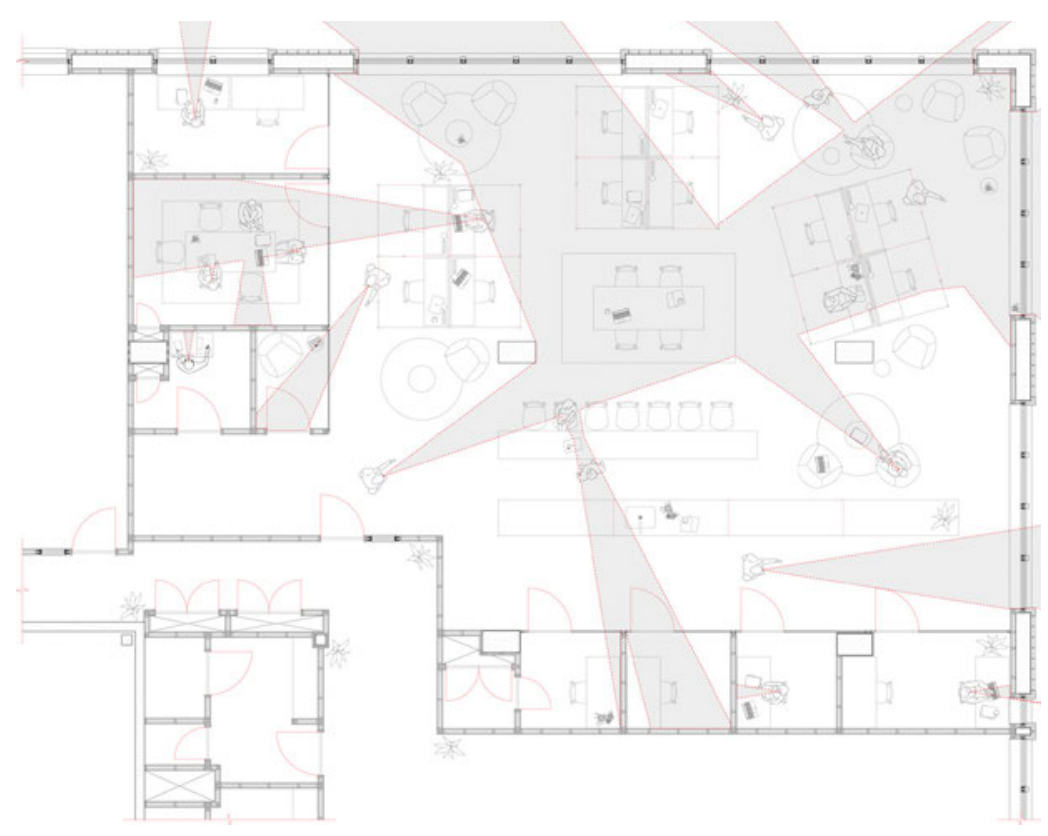

A Figure 6.4 - Sharecuse Office - Employee Sightlines - Author
As a result of Sharecuse's construction, aural interruptions are likely to occur within the office. The mesh construction of the semiformal individual workstations likely does nothing to dampen or mitigate noise levels, and the glazed frontage of the other work areas likely allows for a large portion of this noise to transfer. These factors - when combined with the build's hard surfaces, lack of carpeting, and damping materials - only further this issue. In the redesign of Sharecuse this must be addressed and evaluated through the notational system [Figure 6.5].

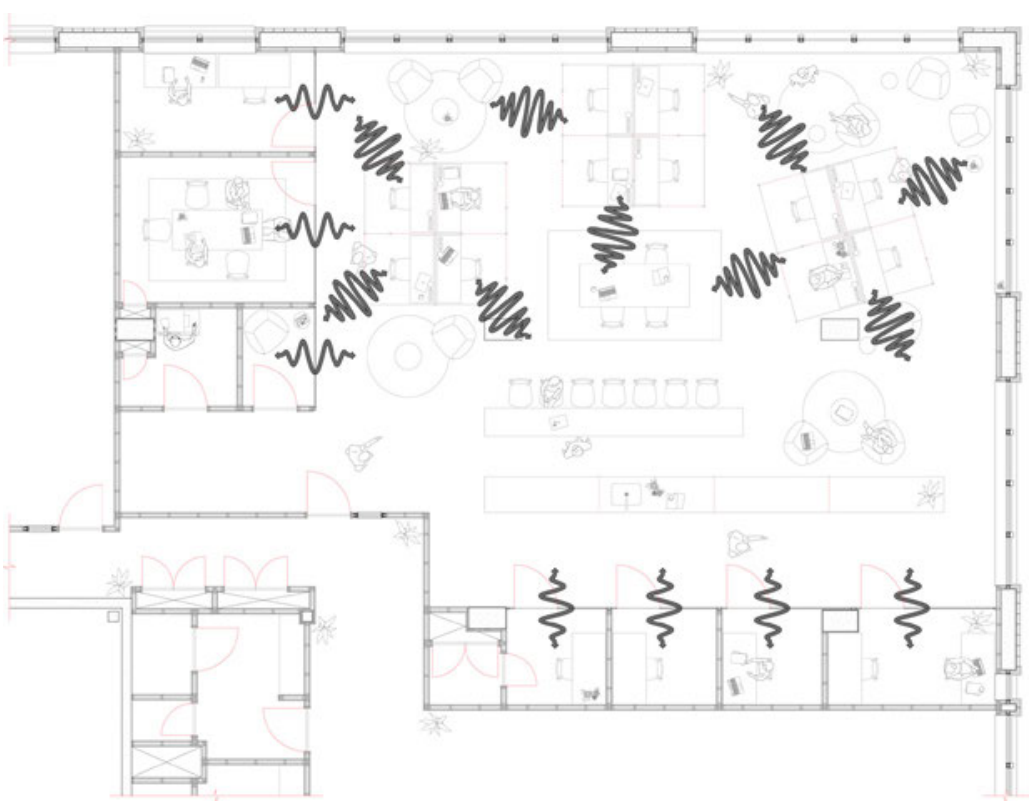

Figure 6.5 - Sharecuse Office - Aural Transfer - Author 
Sharecuse Work Areas:

Formal Individual Work Area

Semi-Formal Individual Work Area

Formal Meeting Area

Informal Meeting Area

Formal Collaborative Work Area

Informal Collaborative Work Area
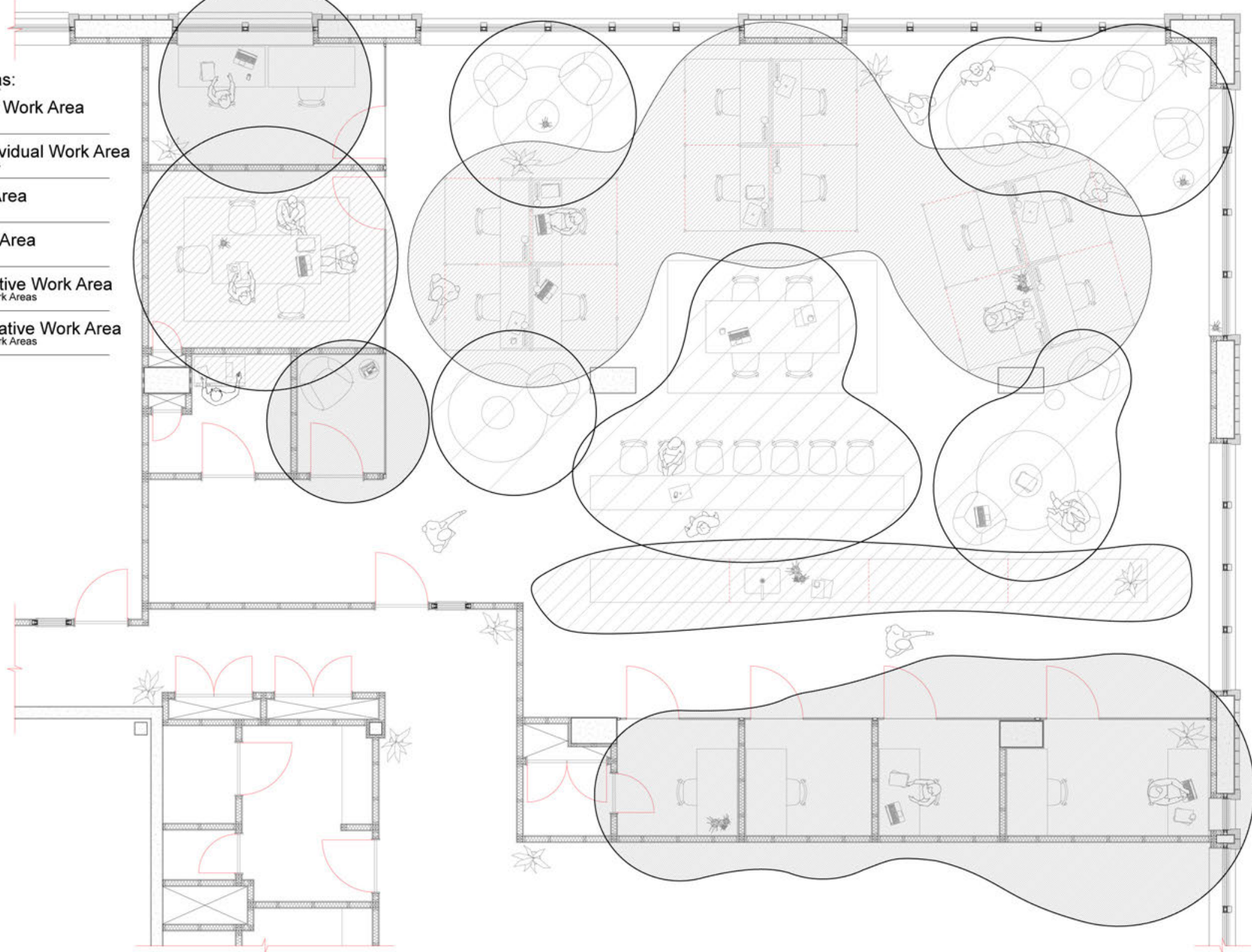
The Sharecuse office design splits its workspaces into a series of loosely defined areas, these primarily favouring open collaboration [Figure 6.6]. The design's glazed work areas that surround the main workspace increase the opportunities for visual interruptions to arise, and limit employee privacy for those within. This is then reinforced by the placement of the design's informal meeting area and incorporated locker system. The semi-formal individual work areas located within the main workspace are surrounded by both formal and informal collaborative work areas. These areas create frequent visual and aural interruptions for the individual work areas, which are then heightened by their mesh construction. It is pertinent that in redesigning Sharecuse, the system endeavours to address these issues. To assist in this, a work area relationship chart has been developed, depicting work areas which may function effectively when situated together, thus limiting unnecessary interruption [Figure 6.7].

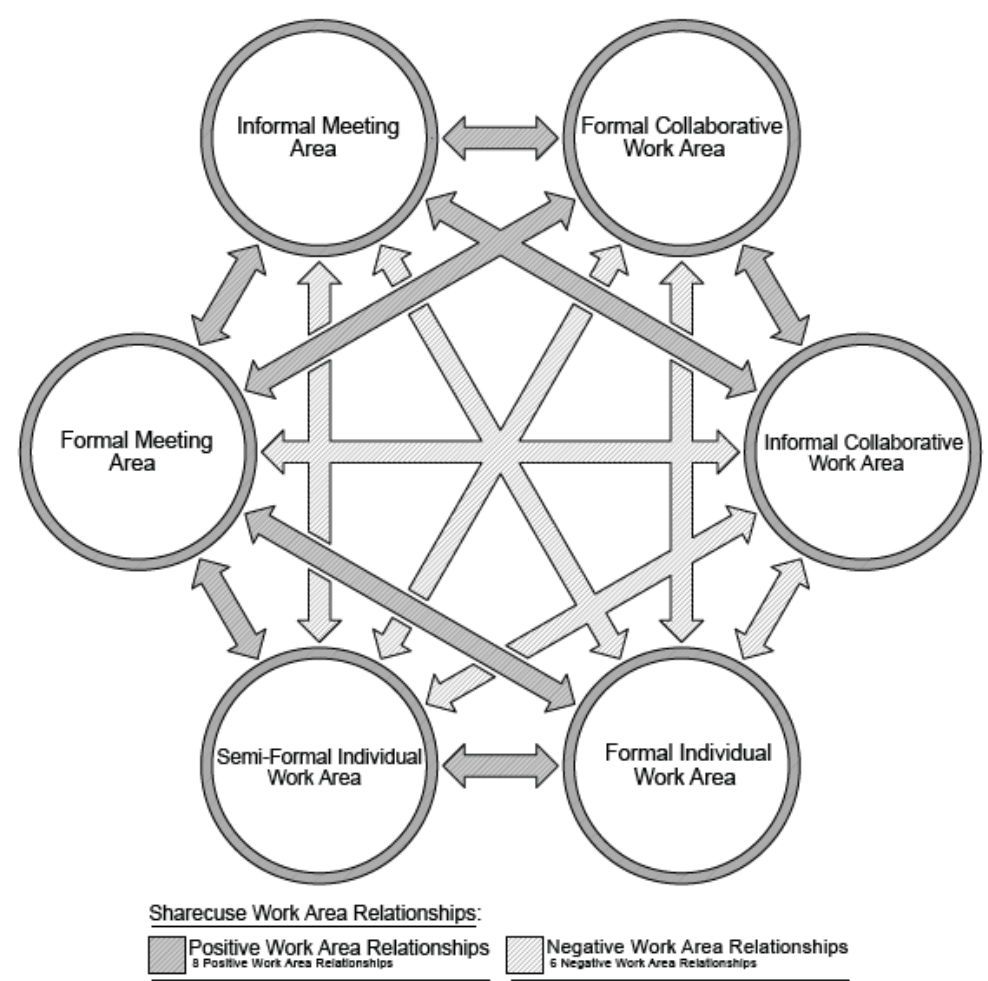




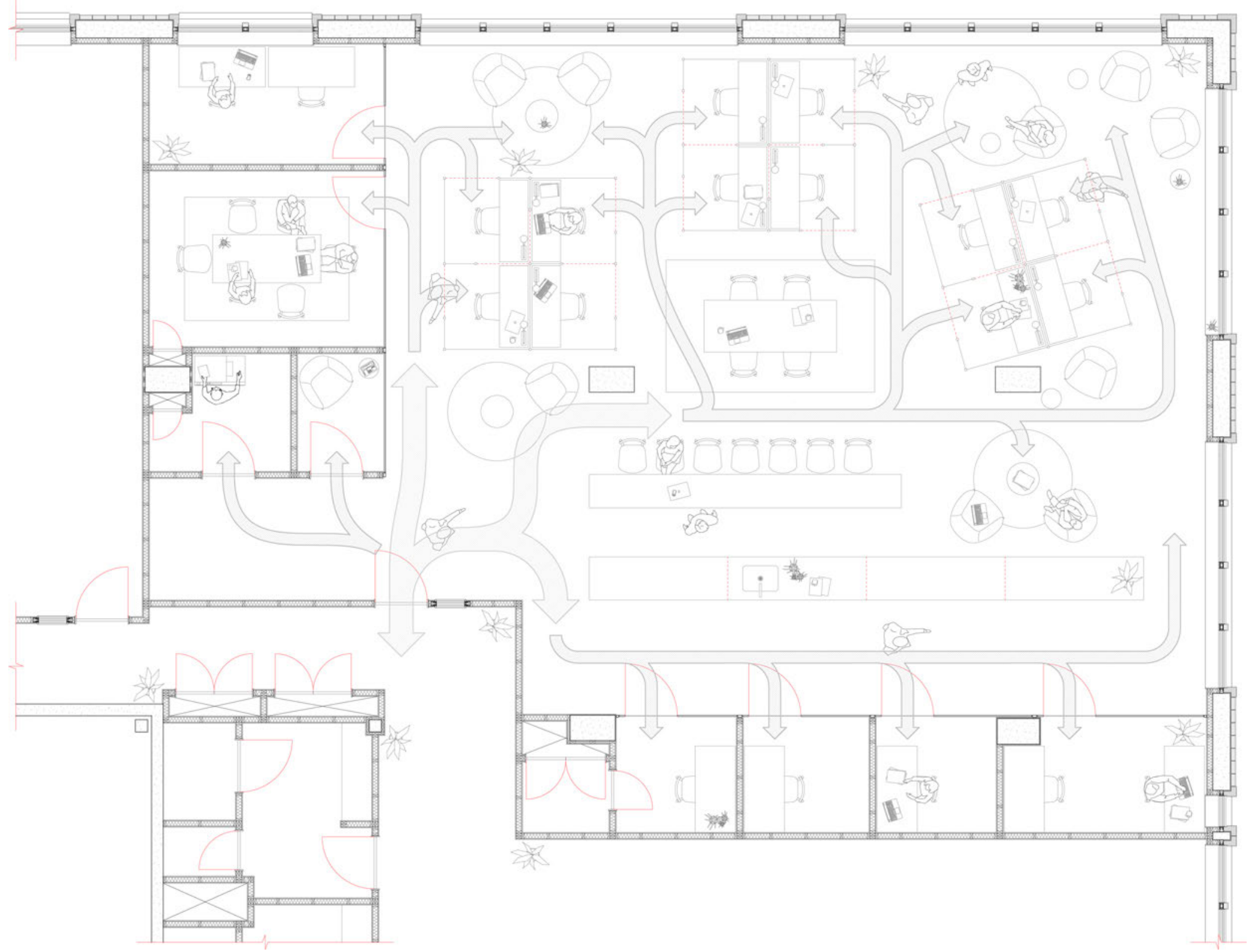


As the design of the Sharecuse office is mostly open and non-linear, there are few clear major movement pathways which employees follow [Figure 6.8]. As a result, a series of minor pathways are formed and woven throughout the office. These pathways move in and around the semi-formal individual work areas. As many of the pathways intersect with this space, there is likely a higher degree of perceived visual interruption (this also true of the surrounding work areas). This issue in turn should be acknowledged when redesigning Sharecuse to mitigate unnecessary visual interruptions. 
Interruption Events:

Using / Checking Paper Documents

Using / Checking Computer

Talking Through Wall

Phone Call

E-Mail Use

$\underset{\text { Interruption } 6}{\text { Cubicle }}$

New E-Mail Notification

Person Arrives

$\underset{\text { Interruption } 9}{\text { Checking Terminal Status }}$

$\underset{\substack{\text { Phone Ringing } \\ \text { Interruption } 10}}{\text { (1) }}$

Voice Message Light

\section{Call Through Wall}

Reminder Notification

Mapped Interruption Events

Not To Interruption Scale
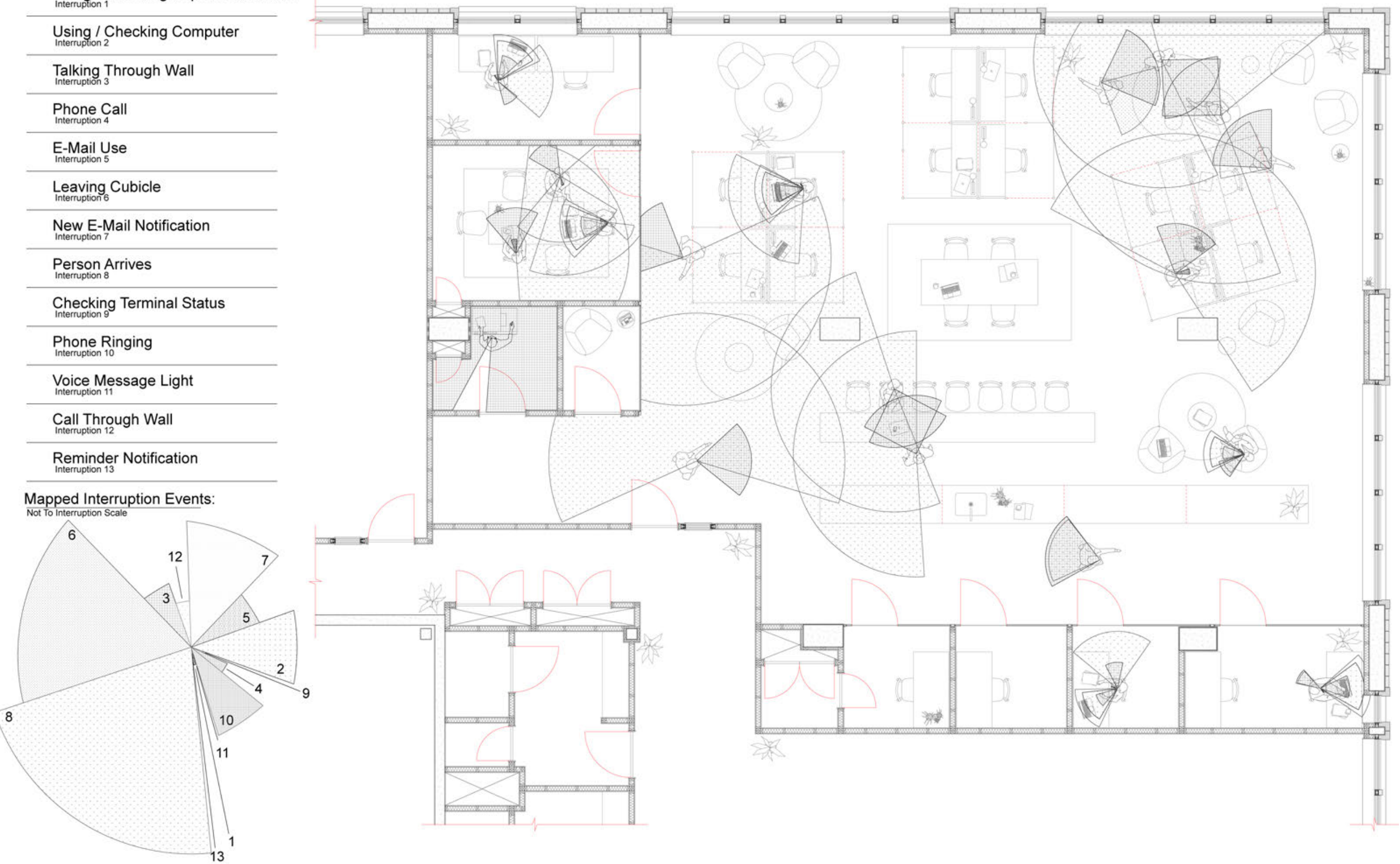
When examining the overall interruptive outcome of the Sharecuse office design [Figure 6.8], it is evident that the perceived interruptive weightings of employees working within the central work area is heightened. In this space these weightings are significantly greater than that of those working within the formal individual work areas. In splitting these interruptive events into their individual weightings, it is evident that this stems primarily from employees moving throughout the office and engaging in conversations [Figures 6.9 - 6.17]. This heightened level of interruption supports the issues discussed earlier, regarding Sharecuse's design. Note this also aligns with my experience of Wigan 501 . In turn this establishes a clear line of inquiry for the notational system to address when redesigning Sharecuse. 


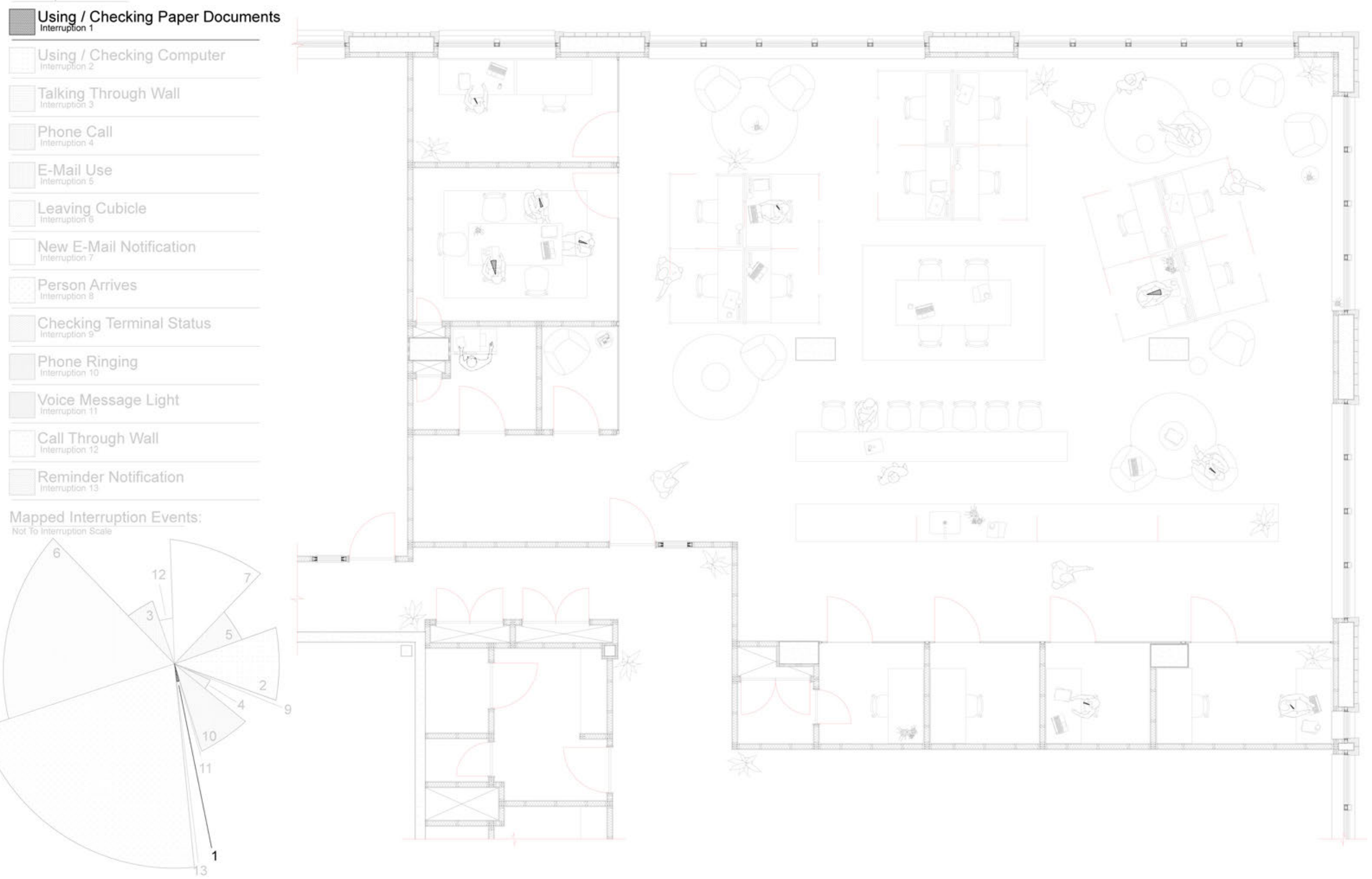


Interruption Events:

Using / Checking Paper Documents

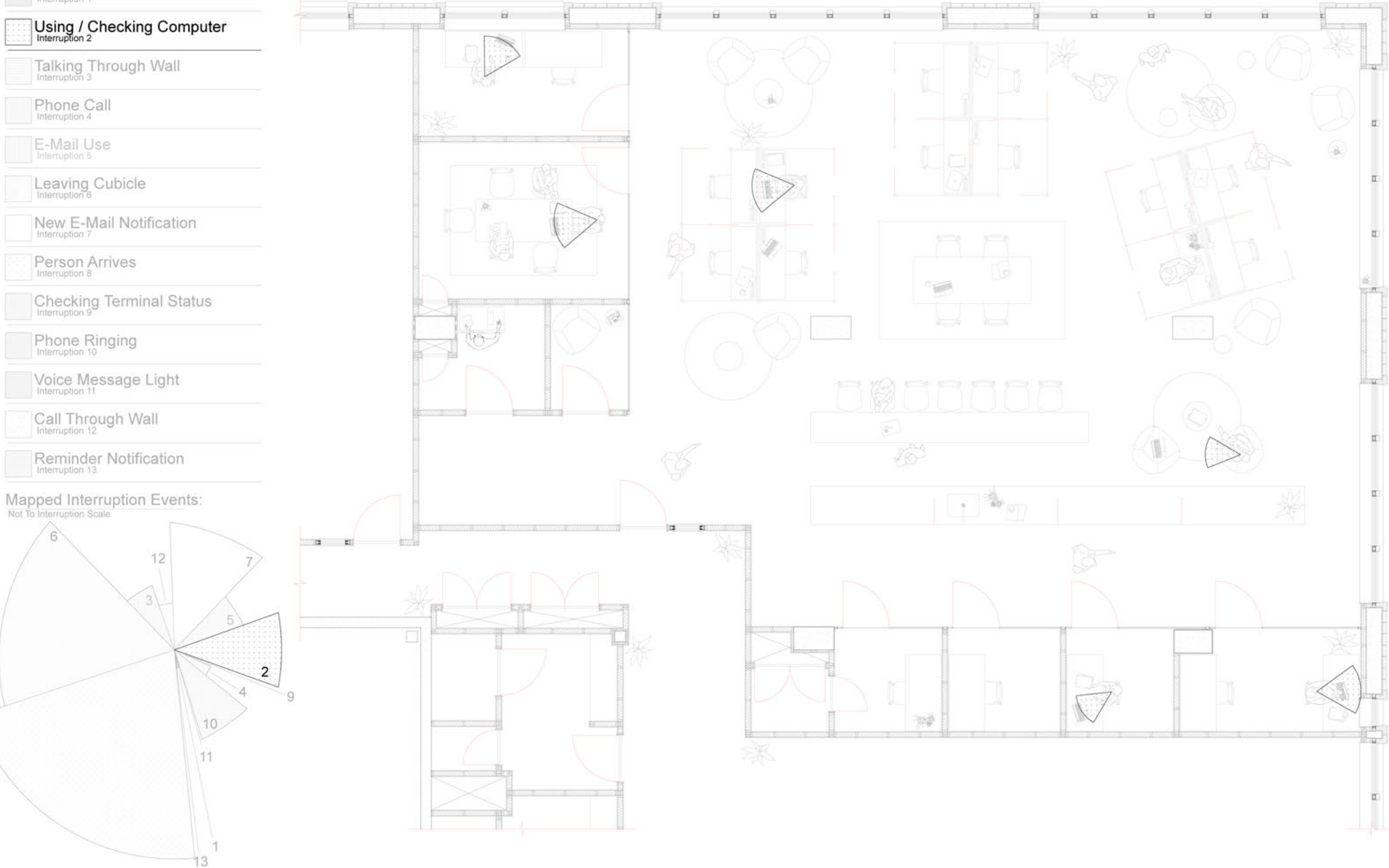


Interruption Events:

Using / Checking Paper Documents

Using / Checking Computer

\section{Talking Through Wall}

Phone Call

E-Mail Use

$\underset{\substack{\text { Leaving Cubicle } \\ \text { Intertutions }}}{ }$

New E-Mail Notification

\section{Person Arrives}

Checking Terminal Status

Phone Ringing

Voice Message Light

Call Through Wall
Interruption 12

Reminder Notification
Internption 13

\section{Mapped Interruption Events:}
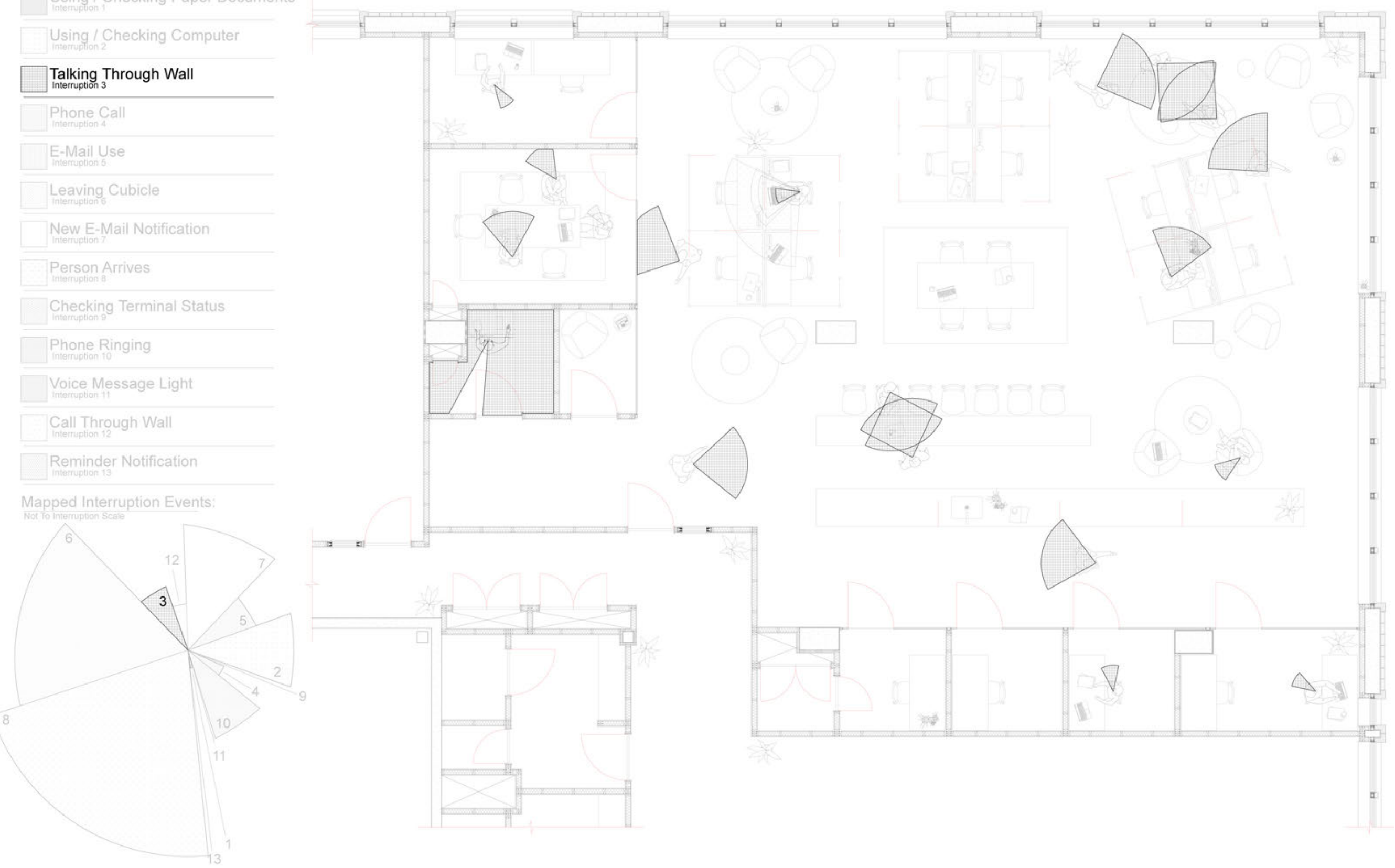
Interruption Events:

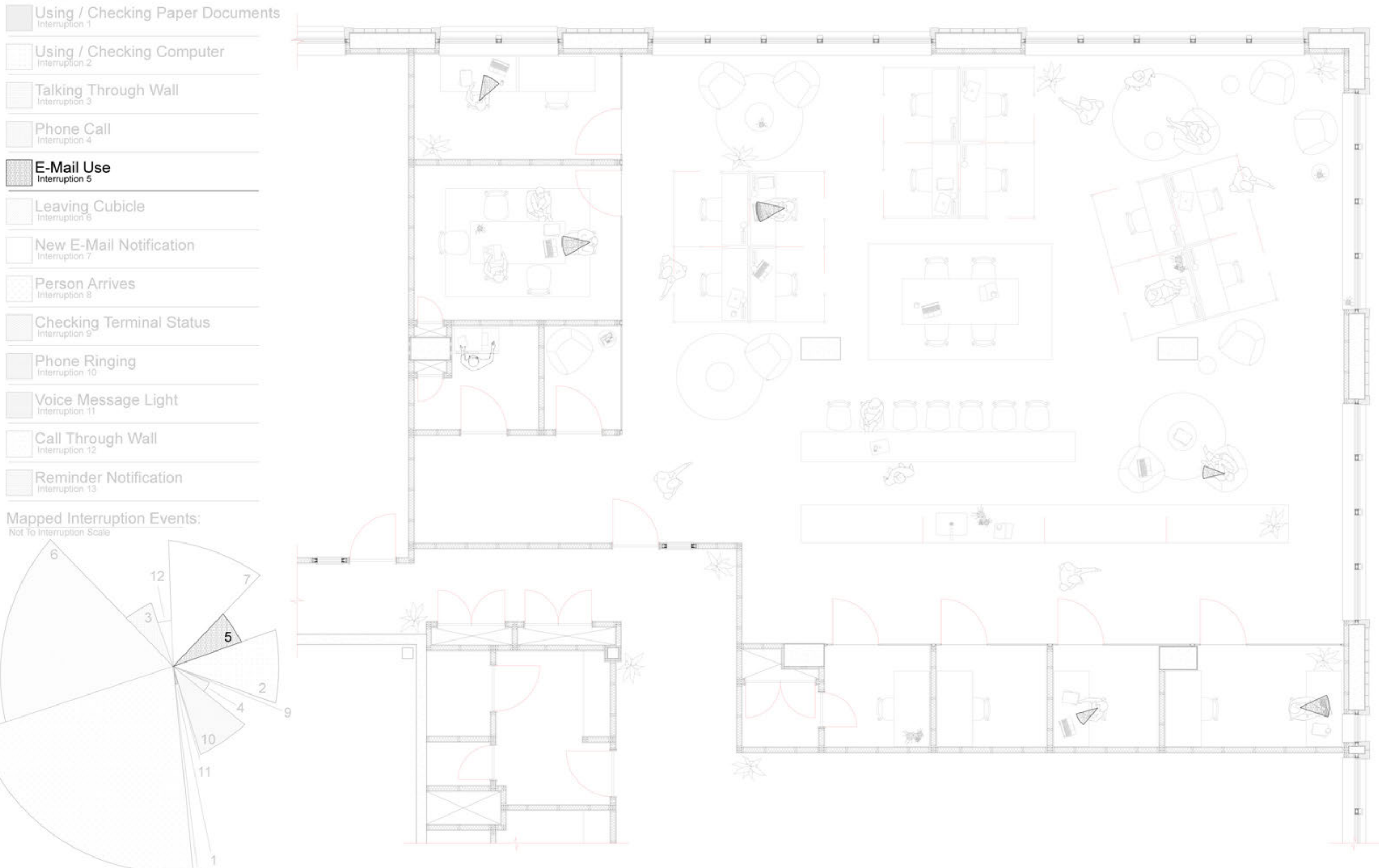


Interruption Events:

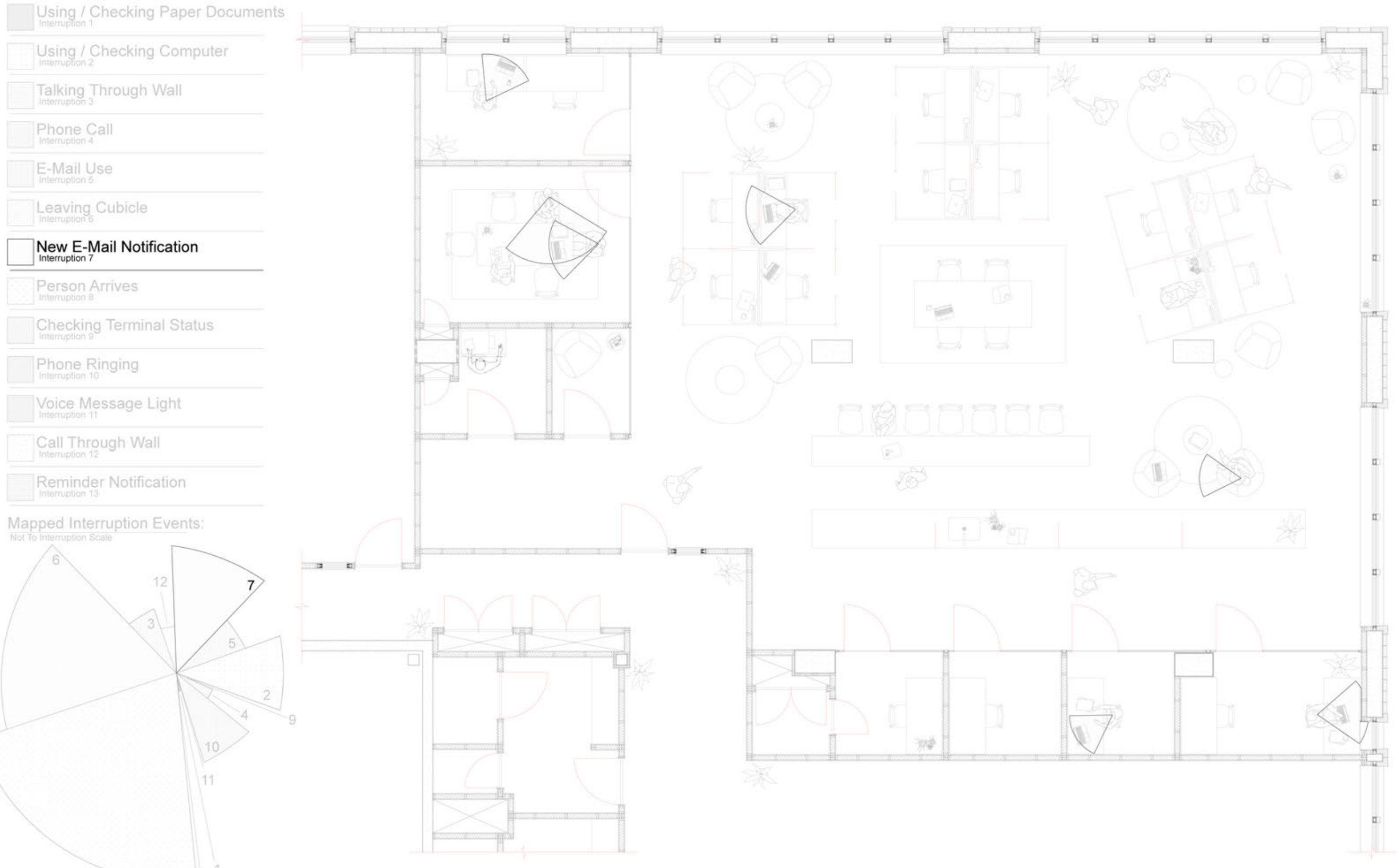


Interruption Events

Using / Checking Paper Documents

Using / Checking Computer

Talking Through Wal

\section{Phone Call}

E-Mail Use

Leaving Cubicle

New E-Mail Notification

\section{Person Arrives}

Checking Terminal Status

Phone Ringing

Voice Message Light Call Through Wall

Reminder Notification

\section{Mapped Interruption Events:}
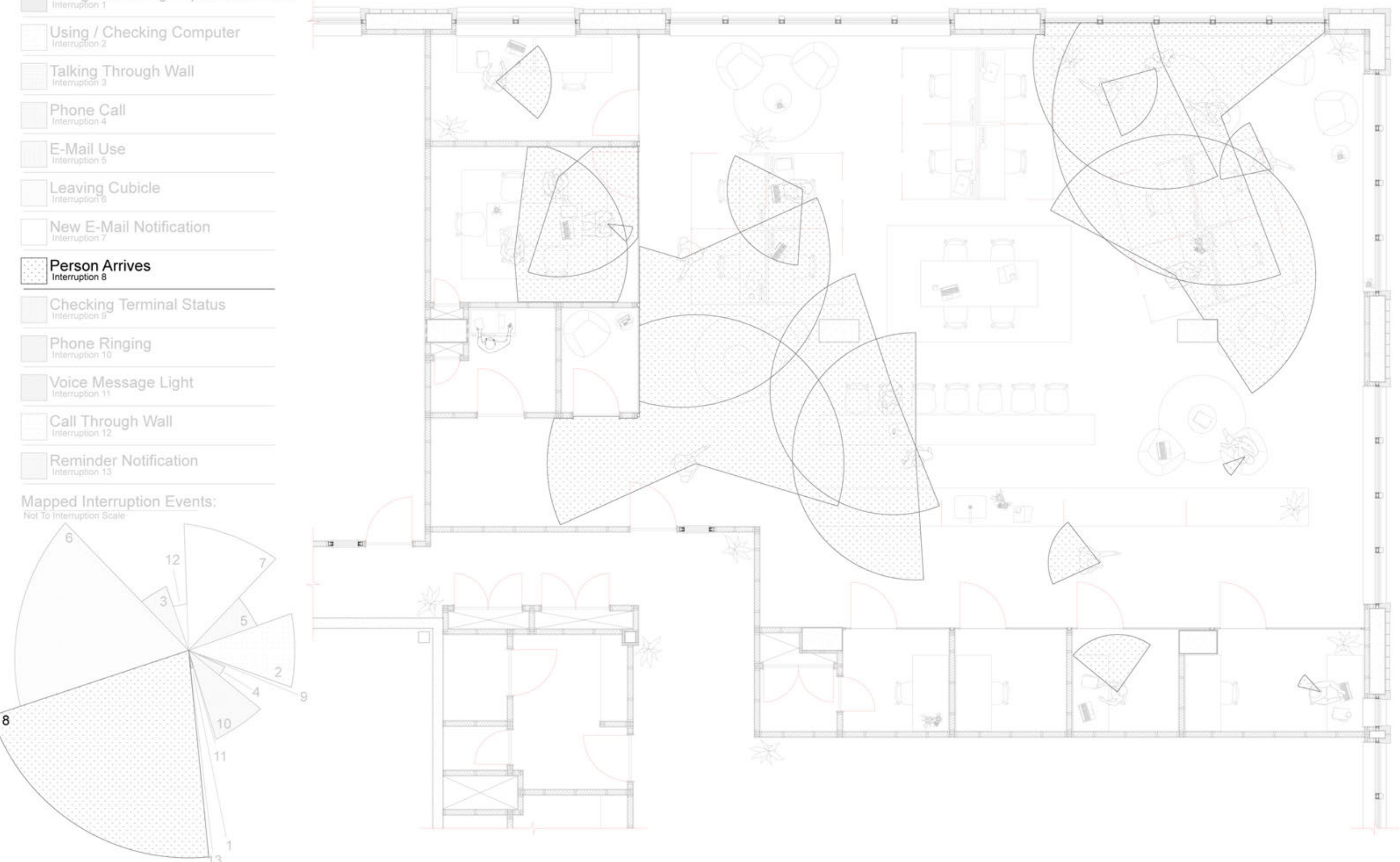

Figure 6.15 - Sharecuse Office Interruption Mapping - Person Arrives - Author 
Interruption Events:

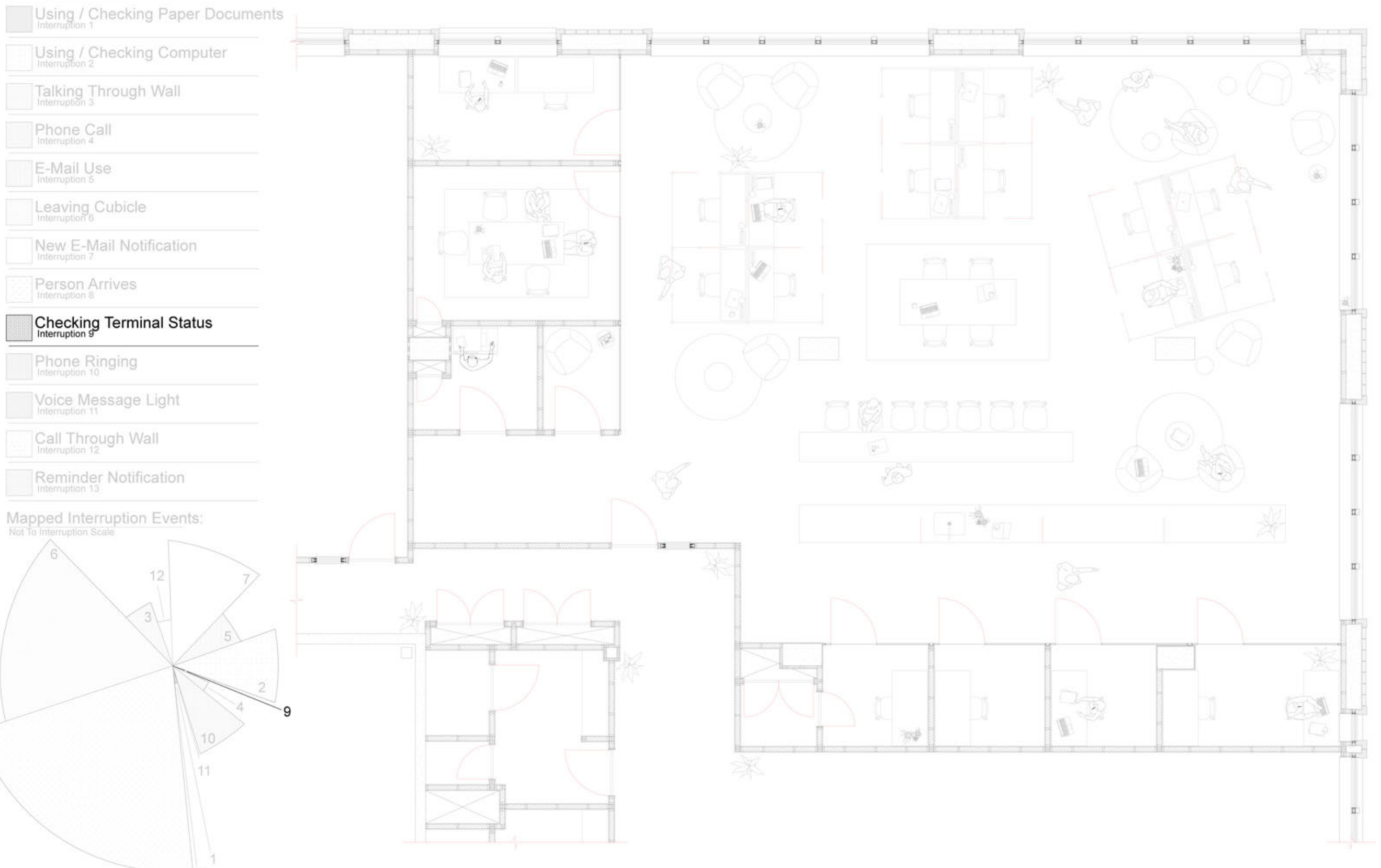


Interruption Events:

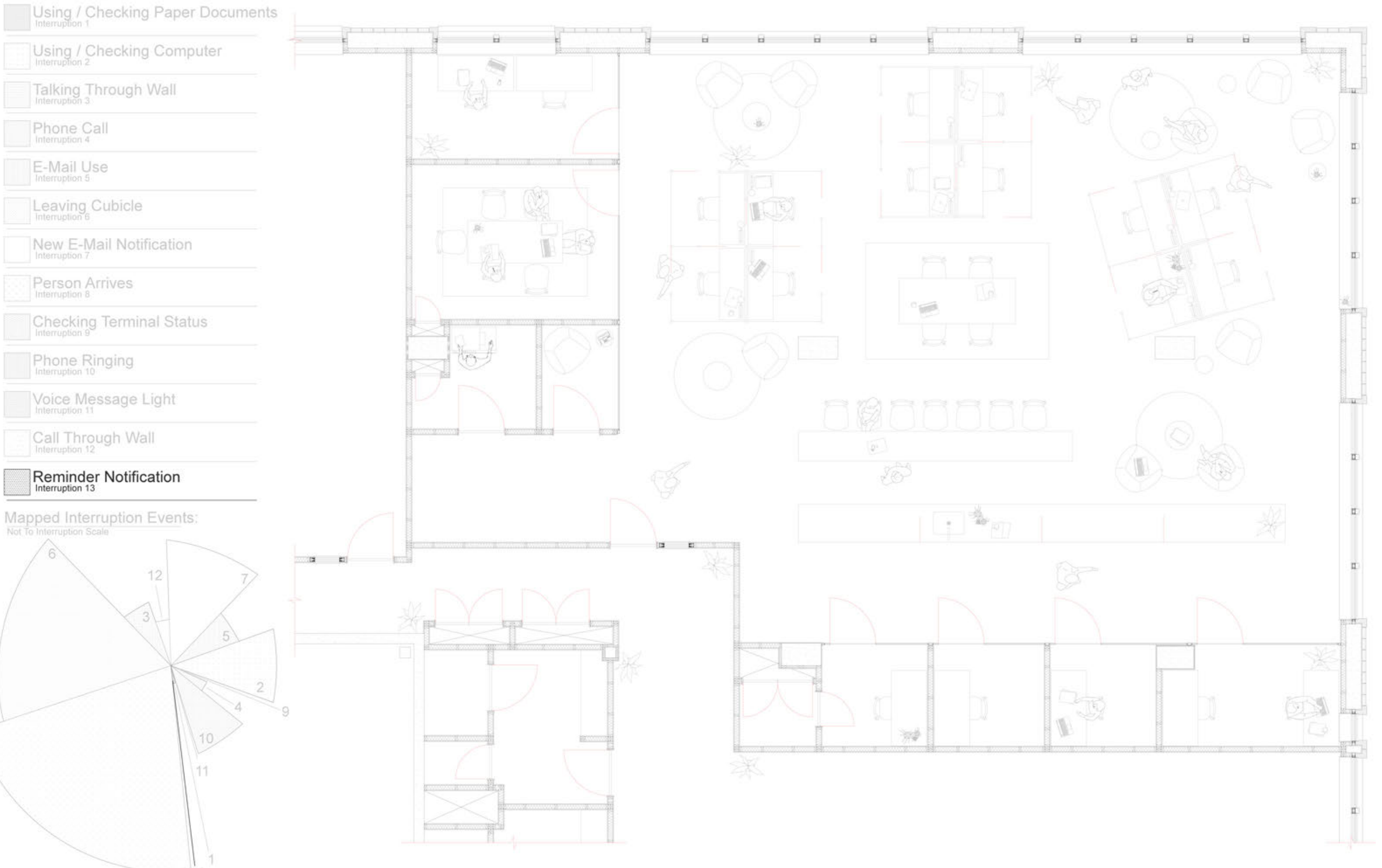




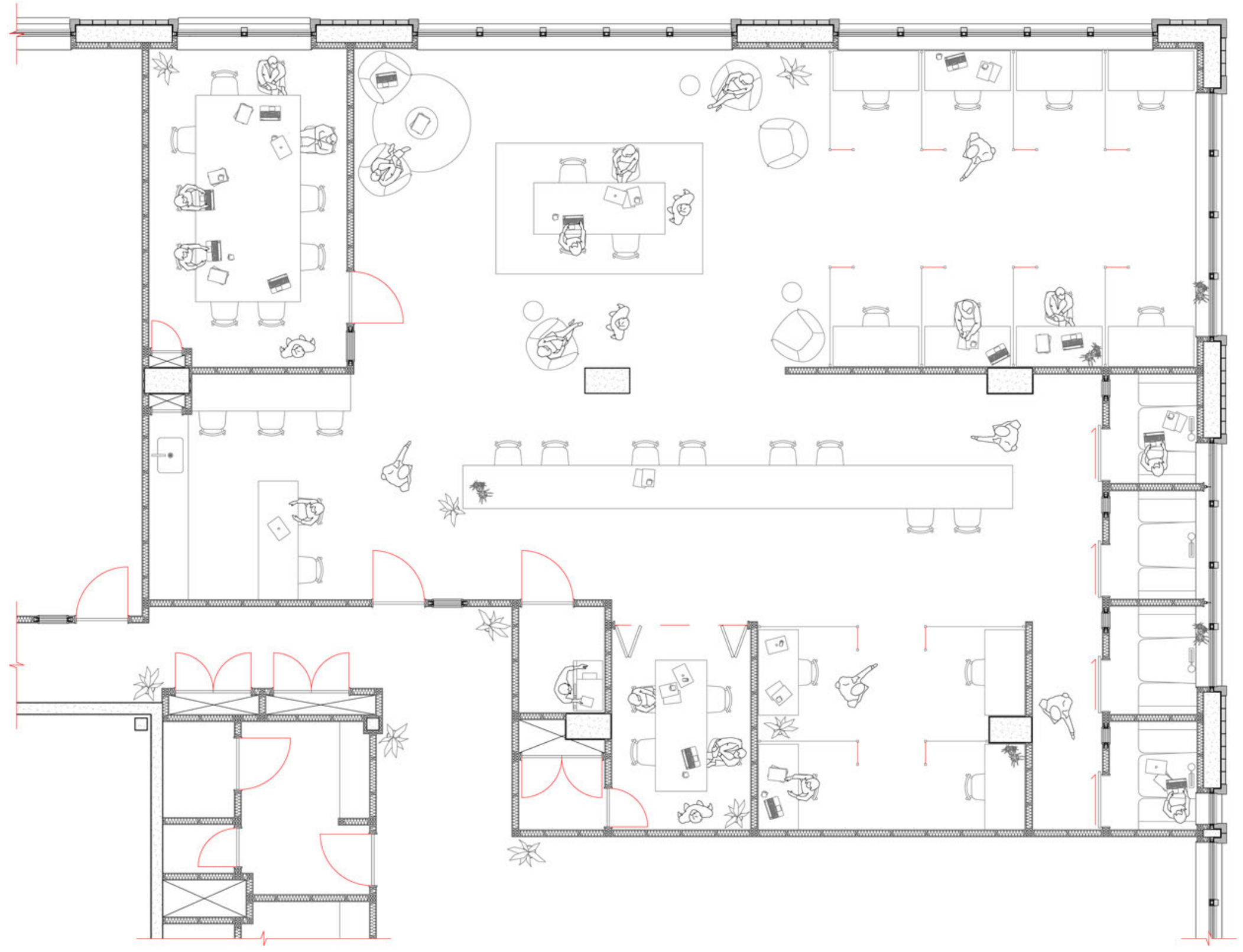


When redesigning the Sharecuse office, several design considerations were made to encourage an effective agile workplace that could not only mitigate interruptive atmosphere in critical work, areas but also support collaboration where appropriate [Figures 6.18 - 6.35]. 
In redesigning the Sharecuse office, the comfortable occupant density has been left unchanged, but an effect of the redesign has been that the maximum occupancy has increased from 46 to 57 . This lowers the maximum occupant density from $4.68 \mathrm{~m}^{2}$ to $3.78 \mathrm{~m}^{2}$ per person, and in turn allows for a greater number of employees present within the office. Alternatively, this also offers employees a greater range of suitable spaces to work from, promoting a greater level of agility in the office [Figure 6.19].

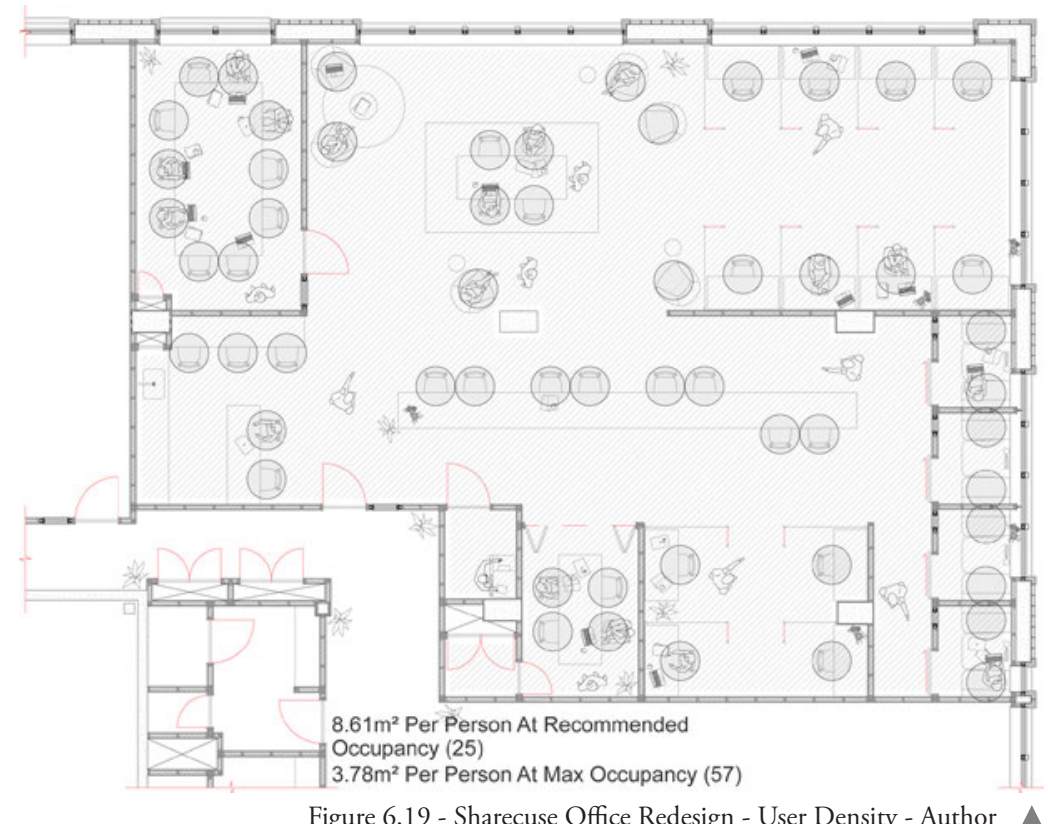

In the mock-up instance of the Sharecuse office, employee sightlines have been examined based only upon their macular vision cone. This reductive examination of the redesigned office highlights the effectiveness of its reduced permeability, demonstrating that it is effective in limiting the visual transparency throughout critical areas - such as the formal and semi-formal individual work spaces. In turn, this reduced visual transparency leads to an improvement in workplace interruption [Figure 6.20].

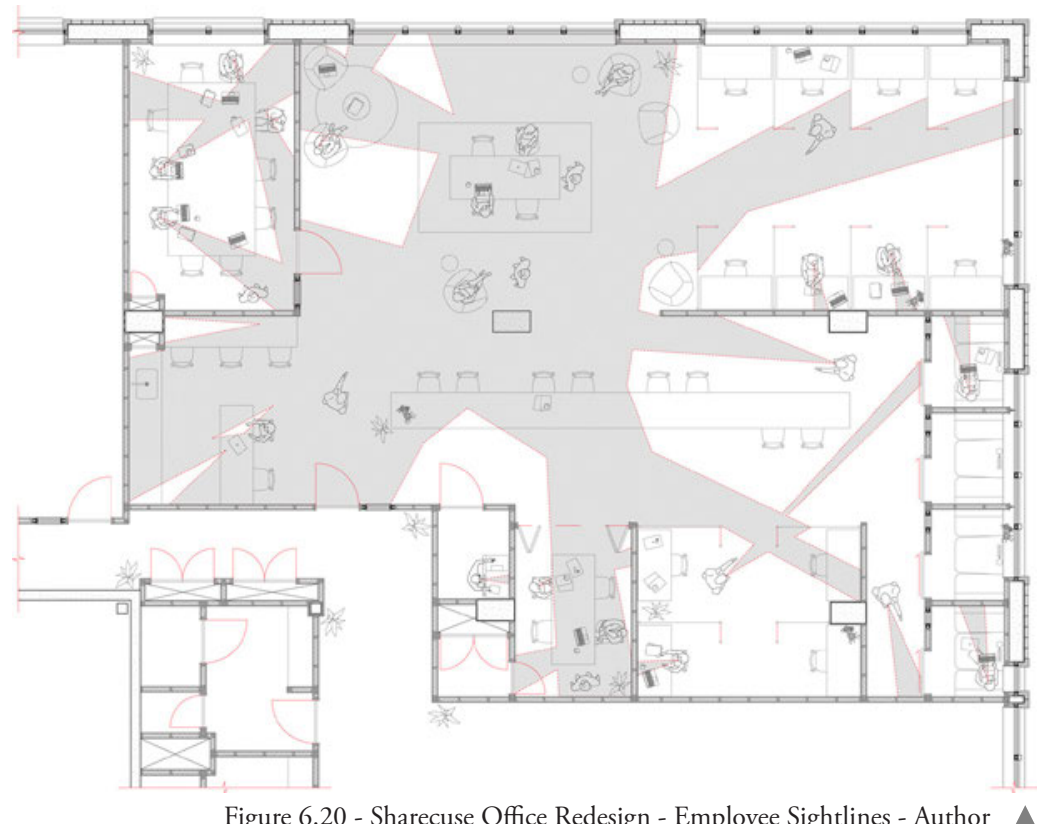


When examining the overall interruptive outcome of the redesigned office, it is evident that the changes made have contributed significantly to reducing interruption within areas such as the formal meeting space and the semiformal individual work areas. In the original design these areas were plagued with frequent visual and aural interruptions stemming from people arriving into the office and engaging in conversation. In the redesign of the Sharecuse office this trend continues to occur, but its effects have been lessened as a result of the emphasis placed upon resolving the designs problematic sightlines, circulation, and sound transfer [Figure 6.21].

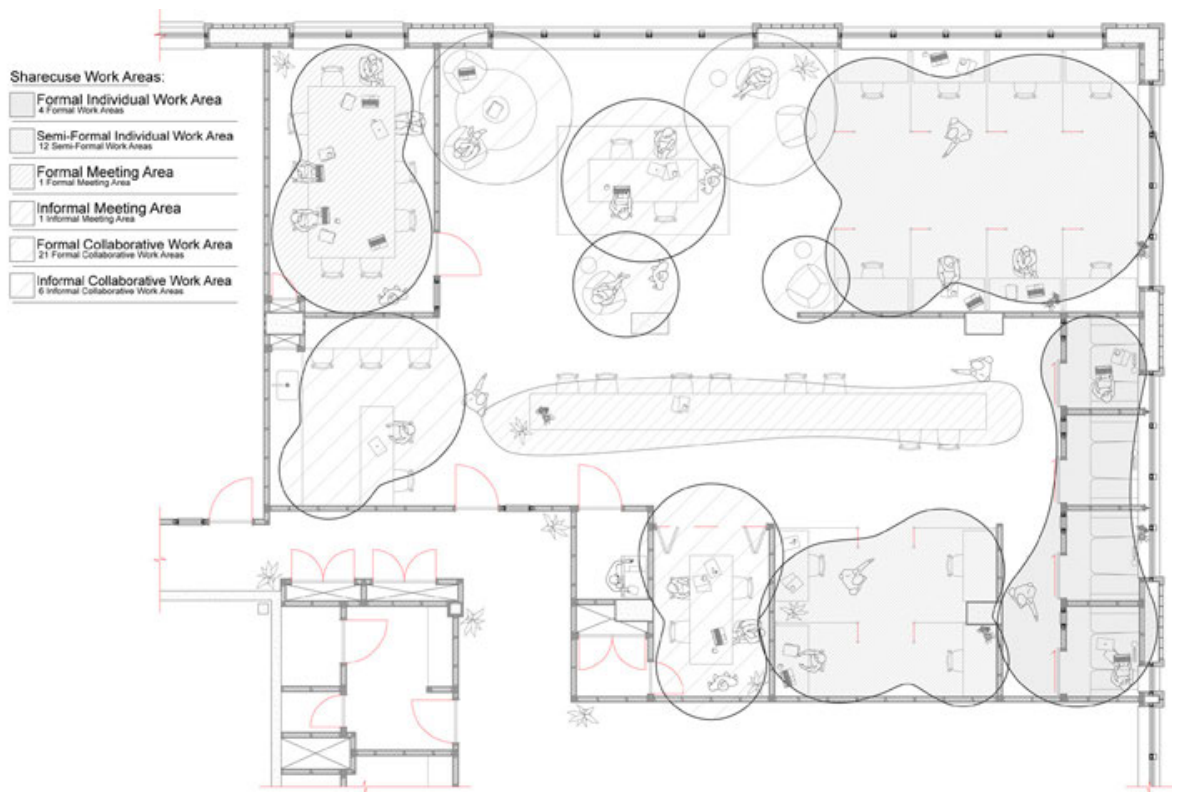

A Figure 6.21 - Sharecuse Office Redesign - Employee Sightlines - Author
When redesigning the Sharecuse office, the space was made to function in a much more linearly manner to effectively guide users through the workplace. This was achieved primarily through the implementation of partitions - both temporary and permanent. By designing the space in this manner, critical areas such as the formal and semi-formal individual working areas could be orientated away from these linear movement pathways to allow for an interruptive reduction [Figure 6.22].

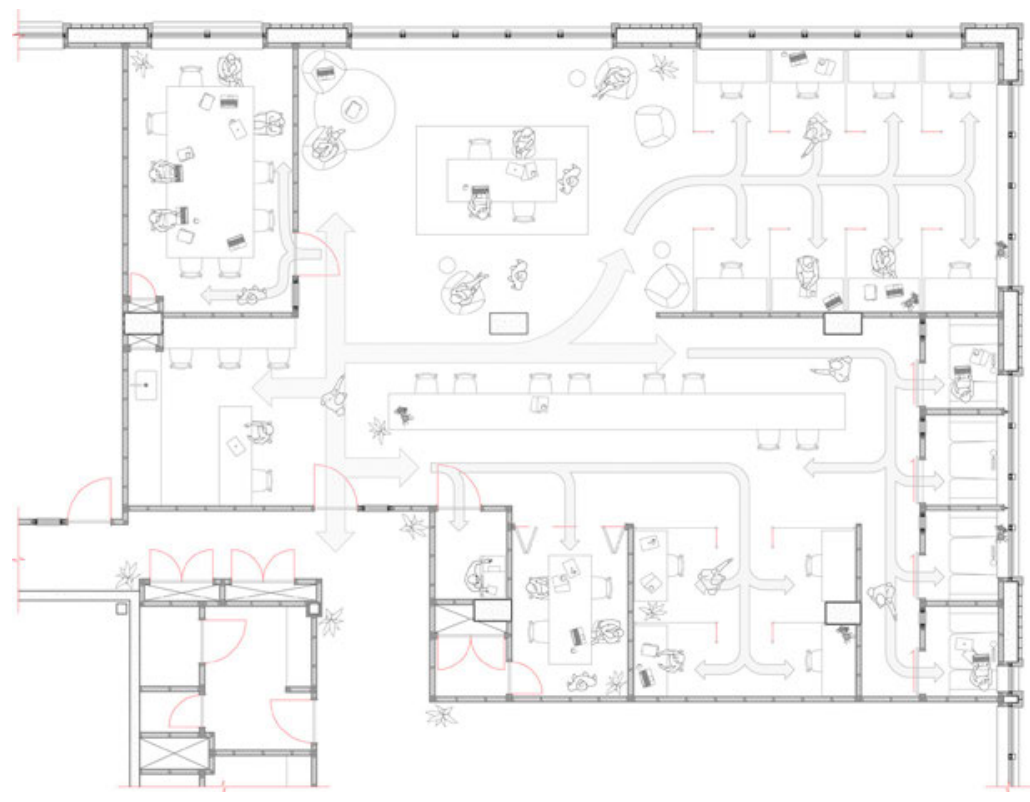

$\Delta$ Figure 6.22 - Sharecuse Office Redesign - Aural Transfer - Author 


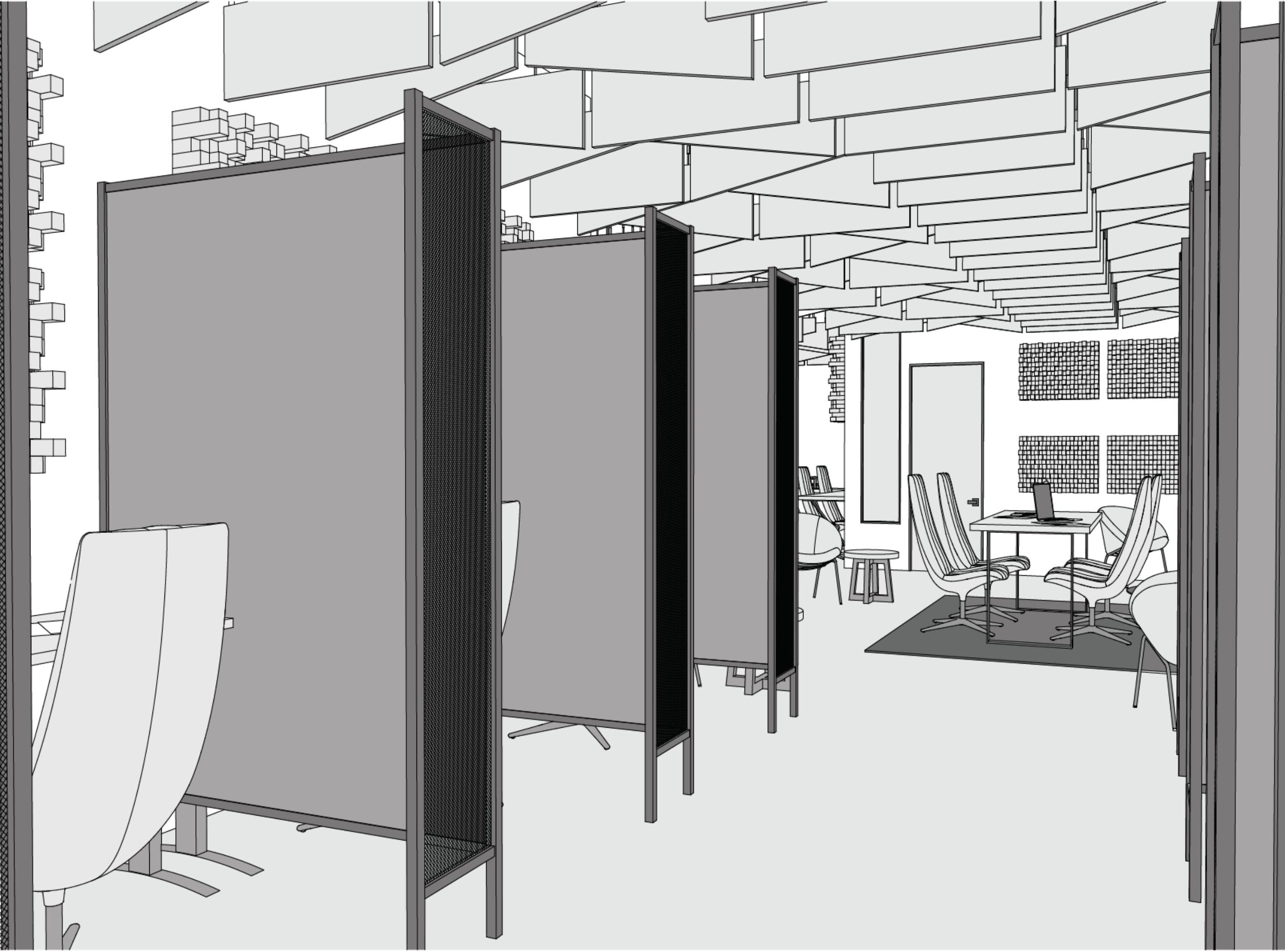


The kitchenette and bench work areas have been located adjacent to the design's entry to promote employee interactions outside of key work areas. This is then reinforced by the placement of formal and informal collaborative work areas [Figure 6.23].

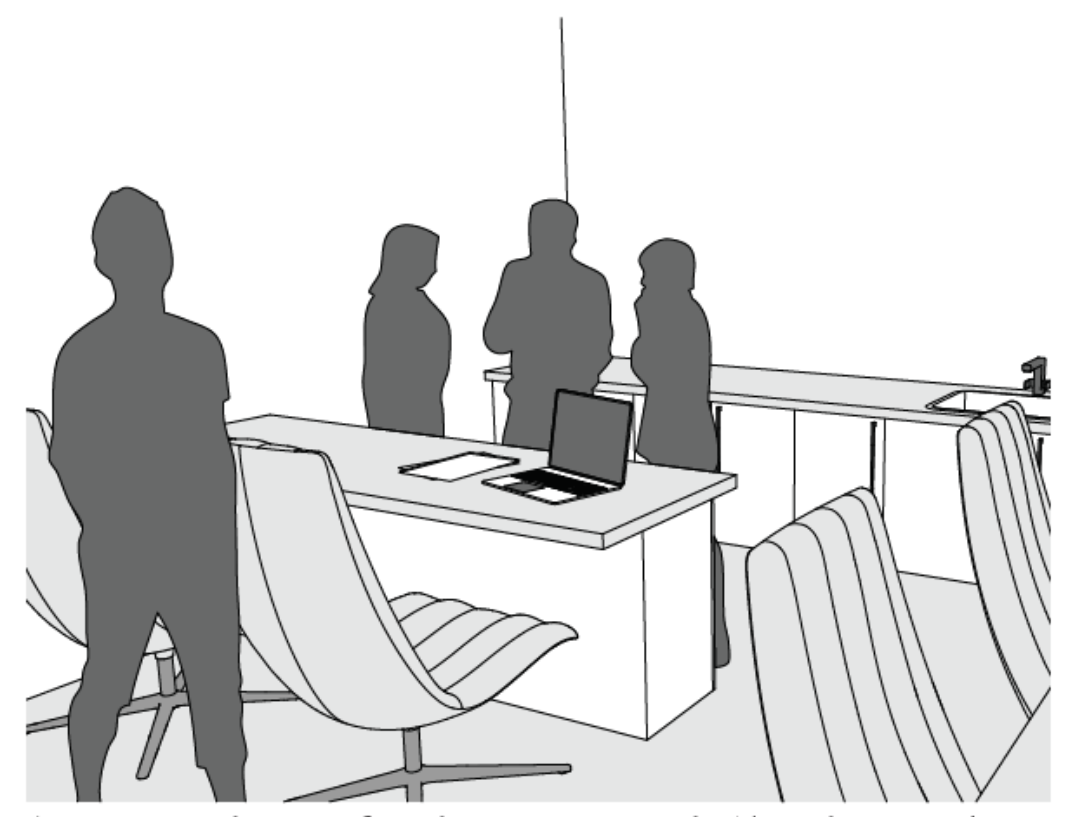

$\Delta$ Figure 6.23 - Sharecuse Office Redesign- Interraction Within The Kitchenette - Author
The mesh desk partitions present within the original office have been improved, now incorporating elements of fabric panelling that work to limit unnecessary visual interruptions whilst also acting as sound absorbers. The mesh elements of the previous design have in part remained, but are now much denser and act as a semi-transparent screen that allows users to quickly determine if a workstation is occupied. These new partitions are freestanding and disconnected from the adjustable desks to ensure that everything can be rearranged if required [Figure 6.24].

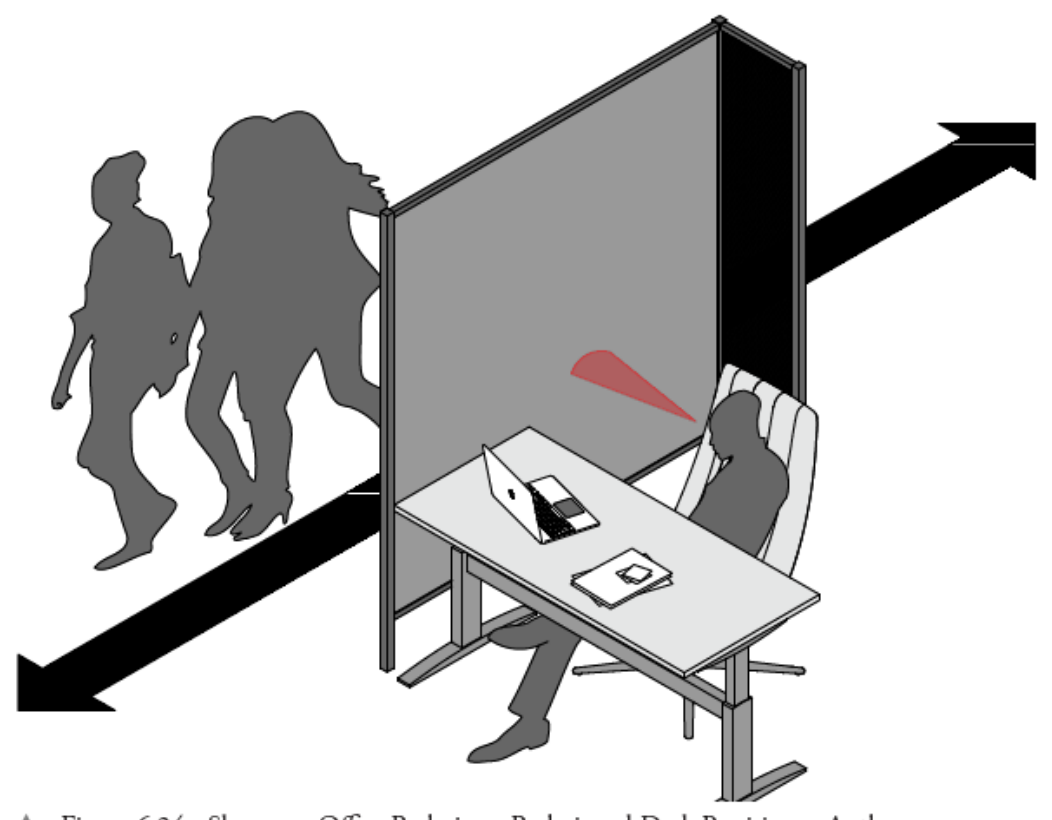

A Figure 6.24-Sharecuse Office Redesign - Redesigned Desk Partitions - Author 

The glazed elements of the previous design have been significantly reduced to mitigate unnecessary visual interruptions within the new formal meeting and individual work areas. However this design element is still in use in some areas to allow employees to quickly determine if a space is occupied without disturbing others [Figure 6.26].

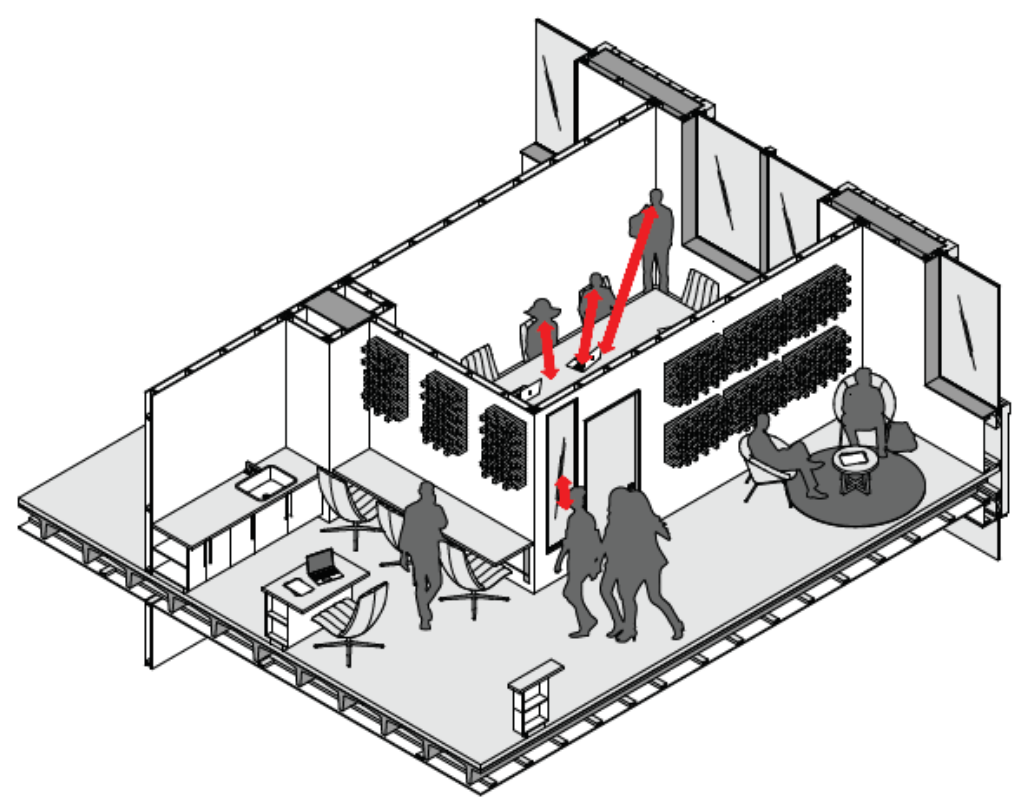

A Figure 6.26 - Sharecuse Office Redesign - Mesh \& Glazed Design Elements - Author
Taking a cue from Sky Headquarters, the Sharecuse redesign's formal individual work areas have been located away from highly collaborative areas to promote greater levels of productivity amongst employees. These areas consist of a series of working pods and - unlike their semi-formal variant - are fully enclosed and soundproofed, mitigating aural transfer from other areas of the office [Figure 6.27].

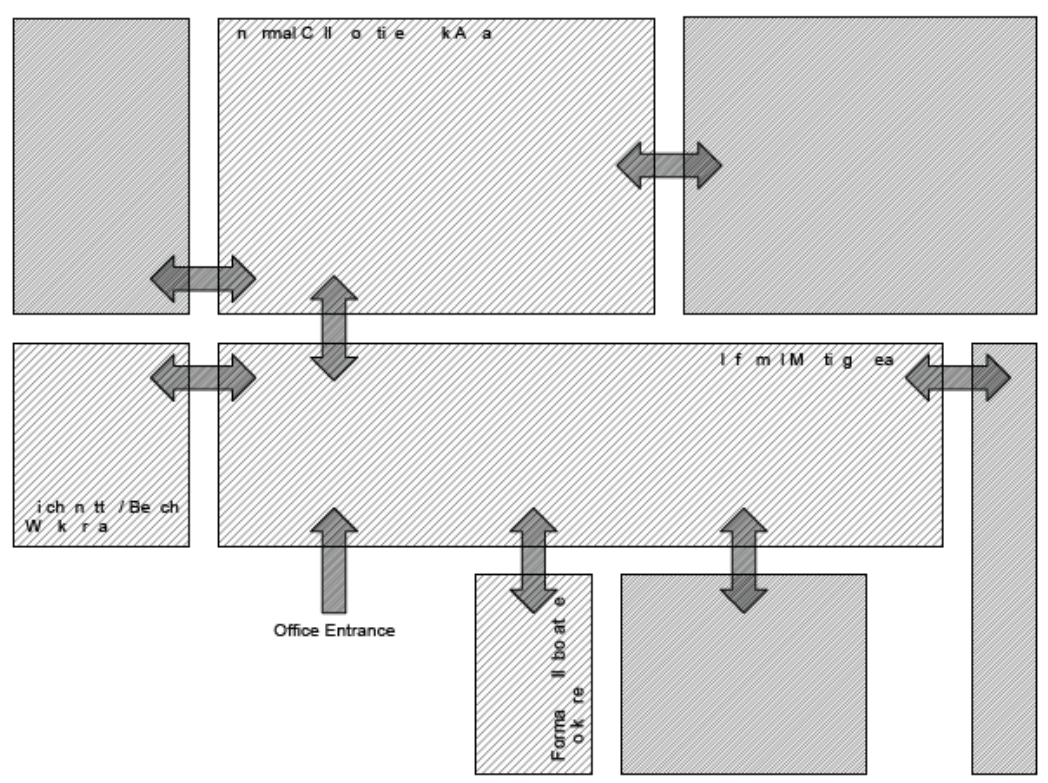

$\Delta$ Figure 6.27 - Sharecuse Office Redesign - Individual Work Areas Away From Entry - Autho 


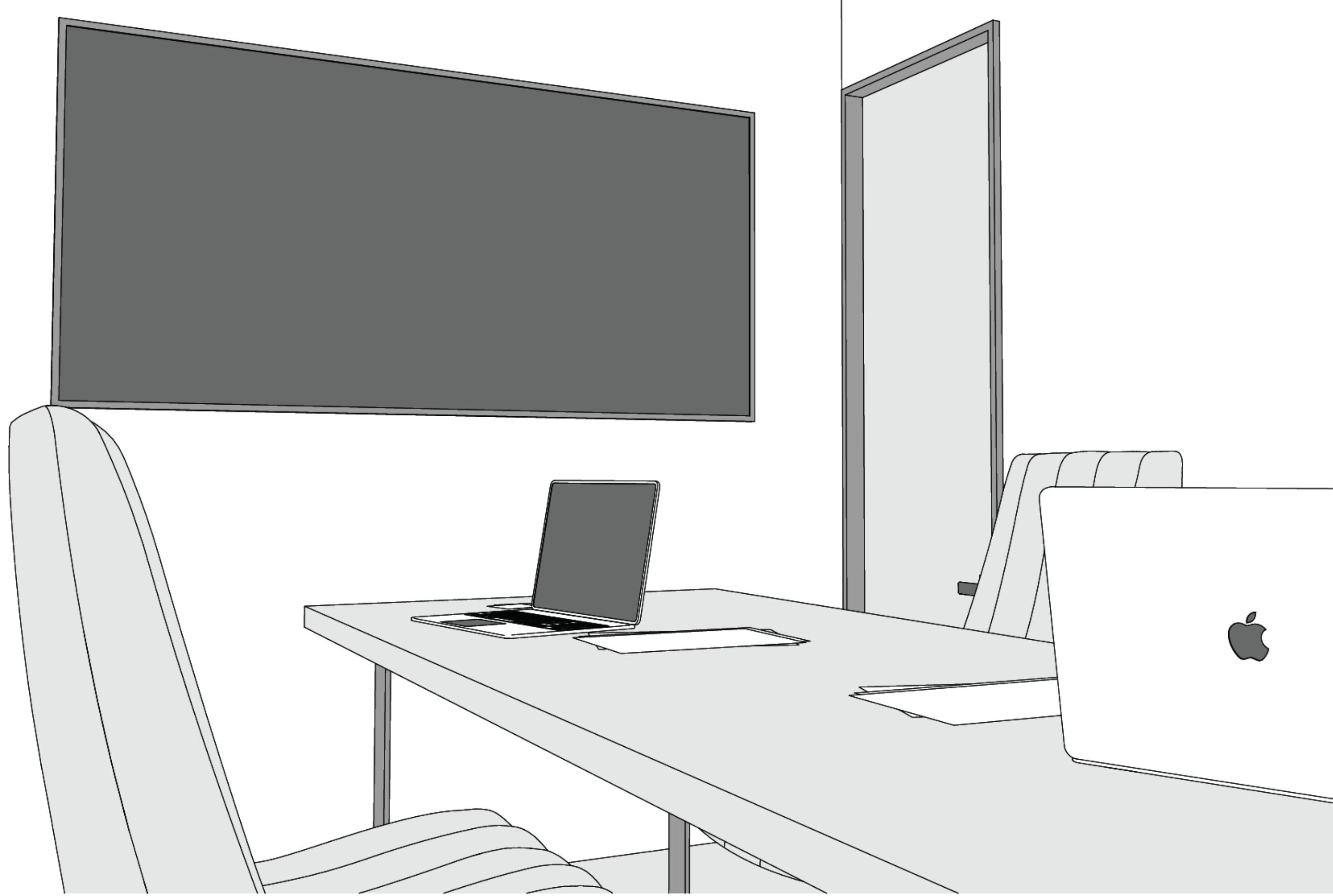


The formal collaborative work area adjacent to the design's smaller semi-formal work area has been equipped with a set of bi-folding doors, providing the option to enclose the space, mitigating aural transfer inwards and outwards [Figure 6.29].

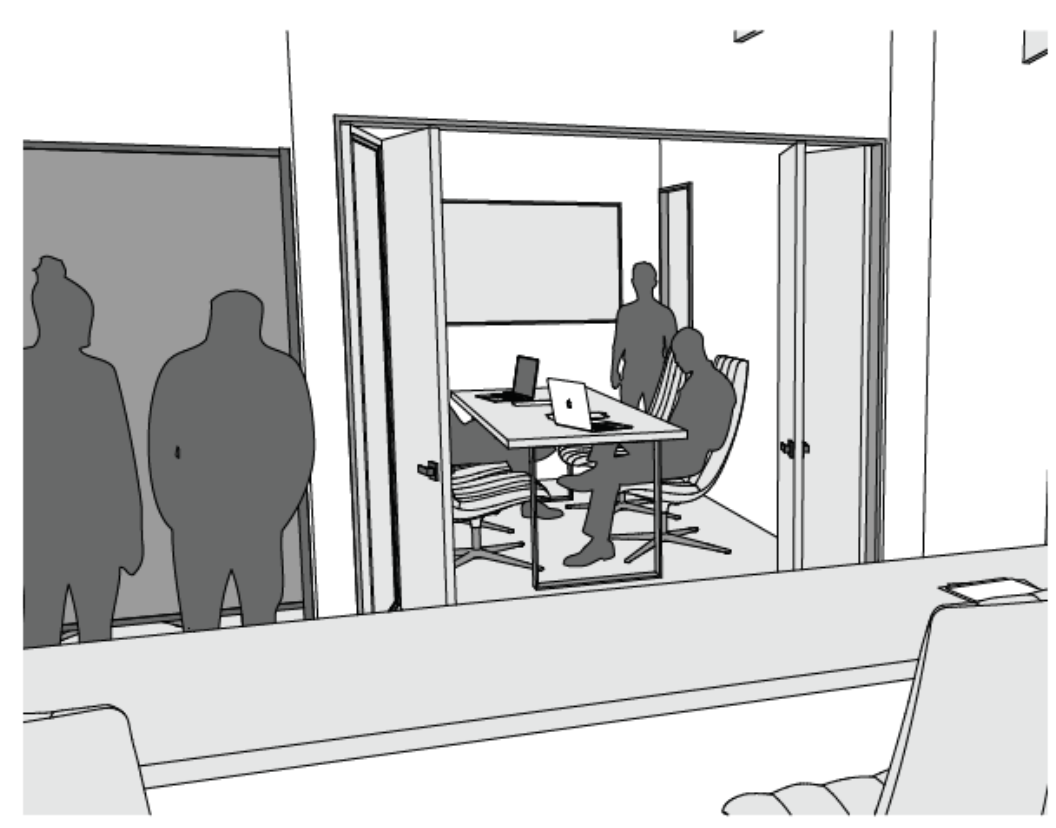

A Figure 6.29 - Sharecuse Office Redesign - Formal Colaborative Work Area - Author
The previous design's locker system and informal meeting island has been maintained in the redesign, but now incorporates a number of bench work stations. This effectively utilises previously dead space and provides additional areas for employees to work from [Figure 6.30].

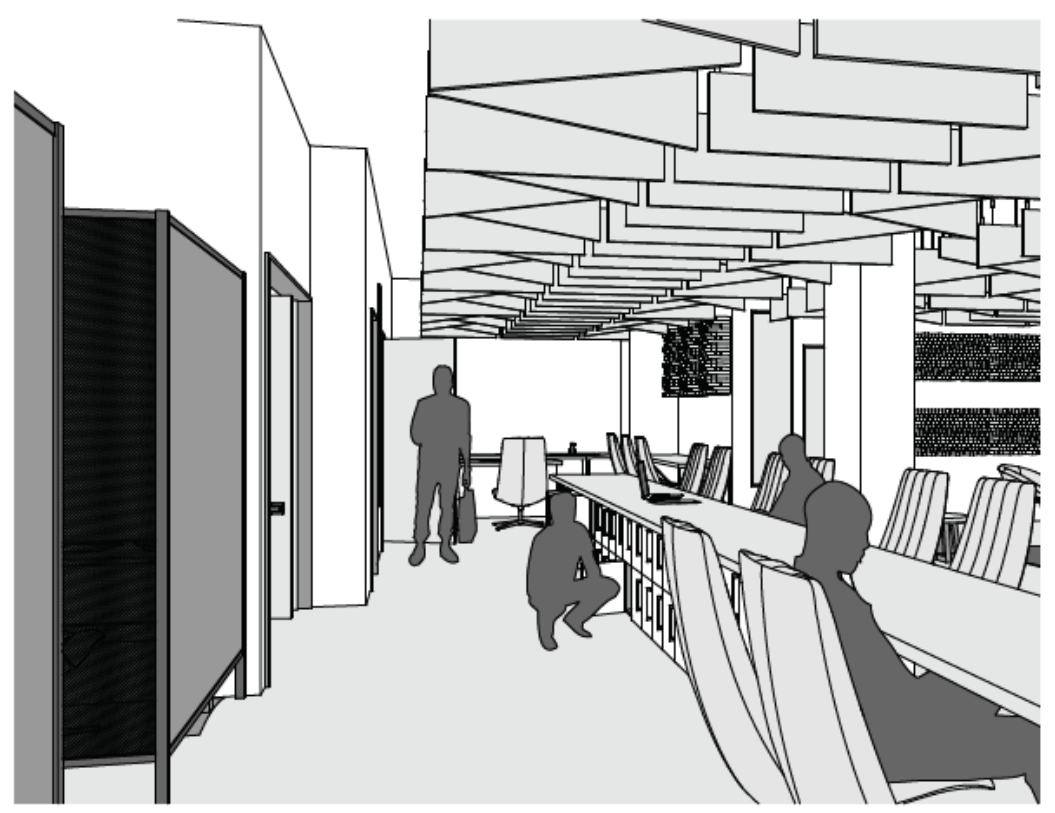

A Figure 6.30 - Sharecuse Office Redesign - Informal Meeting Space Lockers - Author 

Ceiling mounted sound absorbers have been fixed above the design's collaborative and semi-formal work areas to quickly deaden sound throughout the space. These are built from a soft fabric panel which encases a rigid core to adsorb and encourage additional bounces in soundwaves, reducing their energy and by extension their volume [Figure 6.32]. ${ }^{[1]}$

\section{Autex. (2018, May N.D). Autex. Retrieved from Frontier Acoustic Fins: http://www.hecht-} efraim.co.il/prdFiles/products/178_193295_prd_file_3.pdf

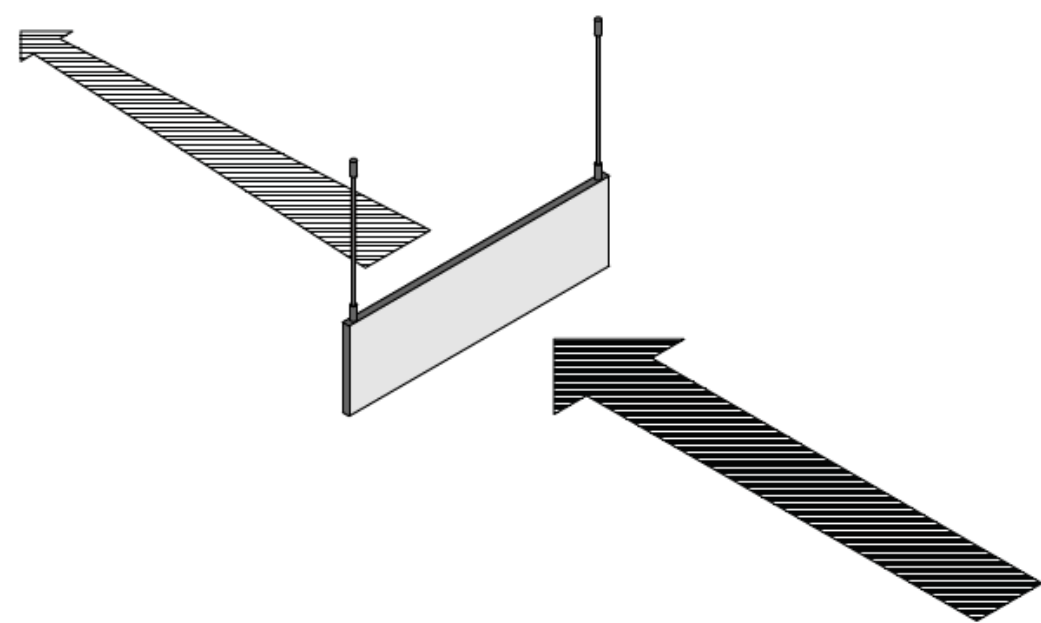

A Figure 6.32 - Sharecuse Office Redesign - Ceiling Mounted Sound Absorber - Author
Rigid sound diffusers have also been wall mounted throughout the office spaces to quickly disperse and scatter sound waves. These are built from a series of varying timber sections which encourage soundwaves to reflect and scatter at odd angles, thereby reducing echo's and soundwave energy in the office whilst also providing visual interest [Figure 6.33]. ${ }^{[1]}$

\section{Perry, T. (N.D). Arqen. Retrieved from Sound Diffusers 101: Free DIY Diffuser Designs: http://arqen.com/sound-diffusers/\#comments}

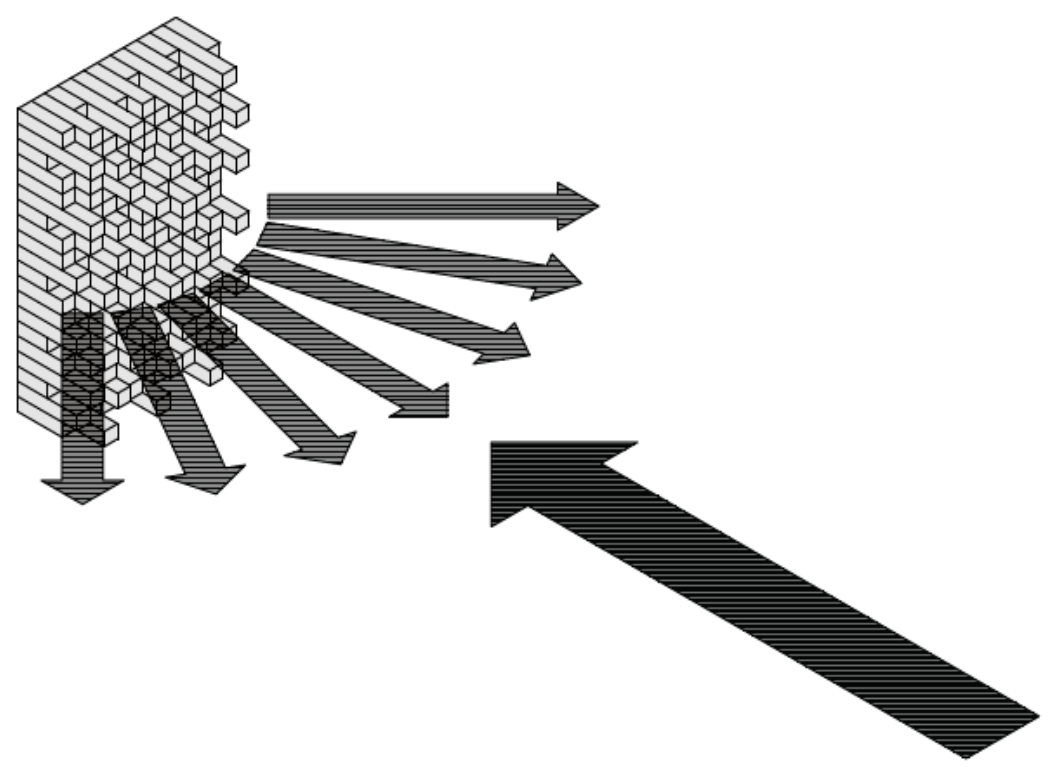

$\Delta$ Figure 6.33 - Sharecuse Office Redesign - Rigid Sound Diffuser - Author 


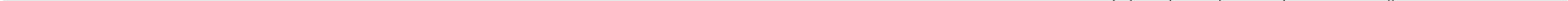




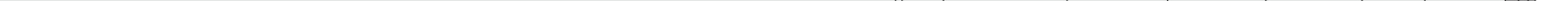


Interruption Events:

Using / Checking Paper Documents

\begin{tabular}{|c|}
\hline $\begin{array}{l}\text { Using / Checking Computer } \\
\text { Interruption } 2\end{array}$ \\
\hline $\begin{array}{l}\text { Talking Through Wall } \\
\text { Interruption } 3\end{array}$ \\
\hline $\begin{array}{l}\text { Phone Call } \\
\text { Interruption } 4\end{array}$ \\
\hline $\begin{array}{l}\text { E-Mail Use } \\
\text { Interruption } 5\end{array}$ \\
\hline $\begin{array}{l}\text { Leaving Cubicle } \\
\text { Interruption } 6\end{array}$ \\
\hline $\begin{array}{l}\text { New E-Mail Notification } \\
\text { Interruption } 7\end{array}$ \\
\hline $\begin{array}{l}\text { Person Arrives } \\
\text { Interruption } 8\end{array}$ \\
\hline $\begin{array}{l}\text { Checking Terminal Status } \\
\text { Interruption } 9\end{array}$ \\
\hline $\begin{array}{l}\text { Phone Ringing } \\
\text { Interruption } 10\end{array}$ \\
\hline $\begin{array}{l}\text { Voice Message Light } \\
\text { Interruption } 11\end{array}$ \\
\hline $\begin{array}{l}\text { Call Through Wall } \\
\text { Interruption } 12\end{array}$ \\
\hline $\begin{array}{l}\text { Reminder Notification } \\
\text { Interruption } 13\end{array}$ \\
\hline
\end{tabular}

Mapped Interruption Events: Not To Interruption Scale
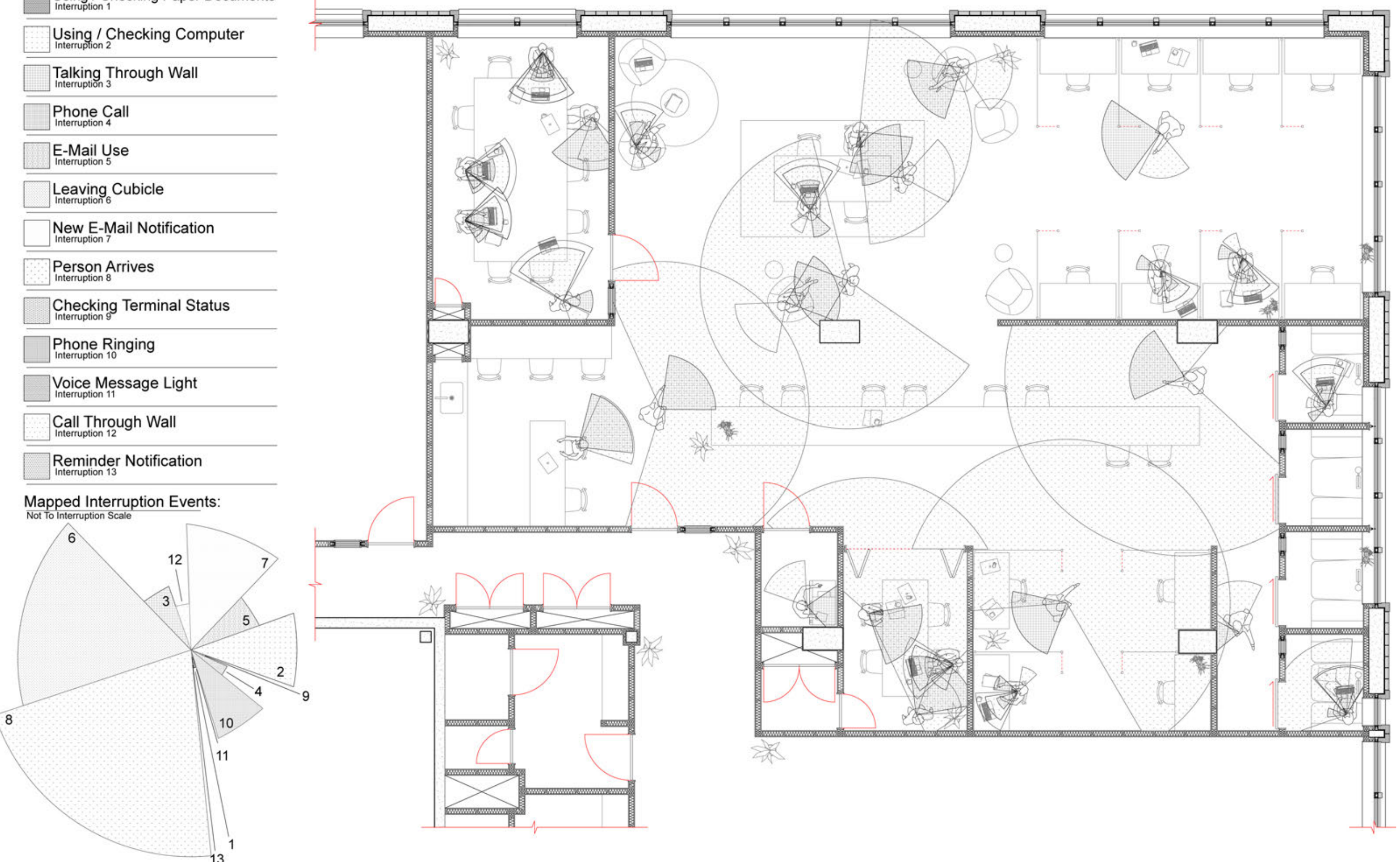


\section{Sharecuse Office - Design Outcomes:}

As I identified earlier within this thesis, the interruptive events of a person arriving and a person engaging in conversation account for the greatest level of an employee's perceived interruptive outcome. Amongst the broad list of interruptive events provided by Gonzales and Mark these were continually demonstrated to be the most prevalent [Figure 6.36]. The Sharecuse redesign in turn elected to prioritise these issues as a design driver. The use of the notational system resulted in these specific findings:

- Originally the event of a person arriving at or moving through the office accounted for an average of $32.65 \%$ of the total perceived interruptive weighting, but by using the notational system as an analytical tool in the design process, this has been reduced to $26.47 \%$ (a reduction of 6.18\%). This reduction has resulted in an $18.92 \%$ improvement in the overall interruptive weighting of this event.

- The event of a person talking originally accounted for an average of $19.31 \%$ of the total perceived interruptive weighting, but through the use of the notational system as an analytical tool in the design process, this has been reduced to $17.30 \%$ (a reduction of $2.01 \%$ ). This reduction has resulted in a $10.37 \%$ improvement in the overall interruptive weighting of this event. 

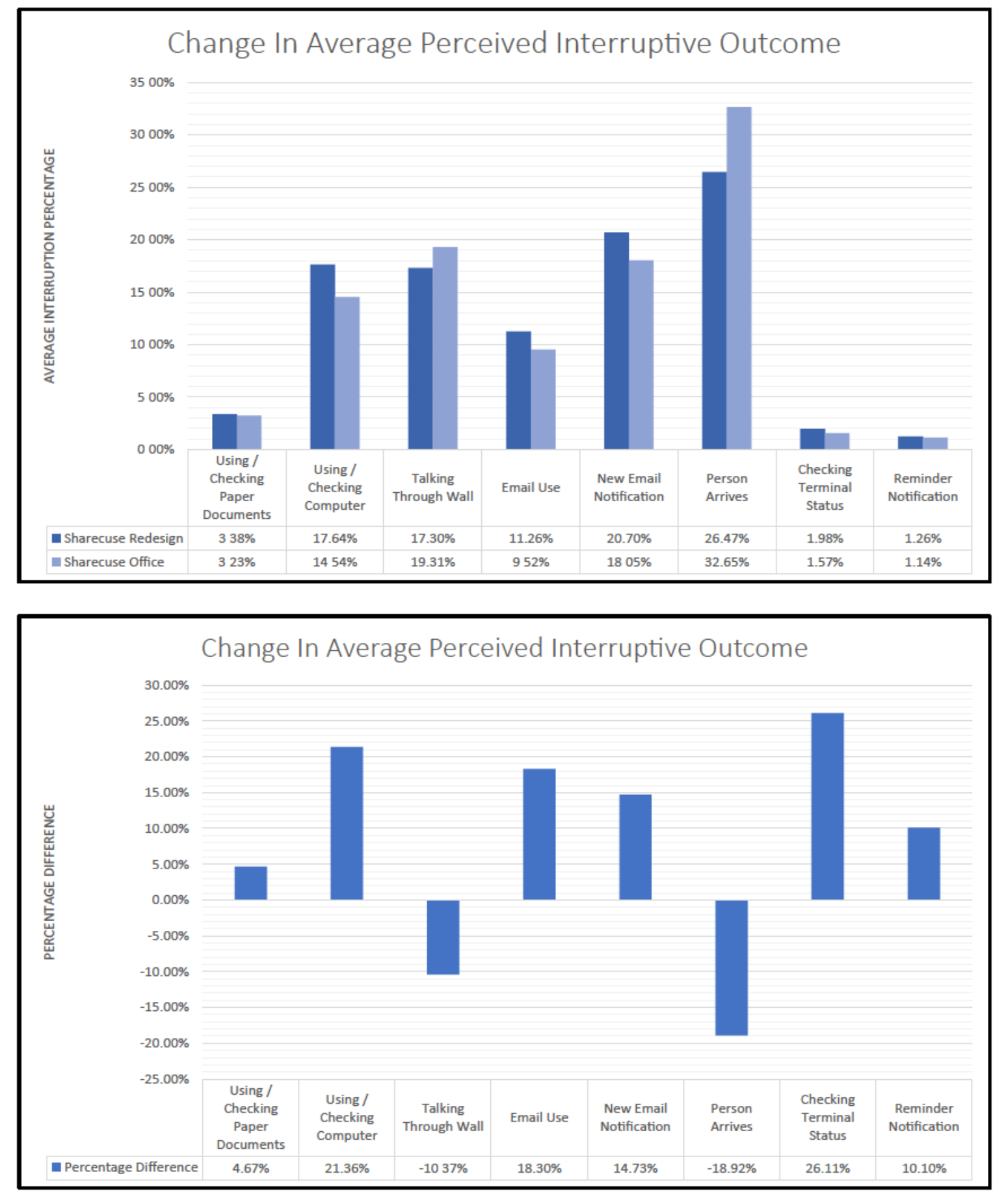
These results are depicted in [Figures $6.37-6.38$ ] and are also presented visually throughout a series of plans which split the interruptive weightings into their individual events [Figures 6.39 - 6.46]. In examining these, it is clear that the interruptive event of a person arriving or engaging in conversation has a minimal effect upon employees working in the identified critical areas such as the semi-formal individual work areas. This promotes employee productivity in these areas, but also allows for visual and aural interactions to operate effectively within collaborative areas. ${ }^{[1]}$

Many of the other perceived interruptive events outlined by Gonzalez and Mark demonstrated a higher level of interruption in the redesign when mapped by the notational system (on average worsening by $15.88 \%$ ). These interruptions stem either from paper documentation or the computer, and worsen likely as a result of the reduced work area. The amount of desk space on average has reduced throughout the Sharecuse office in the redesign, particularly in the formal working pods and the bench working areas. The average work area has fallen from $0.696 \mathrm{~m}^{2}$ to $0.617 \mathrm{~m}^{2}$ per person. This $12.03 \%$ decrease in the employee working area results in them moving computers and documentation from their sensorial peripheries into the main working plane, resulting in a higher interruptive outcome. If this issue proves problematic, the number of total workspaces could be reduced from 57 offering employees more space to work within.

1 Mehta, R., Zhu, R. J., \& Cheema, A. (2012). Is Noise Always Bad? Exploring the Effects of Ambient Noise on Creative Cognition. Journal of Consumer Research, 784-799. 
Interruption Events:

Using / Checking Paper Documents

Using / Checking Computer

Talking Through Wal

Phone Call

E-Mail Use

Leaving Cubicle

New E-Mail Notification

Person Arrives

Checking Terminal Status

Phone Ringing
Internuntion 10

Voice Message Light
Interrution 11

Call Through Wall

Reminder Notification
Intermution 13

Mapped Interruption Events:
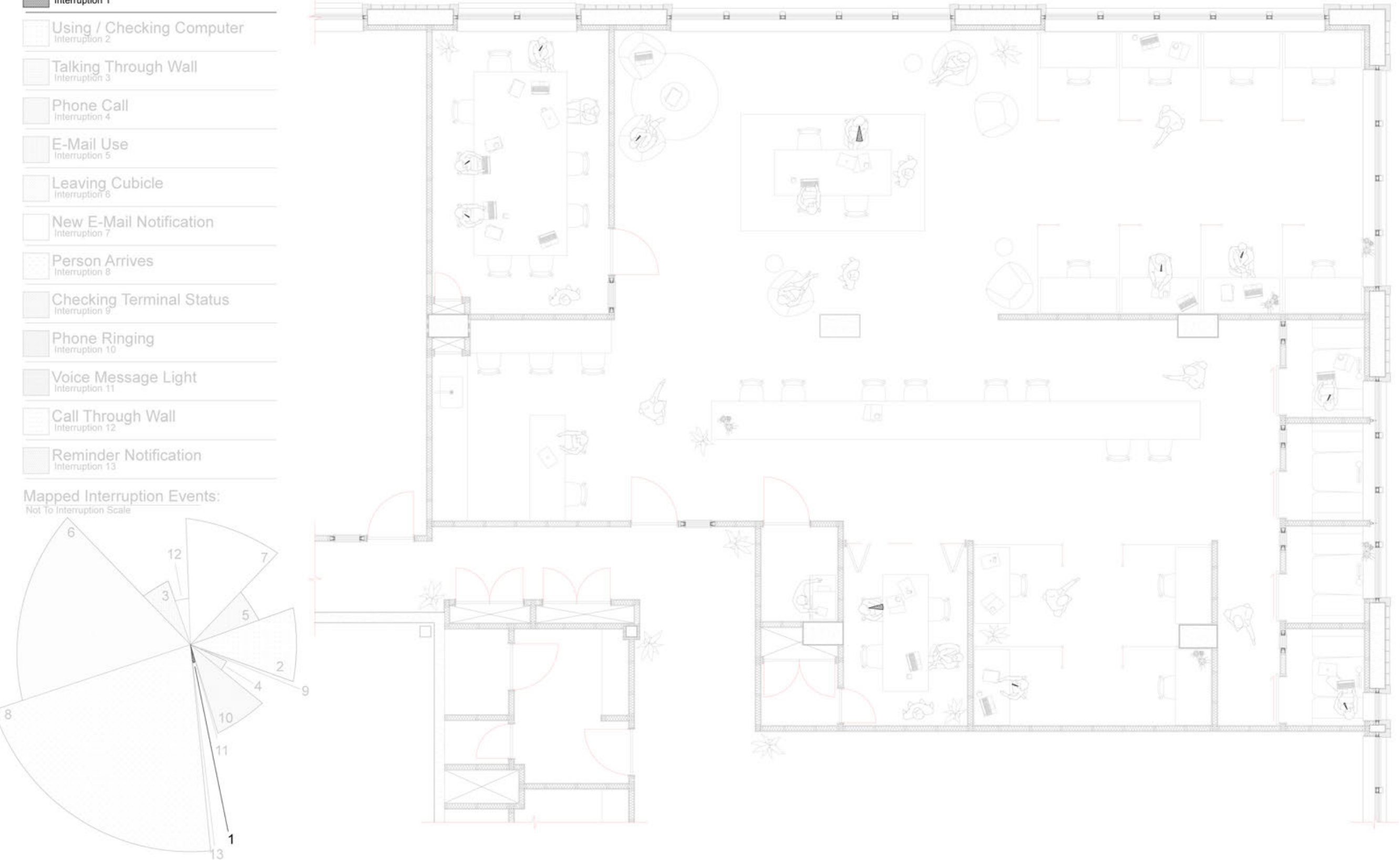
Interruption Events:

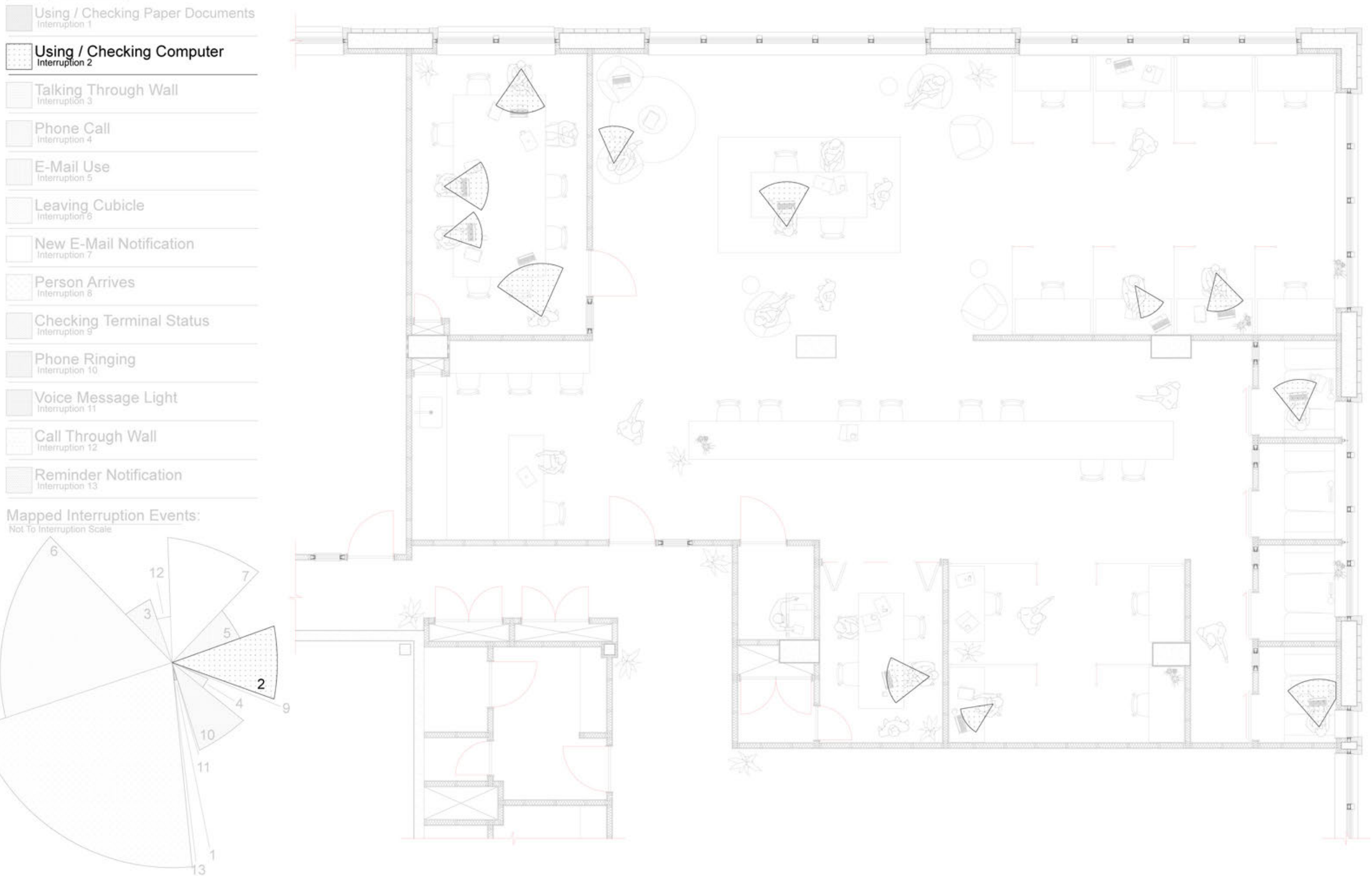


Interruption Events:

Using / Checking Paper Documents

Using / Checking Computer

\section{Talking Through Wall}

\begin{tabular}{|c|}
\hline $\begin{array}{l}\text { Phone Call } \\
\text { Prtertuption } 4\end{array}$ \\
\hline $\begin{array}{l}\text { E-Mail Use } \\
\text { Interruption } 5\end{array}$ \\
\hline $\begin{array}{l}\text { Leaving } \text { Cubicle } \\
\text { Interviption } 6\end{array}$ \\
\hline $\begin{array}{l}\text { New E-Mail Notification } \\
\text { nteruption } 7\end{array}$ \\
\hline $\begin{array}{l}\text { Person Arrives } \\
\text { Interuption } 8\end{array}$ \\
\hline Checking Terminal Status \\
\hline $\begin{array}{l}\text { Phone Ringing } \\
\text { Internution to }\end{array}$ \\
\hline $\begin{array}{l}\text { Voice Message Light } \\
\text { Voive Mon }\end{array}$ \\
\hline $\begin{array}{l}\text { Call Through Wall } \\
\text { Interruption } 12\end{array}$ \\
\hline $\begin{array}{l}\text { Reminder Notification } \\
\text { Internotion } 13\end{array}$ \\
\hline
\end{tabular}

Mapped Interruption Events:

Not To Interruption Scale
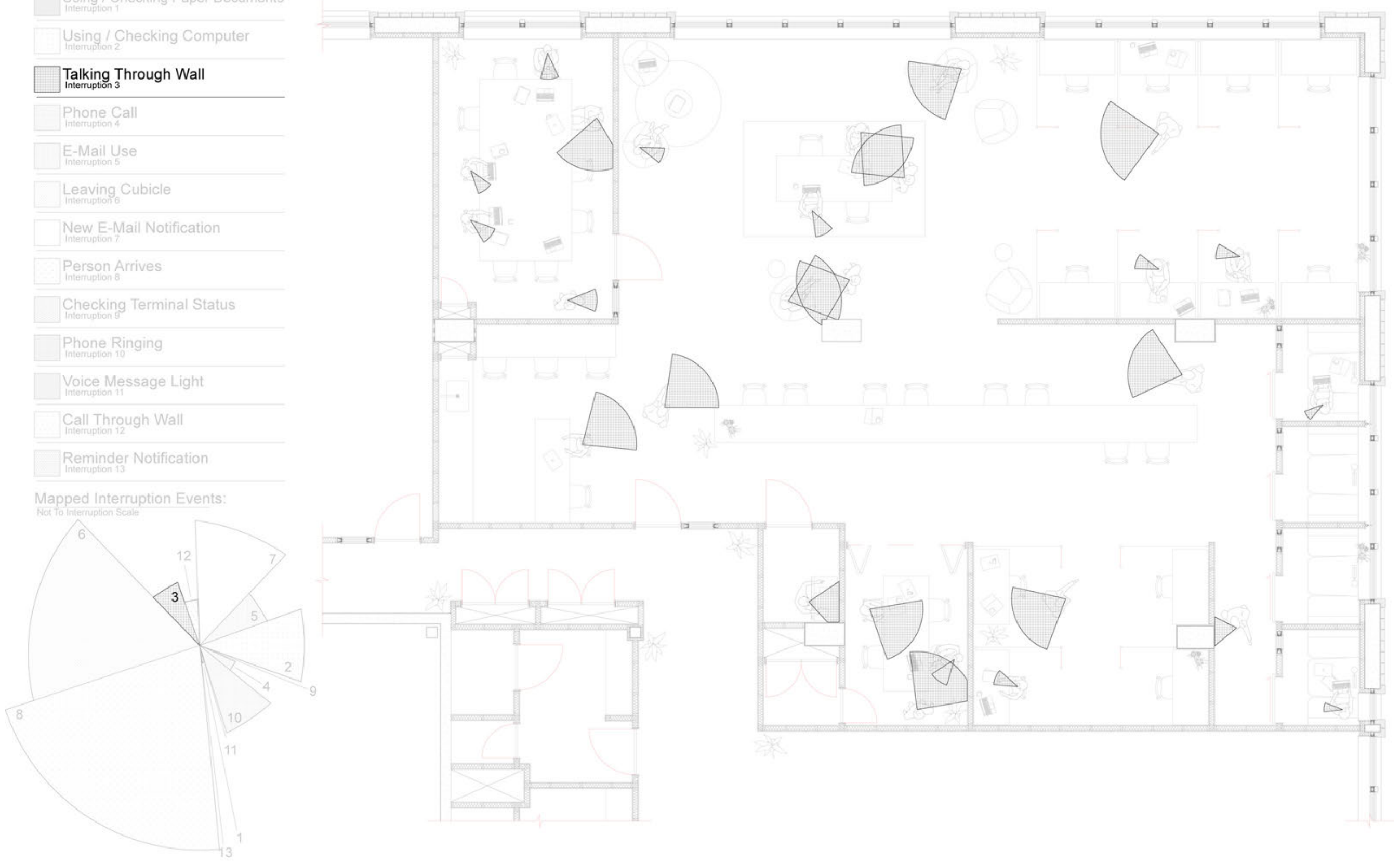
Interruption Events:

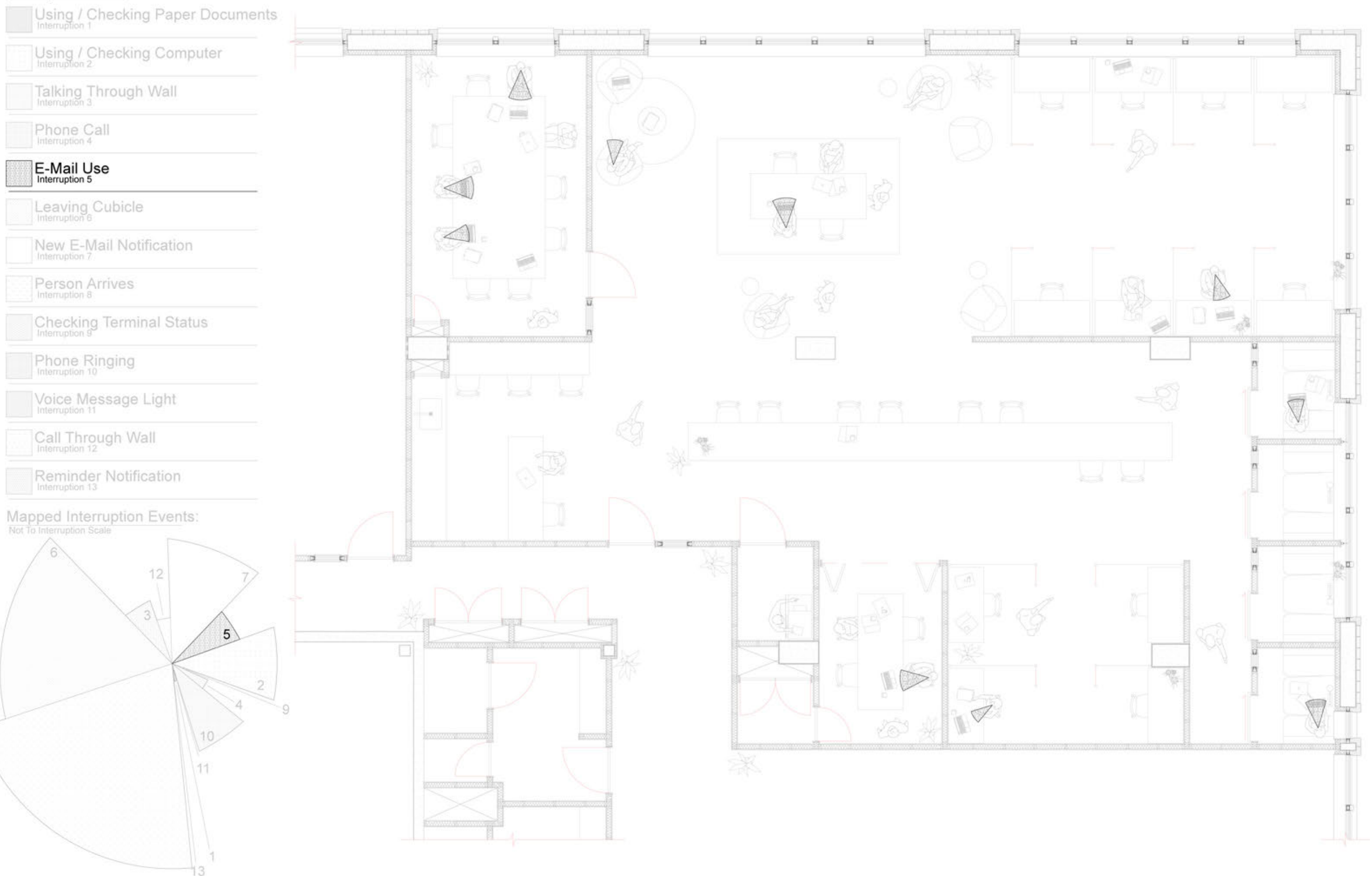




\section{Interruption Events:}

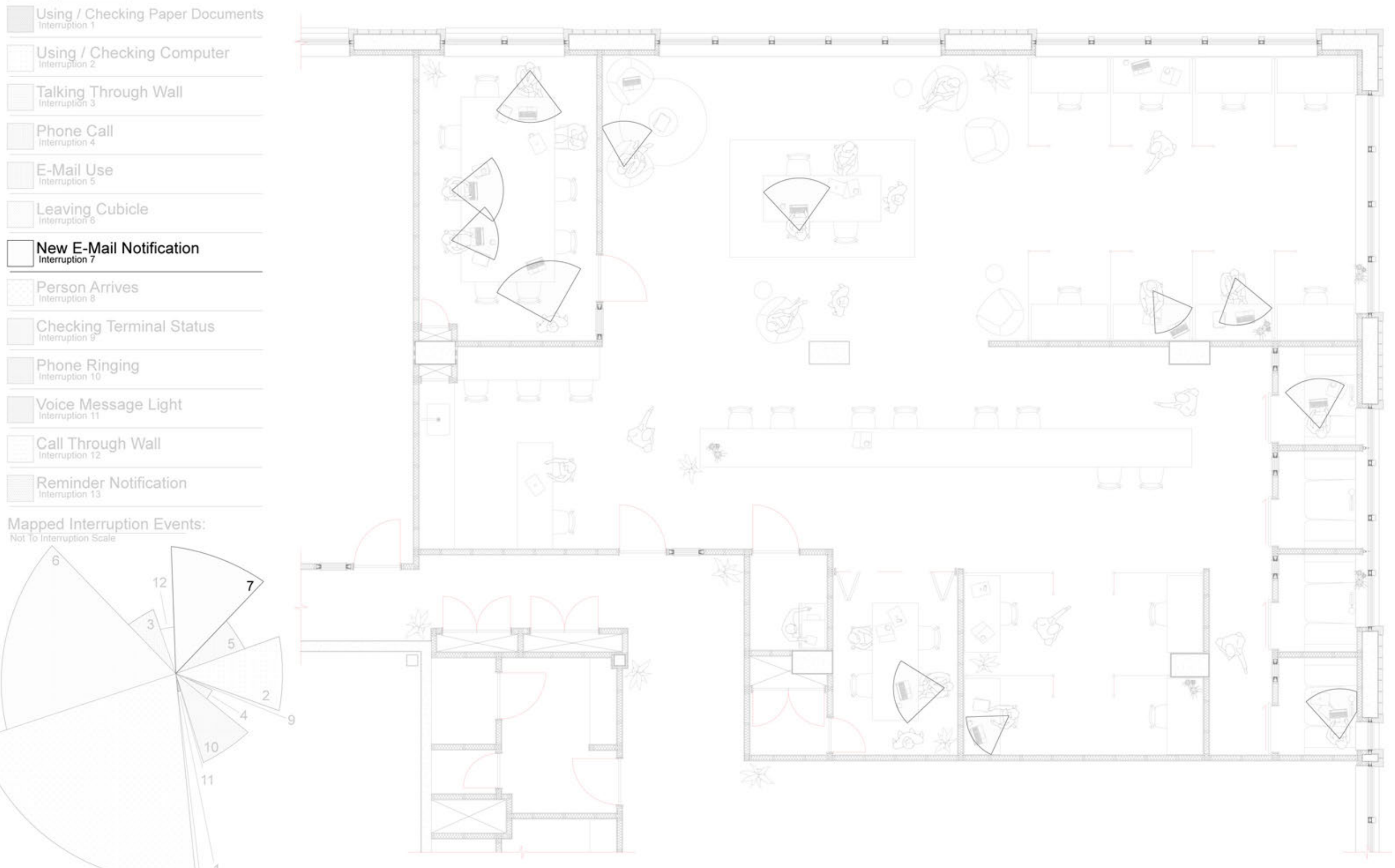




\section{Interruption Events:}

Using / Checking Paper Documents

\begin{tabular}{|c|}
\hline $\begin{array}{l}\text { Using / Checking Computer } \\
\text { Intermpion } 2\end{array}$ \\
\hline $\begin{array}{l}\text { Talking Through Wall } \\
\text { interruption } 3\end{array}$ \\
\hline $\begin{array}{l}\text { Phone Call } \\
\text { intemuption } 4\end{array}$ \\
\hline $\begin{array}{l}\text { E-Mail Use } \\
\text { interruption } 5\end{array}$ \\
\hline $\begin{array}{l}\text { Leaving Cubicle } \\
\text { Interupitiong }\end{array}$ \\
\hline $\begin{array}{l}\text { New E-Mail Notification } \\
\text { Interruption } 7\end{array}$ \\
\hline $\begin{array}{l}\text { Person Arrives } \\
\text { Interruption } 8\end{array}$ \\
\hline $\begin{array}{l}\text { Checking Terminal Status } \\
\text { Interuption }\end{array}$ \\
\hline $\begin{array}{l}\text { Phone Ringing } \\
\text { Interruption } 10\end{array}$ \\
\hline $\begin{array}{l}\text { Voice Message Light } \\
\text { Interuption } 11\end{array}$ \\
\hline $\begin{array}{l}\text { Call Through Wall } \\
\text { Intertuption } 12\end{array}$ \\
\hline $\begin{array}{l}\text { Reminder Notification } \\
\text { intervuption } 13\end{array}$ \\
\hline
\end{tabular}

Mapped Interruption Events:
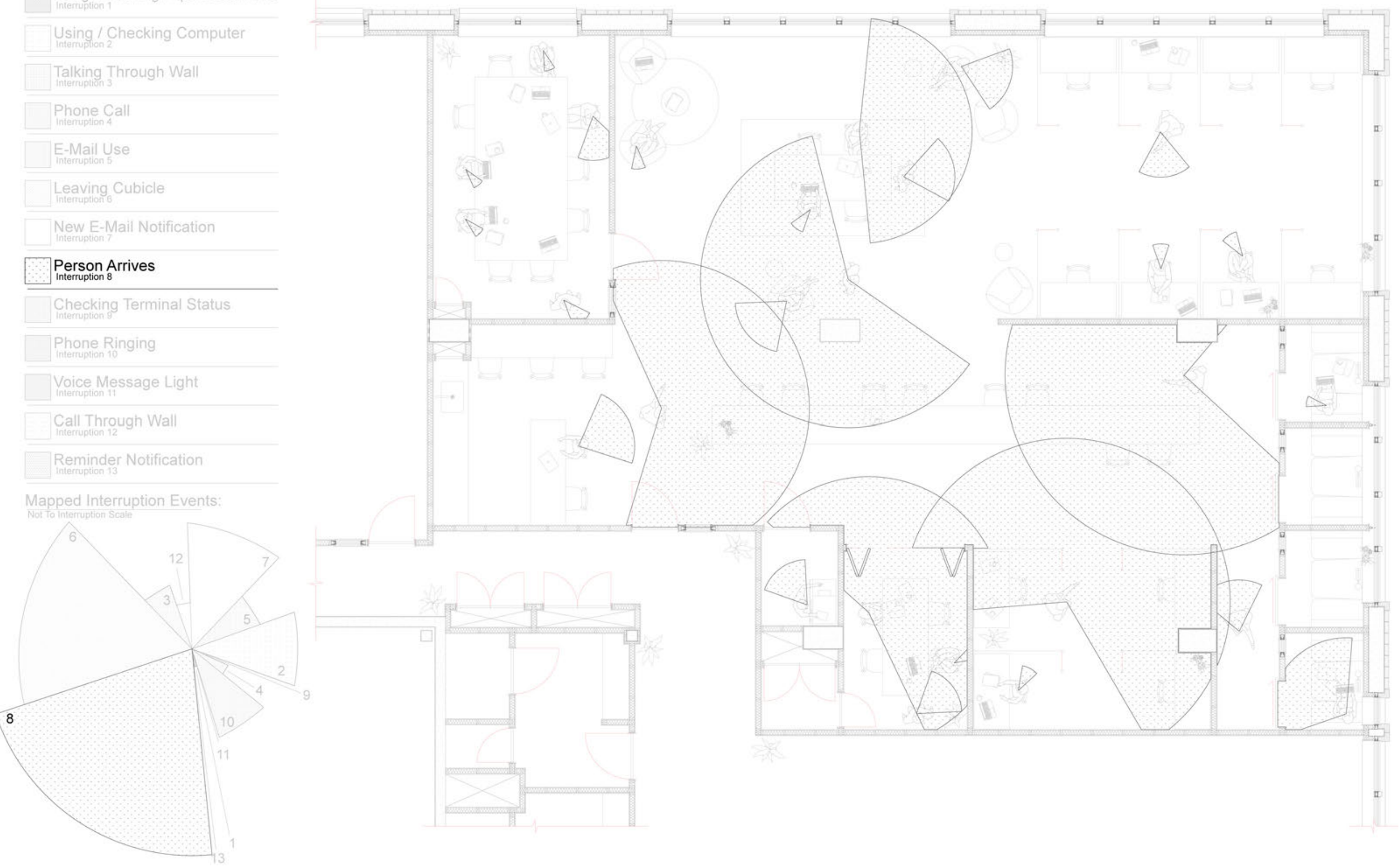

A Figure 6.44 - Sharecuse Office Redesign Interruption Mapping - Person Arrives - Author 
Interruption Events:

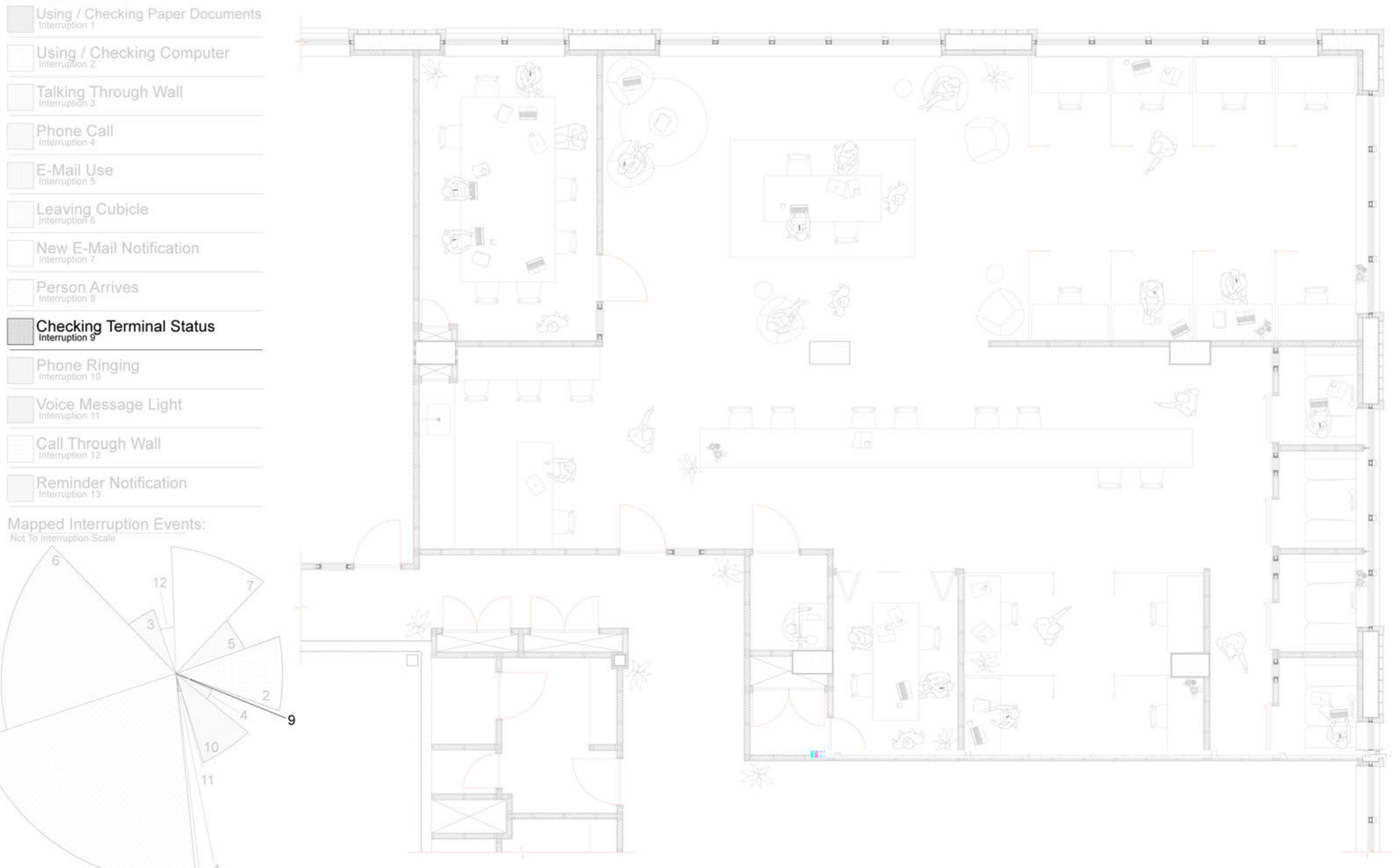


Interruption Events:

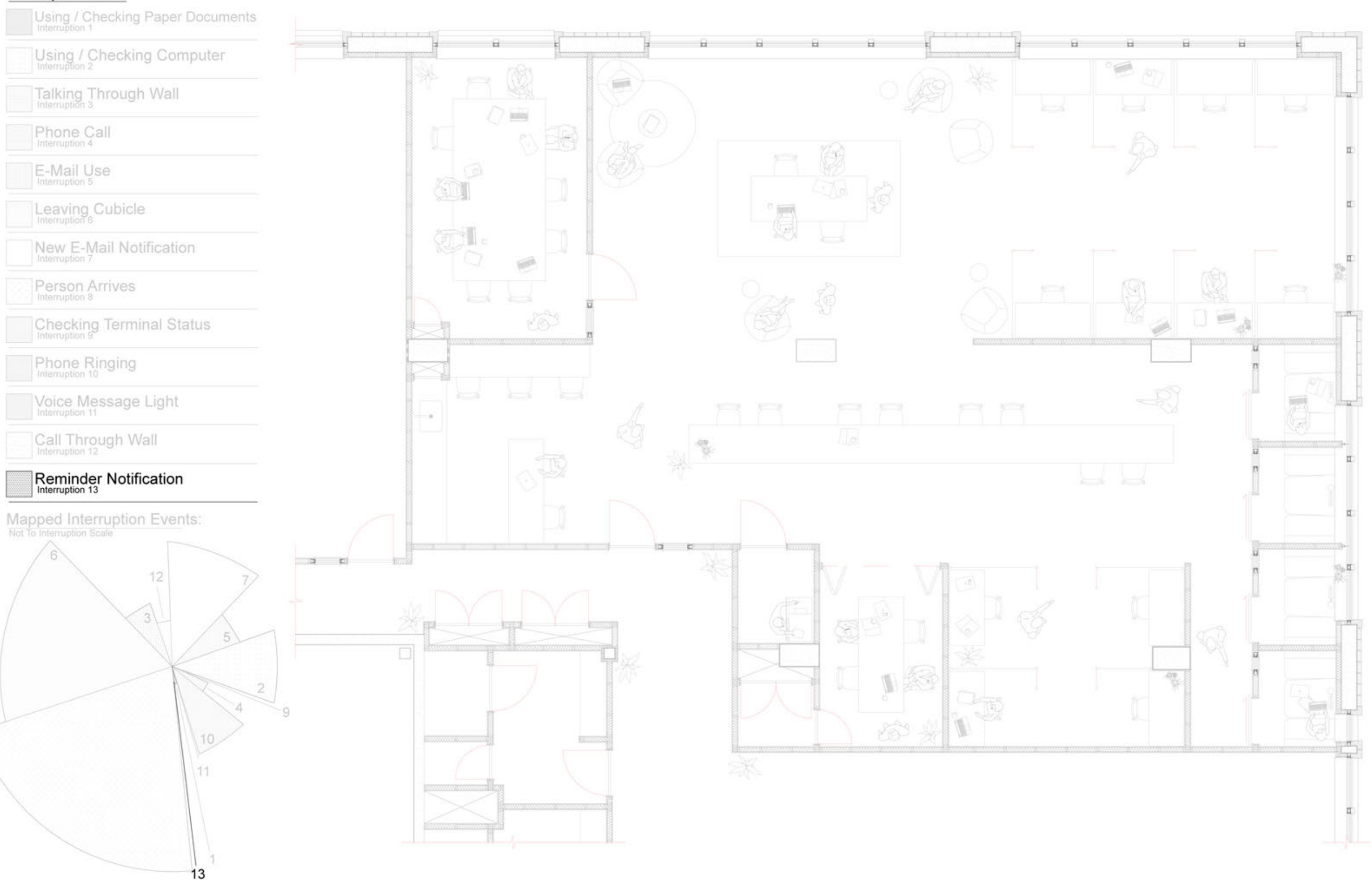

$\Delta$ Figure 6.46 - Sharecuse Office Redesign Interruption Mapping - Reminder Notification - Author 


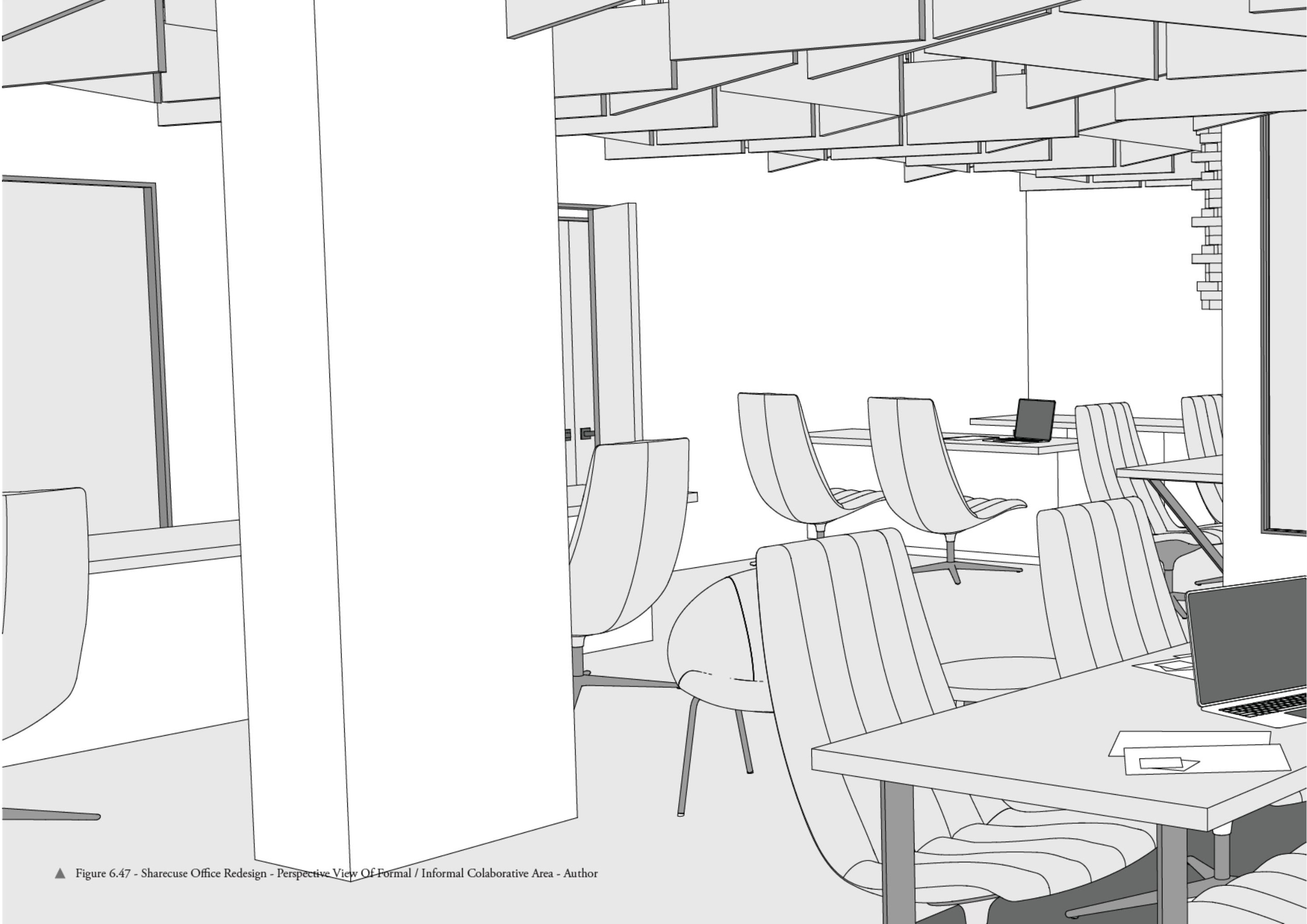




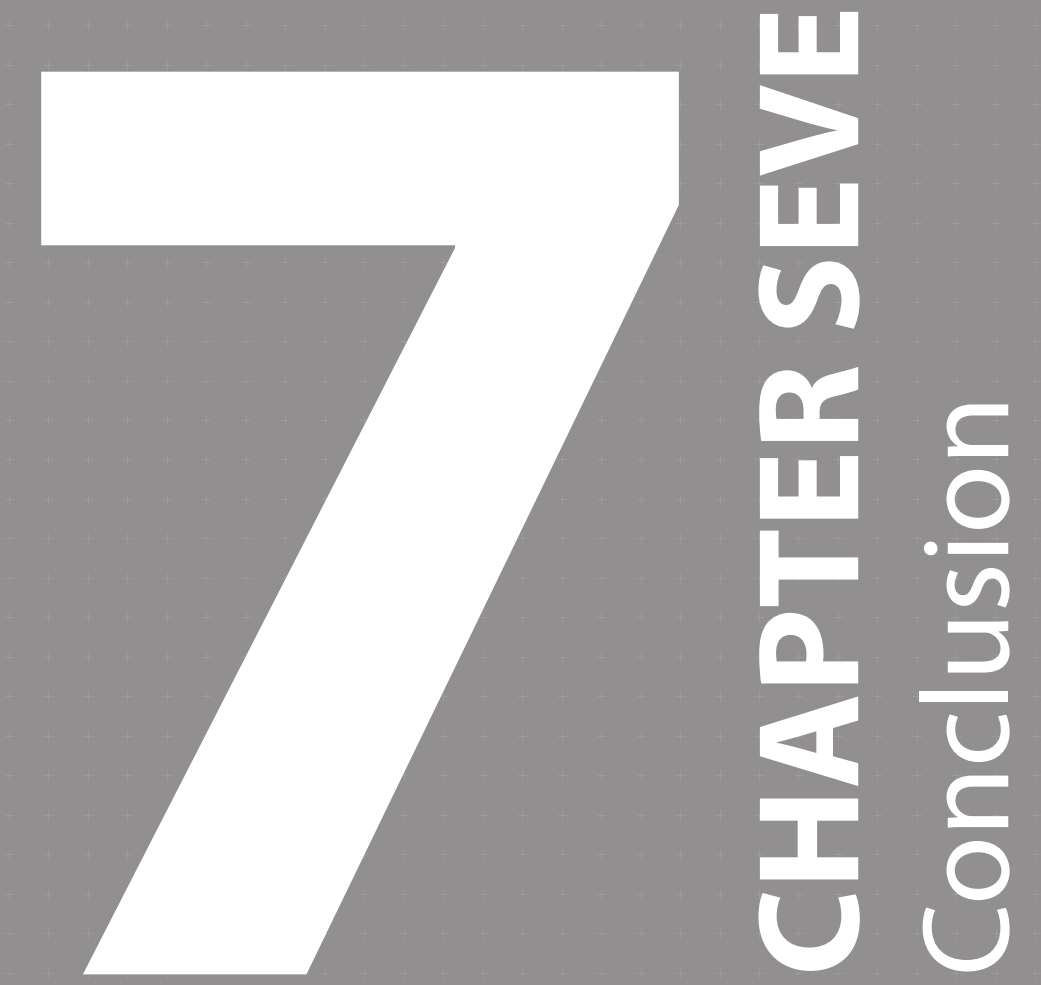





\section{Research Conclusion:}

he interruptive elements of architectural atmosphere were successfully codified in this thesis when examined as a series of interruptive events. These events represent the typical workplace interruptions perceived by an employee such as a person arriving in the office - and were derived from the works of Victor M Gonzalez and Gloria Mark. Through the use of a notational system which utilises these events as its foundation; practitioners are able to engage in the design of interruption aware spaces. By mapping an interruptive event effecting a given employee within the workplace, practitioners can determine the perceived outcome of the interruption based upon their sensorial perceptibility of the events source. By altering the surrounding architecture in relation to the employee and this anticipated interruptive event's source, practitioners are able to affect this outcome: either improving or worsening its effects. In the context of this thesis, the notational system has been utilised to redesign the Syracuse, New York, Sharecuse office, a shared workplace which displayed highly interruptive tendencies as a result of its architectural design. In applying the notational system as an analytical tool, the design's layout, circulatory pathways and sightlines were altered. This resulted in a significant improvement in the design's interruptive outcome, particularly in regard to its individual work areas and meeting spaces.

In utilising the notational system, both in practice and in prior tests, it is evident that the main factors by which an employee's interruptive outcome is influenced is through their sense of sight and hearing. As these two senses account for $92.62 \%$ of our sensorial perceptibility, a clear line of enquiry is established. When engaging in the design of interruption aware spaces, practitioners should prioritise and respond to these senses as they will offer the greatest level of control over the interruptive outcome of the space.
These findings were reinforced when examining my personal interruptive experience within Wigan 501. Across two working days a number of interruptive events were recorded, demonstrating that $46.52 \%$ of my sensorial perceptibility stemmed from my sense of sight, $52.72 \%$ from my sense of hearing, $0.52 \%$ from my sense of touch and $0.24 \%$ from my sense of smell. These findings disputed the works of Lawrence D Rosenblum, and the notational system in response elected to operate on an average of the two values (Sight 64.76\%, Hearing 31.86\%, Smell 1.87\%, Taste $1.51 \%$ ).

Building upon this notion, practitioners should also be considerate of employees arriving at, and talking throughout the office. These events are some of the most interruptive within the workplace and not only effect an employee's sense of sight and hearing, but can also be greatly influenced by their surrounding architectural environment. These events were addressed directly in the redesign of Sharecuse, and their interruptive outcomes were improved over the base design by $18.92 \%$ and $10.37 \%$ respectively, as a result of utilising the notational system as an analytical tool [Figure 7.2].

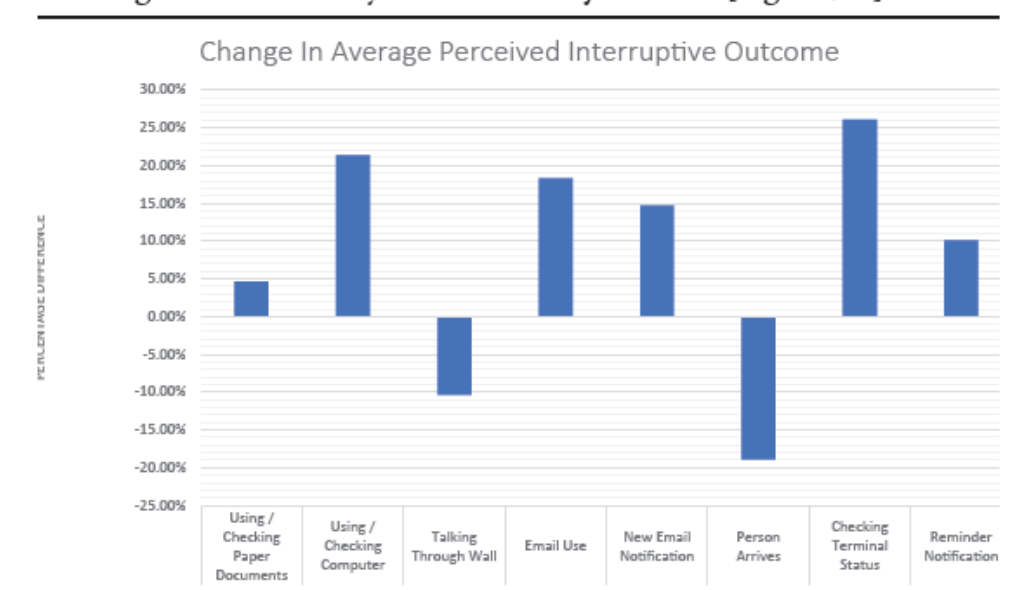




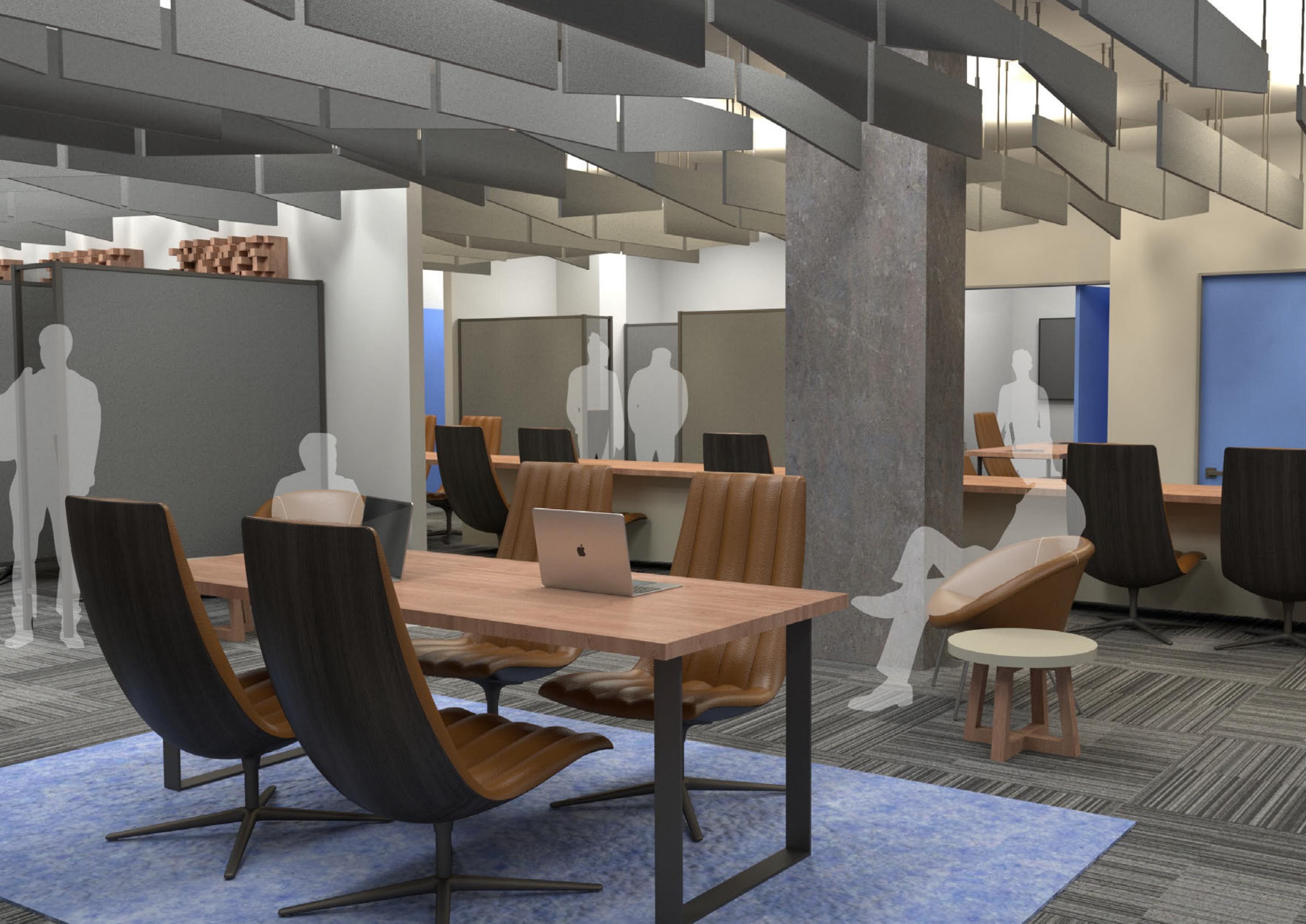


Architectural practitioners capable of engaging with the notational system in this manner should in turn begin to acknowledge and become aware of architecture's ordinary interruptive aspects (by extension, this can offer them control over its outcome). As the wider discipline has been shown to overlook these aspects in the context of both academic and media portrayals, this line of enquiry was previously only effectively explored by practitioners in the context of climatic atmosphere. This sentiment aligns with that of Gernot Bohme, and effectively demonstrates that atmosphere is not only a climatic affair. Atmosphere, even when considered ordinary by the wider discipline such as in the context of the agile office, also incorporates social humanitarian concepts. These concepts have been examined in the context of interruption through this thesis.

The notational system, despite the success shown through this thesis can still be improved. Currently for practitioners to apply the system they must cycle between measuring an employee's sensorial perceptibility of a given event, lodging this within the excel calculator and drafting the resulting outcome. This process at a smaller scale is effective, but quickly becomes laborious when applied at a larger scale and across several interruptive events. These arduous tendencies begin to disconnect the practitioner from the drawing and design process, but not to the extent of the prior simulation-based notational systems.

The sensorial tools developed for the notational system are effective in determining an employee's perceptibility of a given event, and offer practitioners an insight into problematic areas of their design. The tools, despite this success, often fail to account for minor adjustments in the interruptive sources positioning and in turn, only show and employee's perception of a given event broadly. As such, the effects of minor changes in the design outcome may be overlooked, allowing for an interruptive atmosphere to persist. Expanding upon this, architectural details are also overlooked by the system. The notational system fails to consider design properties such as lighting levels, colour and sound absorption, and their effects on the interruptive outcome. These issues - if resolved and implemented within the notational system - would strengthen its analytical abilities, but would also further accentuate is laborious tendencies.

In future works, a parametric interface may serve as a solution to these issues, enabling users to rapidly test, analyse, and iterate upon their design interventions. In exploring this concept, the system may in turn be able to explore interruptive atmospheres outside of the second dimension, thus potentially revealing atmospheric nuances which may have been overlooked.

In future works, researchers may aim to gather interruptive data specific to their office of interest, as the data supplied by Gonzalez and Mark which the system utilises has been assumed as generic and applicable to all office types. This would allow for the system to better reflect the employee experience, and may enable the system to become more robust. In addition to this, future researchers may wish to adapt this system as a framework for the development and design of other notational systems, these examining and addressing the design of other aspects of social atmosphere and their sensorial relationship with its occupants. 


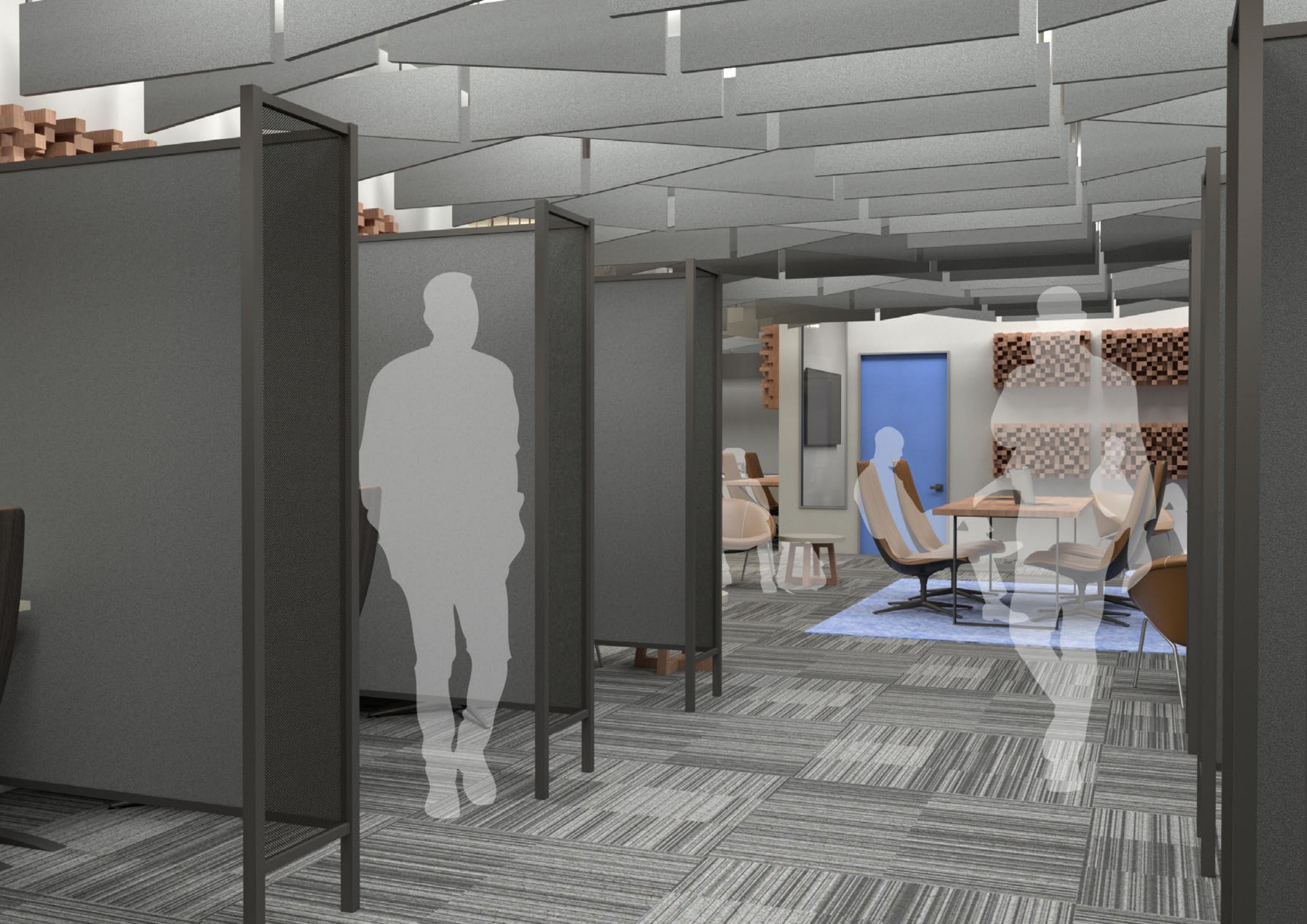




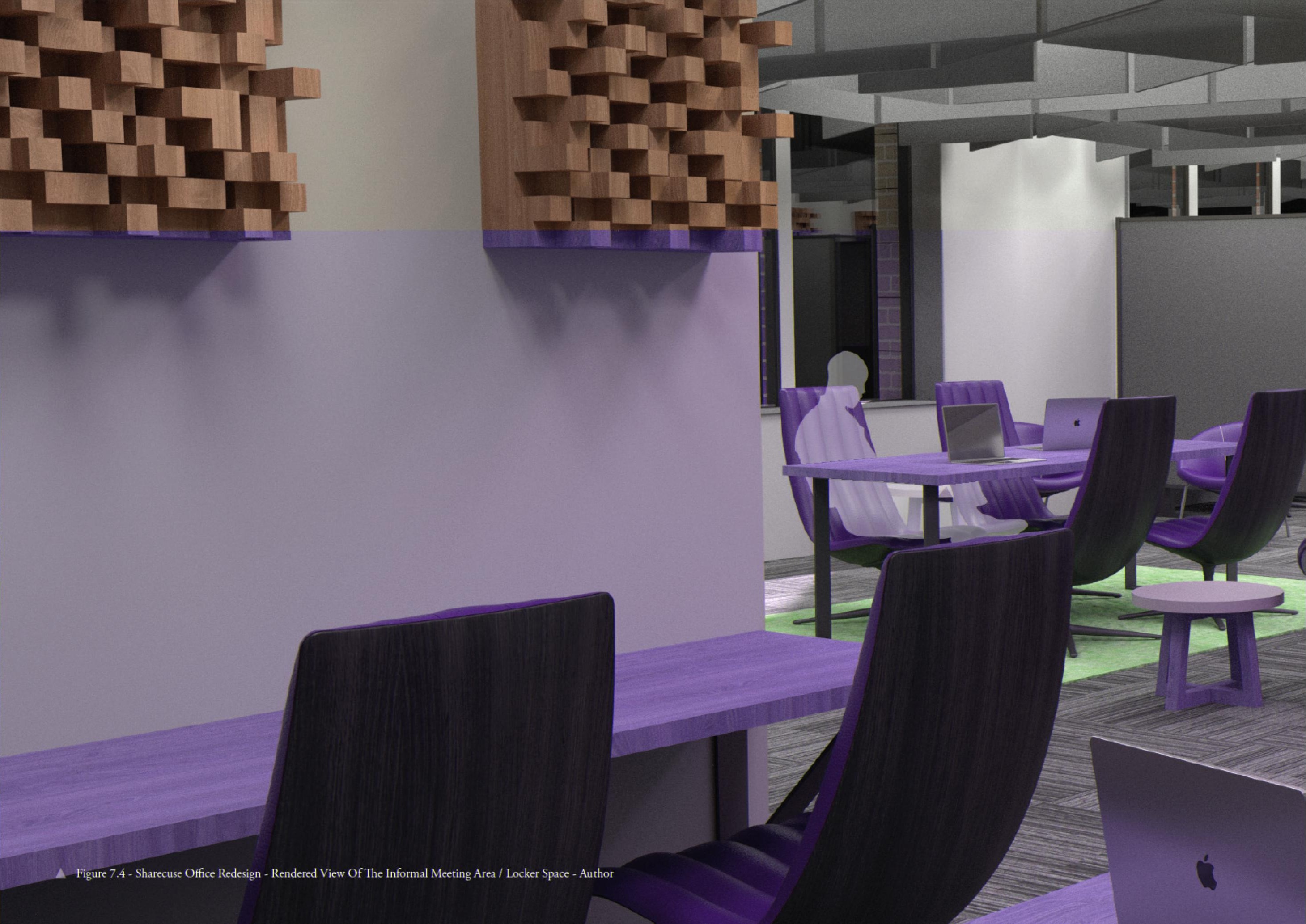




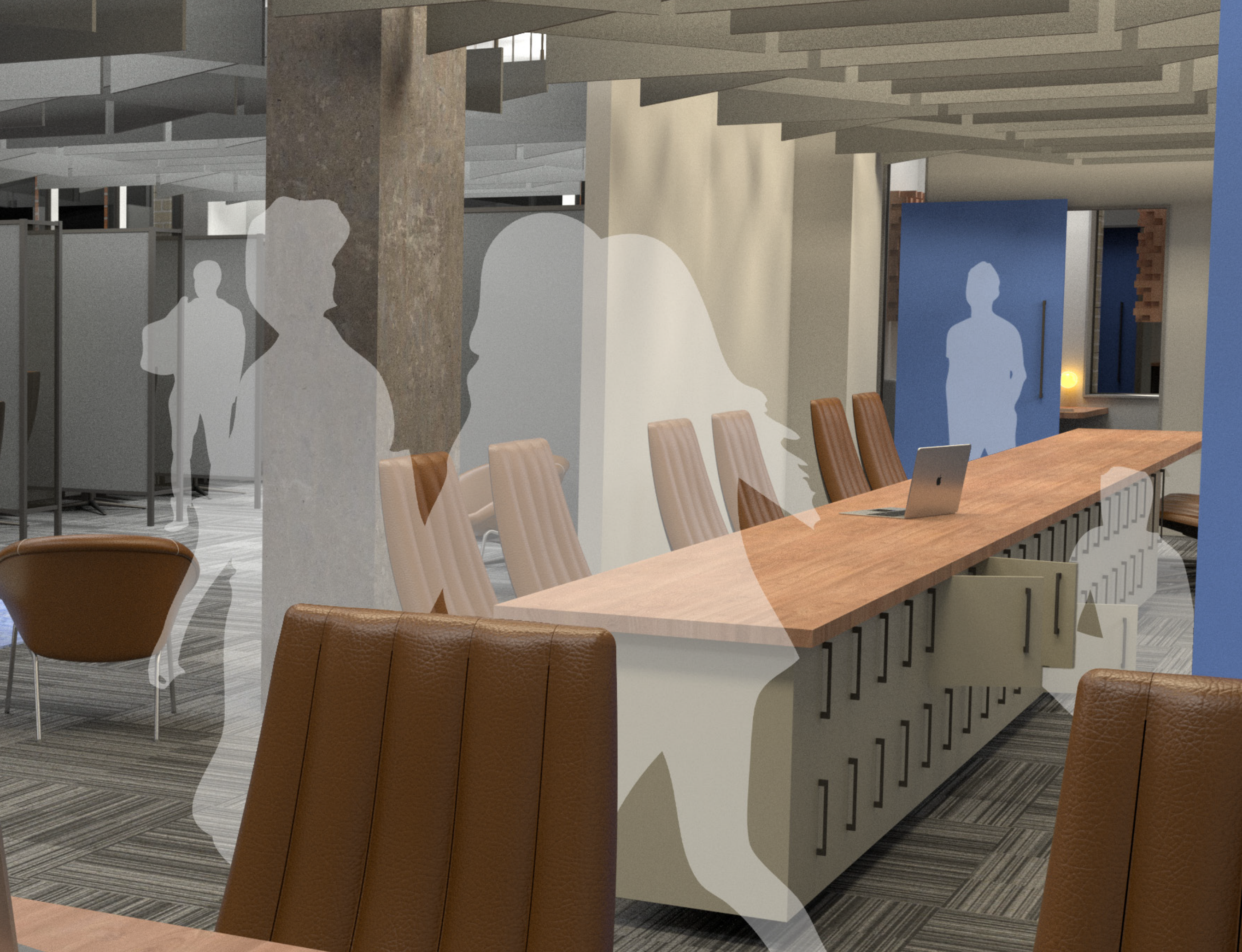




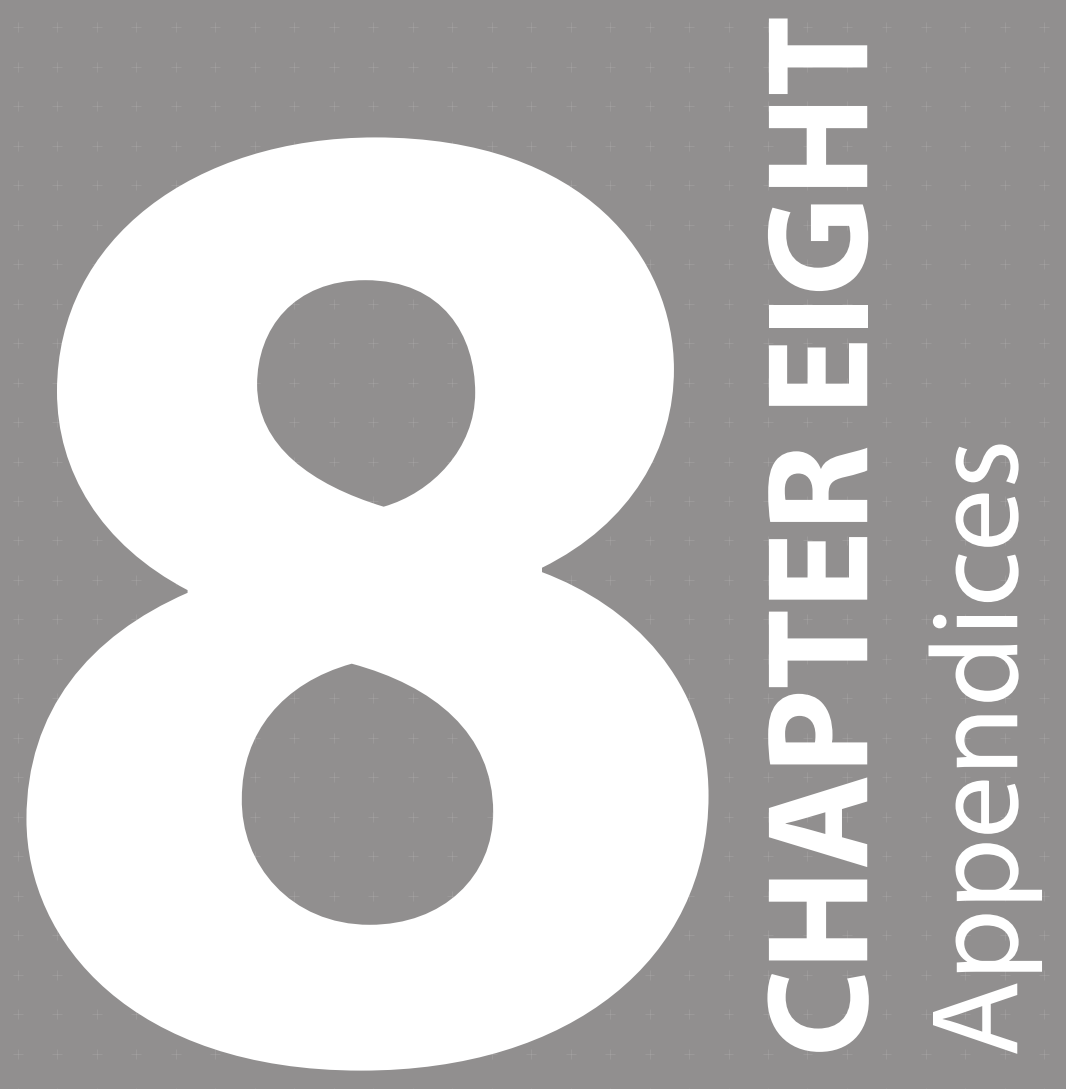



The works thus far will then inform the future works in upcoming cycles

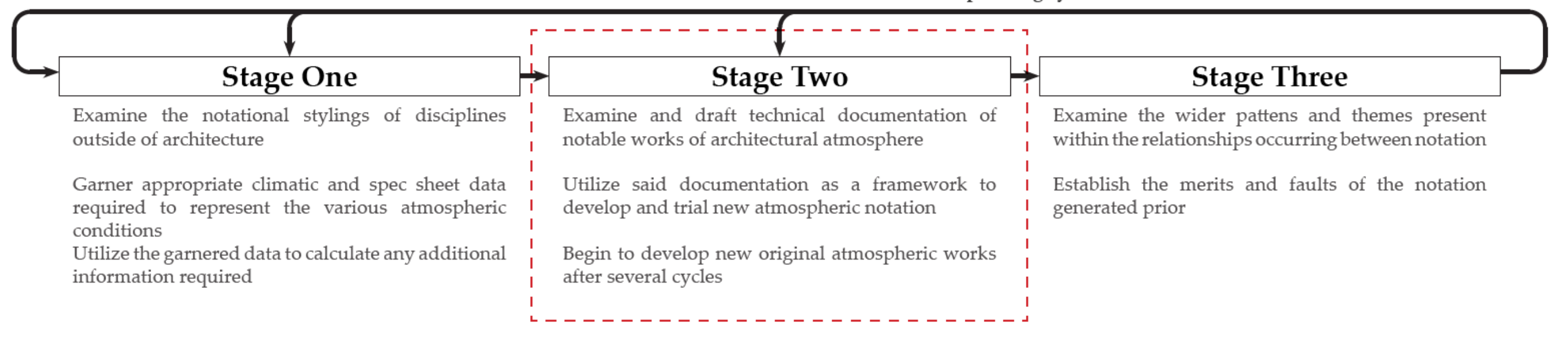


Initially, this thesis intended to examine atmosphere through a broad context, exploring the elements of its formulation as heralded by Mark Wigley. This would examine atmospheric aspects such as sound, light and temperature through a three-stage process.

Stage one of this process endeavoured to explore existing notational standards common within disciplines outside of architecture, pulling from aspects of building science, electrical engineering, meteorology and physics. This process was enacted to identify notational concepts which could be applied to the representation of atmospheric qualities.

Stage two aimed to take these notational concepts and apply them to notable works of architectural atmosphere through drawing, in an attempt to document and codify the atmospheric feeling of a space. Architectural works from the likes of Peter Zumthor were selected for this process, as his designs often exhibit strong atmospheric qualities alluding to feelings of serenity or godliness - for example as demonstrated through Thermas Vals. The developmental process, once refined, would move beyond the use of these design precedents in an attempt to generate an original atmospheric response based upon the knowledge gained from analysing their works.

Stage three of this process would look to the works of stage two, examining the design process and drawing techniques developed to document and codify atmospheric conditions. This stage of the design process is intended to pull from broad design techniques which could be introduced to facilitate the process of atmospheric design. 

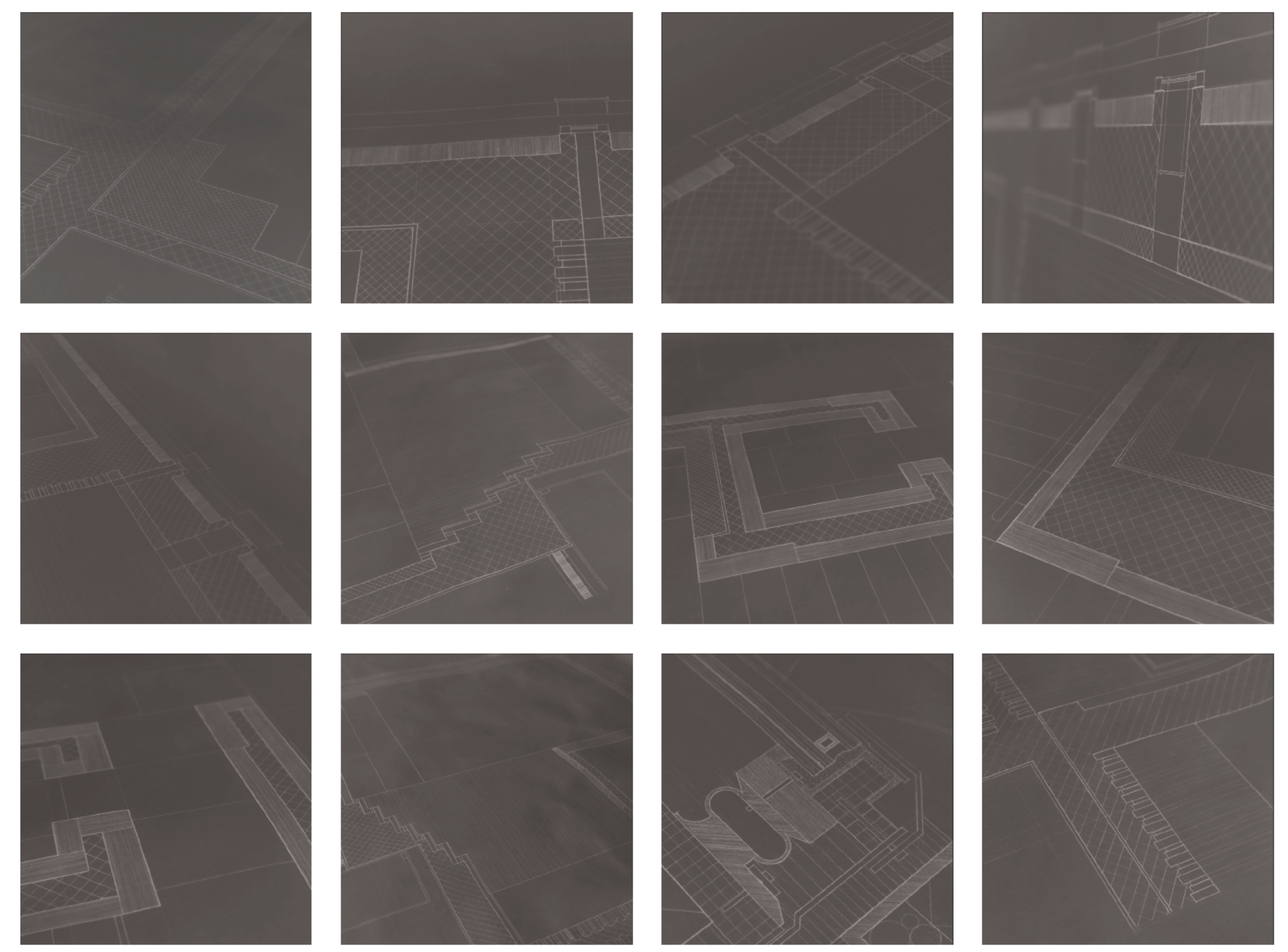
The early works of design stage one focused on recreating a set of technical documents regarding Peter Zumthor's Thermas Vals spa [Figures A1.2 - A1.6]. A floorplan, section, transverse section, and detail view were created of this space. These documents focused on the design's flower bath, as this space was deemed to exhibit a number of varying climatic atmospheric qualities. The design of the flower bath is semi-enclosed by exceedingly tall, valser quartzite walls and dimly lit through a slitted skylight - which mostly serves to illuminate the hallway outside. At the same time, while the flower bath maintains a high temperature, the pools immediately outside its walls are much cooler. It was expected in analysing this space that these various atmospheric elements would overlap, and that climatic notation, once developed, would be overlain atop the drawings to examine and analyse the expected patterns that would have been created. This process was conducted in an attempt to derive and decode its specific surrounding atmosphere. 


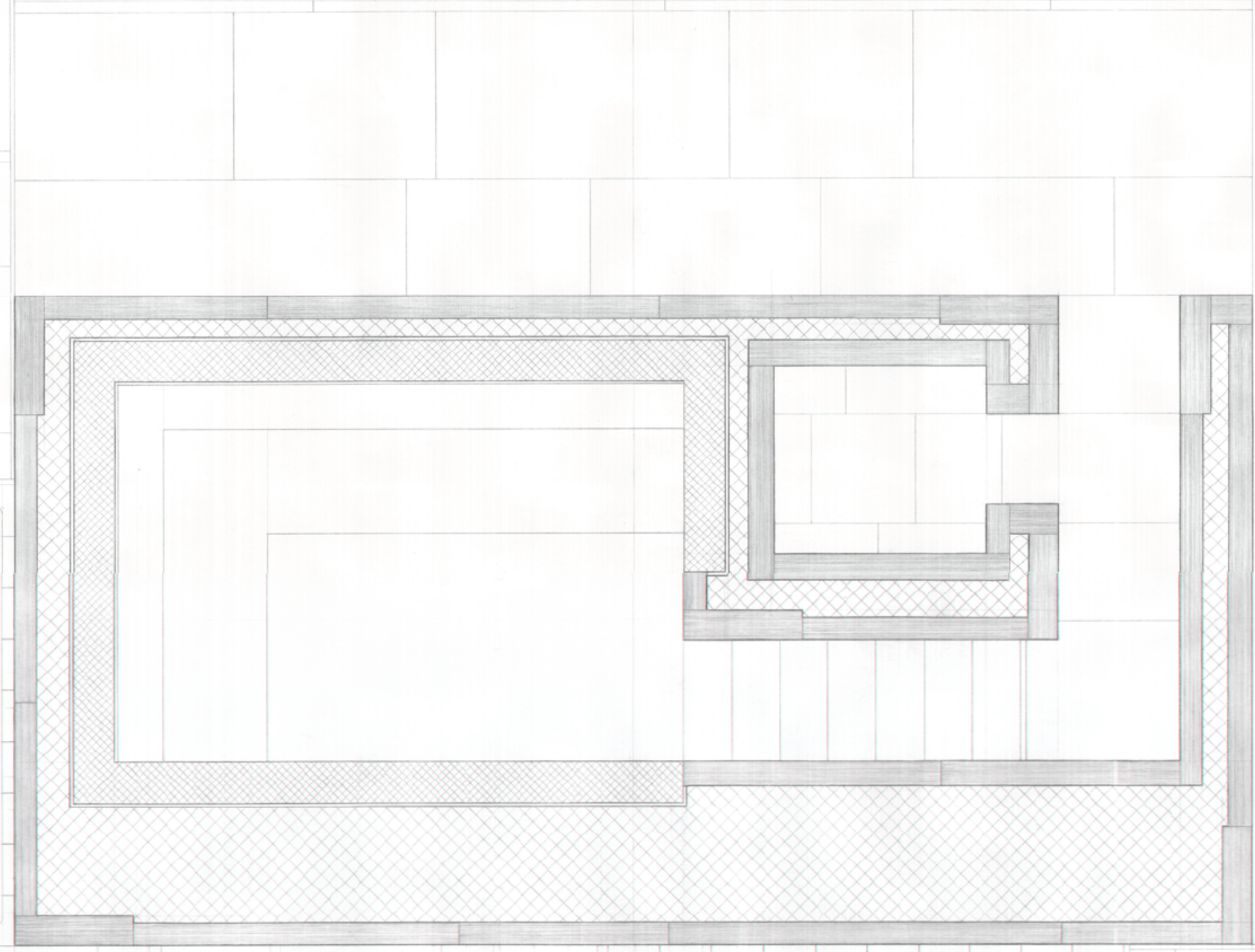

Figure A1.3 - Design Stage One - Thermas Vals Flower Bath Floorplan - No Scale - Author $\boldsymbol{\Delta}$ 


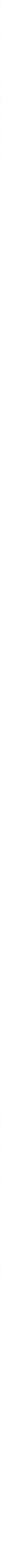




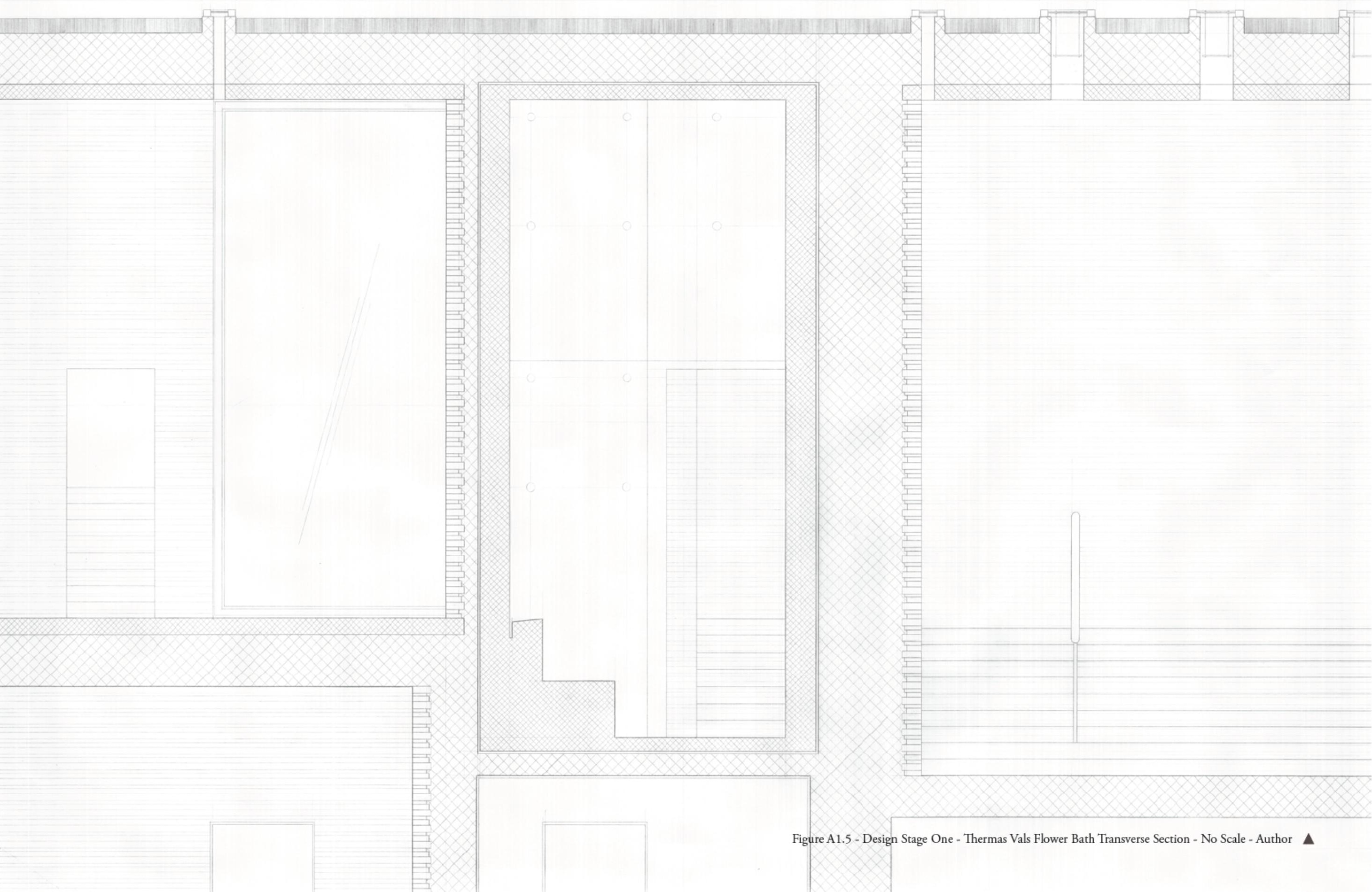




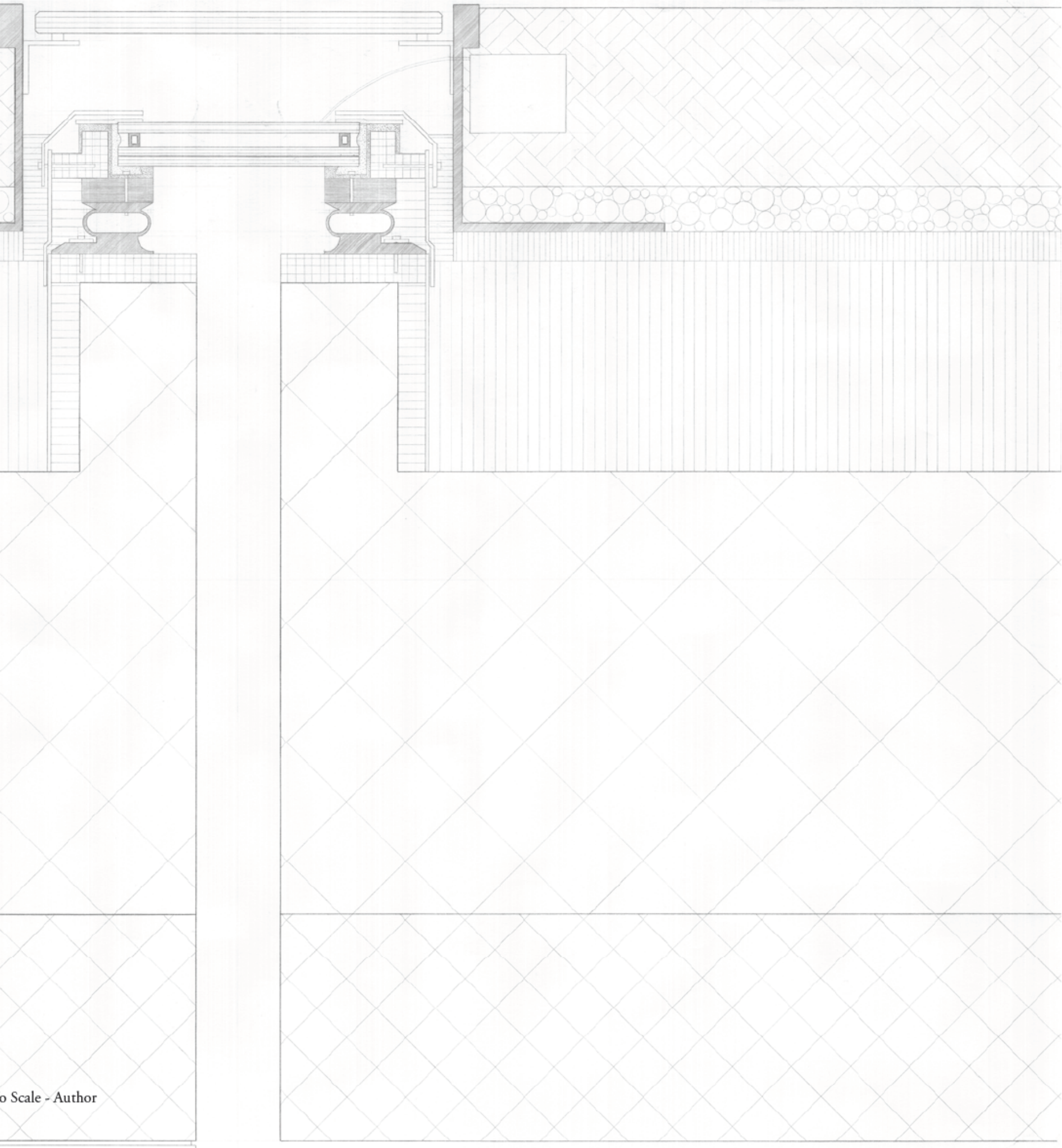


A number of notational systems found outside of the architectural discipline - in professions such as physics and chemistry - were examined and analysed through a series of sketches [Figures A1.7 - A1.10]. When examining notational systems regarding humidity, it was clear that many authors chose to represent this atmospheric phenomenon through a series of particles, visually differentiated from one another through their density. Others opted to utilise either a colour banding system, or a series of arrows and contours to represent particle movement. When examining notational systems regarding lighting, it was clear that many authors favoured colour banding - as this was prevalent throughout the majority of representations. It is noted however that some three-dimensional mappings were also used alongside sketch-based arrow systems. 


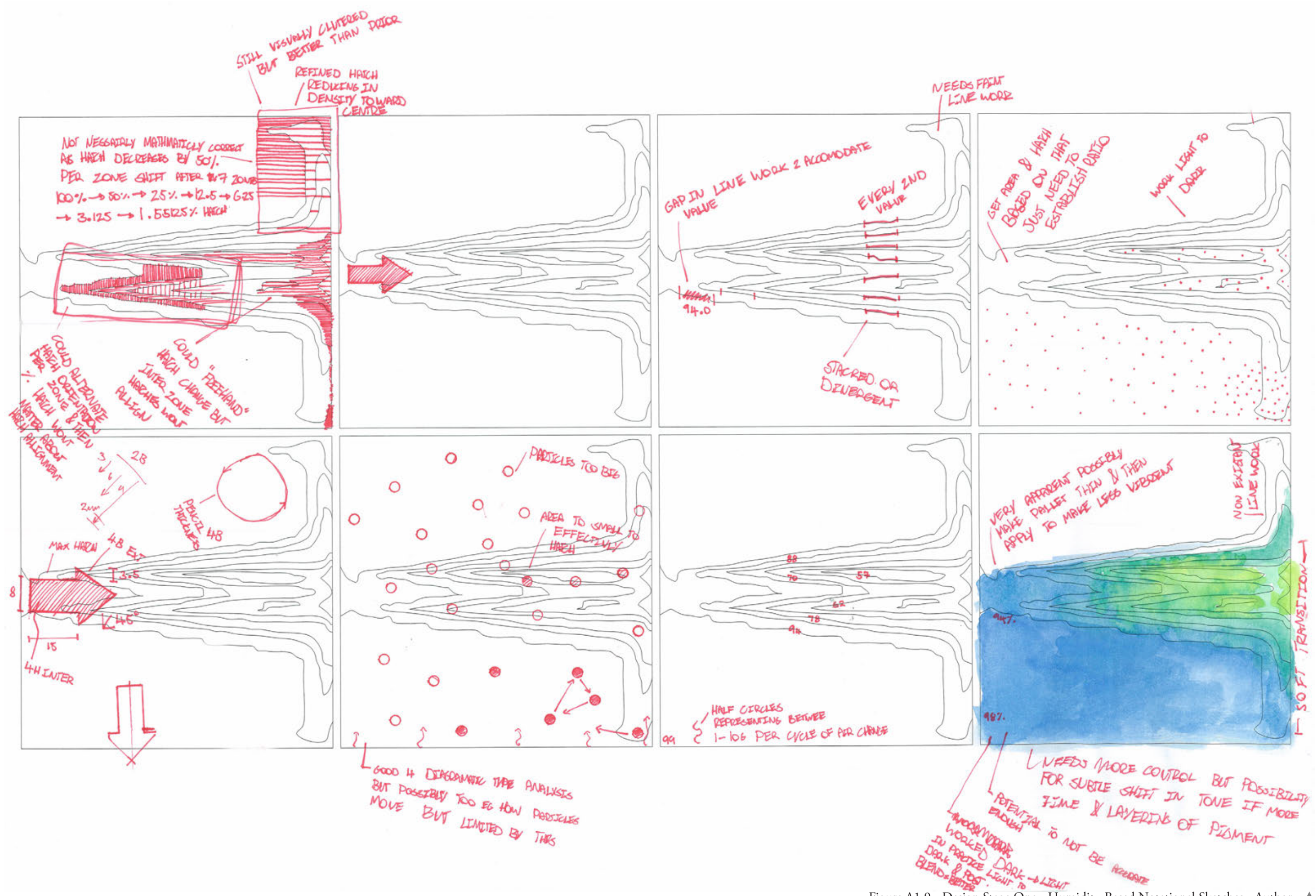




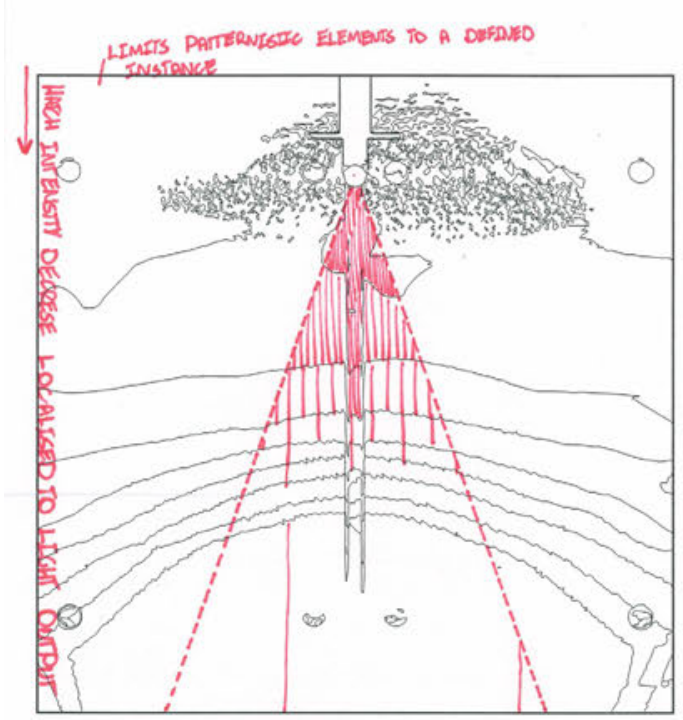

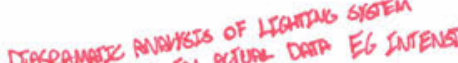

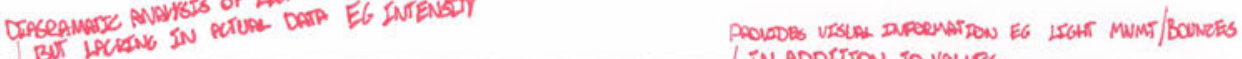
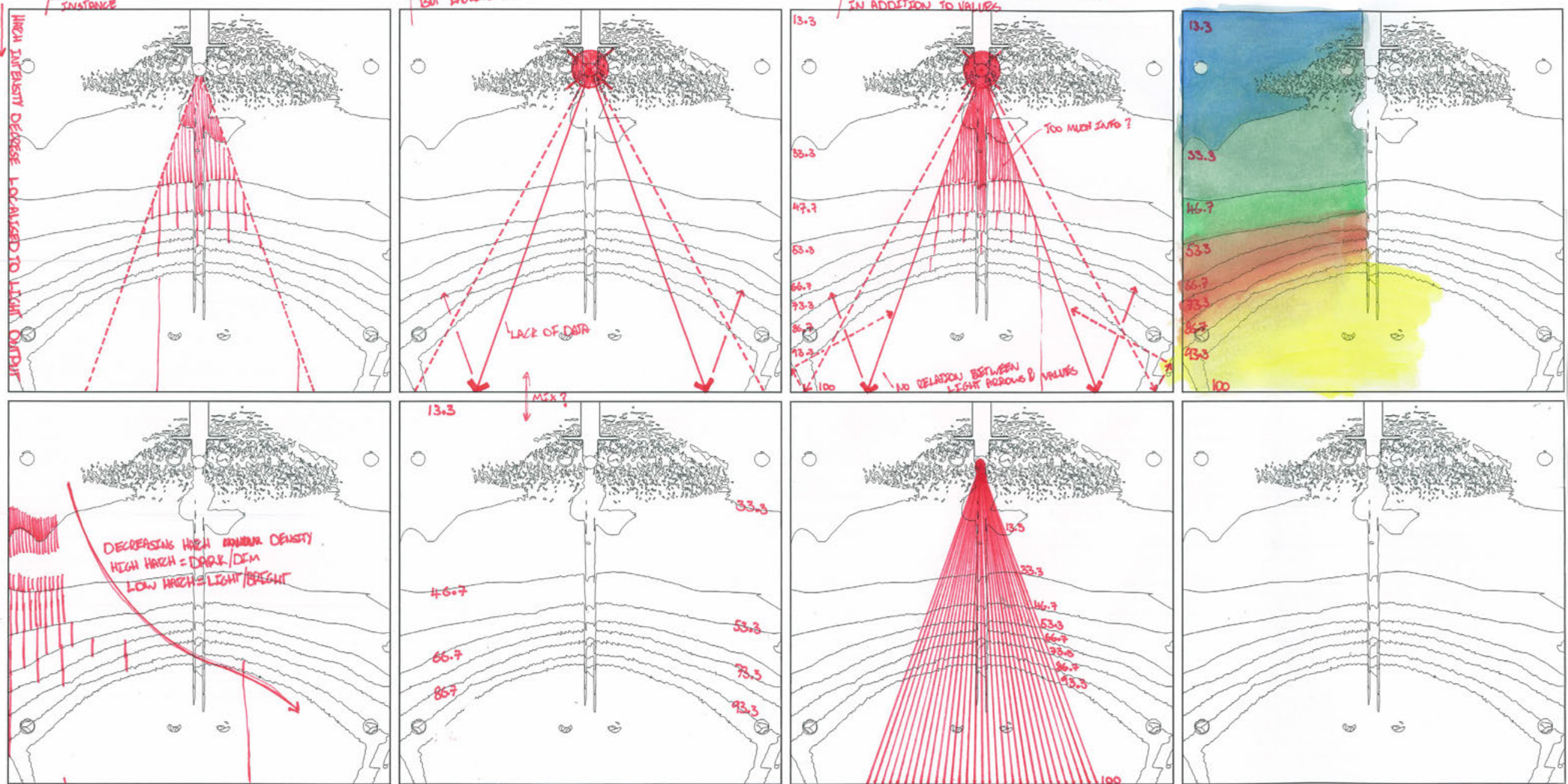

LPAMERNISTS? 


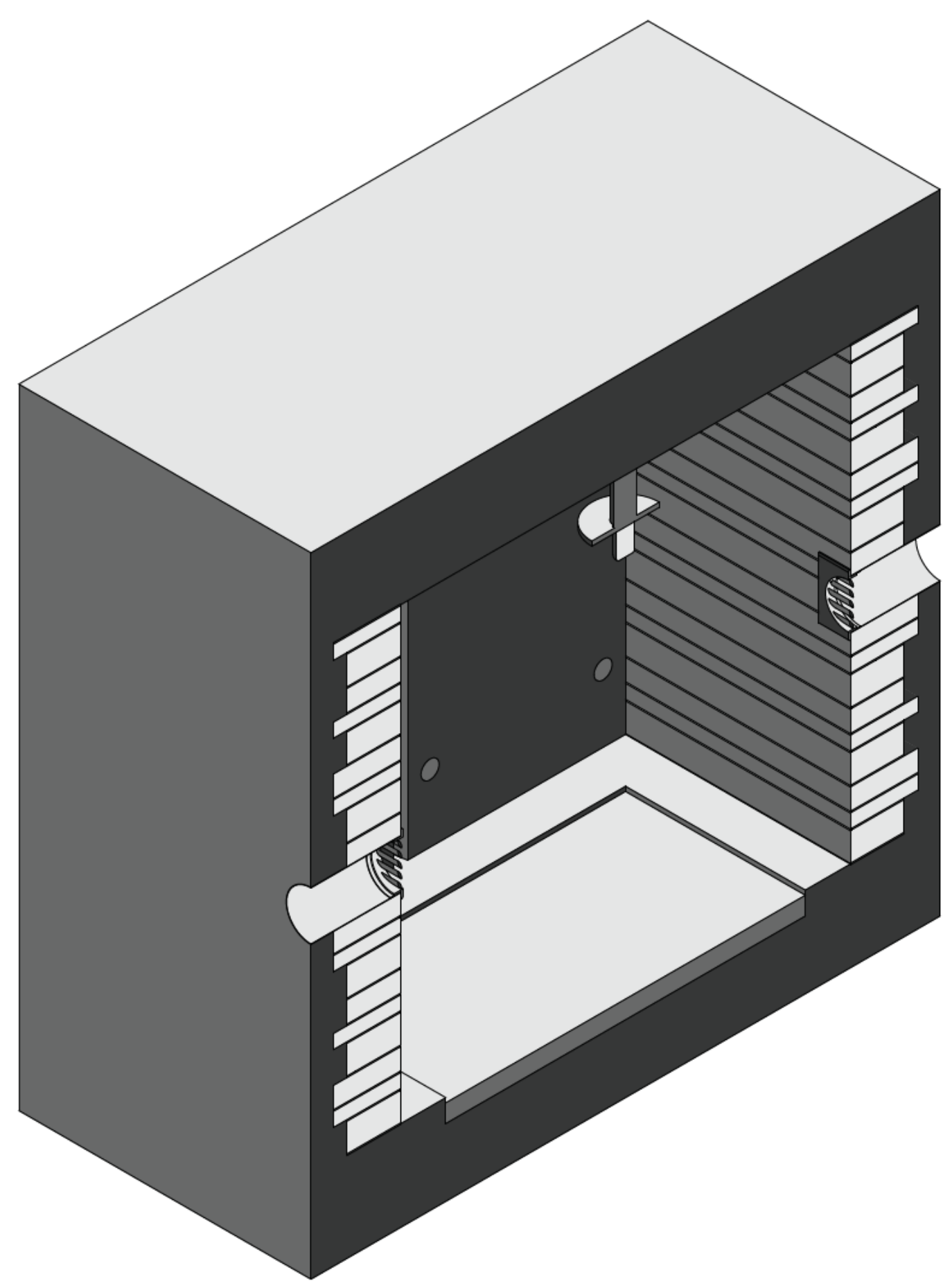


A control space was established to test and develop these notational systems, and was modelled after the design of the Thermas Vals spa [Figure A1.11]. The internal volume of the space measured $1 \mathrm{~m}^{3}$, was constructed from valser quartzite slabs $^{[1]}$ and illuminated using an indirect pendant lighting system designed by Zumthor specifically for the spa ${ }^{[2]}$. These details were established in the control space design to mimic the design of Thermas Vals and provide a semi-accurate substitute in which the notation could be tested.

These notational systems were tested alongside data gathered from digital simulations. An air flow simulation was conducted within the control space using the Simscale software package. From this, a series of contour bands, wind speeds and directional pathways were extracted to act as a framework for the humidity-based notational system to respond to. The Honeybee plug-in for Grasshopper was used to conduct a lighting simulation within the testing cube. From this simulation, a series of colour bands and lighting intensity levels were extracted to act as a framework for the lighting-based notational system to respond to.

\footnotetext{
1 ArchDaily. (2009, February 11). The Therme Vals / Peter Zumthor. Retrieved from ArchDaily: https://www.archdaily.com/13358/the-thermevals
}

2 Viabizzuno. (N.D). Candela Di Vals. Retrieved from Viabizzuno Progettiamo La Luce: https://www.viabizzuno.com/en/products/gruppo/84/\# 

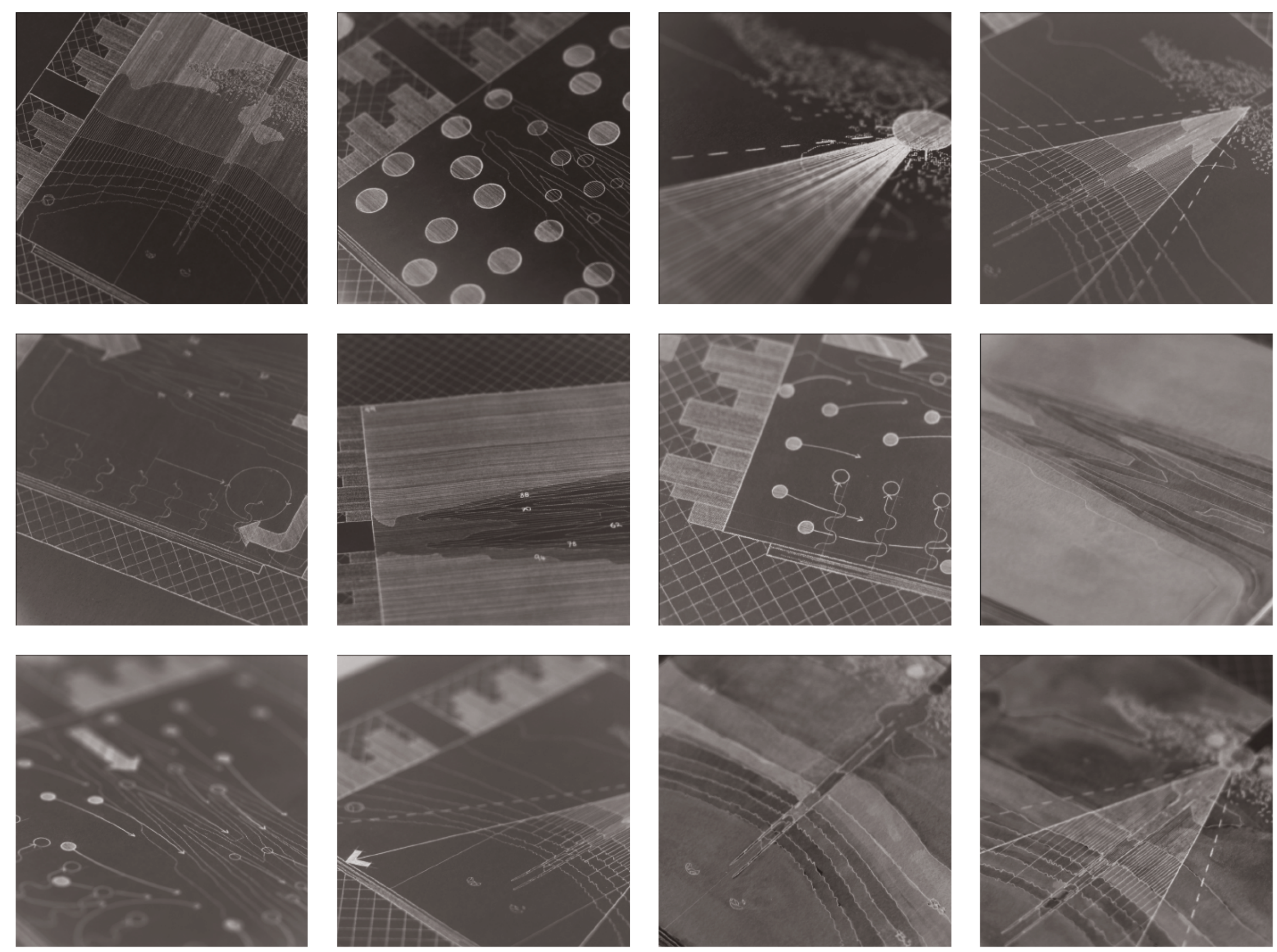
When developing the humidity-based notational system, many of the characteristics identified prior through the sketch analysis were applied in section - this in conjunction with one another. In blending these elements, the system aimed to convey the change in relative humidity within the control space as a result of its internal air speed and air movement pattens. These same principles were then applied in section - this in the context of the lighting-based notational system. The notational characteristics identified prior were applied in conjunction with one another to convey the shift in lighting intensity throughout the control space. This exercise identified a number of potential notational systems which practitioners could implement to map a space's change in relative humidity and lighting intensity at a detailed level, this derived from a series digital simulations [Figures A1.12 - A1.14].

The humidity and lighting-based systems - when developed - were drafted physically, and in turn were determined to be too laborious for practitioners to implement - regardless of the system's design. As these systems were already reliant on digital simulation to map these spatial qualities, their development was elected to continue digitally in an attempt to reduce the working time. 


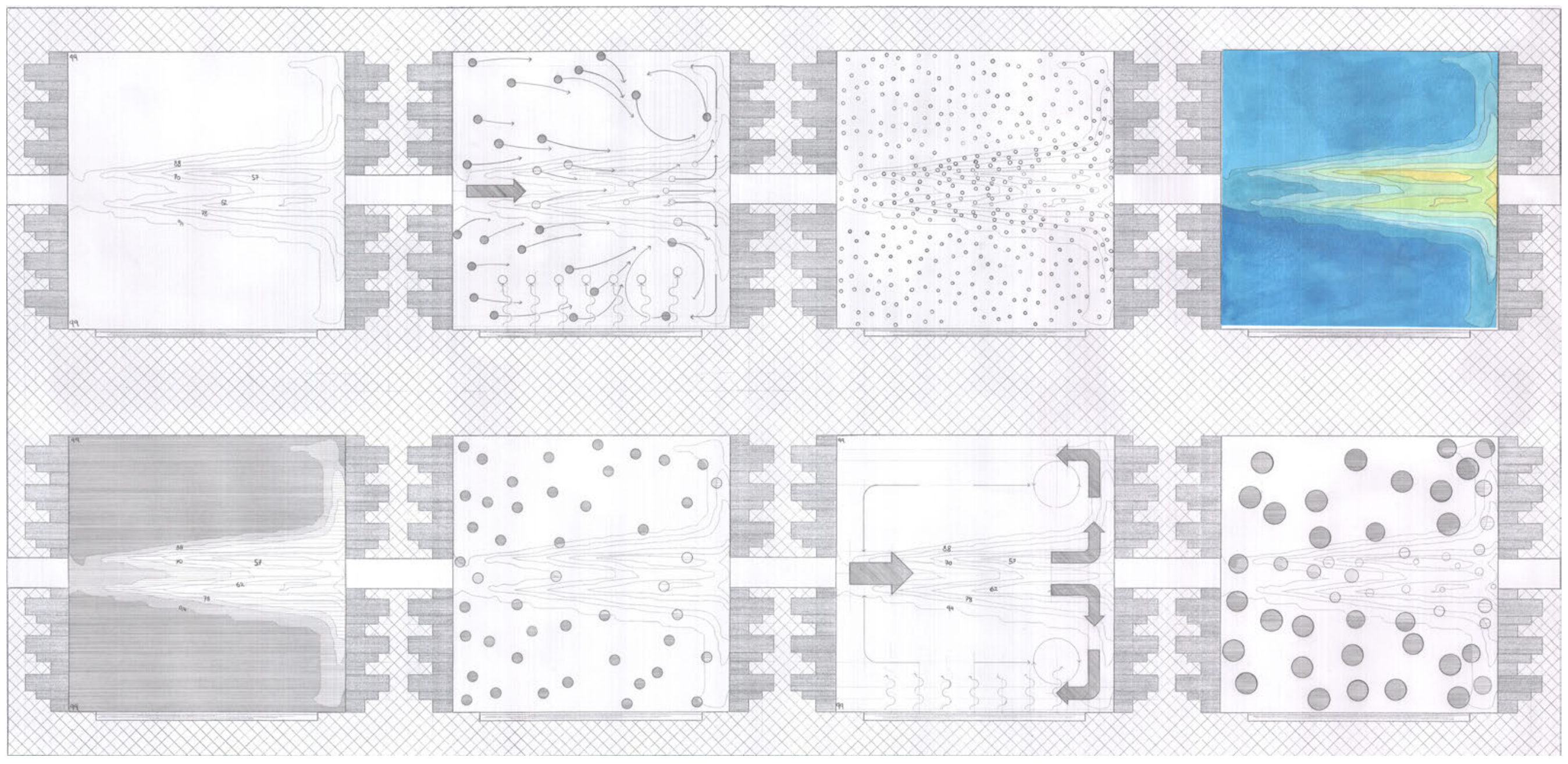




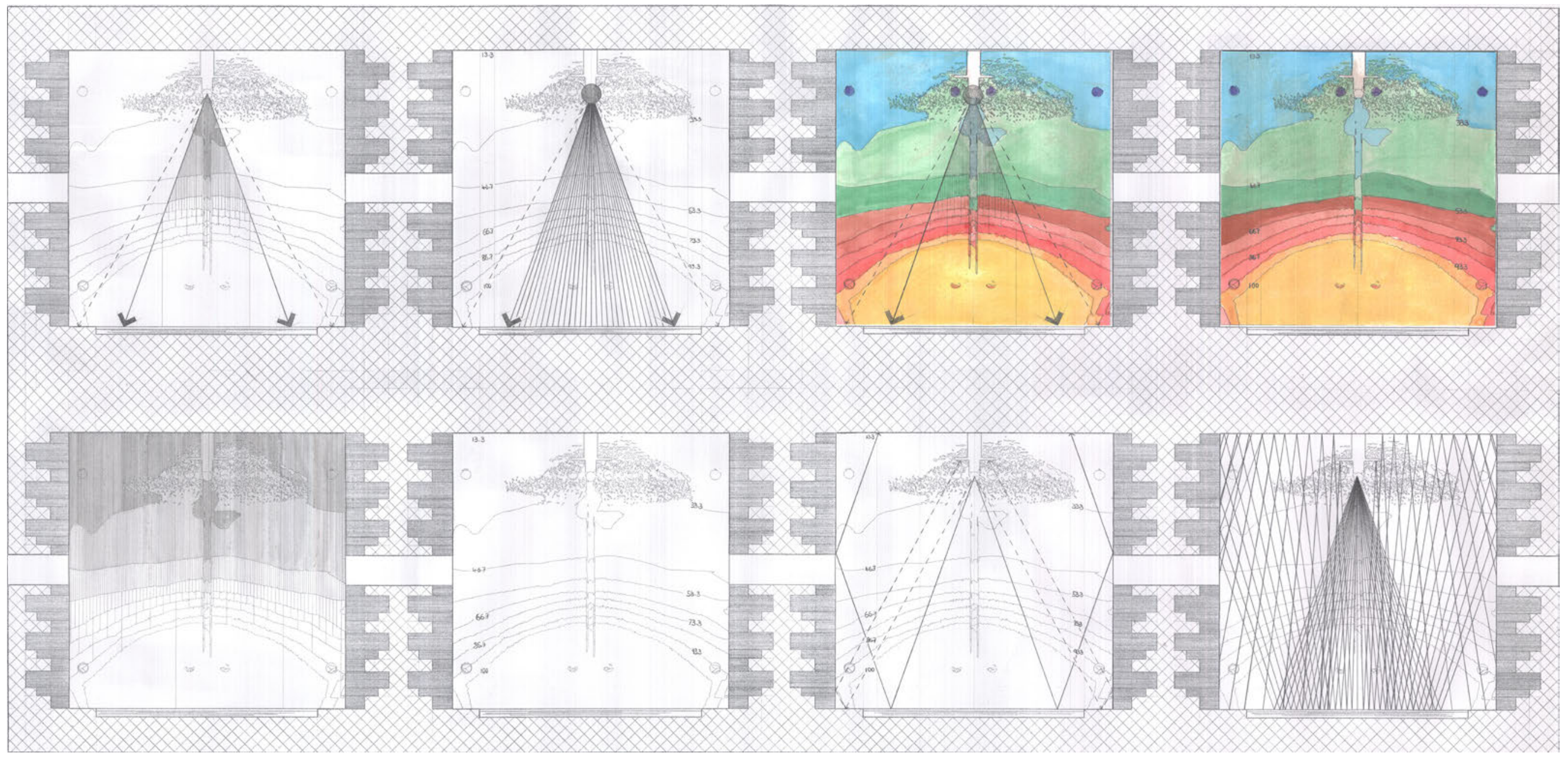



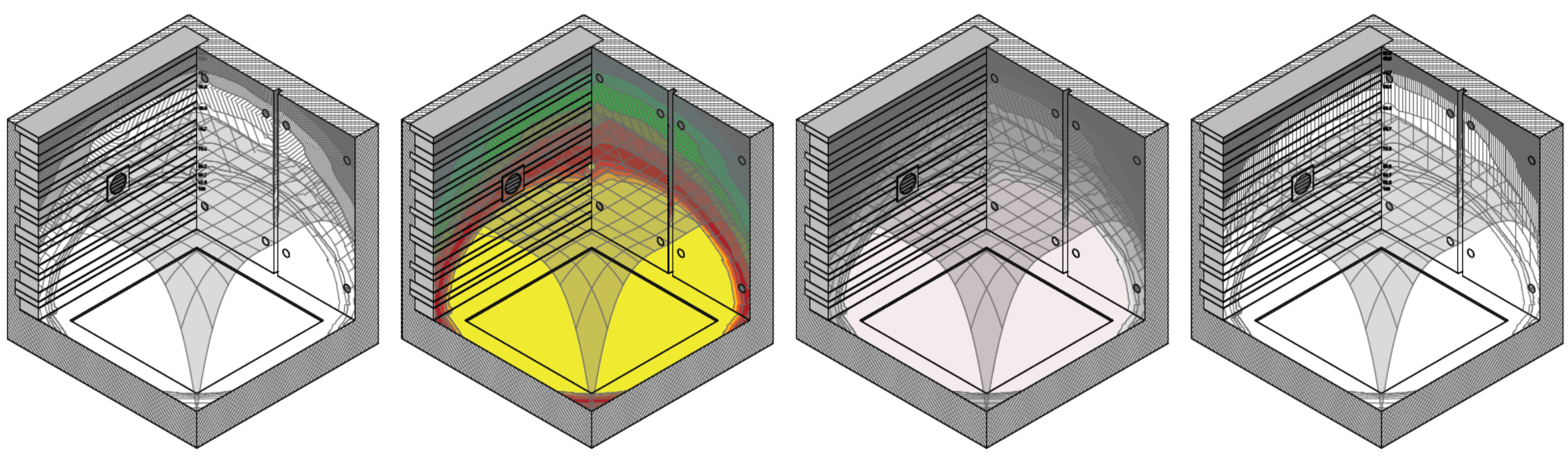
The lighting-based notational system, now operating in a digital environment, was tested in the third dimension [Figure A1.15]. This dimensional shift allowed for the examination and blending of alternative notational characteristics which would not easily translate if examined in plan, or section. The system prioritised the evaluation and validity of a threedimensionally mapped instance. In this instance, a surface plane was constructed and projected from the ground plane based on the lighting intensity levels at that point. This provided an additional layer of graphical representation and understanding of the shift in lighting intensity levels beyond that of hatches, colour fills and text. 


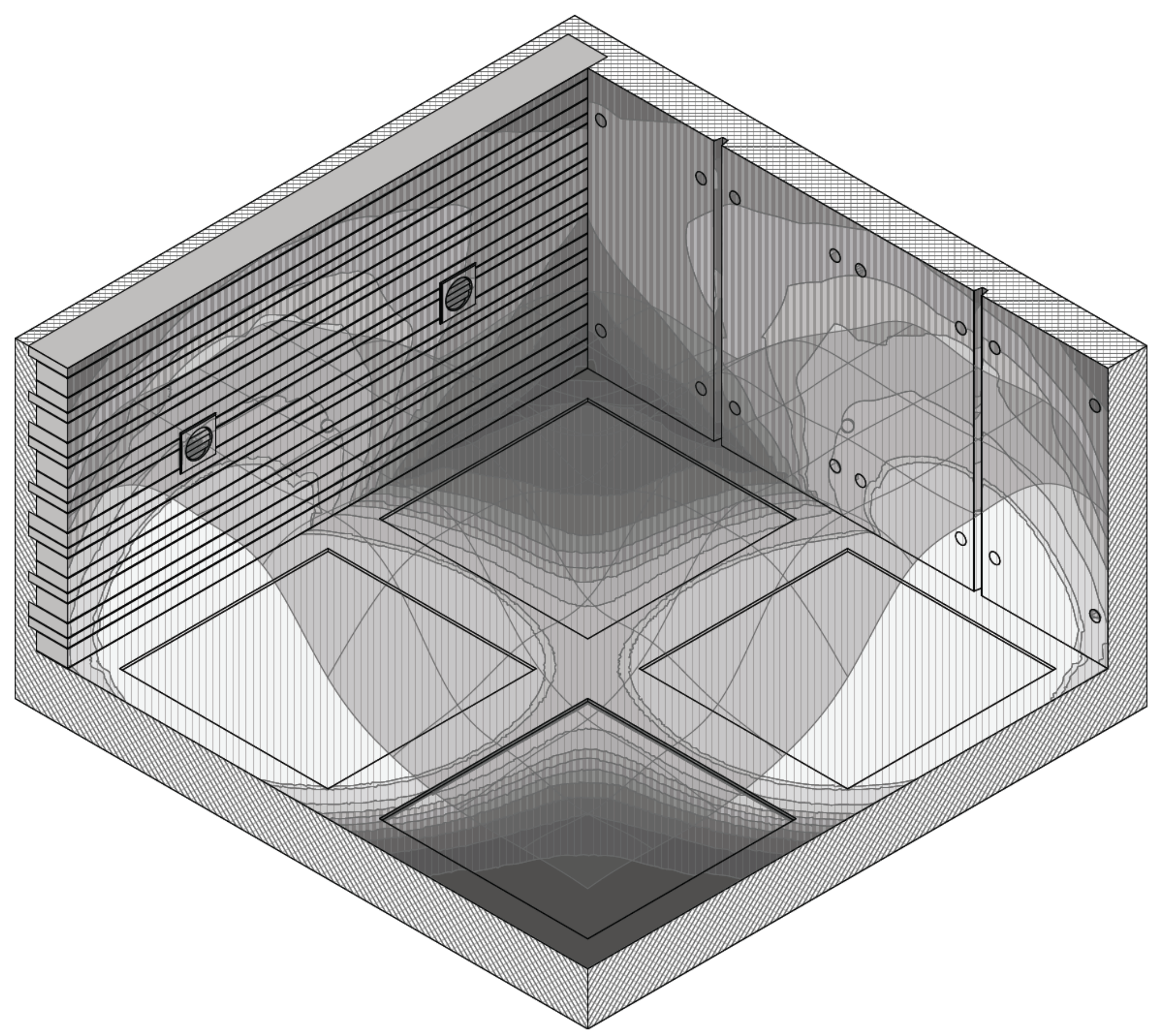


The lighting-based notational system was finalised and used to graphically represent the control spaces shift in lighting intensity [Figure A1.16]. The system facilitated this through an amalgamation of radial hatches emanating from the light's source, a greyscale colour fill, contour bands, text, and a projected surface plane. This system was tested in an enlarged version of the control space to ensure that it remained legible at a larger scale, and was then tested within Thermas Vals. 


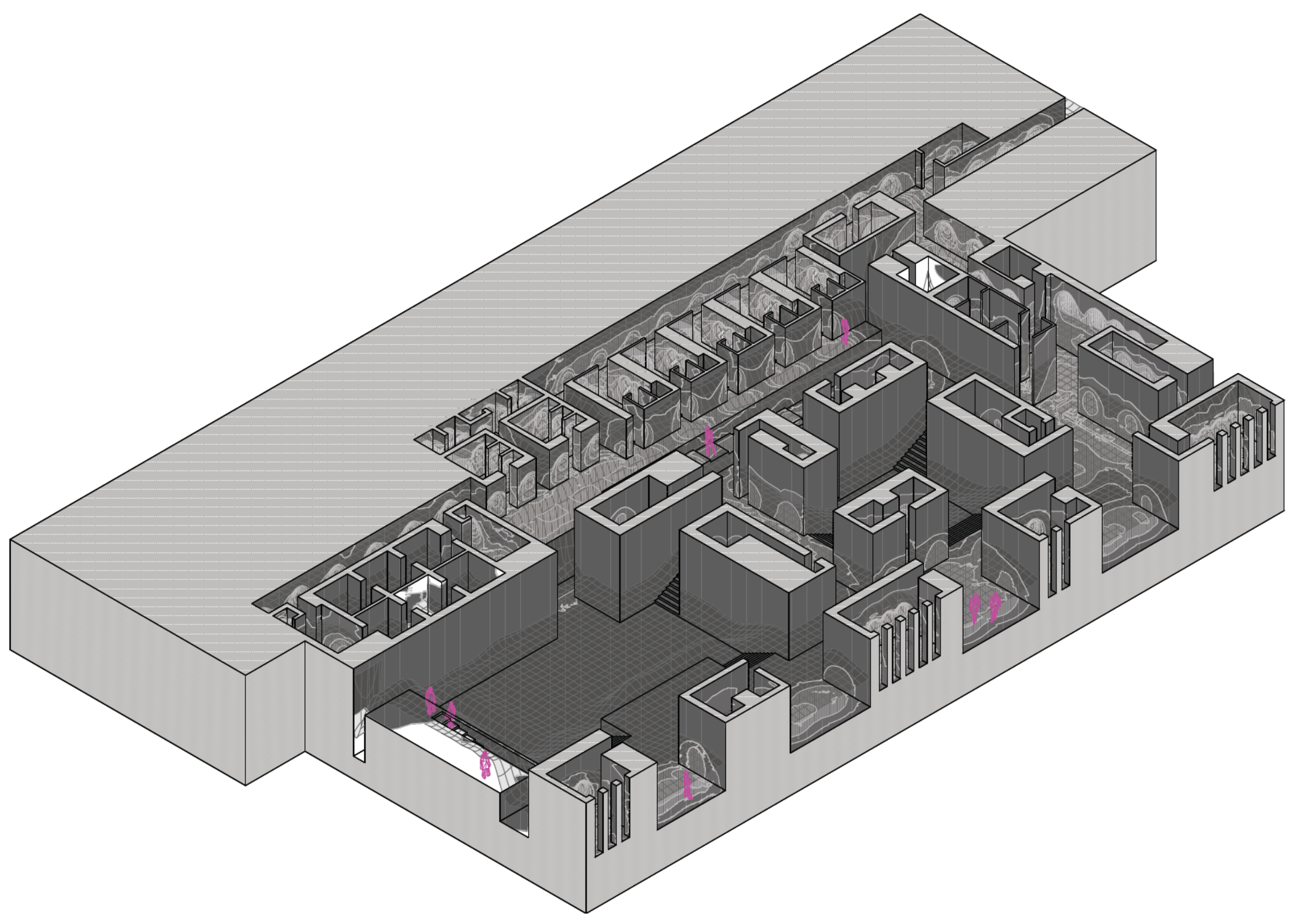


When testing this system in the context of Thermas Vals, several issues became apparent. It was immediately clear that the system does not operate effectively at this scale and is better suited for the analysis and interpretation of a single room's lighting intensity levels, as the details are often lost. Building upon this, the system was shown to be highly laborious to apply - despite working with and relying on a digital output. To apply the system, notational users would first need to gather and process data from Honeybee, only to then construct and add in additional layers of interpretation. This laborious process acts as a point of disconnection, removing practitioners from the design of atmospheric environments and alienating those unfamiliar with the systems foundational software. Ultimately, the notational system in practice can be viewed as a pattern-based reinterpretation of the data produced by Honeybee. Acknowledging this, a similar result is expected if a trial such as this were conducted through the humidity-based notational system within Thermas Vals. As a result of this exploratory process, the research has pivoted to instead examine atmosphere in terms of interruption. As such, this focus moves away from what can be simulated and acknowledges that atmospheres climatic aspects do not account for its totality [Figure A1.17]. 


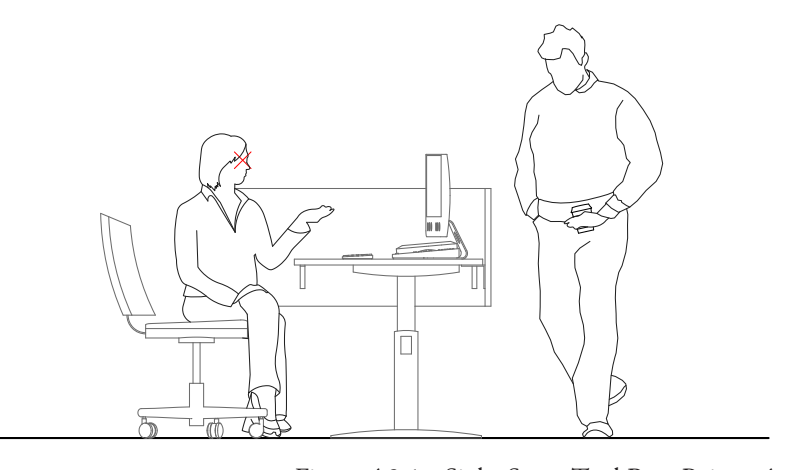

Figure A2.1 - Sight Sense Tool Base Point - Author

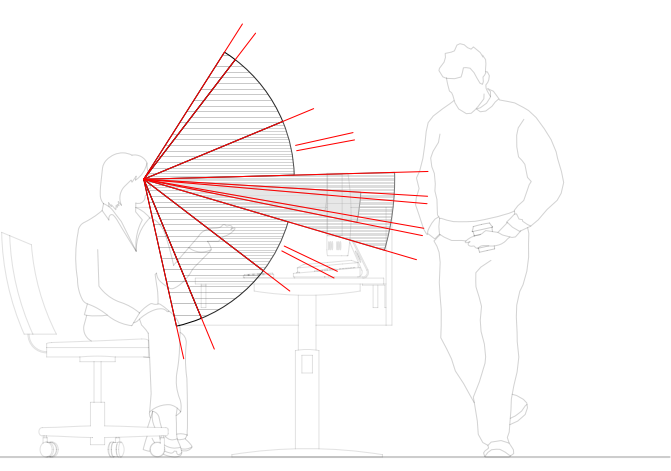

Figure A2.4 - Sight Sense Tool Orientated Toward Work Area - Author

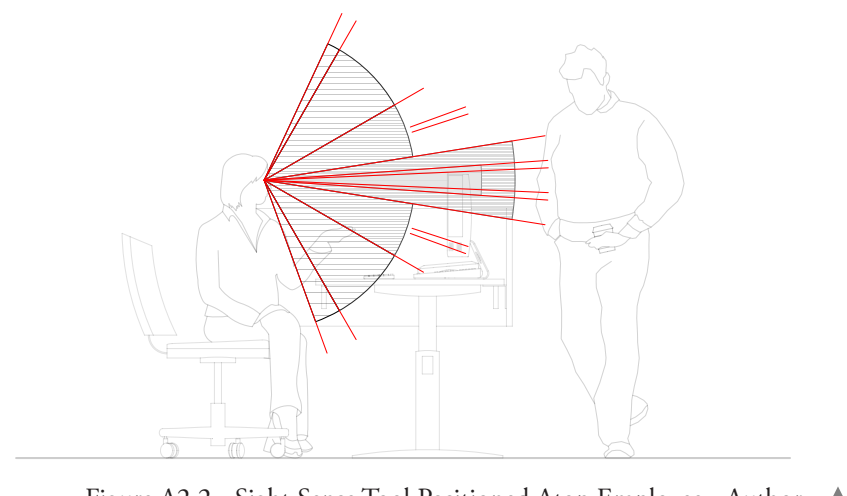

Figure A2.2 - Sight Sense Tool Positioned Atop Employee - Author

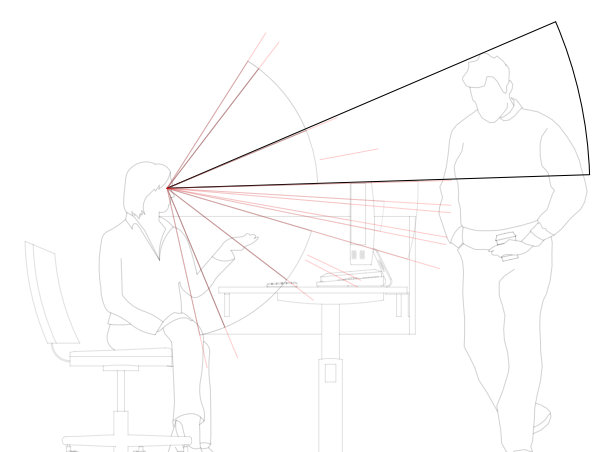

Figure A2.5 - Employee Perceptibility Of Interruptive Event Identified - Author

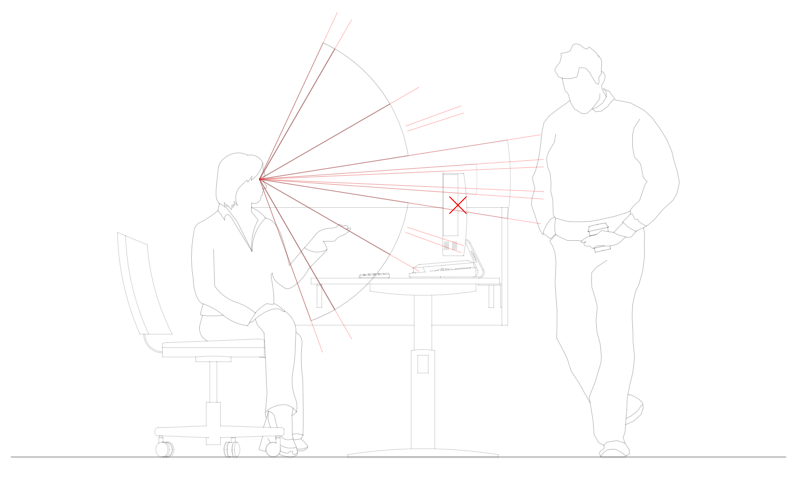

Figure A2.3 - Sight Sense Tool Work Point Identified - Author

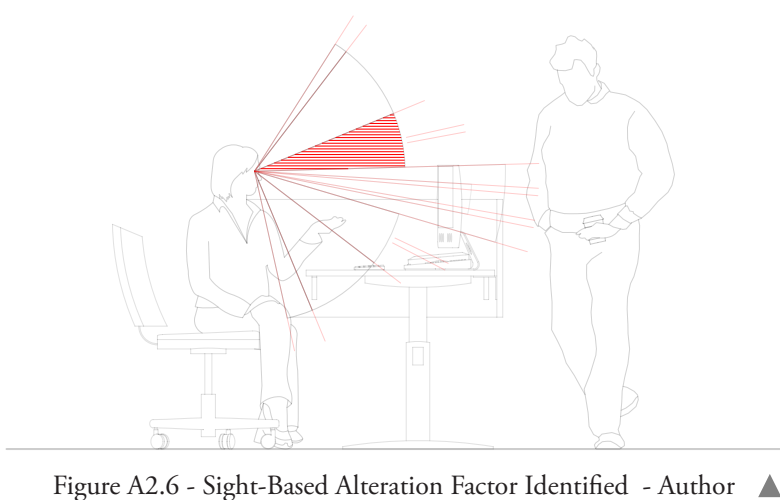


To utilise the notational system, a series of sense tools and calculators has been developed to determine the interruptive impact of an employee's surroundings. As discussed in Chapter Four, these tools serve as a representation of an employee's senses. The tools can determine determine alteration factors, which change the baseline interruptive weightings of events to reflect the impact of the surrounding architecture upon employees.

To utilise the sight sense tool, users must position it on the employee's natural eyeline and angle it from its centre to the current employee work area e.g. the computer screen. To define which vision cone / alteration zone the interruption is perceived through, an average is taken of the visual space occupied by the interruption and is drawn back towards the tool's centre. This highlights which alteration zone the employee perceives the interruption through and allows for an alteration factor to be identified and logged in the calculator [Figures A2.1 - A2.6]. 

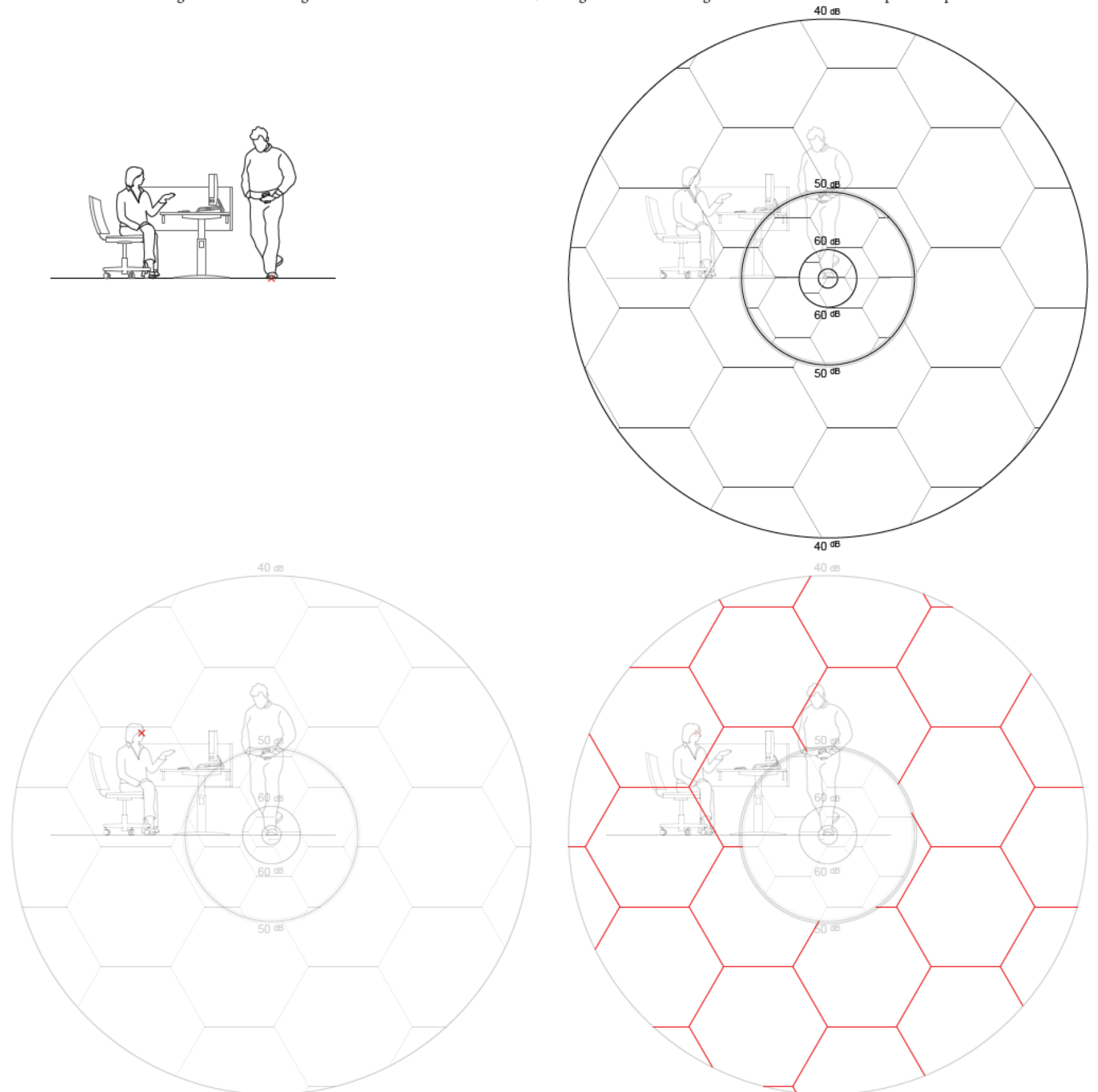

Figure A2.9 - Employee Perceptability Of Interruptive Event Identified - Author

Figure A2.10 - Hearing-Based Alteration Factor Identified - Author 
To utilise the hearing sense tool, users must select the appropriate noise level to represent the interruption and position it on the centre of its noise source. Once orientated, users can then identify what decibel band / alteration zone the employee perceives the interruption through and log its corresponding alteration factor in the calculator [Figures A2.7 - A2.10]. 

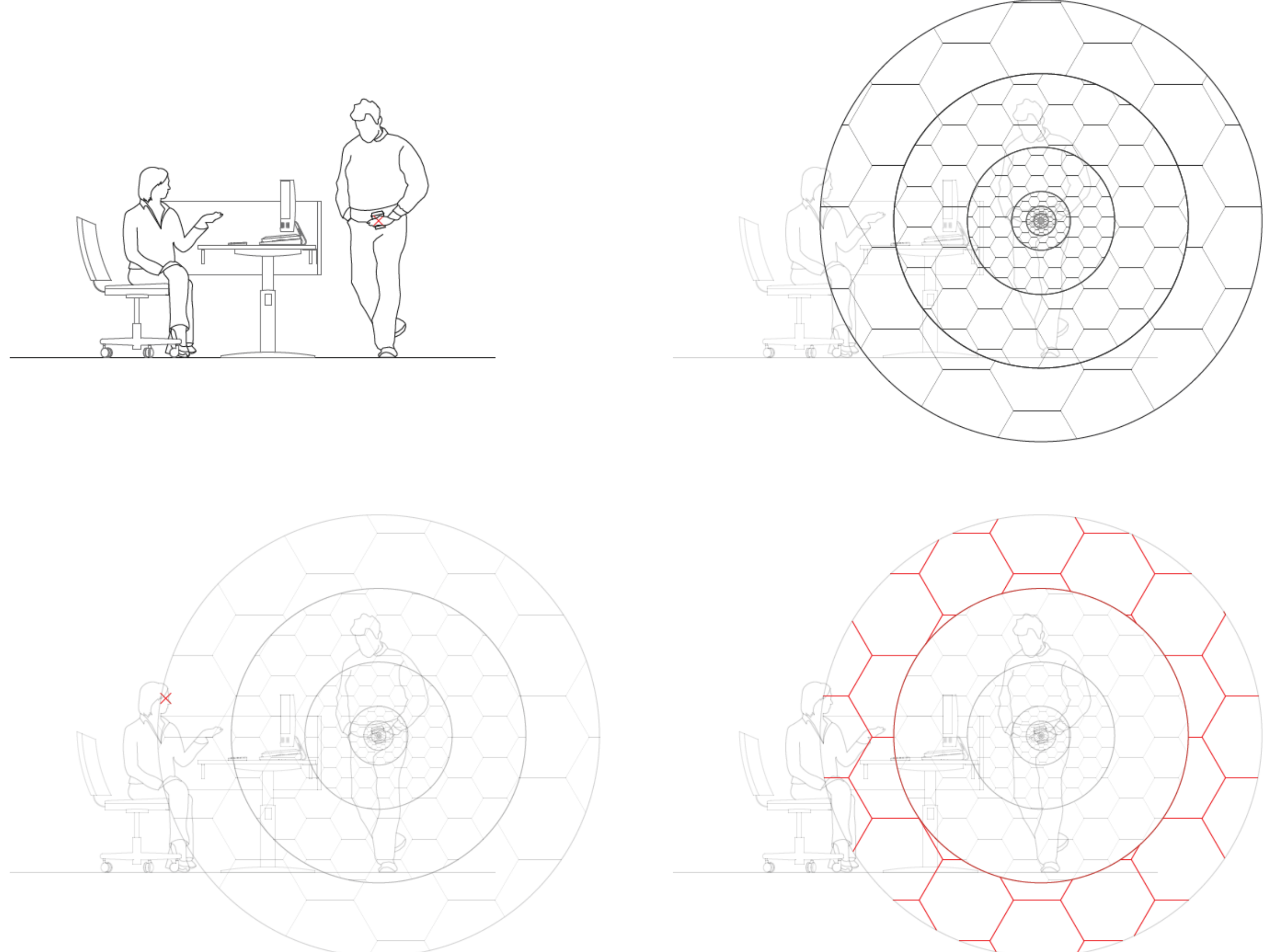
To utilise the smell sense tool, users must position it on the centre of the noise source. Once orientated, users can then identify what scent zone / alteration zone the employee perceives the interruption through and log its corresponding alteration factor in the calculator [Figures A2.11 - A2.14]. 


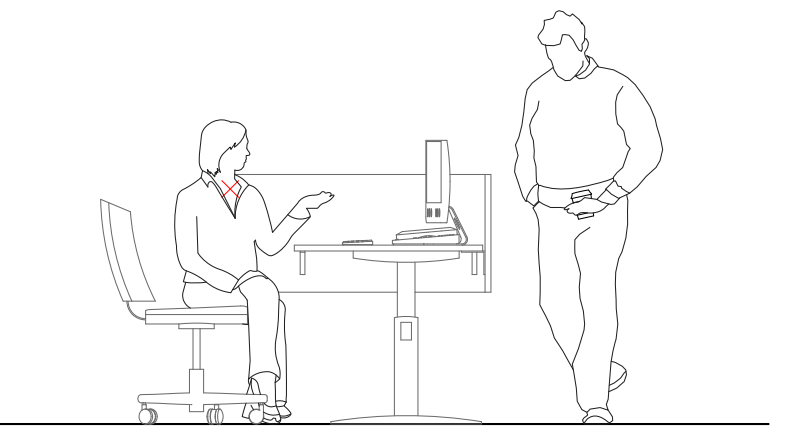

Figure A2.15 - Touch Sense Tool Base Point - Author

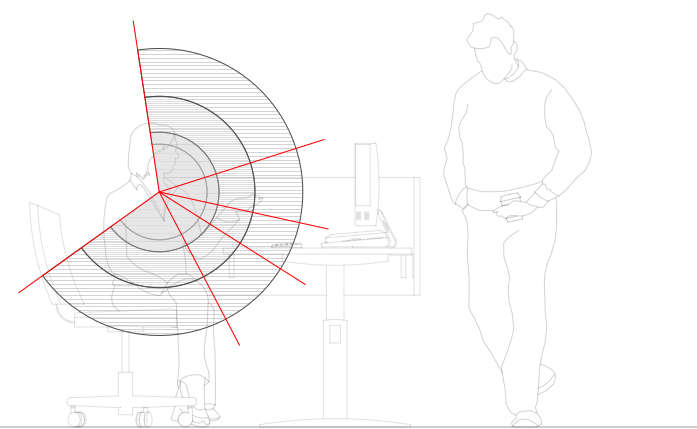

Figure A2.18 - Touch Sense Tool Orientated Toward Work Area - Author

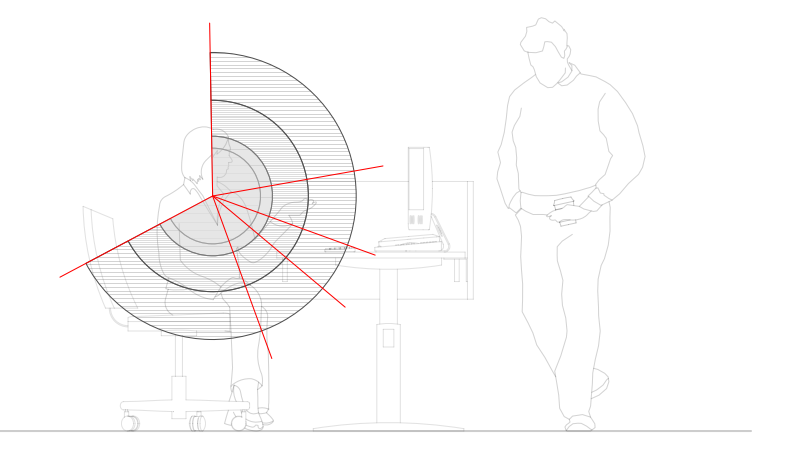

Figure A2.16 - Touch Sense Tool Positioned Atop Employee - Author

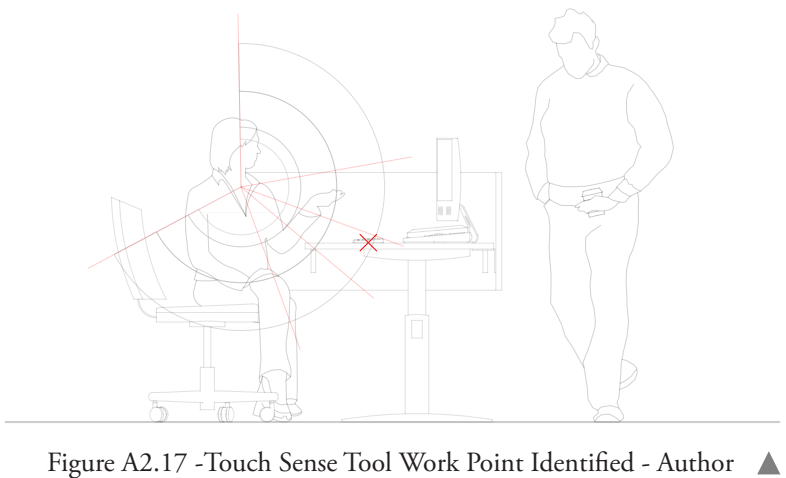

Figure A2.17 -Touch Sense Tool Work Point Identified - Author

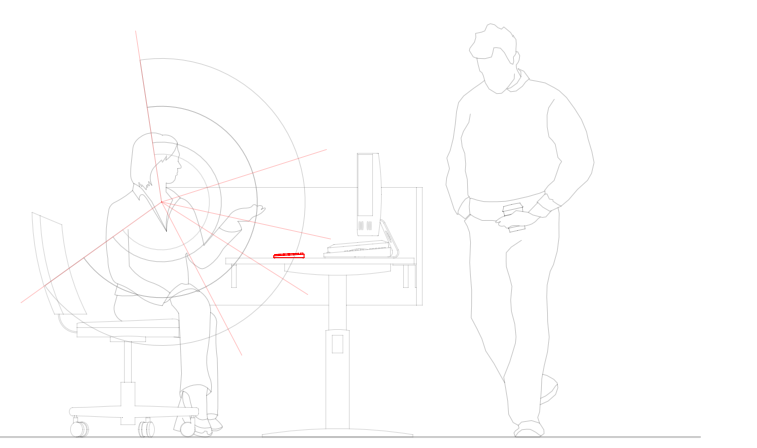

Figure A2.19 - Employee Perceptibility Of Interruptive Event Identified - Author

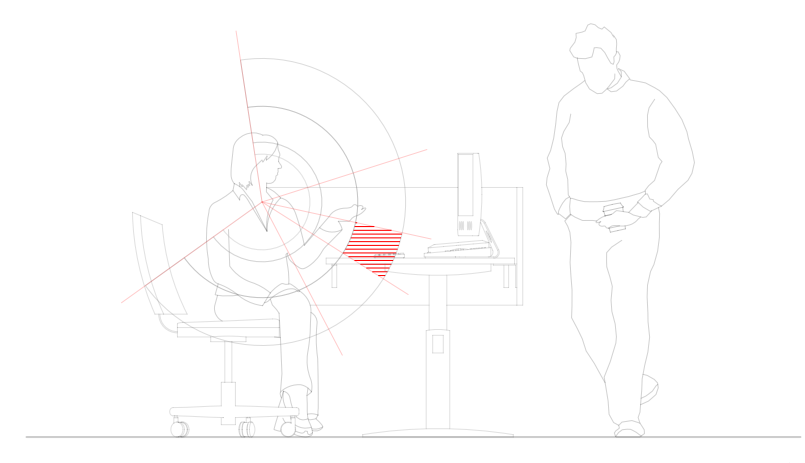

Figure A2.20 - Touch-Based Alteration Factor Identified - Author 
To use the touch sense tool, users must position the tool near the centre of the employee's shoulders and angle it from its centre toward the current employee work area e.g. the keyboard. To define which reach zone / alteration zone the employee perceives the interruption through, users must identify its centre point. The zone which this point occupies will define the alteration factor to be logged within the calculator [Figures A2.15 - A2.20]. 


\begin{tabular}{|c|c|c|c|c|c|c|c|}
\hline What Interruption Type Is Being Examined? & \multicolumn{7}{|l|}{ (Select One) } \\
\hline Checking / Using Paper Documents & \multicolumn{7}{|l|}{ (2) } \\
\hline Checking / Using Computer & \\
\hline Talking Through Wall & \multicolumn{7}{|c|}{ 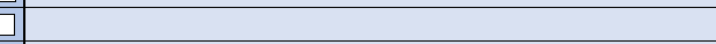 } \\
\hline Phone Call & \\
\hline E-Mail Use & \\
\hline Leaves Cubicle & \multicolumn{7}{|c|}{ 当 } \\
\hline New E-Mail Notification & \multicolumn{7}{|c|}{$\square$} \\
\hline Person Arrives & \multicolumn{7}{|c|}{ 包 } \\
\hline Status On Terminal & \multicolumn{7}{|c|}{ 弱 } \\
\hline Phone Ringing & \multicolumn{7}{|c|}{$\square$} \\
\hline Voice Message Light & \multicolumn{7}{|c|}{ 可 } \\
\hline Call Through Wall & \multicolumn{7}{|c|}{ 光 } \\
\hline Reminder Notification & \\
\hline What Senses Does The Occupant Perceive The Interruption Through? & \multicolumn{3}{|c|}{ (Select All That Apply) } & Percen & tile We & eighting & $\mathrm{g}(\%)$ \\
\hline Sight & & & & & & & 0.8383 \\
\hline Hearing & & & & & & & 0.1111 \\
\hline Smell & & & & & & & 0.0354 \\
\hline Touch & & & & & & & 0.0152 \\
\hline What Vision Zone Does The Occupant Perceive the Interruption Through? & (Select One) & & & & & & \\
\hline $\begin{array}{ll}\text { Central Vision } & \square\end{array}$ & & & & & & & \\
\hline Paracentral Vision & & & & & & & \\
\hline Macular Vision & & & & & & & \\
\hline Near Peripheral Vision & & & & & & & \\
\hline Mid Peripheral Vision & & & & & & & \\
\hline Far Peripheral Vision & & & & & & & \\
\hline Beyond Peripheral Vision & & & & & & & \\
\hline What Decibel Band Does The Occupant Perceive The Noise Through? & (Select One) & & & & & & \\
\hline 0 Decibels & & & & & & & \\
\hline 10 Decibels & & & & & & & \\
\hline 20 Decibels & & & & & & & \\
\hline 30 Decibels & & & & & & & \\
\hline 40 Decibels & & & & & & & \\
\hline 50 Decibels & & & & & & & \\
\hline 60 Decibels & & & & & & & \\
\hline 70 Decibels & & & & & & & \\
\hline 80 Decibels & & & & & & & \\
\hline 90 Decibels & & & & & & & \\
\hline 100 Decibels & & & & & & & \\
\hline 110 Decibels & & & & & & & \\
\hline 120 Decibels & & & & & & & \\
\hline 130 Decibels & & & & & & & \\
\hline 140 Decibels $\quad \square$ & & & & & & & \\
\hline What Scent Zone Does The Occupant Perceive The Interruption Through? & (Select One) & & & & & & \\
\hline $\begin{array}{l}\text { Distance From Source? } \\
\end{array}$ & $0.01 \mathrm{~m} 0.02 \mathrm{~m}$ & $\begin{array}{ll}0.05 \mathrm{~m} & 0.10 \mathrm{~m} \\
\end{array}$ & $0.20 \mathrm{~m}$ & $0.50 \mathrm{~m}$ & $1.00 \mathrm{~m}$ & $1.50 \mathrm{~m}$ & Beyond \\
\hline Very Stable & \begin{tabular}{|l|l|}
$\square$ & $\square$
\end{tabular} & \begin{tabular}{l|l}
$\square$ & $\square$
\end{tabular} & $\square$ & $\square$ & $\square$ & $\square$ & $\square$ \\
\hline Stable & $\square$ & $\square$ & $\square$ & $\square$ & $\square$ & $\square$ & $\square$ \\
\hline Neutral Night & $\square$ & $\square$ & $\square$ & $\square$ & $\square$ & $\square$ & $\square$ \\
\hline Neutral Day & $\square$ & $\square$ & $\square$ & $\nabla$ & $\square$ & $\square$ & $\square$ \\
\hline Unstable & $\square$ & $\square$ & $\square$ & $\square$ & $\square$ & $\square$ & $\square$ \\
\hline Very Unstable & \begin{tabular}{|l|l|}
$\square$ & $\square$ \\
\end{tabular} & $\square$ & $\square$ & $\square$ & $\square$ & $\square$ & $\square$ \\
\hline What Reach Zone Does The Occupant Perceive The Interruption Through? & (Select One) & & & & & & \\
\hline Distance From Source? & $0.4318 \mathrm{~m}$ & $0.762 \mathrm{~m}$ & $1.1176 \mathrm{r}$ & & $1.50 \mathrm{~m}$ & & \\
\hline Immediate Reach Zone & & $\square$ & $\square$ & & $\square$ & & \\
\hline Primary Reach Zone & & $\nabla$ & $\square$ & & $\square$ & & \\
\hline secondary Reach Zone & & $\square$ & $\square$ & & $\square$ & & \\
\hline Tertiary Reach Zone & & $\square$ & $\square$ & & $\square$ & & \\
\hline Beyond Reach Zone & & $\square$ & $\square$ & & $\square$ & & \\
\hline
\end{tabular}


For users to utilise the excel calculator, the examined interruptive event must be selected the relevant alteration zones identified through the sense tools. Once identified and logged by the designer, this information will enable the calculator to factor together the relevant alteration factors, changing the default interruptive event weightings [Figure A2.21]. 


\begin{tabular}{|c|c|c|}
\hline Interruption Type Value Override Calculator & (Uncheck All To Disable Interruption Override) & \\
\hline What Interruption Types Are Being Included In The Examination? & (Select All That Apply) & Percentile Weighting (\%) \\
\hline Checking / Using Paper Documents & $\nabla$ & 0.029574569 \\
\hline Checking / Using Computer & $\nabla$ & 0.173651748 \\
\hline Talking Through Wall & $\square$ & 0.108967262 \\
\hline Phone Call & $\square$ & 0 \\
\hline E-Mail Use & $\nabla$ & 0.117033054 \\
\hline Leaves Cubicle & $\square$ & 0 \\
\hline New E-Mail Notification & $\Phi$ & 0.200537719 \\
\hline Person Arrives & $\Phi$ & 0.339237704 \\
\hline Status On Terminal & $\Phi$ & 0.020243555 \\
\hline Phone Ringing & $\square$ & 0 \\
\hline Voice Message Light & $\square$ & 0 \\
\hline Call Through Wall & $\square$ & 0 \\
\hline Reminder Notification & $\square$ & 0.010754389 \\
\hline What Interruption Type Is Being Examined? & (Select One) & \\
\hline Checking / Using Paper Documents & $\square$ & \\
\hline Checking / Using Computer & $\square$ & \\
\hline Talking Through Wall & $\square$ & \\
\hline Phone Call & $\square$ & \\
\hline E-Mail Use & $\square$ & \\
\hline Leaves Cubicle & $\square$ & \\
\hline New E-Mail Notification & $\square$ & \\
\hline Person Arrives & $\square$ & \\
\hline Status On Terminal & $\square$ & \\
\hline Phone Ringing & $\square$ & \\
\hline Voice Message Light & $\square$ & \\
\hline Call Through Wall & $\square$ & \\
\hline Reminder Notification & $\square$ & \\
\hline
\end{tabular}


In instances where employees are removed from specific interruptions (such as when away from the computer), designers should use the calculator's override option which will reduce the number of interruptive events examined and redistribute their excluded weightings proportionally amongst the other events [Figure A2.22]. 

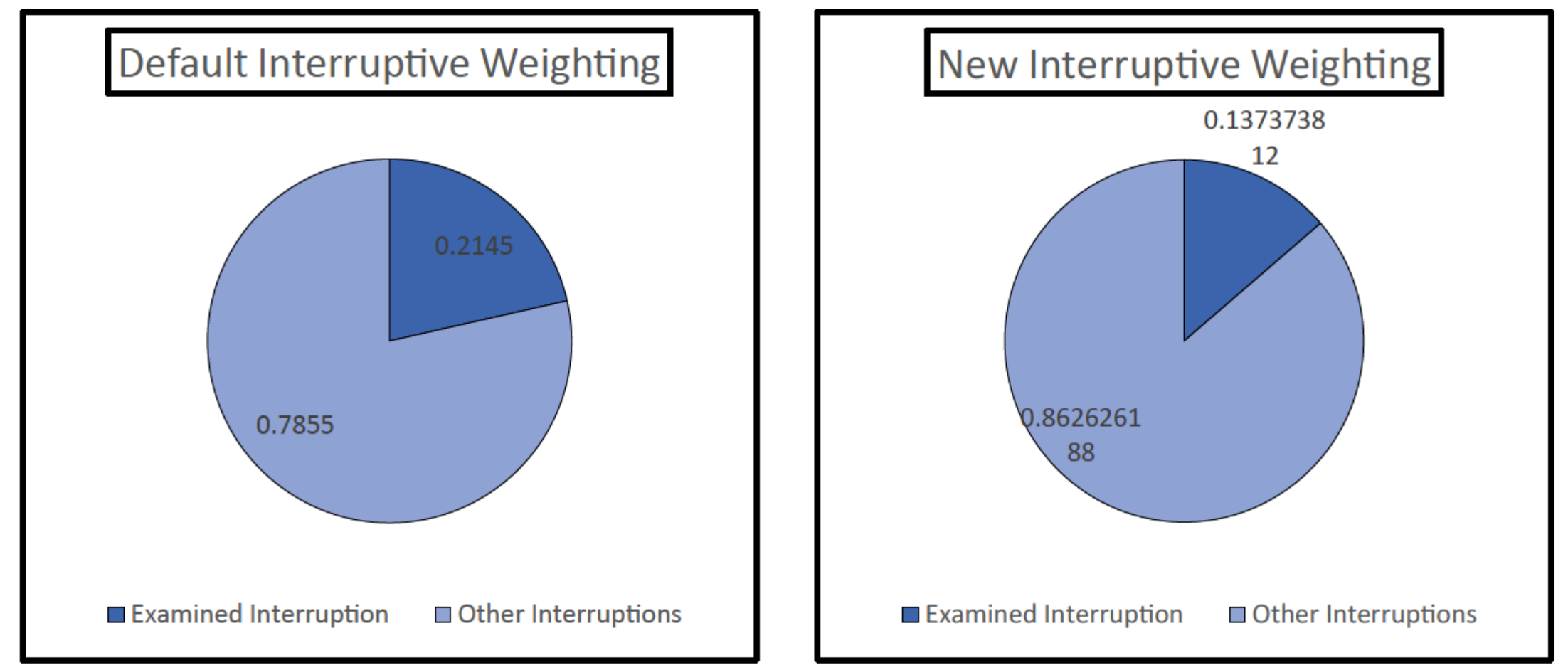
Once all relevant factors have been entered into the excel calculator, a series of charts and numeric outputs will be generated displaying the new interruptive weighting of the examined event. Users will be given the angles and radii of the circular sections for both default and altered instances, thus quickly demonstrating to the designer how much the perceived interruption has increased or decreased as a result of the design [Figure 2.23]. 


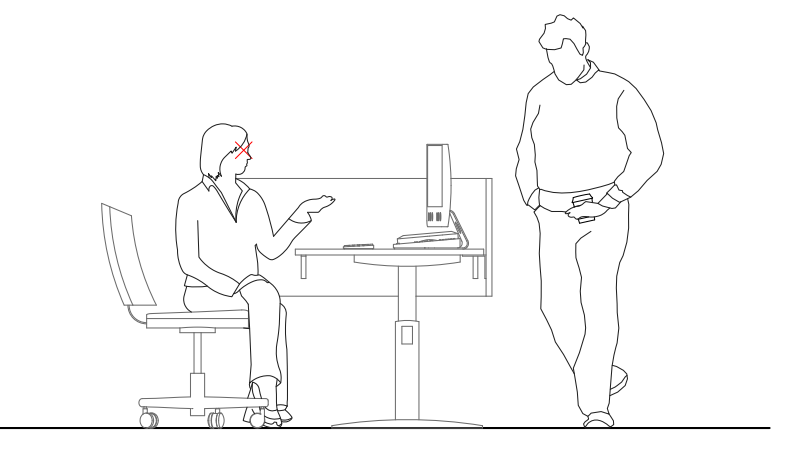

Figure A2.24 - Interruptive Notation Base Point - Author

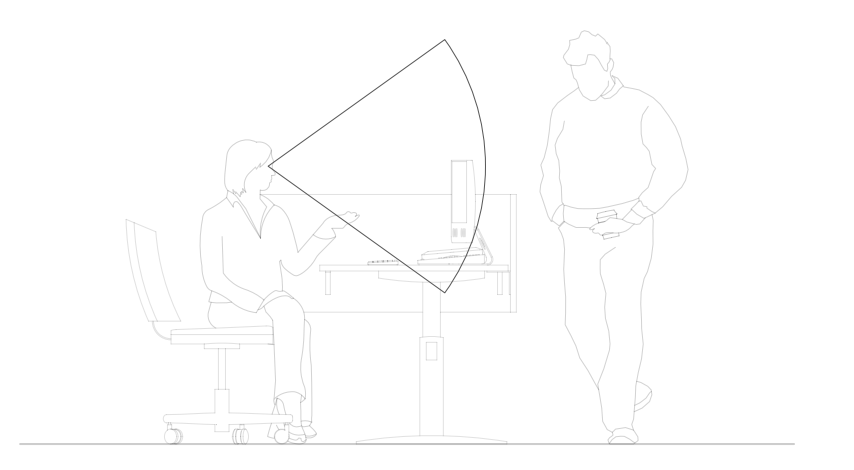

Figure A2.25 - Interruptive Notation Positioned Atop Employee - Author

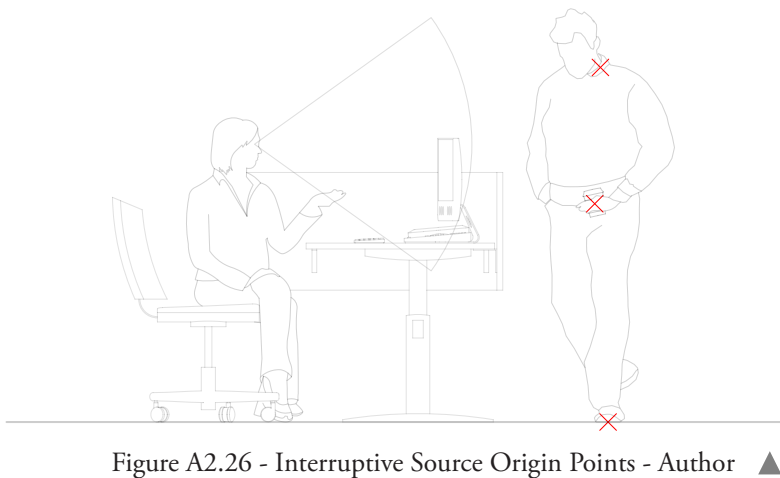

Figure A2.26 - Interruptive Source Origin Points - Author

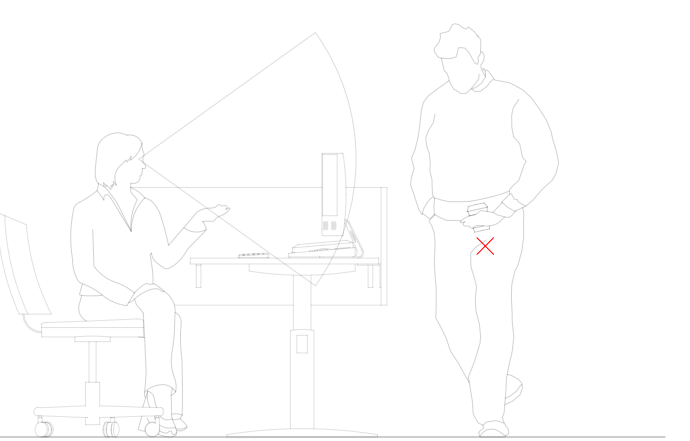

Figure A2.27 - Average Point Between Interruptive Source Origins - Author
Figure A2.28 - Interruptive Notation Orientated Toward Average Point - Author 
To implement the interruptive notational system within a drawing, designers must draft the circular sections from the employees natural eyeline. These values should be generated through the excel calculator and then angled toward the source of the interruptive event. In instances were this event is multisensorial, the circular section should be angled toward the centre point between these sources (e.g. the mid-point between a coffee and the sound source of footsteps). To assist in distinguishing each interruptive event from one another, users should apply a unique hatch pattern and colour to each circular section [Figure A2.24 - A2.29]. 


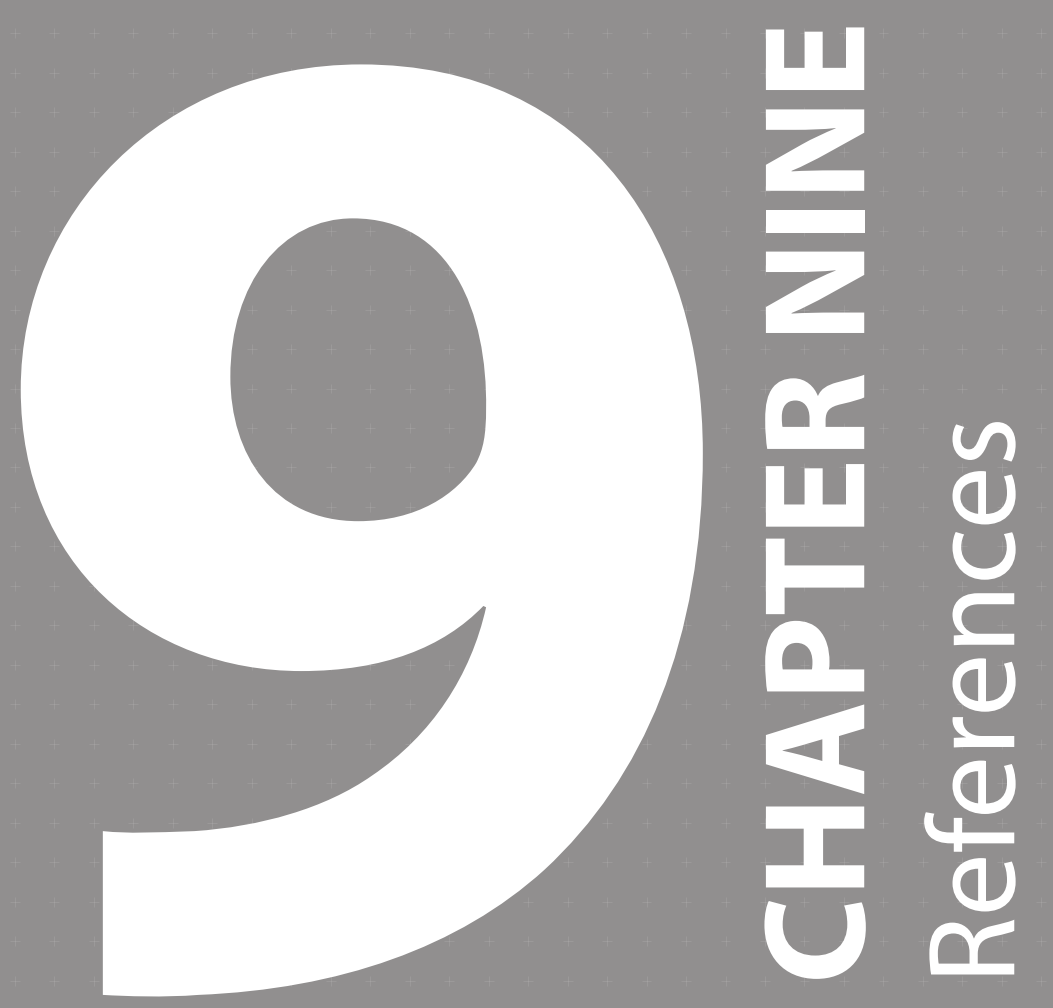





\section{Figures List:}

Figure 2.1 - Milstein Hall Exterior Photographed At Night - Iwan Baan

Baan, I. (2011, N.D). Paul Milstein Hall, Cornell University, Ithaca USA - OMA, Rem Koolhaas. Retrieved from Iwan Baan: https://iwan.com/portfolio/paul-milstein-hall-cornell-university-oma-rem-koolhaas-ithaca-usa/\#6891

Figure 2.2 - Milstein Hall Lecture Hall Interior Photographed At Night - Iwan Baan

Baan, I. (2011, N.D). Paul Milstein Hall, Cornell University, Ithaca USA - OMA, Rem Koolhaas. Retrieved from Iwan Baan: https://iwan.com/portfolio/paul-milstein-hall-cornell-university-oma-rem-koolhaas-ithaca-usa/\#6891

Figure 3.1 - Zenbooth Solo Work Booth - Zenbooth

Zenbooth. (N.D). 1-Person Phone Booth. Retrieved from Zenbooth: https://cdn.shopify.com/s/files/1/1707/5693/ products/office_45b891e8-0065-4ed4-a974-c39c0fa84849_451x@2x.progressive.jpg?v=1577734402

Figure 3.2 - InnoV8 Central Atrium Space - Warren \& Mahoney

Warren \& Mahoney. (2018). Vodafone, Smales Farm. Retrieved from Warren \& Mahoney: https://warrenandmahoney. com/media/images/43A3946web.jpg

Figure 3.3 - InnoV8 Atrium Office View - Warren \& Mahoney

Warren \& Mahoney. (2018). Vodafone, Smales Farm. Retrieved from Warren \& Mahoney: https://warrenandmahoney. com/media/images/_rightColumn/43A4000web.jpg

Figure 3.4 - InnoV8 Meeting Space - Warren \& Mahoney

Warren \& Mahoney. (2018). Vodafone, Smales Farm. Retrieved from Warren \& Mahoney: https://warrenandmahoney. com/media/images/_rightColumn/43A4296web.jpg

Figure 3.2 - InnoV8 Office Cafe Space - Warren \& Mahoney

Warren \& Mahoney. (2018). Vodafone, Smales Farm. Retrieved from Warren \& Mahoney: https://warrenandmahoney. com/media/images/_rightColumn/43A4485web_181017_110745.jpg 
Figure 3.6 - Sky Central Open Atrium Space - Hufton + Crow

Hufton + Crow. (2016). Sky Central / AL_A + PLP Architecture + HASSELL. Retrieved from Arch Daily: https:// images.adsttc.com/media/images/585a/efbb/e58e/ce95/3e00/004f/slideshow/491_Copyright_Hufton_Crow_ N4.jpg? 1482354606

Figure 3.7 - Sky Central Village Model Diagram - PLP Architecture

PLP Architecture. (2016). Sky Central Concept. Retrieved from Arch Daily: https://images.adsttc.com/media/ images/585a/f21f/e58e/ce38/9500/0047/slideshow/Concept_Diagram_-_Organisaiton_of_the_buidling_internals. jpg?1482355225

Figure 3.8 - Sky Central Office Partitions - Craftwand

Craftwand. (2016). Office Partitions, Sky U.K. Retrieved from Craftwand: https://www.craftwand.info/wp-content/ uploads/2017/06/cw_Sky-central_05-1024x724.jpg

Figure 3.9 - Sharecuse Central Working Space - Caylon Hackwith

Caylon Hackwith. (2019). Sharecuse Coworking Space / ARCHITECTURE OFFICE. Retrieved from Arch Daily: https:// images.adsttc.com/media/images/5d8d/7813/284d/d19b/1700/000f/slideshow/17sharecuse_edit.jpg?1569552378

Figure 3.10 - Hardwired Electrical Connection Through Floor - Caylon Hackwith Caylon Hackwith. (2019). Sharecuse Coworking Space / ARCHITECTURE OFFICE. Retrieved from Arch Daily: https://images.adsttc.com/media/images/5d8d/79da/284d/d144/e900/0008/slideshow/02sharecuse.jpg?1569552812

Figure 3.11 - Sharecuse Office Glazed Formal Work Areas - Caylon Hackwith

Caylon Hackwith. (2019). Sharecuse Coworking Space / ARCHITECTURE OFFICE. Retrieved from Arch Daily: https:// images.adsttc.com/media/images/5d8d/7720/284d/d19b/1700/000a/slideshow/09sharecuse_edit.jpg?1569552137

Figure 4.1 - Interruptive Notation - Interruptive Events Percentage Of Total Interruptions - Victor M Gonzalez \& Gloria Mark

Gonzalez, V. M., \& Mark, G. (2004). Table 6. Avg. number and types of interruptions per day. Retrieved from "Constant, Constant, Multi-tasking Craziness": Managing Multiple Working Spheres: Page 118 
Arch Daily. (2016, December 26). Sky Central / AL_A + PLP Architecture + HASSELL. Retrieved from Arch Daily: https://www.archdaily.com/802043/sky-central-al-a-plus-plp-architecture-plus-hassell

Archipreneur. (2019, November 25). New Work Environment: A Flexible Office Space by Architecture Office. Retrieved from Archipreneur: https://archipreneur.com/new-work-environment-a-flexible-office-space/

Architecture Office. (N.D). Sharecuse. Retrieved from Architecture Office: https://architectureoffice.org/sharecuse/

Autex. (2018, May N.D). Autex. Retrieved from Frontier Acoustic Fins: http://www.hecht-efraim.co.il/prdFiles/ products/178_193295_prd_file_3.pdf

Bohme, G. (2013). Atmosphere as Mindful Physical Presence in Space. OASE, 21-32.

Bohme, G. (2014). The Theory of Atmospheres and its Applications. Interstices, 92-99.

Buildings and their Genotypes. (1984). In B. Hillier, \& J. Hanson, The Social Logic of Space (pp. 143-175). Cambridge: The Press Syndicate of the University of Cambridge.

Centre of Hearing and Communication. (N.D). Common Environment Noise Levels. Retrieved from Centre of Hearing and Communication: http://chchearing.org/noise/common-environmental-noise-levels/

Gonzalez, V. M., \& Mark, G. (2004). "Constant, Constant, Multi-tasking Craziness": Managing Multiple Working Spheres. CHI Conference on Human Factors in Computing Systems (pp. 113-120). Vienna: Association for Computing Machinery.

Hassell. (N.D). Sky Central Workplace. Retrieved from Hassell: https://www.hassellstudio.com/project/sky-central

Havik, K., Teerds, H., \& Tielens, G. (2013). Building Atmosphere. OASE, 3-12. 
HMC Architects. (N.D). The Best Flexible Workspace Design Strategies. Retrieved from HMC Architects: https:// hmcarchitects.com/thought-leadership/flexible-workspace-design-strategies-slp/

K2 Space. (N.D). Enabling Agile Working Through Office Design. Retrieved from K2 Space: https://k2space.co.uk/ knowledge/enabling-agile-working-office-design/

Looker, J. (2015). Reaching for Holograms: Assessing the Ergonomics of the Microsoft ${ }^{\mathrm{TM}}$ Hololens $^{\mathrm{TM}} 3 \mathrm{D}$ Gesture Known as the "Air Tap". International Design Congress (pp. 17-23). Gwangju: International Design Congress.

Lungaro, P., Sjoberg, R., Valero, A. J., \& Mittal, A. (2018). Gaze-Aware Streaming Solutions for the Next Generation of Mobile VR Experiences. IEEE Transactions on Visualization and Computer Graphics, 99-109.

Mark, G., Klocke, U., \& Gudith, D. (2008). The Cost os Interrupted Work: More Speed and Stress. Conference on Human Factors in Computing Systems (pp. 107-110). Florence: Association for Computing Machinery.

Mehta, R., Zhu, R. J., \& Cheema, A. (2012). Is Noise Always Bad? Exploring the Effects of Ambient Noise on Creative Cognition. Journal of Consumer Research, 784-799.

New Zealand Government Property Procurement Group. (N.D). Open-plan working environment and consistent design. Retrieved from New Zealand Government Property Procurement Group: https://www.procurement.govt.nz/ property/workplace-design-guidelines/principles-for-office-design/open-plan-working-environment-and-consistentdesign/

Nottage, S. (2018, January 4). Go With The Flow: your scrum teams are interrupted 2,000 times per sprint, choking velocity by 40 per cent. Retrieved from Linkedin: https://www.linkedin.com/pulse/go-flow-your-scrum-teamsinterrupted-2000-times-per-sprint-nottage

Office Principles. (N.D). Designing an Agile Workspace for a Flexible Office. Retrieved from Office Principles: https:// officeprinciples.com/5872-designing-an-agile-workspace-for-a-flexible-workforce/ 
Pak, Y. (2019, June N.D). 7 mistakes to avoid when designing an agile workplace - part 1. Retrieved from Open Sensors: https:/www.opensensors.com/blog/top-7-mistakes-to-avoid-when-designing-an-agile-working-program-part-1

Perry, T. (N.D). Sound Diffusers 101: Free DIY Diffuser Designs. Retrieved from Arqen: http://arqen.com/sounddiffusers/\#comments

Piringer, M., Knauder, W., Petz, E., \& Schauberger, G. (2016). Factors Influencing Separation Distances Against Odour Annoyance Calculated by Gaussian and Lagrangian Dispersion Models. Elsevier, 69-83.

PLP Architecture. (N.D). Sky Central London, UK. Retrieved from PLP Architecture: http://www.plparchitecture.com/ sky-central.html

Ramidus Consulting Limited. (2015). Future Workstyles and Future Workspaces in the City of London. London: The City of London Corporation and The City Property Association.

Rasheed, E., Khoshbakht, M., \& Baird, G. (2021). Office Distractions and the Productivity of Building Users: The Effect of Workgroup Sizes and Demographic Characteristics. Buildings, 1-17.

Rosenblum, L. D. (2010). See What I'm Saying: The Extraordinary Powers of Our Five Senses. New York: W. W. Norton \& Company.

Sengpiel, E. (N.D). Sound (music) and Noise (bang). Retrieved from Sengpiel Audio: http://www.sengpielaudio. com/calculator-levelchange.htm\#: - :text=Doubling $\% 20$ of $\% 20$ the $\% 20$ volume $\% 20$ (loudness, $\% 2$ B 10\%20dB $\% 20$ \%E2\%88\%92\%20acousticians\%20say.\&text=Doubling\%20of\%20sound\%20intensity\%20(acoustic,)\%20in\%20 psychoacoustics $\% 20 \% \mathrm{E} 2 \% 88 \% 92 \% 20$ mostly\%20sensed

South, G. (2018, September 7). The future of the workplace: Inside Vodafone's new North Shore HQ. Retrieved from New Zealand Herald: https://www.nzherald.co.nz/business/the-future-of-the-workplace-inside-vodafones-new-northshore-hq/4YPWLEISTZTADZZWYTUNMFBCBE/ 
Stefansdottir, H. (2018). The Role of Urban Atmosphere for Non-Work Activity Locations. Journal Of Urban Design, 319-335.

Unknown, A. (2009, February 11). The Therme Vals / Peter Zumthor. Retrieved from Arch Daily: https://www.archdaily. com/13358/the-therme-val

Vernet, M., Japee, S., Lokey, S., Ahmed, S., Zachariou, V., \& Ungerleider, L. G. (2019). Endogenous visuospatial attention increases visual awareness independent of visual discrimination sensitivity. Neuropsychologia, 297-304.

Viabizzuno. (N.D). Candela Di Vals. Retrieved from Viabizzuno Progettiamo La Luce: https:/www.viabizzuno.com/ en/products/gruppo/84/\#

Vodafone. (2018, September 5). Vodafone officially opens workplace of the future in Auckland. Retrieved from Vodafone: https://news.vodafone.co.nz/article/vodafone-officially-opens-workplace-future-auckland

Ward, B. (2019, August 23). The Importance of The Neutral Reach Zone. Retrieved from Beyond The Office Door: https://www.btod.com/blog/2017/01/26/the-importance-of-the-neutral-reach-zone/

Warren \& Mahoney. (N.D). Vodafone, Smales Farm. Retrieved from Warren \& Mahoney: https://warrenandmahoney. com/portfolio/new-entry

Wigley, M. (1998). The Architecture of Atmosphere. Daidalos, 18-27.

Workagile. (2019, November 21). Office Design Inspiration: Sky Central, London. Retrieved from Workagile: https:// workagile.co.uk/office-design-inspiration-sky-central-london/

Zenbooth. (2018, May 14). A Guide to Agile Workspaces: Why You Should Transform Your Office Now. Retrieved from Zenbooth: https://zenbooth.net/blogs/zenbooth-blog/an-ode-to-agile-workspaces-why-you-should-transformyour-office-now 
